Universidade de São Paulo

Faculdade de Filosofia, Letras e Ciências Humanas

Programa de Pós-Graduação em Geografia Humana 运fflch

FACULDADE DE FILOSOFIA, LETRASE CIÊNCIAS HUMANAS UNIVERSIDADE DE SÃO PAULO

Melissa Maria Veloso Steda

\title{
Território e informação: produção e consumo de aplicativos na era da computação em nuvem
}

Versão corrigida

São Paulo

2021 


\title{
Universidade de São Paulo
}

Faculdade de Filosofia, Letras e Ciências Humanas

Programa de Pós-Graduação em Geografia Humana

\section{Território e informação: produção e consumo de aplicativos na era da computação em nuvem}

\author{
Versão corrigida
}

Tese de doutorado apresentada à Faculdade de Filosofia, Letras e Ciências Humanas da Universidade de São Paulo para obtenção do título de Doutora em Ciências (Geografia Humana) na linha de pesquisa Território, Economia e Dinâmicas Regionais.

Orientadora: Profa. Dra. María Mónica Arroyo

São Paulo 
Autorizo a reprodução e divulgação total ou parcial deste trabalho, por qualquer meio convencional ou eletrônico, para fins de estudo e pesquisa, desde que citada a fonte.

Catalogação na Publicação

Serviço de Biblioteca e Documentação

Faculdade de Filosofia, Letras e Ciências Humanas da Universidade de São Paulo

S812t

Steda, Melissa Maria Veloso

Território e informação: produção e consumo de aplicativos na era da computação em nuvem / Melissa Maria Veloso Steda; orientadora María Mónica Arroyo São Paulo, 2021.

$277 \mathrm{f}$.

Tese (Doutorado)- Faculdade de Filosofia, Letras e Ciências Humanas da Universidade de São Paulo. Departamento de Geografia. Área de concentração: Geografia Humana.

1. Internet. 2. Softwares. 3. Redes e comunicação de dados. 4. Geografia econômica. 5. Aplicativos. I. Arroyo, María Mónica, orient. II. Título. 


\section{ENTREGA DO EXEMPLAR CORRIGIDO DA DISSERTAÇÃO/TESE}

\section{Termo de Ciência e Concordância do (a) orientador (a)}

\section{Nome do (a) aluno (a): MELISSA MARIA VELOSO STEDA}

Data da defesa: 15/07/2021

Nome do Prof. (a) orientador (a): MARIA MONICA ARROYO

Nos termos da legislação vigente, declaro ESTAR CIENTE do conteúdo deste EXEMPLAR CORRIGIDO elaborado em atenção às sugestões dos membros da comissão Julgadora na sessão de defesa do trabalho, manifestando-me plenamente favorável ao seu encaminhamento e publicação no Portal Digital de Teses da USP.

São Paulo, 06/09/2021

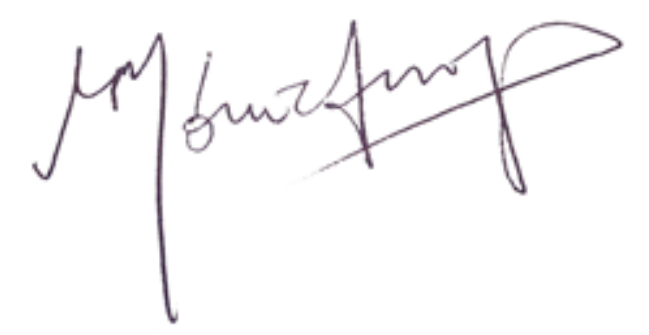

Orientadora: Profa Dra Maria Mónica Arroyo 
Nome: STEDA, Melissa Maria Veloso.

Título: Território e informação: produção e consumo de aplicativos na era da computação em nuvem.

Tese apresentada à Faculdade de Filosofia, Letras e Ciências Humanas da Universidade de São Paulo para obtenção do título de Doutora em Ciências - Área: Geografia Humana.

Aprovado em:

Banca Examinadora

Prof. Dr. Instituição:

Julgamento: Assinatura:

Prof. Dr. Instituição:

Julgamento: Assinatura:

Prof. Dr. Instituição:

Julgamento: Assinatura: 


\section{Agradecimentos}

À professora Mónica Arroyo, pela paciência, compreensão e disponibilidade, e pela orientação sempre inspiradora.

Aos professores Ricardo Castillo e Fábio Tozi, pela leitura e pelas valiosas sugestões feitas durante o exame de qualificação, essenciais para o aprimoramento dos caminhos da pesquisa. Novamente ao professor Fábio Tozi, e também aos professores Carolina Batista Israel e Fabio Betioli Contel, pela leitura atenta e pelas arguições generosas durante a defesa da tese. Suas contribuições foram fundamentais para a continuidade e a finalização deste trabalho.

Aos funcionários e docentes da FFLCH, especialmente do Departamento de Geografia.

Aos colegas da pós-graduação, do Laboplan e do NETS-USP.

Ao Conselho Nacional de Desenvolvimento Científico e Tecnológico (CNPq) pelo financiamento de bolsa de doutorado, processo CNPq n. 140043/20179.

À Fundação de Amparo à Pesquisa do Estado de São Paulo (FAPESP) e à Coordenação de Aperfeiçoamento de Pessoal de Nível Superior (CAPES) pelo apoio, com financiamento da bolsa de doutorado processo nº 2016/22841-5, Fundação de Amparo à Pesquisa do Estado de São Paulo (FAPESP).

À Fundação de Amparo à Pesquisa do Estado de São Paulo (FAPESP) pelo financiamento da bolsa de estágio de pesquisa no exterior processo noㅡ 2019/003282, Fundação de Amparo à Pesquisa do Estado de São Paulo (FAPESP).

As opiniões, hipóteses e conclusões ou recomendações expressas neste material são de responsabilidade da autora e não necessariamente refletem a visão da FAPESP e da CAPES. 


\section{Resumo}

\section{TERRITÓRIO E INFORMAÇÃO: PRODUÇÃO E CONSUMO DE APLICATIVOS NA ERA DA COMPUTAÇÃO EM NUVEM}

No período da globalização, é notável a relevância das tecnologias da informação como componentes essenciais das atividades produtivas, alterando significativamente as dinâmicas do espaço geográfico, da economia, da sociedade e da política. Os aplicativos se tornaram um dos produtos mais ubíquos da indústria de software, tendo sua popularização diretamente relacionada à difusão das conexões móveis à Internet e à maior disponibilidade de aparelhos como os smartphones. Na etapa mais recente de informatização do território, o advento da computação em nuvem trouxe mudanças cruciais para a produção e o consumo dos aplicativos, com especiais implicações para a manipulação de dados e a contratação de serviços em tecnologias da informação. Ainda que a disponibilidade de redes telemáticas seja maior nos grandes centros urbanos do território brasileiro, a produção e o consumo de aplicativos são também notórios naquelas porções onde se expande a agricultura científica globalizada. Diante das novas possibilidades técnicas, os agentes hegemônicos da indústria de tecnologias da informação fomentam a imposição de um consenso para incentivar o consumo de certos tipos de aplicativos, especialmente no Brasil, que detém um dos maiores mercados consumidores do mundo. Por outro lado, o acesso facilitado às redes e aos dispositivos também gera usos emancipatórios das tecnologias, reverberando nos usos do território.

Palavras-chave: software; Internet; redes de telecomunicação; informação; território brasileiro. 


\section{Abstract}

\section{TERRITORY AND INFORMATION: PRODUCTION AND CONSUMPTION OF APPLICATION SOFTWARE IN THE AGE OF CLOUD COMPUTING}

In the period of globalization, the relevance of information technologies as essential components of productive activities is remarkable, significantly altering the dynamics of the space, economy, society, and politics. Application software has become one of the most ubiquitous products in the software industry, and its popularization is directly related to the spread of mobile Internet connectivity and the greater availability of devices such as smartphones. In the most recent stage of the computerization of the territory, the advent of cloud computing has brought crucial changes to the production and consumption of applications, with special implications for data manipulation and the contracting of information technology services. Although the availability of telematic networks is greater in the large urban centers of the Brazilian territory, the production and consumption of applications are also notorious in those areas where globalized scientific agriculture is expanding. Faced with new technical possibilities, the hegemonic agents of the information technology industry promote the imposition of a consensus to encourage the consumption of certain types of applications, especially in Brazil, which has one of the largest consumer markets in the world. On the other hand, facilitated access to networks and devices also generates emancipatory uses of technologies, reverberating in the uses of the territory.

Keywords: software; Internet; telecommunication networks; information; Brazil. 


\section{Lista de tabelas}

Tabela 1. Resultados de buscas em bases de dados de periódicos (agosto/2020) ................ 24

Tabela 1.1. Brasil. Densidade de banda larga fixa por região (2020) ................................... 53

Tabela 1.2. Brasil. Densidade de banda larga móvel por região (2020) ................................. 54

Tabela 1.3. Brasil. Domicílios, por presença de computador e Internet (2019) .................... 69

Tabela 1.4. Fatos e dados relevantes sobre a tecnosfera de conectividade à Internet no

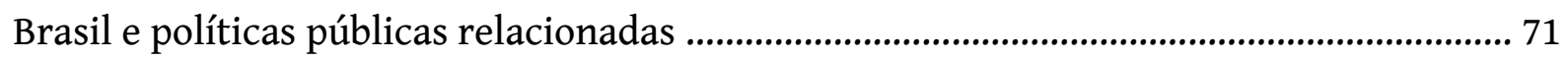

Tabela 2.1. Brasil. Os 10 maiores mercados de computadores (1981) ................................. 104

Tabela 2.2. Brasil. Empresas produtoras de software por código CNAE fiscal informado (2020) 108

Tabela 2.3. Brasil. Empresas produtoras de aplicativos por código CNAE fiscal informado (2020) 109

Tabela 2.4. Brasil. Empresas produtoras de software por porte (2020) .............................. 112

Tabela 2.5. Brasil. Empresas produtoras de aplicativos por porte (2020) .......................... 113

Tabela 2.6. Brasil. Empresas produtoras de software por região (2020) ............................ 115

Tabela 2.7. Brasil. Empresas produtoras de aplicativos por região (2020) ......................... 116

Tabela 2.8. Distribuição de desenvolvedores de aplicativos para Android no primeiro trimestre de 2018, por país

Tabela 2.9. Rendimentos e receita das empresas "Big Tech", em relação ao ano anterior (outubro de 2020) 165

Tabela 2.10. Resumo do desenvolvimento da tecnologia de computação eletrônica em países selecionados 169

Tabela 2.11. Mercado global de software e serviços em TI (2018) ....................................... 169

Tabela 2.12. Produção total de TICs no Brasil (2018) ........................................................ 170

Tabela 2.13. Subdivisões da indústria de software e barreiras a seu desenvolvimento, segundo empresários do ramo

Tabela 3.1. Categorias dos aplicativos mais presentes nas telas iniciais de celulares dos brasileiros 188

Tabela 3.2. Temas relacionados às TI tratados em palestras na feira Agrifutura (2018) .. 206 


\section{Lista de gráficos}

Gráfico 1.1. Brasil. Usuários de Internet (1996-2016) ....................................................... 27

Gráfico 1.2. Brasil. Dispositivo utilizado para acessar a Internet (2014-2019) .................... 51

Gráfico 1.3. Brasil. Evolução dos acessos e densidade de banda larga fixa (2007-2020) ..... 53

Gráfico 2.1. Brasil. Empresas produtoras de software, segundo código CNAE fiscal ........ 108

Gráfico 2.2. Brasil. Empresas produtoras de aplicativos, segundo código CNAE fiscal ..... 109

Gráfico 2.3. Brasil. Empresas produtoras de software por ano de início de atividade (19902019)

Gráfico 2.4. Brasil. Empresas produtoras de aplicativos por ano de início de atividade (1986-2019)

Gráfico 2.5. Brasil. Empresas produtoras de software por porte (2020) 113

Gráfico 2.6. Brasil. Empresas produtoras de aplicativos por porte (2020) 114

Gráfico 2.7. Brasil. Empresas produtoras de software por região (2020) 116

Gráfico 2.8. Brasil. Empresas produtoras de aplicativos por região (2020) 117

Gráfico 2.9. Brasil. Empresas produtoras de software por unidade da federação (2020) . 119 Gráfico 2.10. Brasil. Empresas produtoras de software por unidade da federação, excluindo-se São Paulo (2020)

Gráfico 2.11. Brasil. Empresas produtoras de aplicativos por unidade da federação (2020)

Gráfico 2.12. Brasil. Empresas produtoras de aplicativos por unidade da federação, excluindo-se São Paulo (2020) 121

Gráfico 2.13. Brasil. Número de empresas do ramo de TI (2006-2018) ............................. 148

Gráfico 2.14. Brasil. Pessoal ocupado total no ramo de TI (2006-2018) ............................. 148

Gráfico 2.15. Brasil. Salário médio mensal, em reais, no ramo de TI (2006-2018) ............. 149 


\section{Lista de figuras}

Figura 1.1. Miniaturização de computadores pessoais desenvolvidos pela Apple. Modelos Apple II (1977), Macintosh Plus (1986) e iBook (1999) ............................................................ 36

Figura 1.2. Anéis de fibra óptica Nordeste e Sudeste, operados pela empresa Eletronet .. 55

Figura 1.3. Representação do backbone de Internet no Brasil (2010) ................................. 58

Figura 1.4. Cabos submarinos para conexão à Internet (2021) .......................................... 59

Figura 1.5. Representação da localização dos servidores da Fundação Wikimedia (2006) 82

Figuras 1.6 e 1.7. Servidores da Fundação Wikimedia (2012) 82

Figuras 1.8, 1.9, 1.10 e 1.11. Histórico de aquisições de outras empresas pelas corporações Apple, Amazon, Facebook e Google 86

Figura 2.1. Esquema explicativo de software, plataforma e infraestrutura como serviço 100

Figura 2.2. Apresentação sobre regulação de aplicativos em feira promovida pela Uber (2017) 151

Figura 2.3. Fabricantes de automóveis presentes em feira promovida pela Uber (2017) 152

Figura 2.4. Venda de seguro para automóveis em feira promovida pela Uber (2017) ...... 152

Figura 2.5. Entregadores trabalhando para as empresas Rappi, Glovo e Uber Eats .......... 153

Figura 2.6. Esquema representativo da estrutura produtiva transnacional da Uber ....... 172

Figura 3.1. Principais aplicativos presentes nas telas iniciais de celulares de brasileiros 187

Figura 3.2. Café com oferta de acesso à Internet em Copacabana (Bolívia), 2017 194

Figura 3.3. Lojas de variedades exibindo os logotipos das operadoras de telefonia móvel Entel, Tigo e Viva em San Pedro de Tiquina (Bolívia), 2017 195

Figura 3.4. Aplicativos mais baixados por brasileiros na Google Play Store (30/04/2021) 198

Figura 3.5. Aplicativos mais baixados por brasileiros na AppStore (30/04/2021) 199

Figura 3.6. Detalhe de folder do evento Agrifutura, ocorrido em São Paulo (SP), em 2018 207

Figura 3.7. Anúncio em Teresina (PI) oferece a chamada de carros por aplicativos mediante pagamento 
Figuras 3.8 e 3.9. Detalhes em banners na feira \#InstamarketBR (2019)

Figura 3.10. Folder da empresa Vivo sobre pacote de serviços com acesso gratuito a redes sociais

\section{Lista de mapas}

Mapa 1.1. Brasil. Redes de energia elétrica e registro de domínios de Internet (2018) ..... 61

Mapa 1.2. Brasil. Porcentagem de urbanização dos municípios (2010) ................................ 62

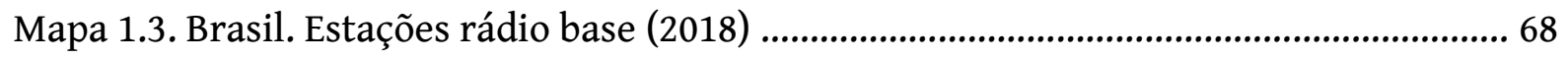

Mapa 1.4. Infraestrutura dos serviços Microsoft Azure ....................................................... 89

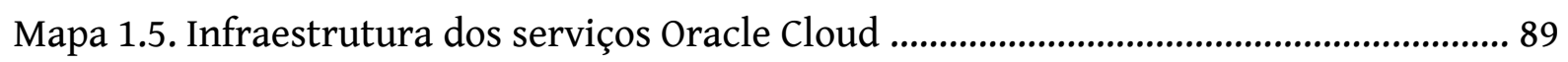

Mapa 1.6. Infraestrutura dos serviços Google Cloud Services - regiões ............................... 90

Mapa 1.7. Infraestrutura dos serviços Google Cloud Services - cabos submarinos ............. 90

Mapa 1.8. Infraestrutura dos serviços Amazon Web Services .......................................... 91

Mapa 2.1. Brasil. Empresas produtoras de software por estado e região (2020) ................ 118

Mapa 2.2. Empresas produtoras de aplicativos por estado (2020) ..................................... 120

Mapa 2.3. Brasil. Municípios com empresas produtoras de software e densidade

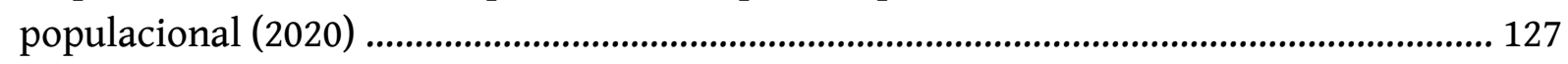

Mapa 2.4. Brasil. Municípios com empresas produtoras de aplicativos e densidade populacional (2020) ................................................................................................................... 128

Mapa 2.5. Regiões de Influência das Cidades ...................................................................... 129

Mapa 2.6. Brasil. Empresas produtoras de software e capitais de estado (2020) ............... 130

Mapa 2.7. Brasil. Empresas produtoras de software e aglomerações produtivas (2020) 131

Mapa 2.8. Brasil. Empresas produtoras de aplicativos, aglomerações produtivas e capitais de estado (2020)

Mapa 2.9. Região Concentrada. Empresas produtoras de software, aglomerações produtivas e capitais de estado (2020)

Mapa 2.10. Região Concentrada. Empresas produtoras de aplicativos, aglomerações produtivas e capitais de estado (2020) 134

Mapa 2.11. Região Nordeste. Empresas produtoras de software, aglomerações produtivas e capitais de estado (2020) 
Mapa 2.12. Região Nordeste. Empresas produtoras de aplicativos, aglomerações produtivas e capitais de estado (2020) 136

Mapa 2.13. Região Centro-Oeste. Empresas produtoras de software, aglomerações produtivas e capitais de estado (2020)

Mapa 2.14. Região Centro-Oeste. Empresas produtoras de aplicativos, aglomerações produtivas e capitais de estado (2020) 138

Mapa 2.15. Região Amazônia. Empresas produtoras de software, aglomerações produtivas e capitais de estado (2020) 139

Mapa 2.16. Região Amazônia. Empresas produtoras de aplicativos, aglomerações produtivas e capitais de estado (2020) 140

Mapa 2.17. Startups “unicórnio" por país (2021) 162

\section{Lista de quadros}

Quadro 2.1. Mercados, serviços e soluções oferecidos em software 105

Quadro 2.2. Famílias ocupacionais que desempenham atividades relacionadas com as tecnologias da informação e comunicação, segundo a Classificação Brasileira de Ocupações (CBO) 146

Quadro 2.3. Características dos paradigmas tecnoeconômicos fordista e das tecnologias de informação e comunicação (TICs) 157

Quadro 2.4. Características de startups “unicórnio” brasileiras (2021) 161

Quadro 3.1. Serviços online oferecidos por meio de aplicativos executados em dispositivos móveis 196

\section{Lista de anexos}

Tabela 1. Brasil. Empresas produtoras de software por ano de criação (1967-2019) ........ 265

Tabela 2. Brasil. Empresas produtoras de aplicativos por ano de criação 266

Tabela 3. Brasil. Empresas produtoras de software por unidade da federação (2020) ..... 267

Tabela 4. Brasil. Empresas produtoras de aplicativos por unidade da federação (2020) . 268

Tabela 5. Profissões fundamentais à produção de software como serviço, listadas na Classificação Brasileira de Ocupações (CBO-2002) 269

Tabela 6. Arranjos Produtivos Locais que desenvolvem software e aplicativos 271 


\section{Lista de acrônimos e siglas}

1G, 2G, 3G, 4G, 5G - Primeira, Segunda, Terceira, Quarta e Quinta Gerações (em comunicação móvel)

$8 \mathrm{~K}$ - Oito mil (pixels)

ABDI - Agência Brasileira de Desenvolvimento Industrial

ABES - Associação Brasileira das Empresas de Software

Anatel - Agência Brasileira de Telecomunicações

ANS - Acordo de Nível de Serviço

Apex-Brasil - Agência Brasileira de Promoção de Exportações e Investimentos

APL - Arranjo Produtivo Local

APTA - Agência Paulista de Tecnologia dos Agronegócios

ARPA - Advanced Research Projects Agency

ARPANET - Advanced Research Projects Agency Network

AWS - Amazon Web Services

Bacen - Banco Central do Brasil

BI - Business Intelligence

BSA - Business Software Alliance

CAPES - Coordenação de Aperfeiçoamento de Pessoal de Nível Superior

CATI - Coordenadoria de Assistência Técnica Integral

CBO - Classificação Brasileira de Ocupações

CD - Compact Disk

CDC - Centro Digital de Cidadania

CDN - Content Delivery Network

Cepal - Comissão Econômica para a América Latina e o Caribe

CERN - European Organization for Nuclear Research

Cetic.br - Centro Regional de Estudos para o Desenvolvimento da Sociedade da Informação

CGI.br - Comitê Gestor da Internet no Brasil

CIDE - Contribuição sobre Intervenção no Domínio Econômico

Conab - Companhia Nacional de Abastecimento

Covid-19 - Coronavirus Disease - 2019 (Doença por Coronavírus - 2019)

CNAE - Classificação Nacional de Atividades Econômicas

CNPJ - Cadastro Nacional de Pessoas Jurídicas

Cobra - Computadores Brasileiros S.A.

Cofins - Contribuição para o Financiamento da Seguridade Social

CPF - Cadastro de Pessoas Físicas 
CPqD - Centro de Pesquisa e Desenvolvimento em Telecomunicações

CRM - Customer Relationship Manager

DeFi - Decentralized Finance

DevOps - Development and Operations

DLT - Distributed Ledger Technology

DoD - Department of Defense

DSP - Demand-Side Platform

DVD - Digital Video Disc

EAQ - Entidade Aferidora da Qualidade

EDI - Electronic Data Interchange

EGTI - Estratégia Geral de Tecnologia da Informação e Comunicação

EI - Empresa Individual

EIRELI - Empresa Individual de Responsabilidade Limitada

ERP - Enterprise Resource Planning

EUA - Estados Unidos da América

FAPESP - Fundação de Amparo à Pesquisa do Estado de São Paulo

FGV - Fundação Getúlio Vargas

FINEP - Financiadora de Estudos e Projetos

FLOSS - Free, Libre and Open Source Software

FTP - File Transfer Protocol

Fundepag - Fundação de Desenvolvimento da Pesquisa do Agronegócio

FUST - Fundo de Universalização dos Serviços de Telecomunicações

GAFAM - Google, Amazon, Facebook, Apple e Microsoft

GB/s - Gigabyte por Segundo

GDPR - Global Data Protection Regulation

$\mathrm{GHz}$ - Gigahertz

GPN - Global Production Network

GPS - Global Positioning System

GV - Google Ventures

HD - Hard Disk

HDD - Hard Disk Drive

HPC - High Performance Computing

HTTP - Hypertext Transfer Protocol

IaaS - Infrastructure as a Service

IBGE - Instituto Brasileiro de Geografia e Estatística

IBM - International Business Machines Corporation

ICANN - Internet Corporation for Assigned Names and Numbers 
ICMS - Imposto sobre Circulação de Mercadorias e Prestação de Serviços

IETF - Internet Engineering Task Force

IME - Instituto Militar de Engenharia

IP - Internet Protocol

IPO - Initial Public Offering

ISP - Internet Service Provider

ISS - Imposto Sobre Serviços

ITA - Instituto Tecnológico da Aeronáutica

IXP - Internet Exchange Point

JSTOR - Journal Storage

LGPD - Lei Geral de Proteção de Dados

LGT - Lei Geral de Telecomunicações

LTDA - Sociedade de Responsabilidade Limitada

Mapa - Ministério da Agricultura, Pecuária e Abastecimento

MB - Megabyte

Mbps - Megabit por Segundo

MCT - Ministério da Ciência e Tecnologia

MEI - Microempreendedor Individual

MISTICA - Metodología de Impacto Social de las Tecnologías de la Información y de la Comunicación en América

MPT - Ministério Público do Trabalho

MTE - Ministério do Trabalho e Emprego

NASA - National Aeronautics and Space Administration

NATU - Netflix, Airbnb, Tesla e Uber

NBS - Nomenclatura Brasileira de Serviços

NIC.br - Núcleo de Informação e Coordenação do Ponto BR

OCB/PA - Organização das Cooperativas Brasileiras no Estado do Pará

OPGW - Optical Ground Wire

OTCA - Organização do Tratado de Cooperação Amazônica

P2P - Peer-to-Peer

PAA - Programa de Aquisição de Alimentos

PARC - Palo Alto Research Center

PC - Personal Computer

PIB - Produto Interno Bruto

PIS/Pasep - Programa Integração Social/Programa de Formação do Patrimônio do Servidor Público

PITCE - Política Industrial, Tecnológica e de Comércio Exterior

PNAD - Pesquisa Nacional por Amostra de Domicílios 
PNBL - Plano Nacional de Banda Larga

PNI - Política Nacional de Informática

PoP - Point of Presence

PTT - Ponto de Troca de Tráfego

PTTMetro - Metropolitan Internet Exchange Point

RECAP - Regime Especial de Aquisição de Bens de Capital para Empresas Exportadoras

REPES - Regime Especial de Tributação para a Plataforma de Exportação de Serviços de Tecnologia da Informação

RMSP - Região Metropolitana de São Paulo

RNP - Rede Nacional de Pesquisa

SaaS - Software as a Service

SACS - South Atlantic Cable System

SCD - Sociedade de Crédito Direto

SCM - Serviço de Comunicação Multimídia

SCS - Software como Serviço

SDD - Solid Disk Drive

Sebrae - Serviço Brasileiro de Apoio às Micro e Pequenas Empresas

SECTI - Secretaria de Ciência, Tecnologia e Inovação

SEI - Secretaria Especial de Informática

SEP - Sociedade de Empréstimo entre Pessoas

SGDC - Satélite Geoestacionário de Defesa e Comunicações Estratégicas

SIG - Sistemas de Informação Geográfica

SM - Salário Mínimo

SMP - Serviço Móvel Pessoal

Softex - Associação para Promoção da Excelência do Software Brasileiro

SQL - Structured Query Language

SRI - Stanford Research Institute

STEM - Science, Technology, Engineering, and Mathematics

STF - Supremo Tribunal Federal

STJ - Supremo Tribunal de Justiça

TCP/IP - Transmission Control Protocol/Internet Protocol

TI - Tecnologias da Informação

TIC - Tecnologias da Informação e Comunicação

TRIPS - Trade-Related Aspects of Intellectual Property Rights

UFRA - Universidade Federal Rural da Amazônia

VTI - Valor de Transformação Industrial

WEF - World Economic Forum 
Wi-fi - Wireless Fidelity

ZB - Zettabyte 


\section{Sumário}

Introdução

Capítulo 1. Informatização do território: condições para a produção de aplicativos ............................................................................................... 26

1.1 Unicidade técnica e mudanças qualitativas das TI: tecnosfera e a primazia da informação .................................................................................. 31

1.2 Transformações no macrossistema técnico para conectividade à Internet no território brasileiro ..................................................................................... 46

1.3 O advento da computação em nuvem como evento geográfico ................. 75

Capítulo 2. Produzindo software como serviço: um bem intangível no mundo globalizado 96

2.1 Novos contratos, novas interações espaciais: tipologia e topologia dos agentes produtores de software como serviço no Brasil ........................... 102

2.2 Mudanças socioespaciais na composição da mão de obra no ramo de software

2.3 Transformações na indústria de software no contexto da globalização 164

Capítulo 3. Do data center à palma da mão: usos dos aplicativos, usos do território 183

3.1 Conectividade e novos padrões de consumo de software na cidade e no campo 189

3.2 Economias do compartilhamento e o estímulo ao consumo de aplicativos: criação e difusão de novos consensos no espaço geográfico 209

3.3 Mais conexões, outros usos possíveis: as TI como campo em disputa .. 224

Conclusão 239

Referências 


\section{Introdução}

Esta tese apresenta os resultados de nossa pesquisa de doutorado, que teve como objetivo investigar a produção e o consumo de software como serviço ${ }^{1}$ (SCS) no território brasileiro. Realizamos uma análise da dinâmica dessa atividade econômica no Brasil e dos fatores que permitem sua existência e reprodução no contexto da informatização do território, processo este que se acentua desde os anos 1970. Especificamente, procuramos compreender esse processo por meio da elaboração de uma tipologia das empresas produtoras de aplicativos no território brasileiro e examinamos as particularidades da divisão territorial do trabalho no contexto da fabricação de bens intangíveis.

A configuração de uma base técnica e de uma base normativoinstitucional têm garantido, sobretudo nas últimas duas décadas, a capilarização de redes telemáticas, especialmente a Internet $^{2}$ fixa e móvel - que facilita a interconexão entre objetos e, como consequência, promove a expansão das atividades de empresas produtoras de SCS. No que diz respeito aos diferentes usos dos aplicativos, nossa investigação é direcionada em termos de consumo consumptivo e produtivo, e dos vários fatores que contribuem para a conformação de um consenso em torno do estímulo ao consumo desse tipo de software. Sua popularização possui estreita relação com o desenvolvimento de tecnologias para Internet e computação em nuvem, como demonstramos com a pesquisa.

O método com o qual trabalhamos para abordar o software como serviço do ponto de vista da Geografia se concentra em três grandes temas fundamentais. Primeiro, apresentamos uma discussão sobre a tecnosfera sem a qual não seriam possíveis o surgimento e a capilarização dos aplicativos. Essencialmente, é onde tratamos da informatização do território e das redes telemáticas que auxiliam a

1 Nesta tese, utilizaremos o termo "aplicativos" de modo intercambiável para tratar desse tipo de software. Mais detalhes sobre sua definição serão apresentados no Capítulo 1.

2 A palavra "Internet" é grafada com letra maiúscula como referência a debates no âmbito de sua governança, especialmente como contraponto à proposta da União Internacional de Telecomunicações (UIT) de utilizar a letra minúscula (KURBALIJA, 2016, p. 18-19). É comum utilizar-se o "i” minúsculo quando se está referindo somente aos cabos e antenas que compõem a infraestrutura da rede. A Internet, no entanto, abarca todas as dimensões de seu complexo uso e desenvolvimento, técnica e politicamente, refletindo a disputa semântica por sua denominação e as relações de poder ali expressas. 
conformar e difundir o meio geográfico atualmente predominante - o meio técnico-científico-informacional -, do qual o software (ou, mais genericamente, a informação) é um elemento crucial.

Em seguida, tratamos da produção desse bem intangível, explorando as características inerentes a seus vários tipos - sendo o software como serviço um deles - e o modo como é produzido. A divisão territorial do trabalho e a topologia das empresas dela derivada dialogam com as diferentes formas de contratos e interações espaciais entre os agentes que compõem o ramo - das pequenas empresas nacionais às gigantes multinacionais, que usam o território diferenciadamente. Elas têm características distintas quanto ao tipo de aplicativo que produzem, porte, localização, receita e quanto ao alcance de suas ações. Especialmente entre as grandes corporações, é cada vez mais comum que empreguem mão de obra precarizada e com a especificidade de poder ser acessada remotamente durante todo o desenvolvimento do produto, em função de fatores como incentivos fiscais e menores custos trabalhistas encontrados em países distantes da matriz da empresa. Tudo isso faz parte do contexto da chamada "economia dos aplicativos", por vezes também referenciada na literatura como "economia do compartilhamento", "economia de plataforma", "capitalismo de dados", "capitalismo cognitivo", "gig economy", entre outros termos.

Nosso terceiro e último foco é nos usos do software como serviço. Para abordá-los, fazemos uma distinção entre o consumo produtivo e o consumo consumptivo dos aplicativos. No contexto da "economia de plataforma", existem estímulos ao consumo do SCS que passam por discussões como a difusão de discursos nas redes digitais, a privacidade na coleta de dados pessoais e usos emancipadores das tecnologias, por agentes não-hegemônicos. Esses usos se desenham conforme a localização dos agentes - por exemplo, em áreas urbanas ou rurais, com maior ou menor acesso a conectividade -, quanto às formas de organização social que adotam ou conforme suas necessidades.

Este trabalho teve como uma das principais estratégias metodológicas a pesquisa em bases de dados. Realizamos explorações dos dados do Cadastro Nacional de Pessoas Jurídicas (CNPJ), disponibilizados trimestralmente pela Receita 
Federal em seu website ${ }^{3}$, que foram manipulados para caracterizar as empresas produtoras de software no Brasil. As informações disponíveis sobre as empresas envolvem nome, data de início de atividade, porte, capital social, localização (desde a unidade federativa até o logradouro), opção por regimes fiscais como Simples e microempreendedor individual (MEI), situação cadastral, entre outras.

A extração dos dados foi feita nos softwares RStudio e SQLite3, com as linguagens de programação $\mathrm{R}^{4}$ e $\mathrm{SQL}^{5}$. Em seguida, fizemos a seleção somente das firmas produtoras de software, a partir do código CNAE fiscal informado (referente à subclasse). A manipulação desse subconjunto de dados e dos outros com os quais trabalhamos, bem como a produção de mapas, tabelas e gráficos, foram feitas na linguagem Python, na suíte de aplicativos de código aberto LibreOffice (similar ao Microsoft Office) e no software Magrit ${ }^{6}$.

Nosso objeto de investigação envolve temas contemporâneos, interdisciplinares e em constante atualização. Ainda que essas características tornem o trabalho mais desafiador, do contato com outras áreas de pesquisa - tais como Ciência da Computação, Sociologia e Ciências Econômicas - emergem novos flancos de ação que enriquecem nossas metodologias, análises e interpretações. Por isso, aproveitamos esta oportunidade para ressaltar a importância de ter acesso a dados abertos e a softwares livres de alto desempenho para manipulação de dados, bem como o papel da comunidade de pesquisadores e programadores que disponibilizam algoritmos gratuitamente na Internet para auxiliar outras pessoas que porventura tenham interesses afins. Sem esses recursos, nosso trabalho teria sido muito mais limitado.

3 Vide endereço web <https://receita.economia.gov.br/orientacao/tributaria/cadastros/cadastro-nacionalde-pessoas-juridicas-cnpj/dados-publicos-cnpj>.

4 R é uma linguagem de programação desenvolvida em 1993, focada em computação estatística. RStudio é um software livre e gratuito utilizado para escrever algoritmos com essa linguagem e visualizar os resultados das análises. Ambos são amplamente utilizados por pesquisadores de diversas áreas.

5 Structured Query Language (em português, Linguagem de Consulta Estruturada) ou SQL é uma linguagem que, por sua simplicidade, se tornou um padrão para pesquisa em bancos de dados relacionais. Foi desenvolvida pela companhia IBM nos anos 1970 (CABRAL et al., 2017, p. 240). SQLite3 é um software utilizado para manipulação de dados com a linguagem SQL.

6 Python é uma linguagem de programação de código aberto lançada em 1991, utilizada largamente em vários campos do conhecimento e indústrias. Magrit é um software livre para cartografia temática que funciona dentro do navegador (browser) - chamado também de "aplicação web" ou "web app" -, disponível em $<$ http://magrit.cnrs.fr/>. 
As tecnologias da informação (TI) se assentam como fator central de uma das maiores transformações pelas quais a humanidade tem passado. Para além da história das tecnologias em geral, as TI têm sua própria trajetória de complexificação e diversificação, como resultado da associação de elementos técnicos, políticos, sociais, econômicos e culturais. Dentre a miríade de componentes do universo das TI, o software (ou programa de computador) é um dos mais fundamentais e populares, pela possibilidade de ser utilizado em uma grande variedade de atividades cotidianas e de processos produtivos. A automação de tarefas simples e complexas levou e continua levando a significativas alterações e a novas perspectivas de análise em diversos campos, tais como a divisão territorial do trabalho e as relações sociais no espaço geográfico.

A relevância do software como serviço vem tanto da imensa capilaridade de seu uso (inclusive para geração de renda, como no caso dos entregadores) quanto das características muito particulares a seu processo produtivo - já que se trata de um bem intangível que, conforme revela sua própria denominação, é distribuído via contratos de prestação de serviços. Outro atributo basilar dos aplicativos é o funcionamento atrelado à conectividade, ou seja, à disponibilidade de redes telemáticas e dispositivos informacionais - por exemplo, aqueles que possuem o chip como um elemento central de seu funcionamento e têm a possibilidade de conexão à Internet, como computadores e telefones celulares. Tais redes e equipamentos, por sua vez, não são distribuídos uniformemente no espaço; no entanto, é patente que estão se disseminando rápida e drasticamente pelo mundo, sobretudo nos últimos 30 anos.

De acordo com Santos (2009), esse tipo de transformação técnica também autoriza novas divisões sociais e territoriais do trabalho, como consequência de mudanças no paradigma tecnológico e de ações e decisões políticas. Emergem novas relações de trabalho e novos nexos entre os agentes e o espaço, que podem ser interpretados como novos usos do território (SANTOS, 2009; SILVEIRA, 2012). Silveira (2012, p. 210) observa que

Hoje, a partir dos fatores tecnológicos, organizacionais, informacionais, financeiros da produção, tem lugar uma profusão de objetos técnico-informacionais, que conhecem uma difusão mais 
rápida, em famílias e sistemas, com permanentes substituições e indispensáveis recomposições de suas relações sistêmicas.

Identificamos o surgimento e a propagação do uso dos aplicativos como um grande exemplo do processo mencionado pela autora. Sua disseminação passou a se intensificar após meados dos anos 2000, coincidindo com a origem da tecnologia da computação em nuvem, que promoveu a adoção de contratos de prestação de serviços em TI mais flexíveis. Teve início, então, uma considerável reorganização na família de técnicas do campo das TI, indissociada de novas características no comportamento dos agentes que participam desse ramo econômico. Em outras palavras, houve um rearranjo nos sistemas de objetos e ações envolvidos na produção de software, com modificações profundas nas dinâmicas do espaço geográfico.

Ainda que extraordinárias, essas mudanças não são tão perceptíveis no dia a dia: acabamos mergulhados numa abundância de produtos tecnológicos, acompanhando o lançamento de novos aparelhos e aplicativos em velocidade difícil de acompanhar. Como consequência, assenta-se na sociedade um estado de confusão dos espíritos que abre caminho ao uso imperialista das técnicas (SANTOS, 2000, p. 37; 52), expresso pelo poder político e financeiro dos oligopólios de TI.

A despeito da urgência do tema, causa inquietação perceber um desajuste entre sua relevância para explicar e compreender o mundo contemporâneo e a produção acadêmica nas Ciências Humanas, em geral, e na Geografia, em particular. Justamente por sua evidente interdisciplinaridade, espera-se que diversas áreas do conhecimento estejam acompanhando e debatendo as implicações do uso de tecnologias contemporâneas, como a propagação dos aplicativos e da computação em nuvem. Não é necessariamente o que se verifica ao realizar uma pesquisa em bases de dados de periódicos disponíveis na Internet: como exemplo, a Tabela 1 traz os resultados de uma busca por artigos em português combinando o termo "Geografia" e as palavras-chave listadas, relacionadas a nossos interesses de pesquisa. 
Tabela 1. Resultados de buscas em bases de dados de periódicos (agosto/2020).

\begin{tabular}{|c|c|c|c|c|}
\hline Portal & CADEC & ICTOD & Whb of Crianos & Conglo coholom \\
\hline Palavra-chave & Gin & ה & The of Ge & 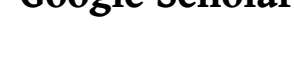 \\
\hline Software & 6.609 & 458 & 31 & 93.500 \\
\hline Informação & 4.038 & 543 & 92 & 635.000 \\
\hline Informática & 3.277 & 308 & 59 & 113.000 \\
\hline Aplicativo & 248 & 2 & 5 & 26.600 \\
\hline Computação & 229 & 15 & 2 & 37.800 \\
\hline Conectividade & 157 & 2 & 4 & 21.400 \\
\hline $\begin{array}{l}\text { Programa de } \\
\text { computador }\end{array}$ & 31 & 1 & 1 & 4.700 \\
\hline Computação em nuvem & 3 & 0 & 0 & 987 \\
\hline
\end{tabular}

Fonte: elaboração própria, com base nos websites das bases de dados Periódicos CAPES (busca por artigos revisados por pares), JSTOR, Web of Science e Google Scholar.

Uma consulta por "Geografia" e "software como serviço" ou "software as a service" sequer retorna resultados, com exceção da ferramenta Google Scholar, que traz 121 e 262 resultados para cada termo, respectivamente. Este website faz uma indexação mais ampla na web, e por isso apresenta números tão altos em relação às demais bases. Nossa consulta revela, então, que os resultados vão rareando em direção a tecnologias mais recentes, como a computação em nuvem e o software como serviço. Além disso, a imensa maioria dos artigos encontrados não abordava diretamente os temas selecionados, e sim aqueles aos quais as tecnologias são transversais - especialmente Ensino de Geografia (por exemplo, uso de aplicativos em sala de aula), Cartografia e Sistemas de Informação Geográfica (SIG).

Outros aspectos que pudemos observar foram que o portal JSTOR pareceu trazer resultados com maior relevância dentro dos assuntos que buscamos; e, numa pesquisa mais abrangente, a plataforma Web of Science acusou muito mais resultados em inglês e dos Estados Unidos do que de qualquer outro país ou idioma, confirmando uma tendência dos conteúdos disponibilizados na Internet em geral. É alarmante que essas questões não estejam sendo endereçadas tão intensamente pela Geografia no Brasil, um dos maiores mercados 
consumidores de aplicativos no planeta - justamente num ramo econômico que depende do sustento de uma ampla base de usuários e da crescente conectividade dos territórios.

Apesar da imensa e exponencialmente maior quantidade de informação disponível para análise a cada dia, o tema das TI parece nos atropelar. Os aplicativos são utilizados para finalidades das mais variadas: comunicação, acesso à informação, comércio eletrônico, prestação de serviços públicos, telemedicina, trabalho remoto, ensino à distância e fruição cultural (CETIC.BR, 2020, p. 3). As transformações são tantas, em tantas instâncias e com disseminação tão ampla, que acabamos imersos num contexto demasiadamente complexo para se analisar. Contudo, procuramos mostrar nesta pesquisa que podemos tomar parte no debate sobre os aplicativos, a partir do método geográfico e de áreas correlatas.

Por fim, deixamos o registro de que boa parte desta tese foi redigida durante a pandemia do novo coronavírus, o que implicou em diversas alterações em nossa metodologia. Antes da crise sanitária, pudemos realizar visitas técnicas a uma série de feiras especializadas em TI, que são citadas em diversos momentos na tese, mas com o período de isolamento, o trabalho de campo já não era uma opção. Certamente, as consequências do atual momento histórico serão sentidas por muito tempo, e reforçam a necessidade de se estudarem as TI, que ganharam ainda mais relevância nesse contexto. 


\section{Capítulo 1. Informatização do território: condições para a produção de aplicativos}

Se estiver lendo este texto em formato eletrônico, você provavelmente está utilizando um sistema operacional e leitores de documentos de texto produzidos por alguma das maiores corporações do ramo de informática (por exemplo, Microsoft ou Adobe). Durante suas atividades cotidianas, eventualmente acessará um portal de buscas como o Google, ou se conectará com outras pessoas por aplicativos como WhatsApp e Facebook, em smartphones produzidos por firmas como Samsung e Apple. Os dados recebidos em seu aparelho certamente vieram de um data center, e podem ter passado por um sistema de computação em nuvem operado por um serviço como o Amazon Web Services.

A ubiquidade e a permeabilidade das grandes firmas de TI denotam sua dominância nas mais variadas atividades de pessoas e organizações. Utilizar softwares, sejam os aplicativos de celular ou programas em computadores portáteis (laptops), tornou-se uma atividade corriqueira para grande parte das pessoas: estima-se que havia 3,4 bilhões de usuários da Internet no mundo em 2016 (ROSER; RITCHIE; ORTIZ-OSPINA, 2021). No mesmo ano, o Brasil chegaria ao quarto lugar entre os países com maior número de internautas, totalizando por volta de 126 milhões (Gráfico 1.1). Em 2020, atingiu o posto de terceiro maior mercado de aplicativos do mundo. Mas é preciso contextualizar essas mudanças técnicas. Em que se assenta a profusão de tais tecnologias, e como se situam os softwares como serviço nesse processo? Quão desigual ele foi e é nos territórios, especialmente na formação socioespacial brasileira? 
Gráfico 1.1. Brasil. Usuários de Internet (1996-2016).

Brasil. Usuários de Internet (1996-2016)

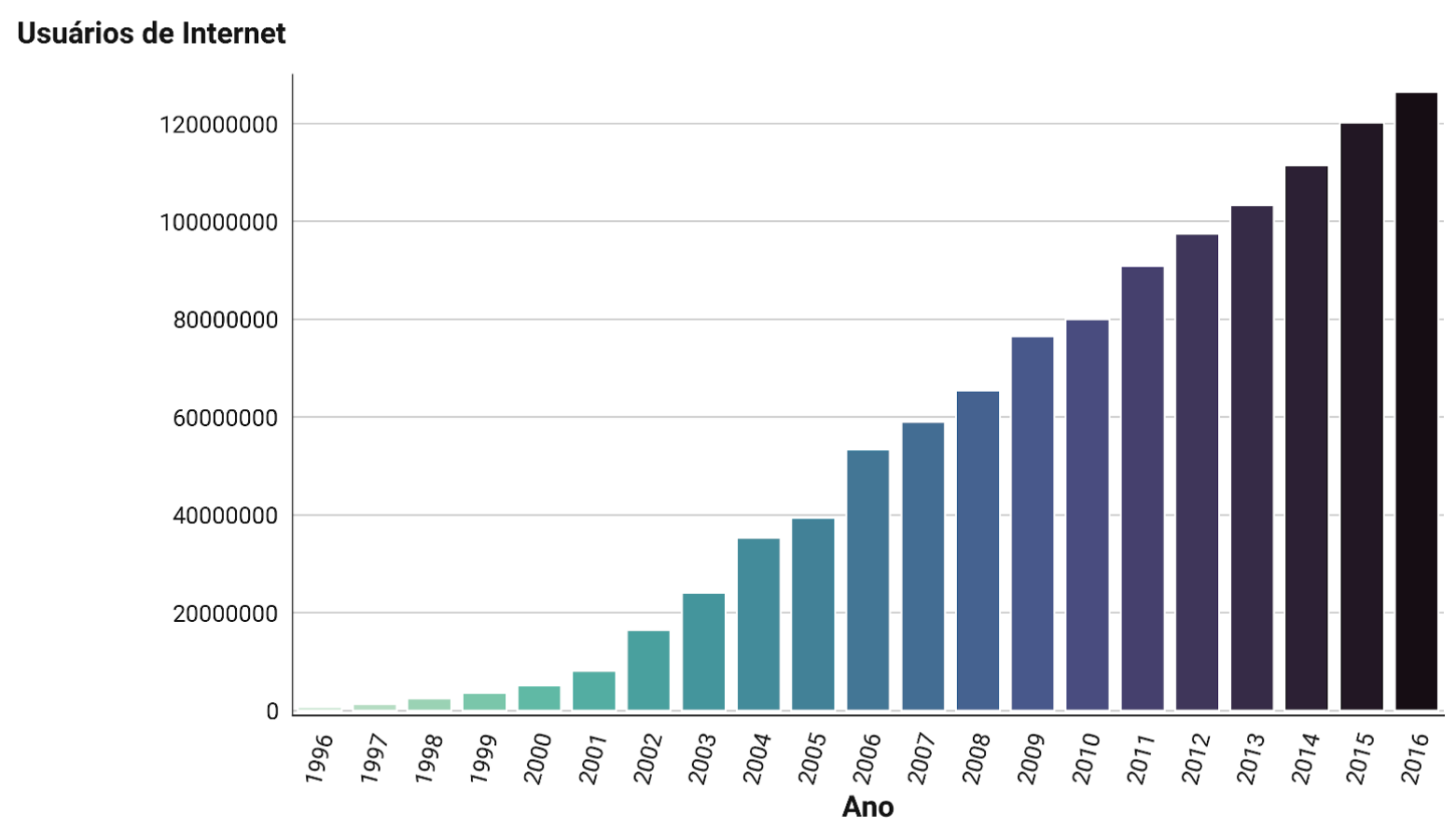

Fonte: Our World in Data, 2021. Elaboração própria.

Fonte: elaboração própria, a partir de Roser, Ritchie e Ortiz-Ospina (2021).

O cenário acima se desenha num contexto em que, conforme assinala Silveira (2016, p. 99), “amparados na convergência técnica e nas necessidades contemporâneas da produção e comunicação de ideias, imagens e dados em geral, telefones celulares, computadores, equipamentos de fotografia e vídeo tornam-se mais acessíveis às diversas camadas sociais". Essas necessidades se tornam gradualmente mais numerosas específicas, ao passo que ampliam-se as possibilidades de usos do território por todos os agentes.

É ainda nessa circunstância que se configura o atual momento do período técnico-científico-informacional (século XXI): a informatização do território aprofundou-se a ponto de permitir o surgimento de novos objetos, como os aplicativos, cujo uso rapidamente capilarizou-se no cotidiano das pessoas. No meio geográfico homônimo, caracterizado por Santos (2009, p. 235), predominam os objetos elaborados a partir da ciência e da informação, cujas técnicas autorizam novidades nos processos produtivos e nas relações entre os agentes entre si e no 
território. As TI passam a cada vez mais mediar tais relações, sendo um elo relevante dos nexos que se conformam no espaço geográfico, e a produção e o uso de software como serviço são amparadas por uma série de fatores. Neste momento, iremos nos concentrar no processo de informatização do território para entender como se dá essa dinâmica no Brasil.

Uma história de modernização incompleta do território brasileiro condiciona a difusão dessas novas técnicas. As infraestruturas de conectividade e comunicação se popularizam em conjunto com a emergência de novos nexos normativos, e tecnologias como o smartphone chegam mesmo a condicionar as interações espaciais, conforme estudado por Bertollo (2019).

As técnicas de comunicação em ascensão ou consolidadas neste período, como cabos de fibra óptica, antenas de radiofrequência, servidores e data centers, constituem uma base técnica para o funcionamento dos aplicativos que tem origens em paradigmas econômicos e tecnológicos pretéritos. Se anteriormente predominavam redes de telégrafo ou telefonia, por exemplo, hoje a Internet, em seu caráter híbrido de materialidade e virtualidade ${ }^{7}$ (EVASO, 2006, p. 27), é a rede por excelência da comunicação globalizada.

Como aponta Santos (2009, p. 332), “já que a técnica é também social, pode-se lembrar que sistemas de objetos e sistemas de ações em conjunto constituem sistemas técnicos, cuja sucessão nos dá a história do espaço geográfico". Portanto, a evolução técnica (por exemplo, em transportes e comunicações) dialoga com o desenvolvimento de condições históricas e com as heranças espaciais dos lugares, regiões e territórios, levando à predominância de um conjunto de sistemas técnicos sobre outros. Alguns exemplos são os paradigmas do trem e telégrafo; do avião, telefone e automóvel; e o das redes telemáticas e logística moderna.

No âmbito produtivo, o paradigma da indústria 4.0, vigente neste período histórico, caracteriza-se pela priorização de investimentos pelos agentes

7 "Chamamos de conectividade aquilo que é constituído pelos sistemas de engenharia disponíveis e seus acessórios e complementos, enquanto a virtualidade é constituída pela circulação eficaz dos dados que permeiam tais sistemas. $O$ conjunto gerado pela parceria entre conectividade e virtualidade constitui a totalidade da Internet" (EVASO, 2006, p. 27). 
hegemônicos em áreas como integração de sistemas, segurança cibernética, Internet das Coisas, inteligência artificial, machine learning e big data ${ }^{8}$. É nesse contexto que tem-se o desenvolvimento das indústrias de computadores, produtos eletrônicos, de software e telecomunicações (FREEMAN; PEREZ, 1988). Já o atual paradigma da circulação é baseado nas redes telemáticas e na logística moderna, permitindo a teleação e a comunicação à distância entre dispositivos diversos. Há uma ênfase na coleta, no armazenamento e na transmissão de informações, conformando-se as condições para o que Blanco (2015) denomina hipermobilidade - não excluindo-se o fato de que a mobilidade é um atributo relativo, de modo que alguns agentes são "mais móveis" em relação a outros e a depender das tecnologias que utilizam.

Esses fatores vêm se configurando principalmente desde a terceira Revolução Industrial, quando a busca por crescente automação estimulou o desenvolvimento de tecnologias como computadores, chips, microeletrônica, transistores, robótica, circuitos eletrônicos e os softwares. Lembramos, com Sposito (2019, p. 19), que o atual momento de quarta Revolução Industrial, "como ocorreu com as revoluções industriais anteriores, é um processo desigual e combinado que não se territorializa de maneira homogênea ou, pelo menos, com alguma possibilidade de equidade", de modo que a própria desigualdade entre os territórios fomenta diferenciações regionais e nacionais no que tange às tecnologias da informação9. Possas (2006, p. 36) deixa clara a relevância das inovações tecnológicas em TI para chegarmos ao atual estado dos sistemas técnicos:

Na medida em que uma inovação se situa num mesmo paradigma tecnológico, isso significa que o produto mantém as suas principais

8 Os dados que trafegam nas infovias e são manipulados por meio de softwares estão geralmente organizados em tamanho nível de sofisticação que são chamados de "big data" - uma "tecnologia de grande volume em armazenamento de dados gerada a cada dia. Essa tecnologia atua com os 3 'Vs': velocidade, variedade e volume. Isso permite uma análise em tempo real de milhares de informações" (CABRAL et al., 2017, p. 41).

9 "A preocupação com a quarta Revolução Industrial justifica-se por: 1) é um processo que está em pleno desenvolvimento, ou seja, no momento, convive-se com as transformações que estão ocorrendo nos processos produtivos e na divisão territorial do trabalho; 2) como ocorreu com as revoluções industriais anteriores, é um processo desigual e combinado que não se territorializa de maneira homogênea ou, pelo menos, com alguma possibilidade de equidade; 3 ) as diferenciações regionais e nacionais tendem a se potencializar por causa do "ponto de partida": a desigualdade entre territórios e nações" (SPOSITO, 2019, p. 19). 
características físicas, e que seu processo de produção se apoia nos mesmos princípios científicos e numa mesma base técnica. As alterações ocorrem, mas a maior parte dos atores, das atividades, dos materiais e dos conhecimentos envolvidos permanecem os mesmos. Uma mudança de paradigma, entretanto, pode significar uma modificação realmente drástica em todos esses elementos. Pensemos, por exemplo, no que significou a migração das máquinas de escrever para os computadores. Tudo mudou - os fornecedores, a tecnologia relevante etc.

Tais mudanças são como megatendências que se espalham pelo mundo com notável velocidade, amplitude e profundidade, de modo a gerar um impacto sistêmico (SCHWAB, 2016; 2018; SPOSITO, 2019, p. 22-23). Foi no século XX, com a terceira Revolução Industrial, que se intensificou a produção de computadores, chips, transistores e circuitos eletrônicos e ferramentas para microeletrônica e robótica. Tais objetos técnicos possibilitaram a modernização das indústrias de telecomunicações, radiodifusão, aeroespacial, biotecnologia, petroquímica e aviação, entre muitas outras, nos aproximadamente 40 anos do chamado ciclo da eletrônica (SPOSITO, 2019, p. 26).

Já a quarta Revolução Industrial, mais perceptível desde a virada para o século $\mathrm{XXI}^{10}$, se assenta em "uma internet mais ubíqua e móvel, por sensores menores e mais poderosos, que se tornaram mais baratos, e pela inteligência artificial e aprendizagem automática (ou aprendizagem da máquina)" (SCHWAB, 2016, p. 16). Contudo, como em outras etapas de difusão do meio técnico-científico e do meio técnico-científico-informacional, boa parte da população do planeta está excluída do acesso às citadas inovações tecnológicas.

Daí se pode entender que os modernos objetos informacionais são meio de realização do que Santos $(2009$, p. 333) chama de "sincronização despótica" dos tempos, sendo funcionais ao alinhamento dos lugares e dos agentes à "velocidade do mundo". Apenas alguns deles conseguirão estar sincronizados, ainda que os contextos se alarguem e se tornem mais espessos, criando-se uma crescente interdependência entre os subespaços (SANTOS, 2009, p. 254).

10 Silveira $(2009$, p. 21) prefere definir como "quinta revolução e evolução logística" a modernização que vem ocorrendo desde o final do século XX, a partir principalmente do Japão, dos Estados Unidos e de partes da Ásia. O autor lista como fatores característicos "maior integração comercial, infovias, autoestradas, telemática, trens de alta velocidade, fibra ótica, comunicação via satélite etc.". 
Tendo em conta as especificidades das formações socioespaciais (SANTOS, 1977), ou seja, as características inerentes a cada subespaço que mediam a chegada de vetores de modernização, é que se percebe o papel ativo do território. Assim também fica mais claro que nem todas as partes do mundo respondem igualmente às demandas da globalização, das quais fazem parte a difusão de redes e equipamentos. Em outras palavras, as ordens globais não se realizarão da mesma maneira em cada formação socioespacial, de modo que mesmo as ações hegemônicas encontram resistências e condições que moldam seu funcionamento em cada porção do território.

Note-se que os modernos objetos técnicos podem se organizar em (ou mesmo conter em si) microssistemas ou sistemas de gigantesca dimensão, como é o caso dos macrossistemas de comunicação ou de provisão de energia elétrica (SANTOS, 2009, p. 253). Seguindo trajetória similar à destes últimos, atualmente a informação passa a ser meio de união entre diversas partes de um território (idem, 2009, p. 167). O processo de informatização está alicerçado sobre a existência de redes técnicas, que podemos entender como um sistema de objetos, ou partes de um macrossistema técnico ${ }^{11}$ (HUGHES, 2008; SANTOS, 2009) que, por sua vez, resulta num conjunto de intencionalidades, exigências, necessidades e comportamentos dos agentes que dele se utilizam - um par dialético, portanto, de tecnosfera e psicosfera (RIBEIRO, 1991; SANTOS, 2009; KAHIL, 2012).

\subsection{Unicidade técnica e mudanças qualitativas das TI: tecnosfera e a primazia da informação}

As redes e os objetos técnicos usados para a circulação de dados e a

\footnotetext{
11 Os macrossistemas técnicos são uma pluralidade de redes "sem os quais os outros sistemas técnicos não funcionariam". Eles "promovem grandes trabalhos (barragens, vias rápidas de transporte terrestre, aeroportos, telecomunicações, etc.) [...], e constituem o fundamento material das redes de poder" (SANTOS, 2009 , p. 177-178). De acordo com Ribeiro (2015, p. 100), "pode-se considerar que alguns macrossistemas apresentam um caráter mais estratégico e uma condição mais necessária, como o elétrico e o de comunicação, que além de garantirem o funcionamento de todos os outros macrossistemas, também garantem a produção, distribuição e uso da maioria dos bens e serviços da maior parte das organizações das sociedades atuais".
} 
comunicação entre as pessoas são um dos elementos do meio técnico-científicoinformacional de mais rápida apreensão na vida cotidiana. Ao olhar ao redor em um ônibus, em um restaurante ou até na sala de aula, é possível ver muitas pessoas utilizando um smartphone, por exemplo. Grande parte das conversas é feita por email ou aplicativos de mensagens.

Mas um salto na difusão e no aprimoramento dessas tecnologias é notável especialmente nas três últimas décadas (desde os anos 1990); em termos de usuários de dispositivos, consolidou-se um imenso mercado consumidor. A indústria de informática acompanhou esse movimento, tanto na produção de hardware quanto na de software - respectivamente, as indissociáveis dimensões tangível e intangível dos produtos computacionais, dado que um não pode funcionar sem o outro.

O Brasil se insere, com seus macrossistemas técnicos de comunicação (SANTOS; SILVEIRA, 2011) nesse fenômeno de alcance planetário. Gradativamente, vai aumentando o grau de integração eletrônica do território (CASTILLO, 1999). Estados, empresas e a sociedade civil, cada agente a seu modo, impulsionam as inovações tecnológicas que levam a incrementos no alcance e na capacidade desses sistemas, e consequentemente a alterações de uso e organização dos territórios. Esses incrementos se expressam, por exemplo, pela disponibilidade de velocidades de acesso à Internet cada vez maiores, tanto para usuários estatais ou corporativos (que exigem maior capacidade de transmissão de dados pela rede, pelas funções que desempenham através dela) quanto para pessoas físicas.

O desenvolvimento das técnicas da informação permite que as demais técnicas existentes se comuniquem entre si (SANTOS, 2000, p. 25), colocando-se como um elemento mediador fundamental. Afirma Dowbor (2020, p. 29) que "a tecnologia é hoje o principal fator de produção", tendo em vista que os bens intangíveis controlam a maioria dos sistemas produtivos tradicionais. "A era digital, com os seus novos processos tecnológicos, suas novas formas de apropriação do excedente e dos sistemas políticos, não substitui nem a agricultura nem a indústria, mas passa a submetê-las a uma nova lógica" (DOWBOR, 2020, p. 38). É, de fato, o que se observa no mercado de aplicativos, desenvolvidos para as 
mais diversas finalidades - por exemplo, com a teleação na indústria, com as aplicações na agricultura moderna e em momentos excepcionais, como a crise sanitária de 2020.

Conforme notado por Santos (2000, p. 27), o computador é a peça central da unicidade técnica planetária, assim como é relevante a Internet. Eles também são imprescindíveis para a computação em nuvem (no caso, os servidores e as redes), e sua modernização leva cada vez mais à unicidade do tempo, sobretudo por conta da possibilidade de existirem grandes redes de computadores interconectados. Isto não implica, necessariamente, em contiguidade, tendo em vista que há possibilidades de conexão por satélites e antenas, além do uso de hospedagem de informações em servidores remotos.

Essas unicidades, junto com a capilarização, a hipertelia e a miniaturização dos objetos técnicos informacionais, formam a tecnosfera propícia ao crescente uso dos aplicativos. Tais objetos tornam-se mais potentes e mais baratos; no entanto, os lugares evidentemente continuam a apresentar diferentes graus de densidade informacional. Um dos fatores que resultam nessas desigualdades são os impulsos globais, ou as "ações e relações da economia, da cultura e da política mediada por interesses internacionais ou internacionalizados, [que] nasce em diálogo com o conceito de globalização" (SILVA, 2014, p. 34).

No âmbito da globalização, se reconhece o período técnico-científicoinformacional - especialmente após a Segunda Guerra Mundial, afirmando-se nos anos 1970 (SANTOS, 2009). Para compreendê-lo, é preciso levar em conta o estado das técnicas e o estado da política, que são inter-relacionados. Isto pois "as técnicas são oferecidas como um sistema e realizadas combinadamente através do trabalho e das formas de escolha dos momentos e dos lugares de seu uso" (SANTOS, 2000, p. 23).

Nesse processo de transformação do meio geográfico, incorporam-se a ele novas técnicas, carregadas de alta carga informacional. O software ocupa um papel especial nesse sentido pois, pela via da automatização de tarefas, permite que diversas máquinas funcionem e se conectem. Por conta disso, os sistemas técnicos se tornam potencialmente mais complexos, passando a exigir níveis mais 
aprimorados de desenvolvimento tecnológico, regulação atualizada e investimentos. Especificamente nesse universo, o software como serviço facilita a conexão entre equipamentos, dado que se baseia nas redes telemáticas, sobretudo a Internet (MÄKILÄ et al., 2010). Tais funções promovem a difusão e a popularização do SCS, concomitantemente com a própria Internet, por volta dos últimos 15 anos. Mas é necessário compreender que, por mais que esse mundo mediado pela informação pareça trivial e comum, ela é um recurso seletivo e estratégico:

Os sistemas produtivos contemporâneos, particularmente as hegemônicas corporações globais, dependem de conhecimentos estratégicos para que possam criar, por meio daqueles lugares escolhidos, um cenário mundial de competitividade. A informação, nesse contexto, se define como um recurso estratégico, utilizado de forma seletiva e hierárquica, ainda que circule mundialmente em volumosas quantidades (BERNARDES, 2011, p. 414).

A proposta de Bernardes (2011) apresenta uma perspectiva crítica do uso da informação. Uma abordagem neoclássica tradicional vê a tecnologia como bem público não rival e não exclusivo, e o progresso técnico como resultado nãointencional das decisões de agentes variados: "consumidores aperfeiçoando suas habilidades profissionais, empresas realizando suas atividades de pesquisa e desenvolvimento, sistemas de ensino (principalmente universidades) e centros de pesquisas" (HIGACHI, 2006, p. 73). Ver a geração de tecnologias como variável exógena ao sistema econômico significava assumi-la como fato dado, reduzindo os problemas tecnológicos a questões de escolhas entre as alternativas disponíveis, em vez de questionar-se sua produção, por quem, quando e como. A ciência, por sua vez, era vista com certo otimismo, como fonte de melhorias para libertar o ser humano das difíceis tarefas de reprodução social (PESSALI; FERNÁNDEZ, 2006, p. 89; 94).

A suposta não-rivalidade entre agentes que se apropriam das TI significaria que o conhecimento tecnológico poderia ser utilizado por uma quantidade indeterminada de empresas, por longos períodos, sem desgaste e custos adicionais. No entanto, em indústrias como a de chips de computadores, ainda que o projeto possa ser compartilhado por pessoas teoricamente em 
qualquer lugar do mundo, não se cancelam o caráter excludente e a apropriação dos resultados econômicos do modo como se usa a tecnologia. O sistema de patentes é uma grande ferramenta para essa apropriação (PESSALI; FERNÁNDEZ, 2006, p. 74-75) e aponta para uma fetichização da inovação, que, como descreve Tunes (2019, p. 139),

É a associação entre inovação com tecnologia, como se tudo que fosse inovador necessariamente tivesse relação direta com a alta tecnologia. Essa confusão se justifica porque os produtos e serviços-símbolo hoje, os smartphones, tablets, aplicativos, internet das coisas, dentre outras parafernálias eletrônicas e digitais, fazem essa associação direta.

Evidentemente, essas e quaisquer tecnologias não são neutras: "uma tecnologia pode tornar-se espúria ao ser controlada por estruturas de poder social, canalizando os benefícios sociais por ela gerados para certos grupos de interesse". Um exemplo é a produção de álcool automotivo, quando apropriadas por grandes organizações, em vez de funcionar também como insumo para cooperativas de produtores e pequenos e médios agricultores (PESSALI; FERNÁNDEZ, 2006, p. 9596). Tal apropriação pelos grandes agentes pode provir de fatores como negociações com governos e outros produtores influentes, constituindo círculos de cooperação que acabam afetando as redes de distribuição, custos e regulamentações para viabilização de alternativas.

Compreender os usos e as características das tecnologias, incluindo as intencionalidades com as quais são criadas e utilizadas, nos auxilia a revelar e analisar os usos do território. Conforme apontam Santos et al. (2000, p. 12), “o território usado, visto como uma totalidade, é um campo privilegiado para a análise, na medida em que, de um lado, nos revela a estrutura global da sociedade e, de outro lado, a própria complexidade do seu uso". Daí se entende também que o convívio entre agentes hegemônicos e hegemonizados no território, exercendo diferentes graus de comando sobre ele, leva a um arranjo singular das ações e dos objetos, conforme se vê na produção e no uso de software.

No caso dos computadores, o transistor é exemplo de uma tecnologia proveniente dos países centrais que sofreu miniaturização, acompanhando a 
própria mudança de tamanho dos hardwares (Figura 1.1), e que é essencial para os dispositivos informacionais. Ele atua como um interruptor elétrico que forma os dígitos binários que embasam a computação moderna. Transistores estão nos processadores e consomem energia; por isso, quanto menores forem, em maior quantidade caberão em um chip e maiores serão a capacidade de processamento e o desempenho de um processador.

Figura 1.1. Miniaturização de computadores pessoais desenvolvidos pela Apple. Modelos Apple II (1977), Macintosh Plus (1986) e iBook (1999).

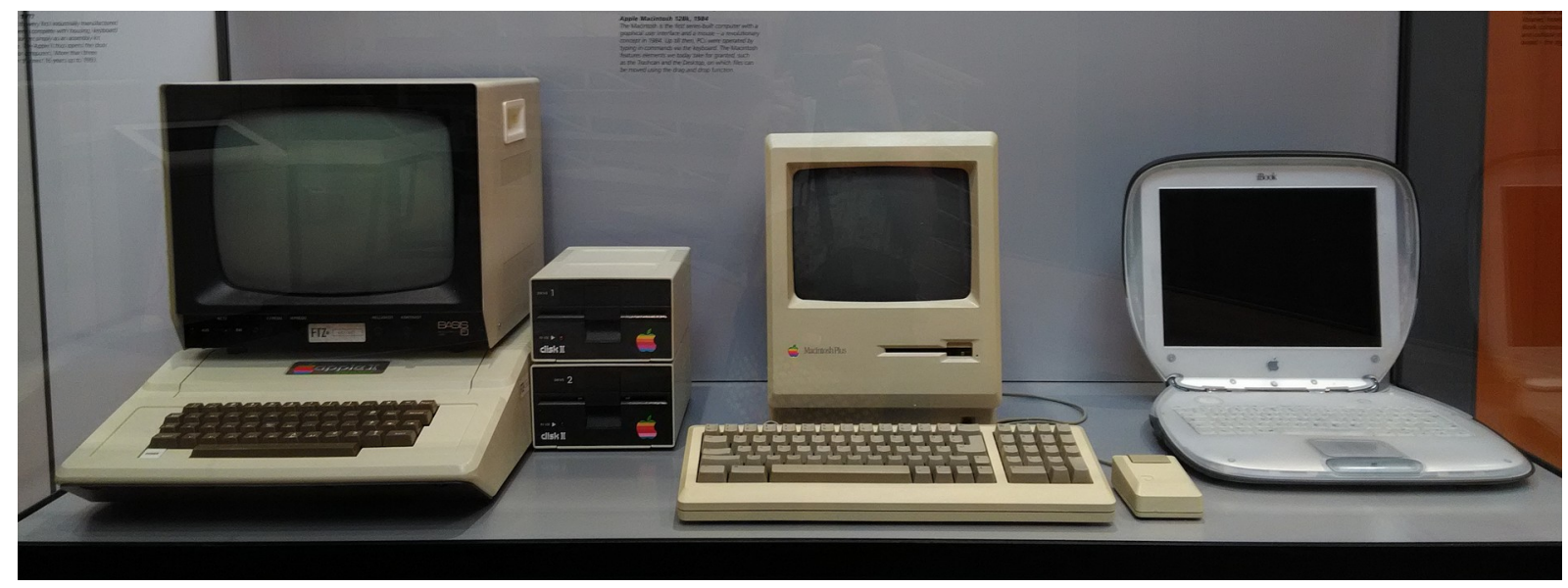

Fonte: autoria própria. Museu da Comunicação (Frankfurt, Alemanha), 2018.

No atual momento do período técnico-científico-informacional na formação socioespacial brasileira, observam-se uma série de incongruências, características do desenvolvimento desigual e combinado. Crescem os índices de inclusão digital, o acesso à informação se banaliza (até certo grau) e os dispositivos eletrônicos são cada vez mais docilizados; porém, sobre técnicas mais complexas (como as mais sofisticadas utilizadas em computação em nuvem, por exemplo), crescem o domínio e a centralização de agentes especializados. Nem todos os canais por onde trafega e se manipula a informação se democratizam uniformemente. Num paralelo com os circuitos da economia urbana (SANTOS, 2004), existe um abismo quanto a níveis de capital, tecnologia e organização entre as corporações responsáveis pelos data centers e os trabalhadores que utilizam aplicativos como o WhatsApp para comunicações cotidianas. 
Ainda assim, a informatização dos territórios é um processo hoje universalizado, e a unicidade técnica e das normas chega a atingir, neste momento histórico, a escala extra-planetária. Monserrat Filho (2007, p. 154) aponta como já é necessário um possível projeto de gerenciamento de tráfico espacial (majoritariamente de satélites): "esse sistema é pensado como uma rede global de normas técnicas e jurídicas destinadas a promover (...) o acesso ao espaço, as operações no próprio espaço e aquelas de retorno à Terra, livres de quaisquer interferências físicas ou de radiofrequência". O autor sugere um modelo de compartilhamento entre países de informações sobre satélites e espaçonaves, num sistema extremamente detalhado, dado que suas operações envolvem alto custo e alto risco. Já Mbembe (2017) nota, sobre a África, que

0 advento da mídia computacional no continente não foi apenas um evento tecnológico de considerável significância. Ele também conduziu a uma nova estética e sensibilidade cultural que muitos chamam de Afropolitanismo.

Em sua instância mais simples, o Afropolitanismo (...) pode ser reconhecido pela extensão com a qual o lugar é moldado e transacionado por recursos simbólicos globais e imaginários da circulação.

O computador e o celular são os vetores tecnológicos chaves do Afropolitanismo. Eles tornaram-se reservas portáteis de conhecimentos e dispositivos cruciais que mudaram o modo como o novo Africano fala, escreve, comunica-se, imagina quem ele ou ela é, ou até se relaciona com outros e com o mundo em geral (tradução nossa).

Constitui-se uma nova ideia de mundo, na qual os usos da tecnologia se estendem mesmo a lugares distantes dos centros mais dinâmicos da economia. As atividades econômicas em geral, não apenas em nichos como o comércio eletrônico, são agora mediadas pelas novas tecnologias, expressando a difusão do meio técnico-científico-informacional. Uma das razões para isso, conforme aponta Harvey (2010, p. 151), é o fato de que

As informações precisas e atualizadas são agora uma mercadoria muito valorizada. $O$ acesso à informação, bem como seu controle, aliados a uma forte capacidade de análise instantânea de dados, 
tornaram-se essenciais à coordenação centralizada de interesses corporativos descentralizados.

A informatização do território é, ela própria, um pilar de sustentação do fenômeno de difusão dos aplicativos no Brasil. A partir dela, com todas as suas desigualdades em termos de desenvolvimento tecnológico e distribuição no espaço, observa-se um processo de "dataficação" da sociedade e do mundo (MILAN; VAN DER VELDEN, 2016). Em 2018, a quantidade de dados criados, capturados, copiados e consumidos no mundo foi de 33 Zettabytes (ZB), ou 33 trilhões de Gigabytes; em apenas dois anos, esse número saltou para $59 \mathrm{ZB}$, e estima-se que chegará a 175 ZB até 2025 (VOPSON, 2021). Nesse contexto, toma protagonismo a exploração de ideias, e as mercadorias tornam-se cada vez menos palpáveis: "é assim que o ensino técnico, os softwares, as indústrias químicas, de telecomunicações e, sobretudo, de serviços estão, aos poucos, exercendo primazia sobre as indústrias de transformação" (WOLFF, 2005, p. 127).

Santos (2009, p. 184) se baseia em Pastré (1983, p. 9) e Paché (1990, pp. 89-90) para definir a informatização como "um novo modo dominante de organização do trabalho", pois a informação ganha campo como elemento concentrador de poder, bem como tem papel fundamental na circulação de mercadorias e na regulação de estoques e circuitos produtivos. Por isso mesmo, a informação mais essencial passa a circular somente em campos restritos e exclusivos, como aqueles ocupados pelas corporações transnacionais. Por sua vez, estas também acabam por construir o "tempo real" que controla diversas outras atividades (idem, p. 185).

Grande parte do controle sobre o tempo é hoje feito por meio de algoritmos, entendidos como sequências finitas de instruções. Na computação, programar significa escrever instruções (algoritmos) em qualquer linguagem que a máquina compreenda. 0 primeiro algoritmo foi desenvolvido pela matemática e escritora Ada Lovelace, no século XIX, para processamento pela máquina analítica de Charles Babbage, na Inglaterra. Ainda que não necessariamente computemos dados ao utilizar um computador, sua origem está nas antigas máquinas de calcular, cuja criação também é creditada a Babbage. A seguinte expressiva 
novidade técnica seria a máquina de Herman Hollerith, datada do final do mesmo século, que utilizava cartões perfurados para lidar com maiores volumes de dados - por exemplo, aqueles coletados no censo estadunidense. Outros avanços significativos na computação foram feitos para codificar e decodificar mensagens durante a Segunda Guerra Mundial, destacando-se o trabalho do britânico Alan Turing (BYNUM, 2018, p. 333-335).

As máquinas mencionadas funcionavam por meio de válvulas que acabavam aquecendo demasiadamente. Uma tecnologia de miniaturização foi fundamental para contornar esse problema: o transistor, desenvolvido no final dos anos 1940. Seu tamanho diminuto permitia que fosse inserido em aparelhos eletrônicos diversos, a fim de amplificar e trocar sinais eletrônicos (BYNUM, 2018, p. 336). Os transistores e os circuitos eletrônicos modernos compõem a indústria de materiais semicondutores, fundamental para a conformação do meio técnicocientífico-informacional. Podemos considerar essa uma das maiores mudanças técnicas que levaram ao estado da arte da indústria de aplicativos, junto à popularização da Internet e ao advento da computação em nuvem.

Quanto ao desenvolvimento tecnológico que levou ao atual estado de circulação e manejo de informações pelo planeta, Carr (2004, p. 17-18) propõe uma distinção entre o que chama de tecnologias proprietárias e tecnologias infraestruturais. As primeiras podem ser posse de uma única empresa, por meio de mecanismos como as patentes (por exemplo, na indústria farmacêutica), pela criação de novos processos ou materiais. Enquanto estiverem protegidas de seus competidores, elas podem garantir vantagens estratégicas de longa duração e altos lucros para suas detentoras.

Já as tecnologias infraestruturais são aquelas que oferecem maior valor à medida que são compartilhadas, em vez de usadas isoladamente. $\mathrm{O}$ autor dá $\mathrm{O}$ exemplo da empresa Rainhill Trials, que detinha os direitos sobre toda a tecnologia necessária para criar ferrovias: eles poderiam optar por implantar redes próprias entre seus fornecedores, fábricas e distribuidores, e até mesmo utilizar seus próprios trens nas vias. No entanto, para a economia de modo geral, gera-se muito mais valor compartilhando uma rede aberta, tornando seu compartilhamento 
praticamente inevitável. Ainda que elas possam se confundir com tecnologias proprietárias em estágios iniciais de desenvolvimento dentro de uma determinada empresa, as redes de ferrovias, telégrafos, energia elétrica ou rodovias passam a ser parte fundamental da infraestrutura geral da economia.

Para Santos (2009, p. 184), o computador é um símbolo do atual período histórico que se encontra na base da telemática e da teleinformática - exemplos de tecnologias que se tornaram infraestruturais. Ele é uma máquina que permite unificar os processos produtivos e monitorar o tempo de diversas operações com grande precisão: "é a partir do computador que a noção de tempo real, um dos motores fundamentais da nossa era, torna-se historicamente operante" (SANTOS, 2009 , p. 185). No entanto, para se chegar ao atual formato dos computadores, houve um acúmulo de inovações em grande parte originadas dos países centrais, especialmente dos Estados Unidos. Em 1956, a hoje multinacional IBM ${ }^{12}$ lançou desde seus laboratórios em San José o Disk Drive, a primeira unidade de disco. Uma pilha de 50 discos era capaz de guardar 3,8 MB de dados, o que equivale aproximadamente ao tamanho digital de uma canção, nos anos 2000. Mesmo antes disso, a empresa já utilizava cartões perfurados (punched cards) para algumas de suas primeiras operações de computação, incluindo o processamento de dados do Censo no Brasil, onde está presente desde 1939.

Outras firmas e instituições estadunidenses foram relevantes para o desenvolvimento da computação. A Intel, fundada em 1968, hoje povoa dispositivos pelo mundo com microprocessadores que contribuíram para a miniaturização das máquinas; em 1969, o robô Shakey era criado no Stanford Research Institute (SRI) como um precursor da inteligência artificial e do aprendizado de máquina, pois podia raciocinar sobre suas ações sem o controle humano - por exemplo, ao criar um "mapa" de seu ambiente, movimentando-se e evitando obstáculos. 0 que se encontra hoje em dia em máquinas agrícolas parece se assemelhar muito a esse tipo de tecnologia, seminal à época.

No início dos anos 1970, os pesquisadores do Xerox PARC (Palo Alto

12 A IBM foi uma empresa pioneira no processamento de dados no mundo, e passou a atuar no Brasil em 1917. Foi contratada pelo governo brasileiro em 1920, para realização do censo demográfico, e também passou a atender clientes da indústria e do comércio (NEVES, 2017, p. 34). 
Research Center) inventaram o Alto, um computador que continha inovações como o mouse e a interface gráfica do usuário. No mesmo período, eram criados protótipos de jogos como o Pong, para o console Atari, e eram lançados computadores como o Apple-I, ao qual os usuários deveriam conectar apenas um teclado, uma fonte de energia e uma televisão para terem um sistema em funcionamento. Já um dos primeiros exemplos de computação móvel foi o PalmPilot, criado em 1996, que de certa forma introduziu o hábito de carregar um dispositivo, como atualmente se faz com o smartphone. No âmbito do armazenamento, em 1999 a Google lançava o Google Server Engine, com 80 PCs e equipamentos de rede (networking) para responder às solicitações de pesquisas enviadas à empresa. Ela ainda construía seus próprios servidores com partes de computadores comerciais de fácil acesso, o que parece inimaginável nos anos 2020.

Os primeiros computadores brasileiros começaram a ser desenvolvidos na década de 1960. O atual Instituto Militar de Engenharia (IME) lançou a máquina "Lourinha" em 1960, e o Instituto Tecnológico da Aeronáutica (ITA) apresentou o "Zezinho", em 1961. Já a Universidade de São Paulo desenvolveu o "Patinho Feio" em 1972, que a levou a estabelecer contratos com a Marinha e agências de fomento para realizar um protótipo de computador digital, o G-10. A Universidade Estadual de Campinas, por sua vez, trabalhou numa proposta chamada "Cisne Branco" (NEVES, 2017, p. 33-34).

A primeira empresa nacional de computação foi a estatal Computadores Brasileiros S/A (Cobra), nascida em 1974. A partir de 1981, passaram a ser comercializados os primeiros microcomputadores comerciais fabricados no Brasil, a partir do modelo D-8000, da empresa Dismac (com sede em Manaus - Amazonas). Conectar-se à Internet em domicílio somente seria possível a partir de 1995. Notese que o início do desenvolvimento dos computadores se deu pelo interesse dos militares em automatizar navios de guerra com tecnologia nacional, e não havia componentes de informática nacionais disponíveis, de modo que os materiais precisavam ser importados, adaptados ou recriados localmente (NEVES, 2017, p. 33-34).

O Museu da História do Computador, em Mountain View (Estados 
Unidos), lista como algumas das tecnologias fundamentais para o desenvolvimento da computação: máquinas calculadoras; cartões perfurados; computadores analógicos; computação em tempo real; computadores mainframe; memória e armazenamento; supercomputadores; minicomputadores; inteligência artificial e robótica; computação gráfica; jogos de computador; computadores pessoais; computação móvel; redes de computadores; e a Web.

A partir de estudos sobre redes, a Internet pode ser definida como uma rede de dados na qual os computadores são os nós, e as ligações entre eles (como cabos de fibra óptica ou de telefonia) são as arestas. Mas ainda que seja tão amplamente utilizada e cuidadosamente projetada, é exatamente por conta de suas características que é difícil apreender a real estrutura da Internet (NEWMAN, 2018, p. 1-3). A função da Internet é transportar dados entre dispositivos, dividindo a informação em pacotes enviados de nó a nó, até chegarem ao destino. Não necessariamente a menor distância geográfica significa que os dados chegarão no menor tempo possível, pois existem falhas e gargalos no tráfego e diferenças qualitativas entre partes da rede. $O$ território é um condicionante incontornável para qualquer operação digital que dependa da Internet.

A Internet não é o único exemplo de rede tecnológica. Também entram nesse grupo as redes de telefonia, rodoviária, ferroviárias e aeroviárias, além daquelas para distribuição de energia elétrica, água, esgoto, óleo e gás, e mesmo as intranets (redes de comunicação privadas intra ou interfirmas). No entanto, as redes digitais são muito mais abstratas, como é o caso da World Wide Web - que corresponde às páginas web e suas conexões, os hyperlinks (que permitem a navegação acessando páginas por cliques). Um hyperlink é uma localização virtual e sem endereço físico, tendo apenas um código virtual que permite o trânsito de pacotes de dados. Ainda que muitas vezes sejam tratadas como sinônimos, a Web é diferente da Internet, pois esta pode ter conexões via cabos ou radiofrequência e nós que não necessariamente são páginas web (NEWMAN, 2018, p. 3-4).

Todos os dias, estima-se que sejam gerados no mundo 500 milhões de tweets, 294 bilhões de e-mails e 4 milhões de Gigabytes de dados do Facebook. Em por volta de 150 anos, o número de bits poderia exceder o de todos os átomos no 
planeta. Ainda que as tecnologias computacionais tenham mudado com cada vez mais rapidez desde a criação do transistor, em 1947, e do microchip integrado, em 1956, há séculos a humanidade já vinha utilizando outros modos de armazenar informações, como em pinturas em paredes e livros. Os data centers são, de certa forma, uma expressão extremamente contemporânea disso.

o que é mais notável é o acelerado passo com que se atingiram, em apenas 50 anos, inimagináveis níveis de capacidade de processamento de dados, tecnologias sem fio, a Internet, inteligências artificiais, telas e displays, além de avanços em comunicações, transportes, genética, medicina e exploração espacial, entre outras áreas. Como destaca Vopson (2021), a introdução do armazenamento de dados digital mudou a forma como a sociedade produz, manipula e guarda informação, sobretudo após 1996, quando o armazenamento digital passou a ter melhor custo-benefício do que usar papel. Por conta disso, hoje se pode escolher entre o armazenamento magnético (em fitas ou Hard Disk Drives - HDD, ou discos rígidos), os discos ópticos (CD, DVD, Blu-Ray) ou as memórias com semicondutores (os pendrives ou Solid Disk Drives - SDD), cada um com suas aplicações próprias ${ }^{13}$.

Quanto se trata de conjuntos de dados caracterizados como big data, são necessários ambientes computacionais com a capacidade de armazenar, transferir, processar e compartilhá-los em pouco tempo, para exploração e análise estatística. Para isso, são utilizados recursos de computação de alto desempenho conhecidos como high performance computing (HPC), que vêm substituindo antigas arquiteturas centradas num computador mainframe. Sistemas mais modernos, chamados de grids ou clusters, são menos custosos e de mais simples manutenção e acesso, pois combinam uma série de processadores "num equipamento gerenciado por um sistema operacional capaz de efetuar processamento paralelo e de executar muitas tarefas simultaneamente, sendo o seu uso compartilhado por vários usuários" (IBGE, 2019, p. 32).

Existem por volta de 600 data centers de "hiperescala" (com mais de 5.000 servidores) no mundo, sendo por volta de $39 \%$ localizados nos Estados

130 armazenamento em memórias semicondutoras costuma ser preferível para eletrônicos portáteis, enquanto o armazenamento óptico é mais utilizado para filmes, softwares e jogos. Para armazenamento de informações de alta capacidade, costuma-se usar o tipo magnético, o que inclui computadores pessoais e servidores (VOPSON, 2021). 
Unidos, enquanto $30 \%$ se dividem entre China, Japão, Reino Unido, Alemanha e Austrália. Aproximadamente dois desses hiper-data centers têm de ser construídos a cada par de anos, para acompanhar a demanda por armazenamento digital, o que também requer uma quantidade de energia que, em 110 anos, superará o total consumido no planeta hoje (VOPSON, 2021). Ademais, observa-se a aceleração da chamada Lei de Moore (enunciada informalmente por Gordon Moore, em 1975): “o número de transistores incorporados a um chip irá aproximadamente duplicar-se a cada 24 meses". Nos maiores microprocessadores, isso ocorreu entre 1971 e 2010, mas não mais acompanha a realidade das modernizações.

Entre as tecnologias para conectividade mais utilizadas atualmente, destaca-se o wi-fi (Wireless Fidelity), que possibilita a transmissão de dados via internet sem a necessidade de utilização de cabos, usualmente via frequências de rádio, radiação infravermelha e outras. Ainda assim, é necessário um modem conectado a um cabo de rede do tipo Ethernet, que se liga ao backhaul, a conexão com redes de Internet de maior extensão. Os tipos de rede mais comuns encontrados nos modems para oferta de internet fixa em banda larga em residências possuem as frequências de $2,4 \mathrm{GHz}$ e $5,0 \mathrm{GHz}^{14}$. Ondas na frequência 2,4 GHz são mais utilizadas e atingem maiores distâncias, porém menores velocidades. Já as ondas na frequência 5,0 GHz atingem velocidades maiores, porém têm menor alcance em distância. Também trata-se de uma rede com sinal mais estável que o de 2,4 GHz, pois sofre menos interferência de sinais de celulares (dos tipos $3 \mathrm{G}$ e 4G) e costuma ter menos aparelhos conectados a ela. É mais vantajosa para usuários que desejem realizar atividades como download de arquivos, assistir a vídeos em alta qualidade e acessar jogos online, que consomem muita banda.

O único website homologado pela Anatel para teste de velocidade (a fim de verificar se está de acordo com aquela contratada pelo cliente) é a página da Entidade Aferidora da Qualidade (EAQ) ${ }^{15}$. Em 2012, a empresa de consultoria Pricewaterhousecoopers foi escolhida como essa entidade, com um software

14 "O número de bits por segundo que se pode transmitir através de um canal qualquer (um fio de cobre, um radioespectro ou uma fibra ótica) é sua largura de banda. Ela mede quantos bits podem passar por um determinado condutor" e, quanto mais complexo for o tipo de dado (por exemplo, de sons para imagens), maior a quantidade de bits necessários por segundo para transmiti-lo (NEGROPONTE, 1995, p. 21). É uma medida da capacidade de envio de informação por um determinado canal (idem, p. 27).

15 Disponível em: <http://www.brasilbandalarga.com.br/>. 
desenvolvido pela Speed Test. A seleção foi feita pelas firmas de telecomunicações que atuam no território brasileiro, em processo coordenado pela Anatel. Também competiram o NIC.br e a empresa paulistana ISPM Serviço de Informática (TELESÍNTESE, 2012).

Hoje, mais do que nunca, a existência de tecnologias como o big data levou a uma "revolução informática e do controle" e a um estado de "mobilidade generalizada (dos homens, da energia, dos usos, dos produtos, no tempo e no espaço), uma mobilidade medida, controlada, prevista, que assegura aos centros de decisão um real poder sobre os outros pontos do espaço" (SANTOS, 2009, p. 184). Diante de tamanha quantidade de informações disponíveis, inclusive sobre localização de atividades e agentes no território, tem-se uma situação de exacerbada cognoscibilidade do planeta, numa grande expressão do conhecimento como recurso (SANTOS, 2009, p. 241-242). A respeito da capacidade de utilizar informações geoespaciais, Monserrat Filho (2007, p. 145) aponta que ela

É fundamental para uma série de atividades com impacto direto sobre o desenvolvimento nacional. 0 monitoramento ambiental, o gerenciamento de recursos naturais, a meteorologia, a prevenção e a mitigação de desastres naturais, a criação de sistemas cartográficos nacionais para fins de planejamento territorial - são apenas alguns exemplos de como os dados geoespaciais passam a desempenhar papel indispensável na promoção do desenvolvimento nacional sustentável (MONSERRAT FILHO, 2007, p. 145).

Já alguns usos de Internet das Coisas e inteligência artificial são versões conectadas à Internet dos dispositivos "wearable" (que se pode vestir), como relógios, óculos e fones de ouvido; caixas de som e eletrodomésticos, em casa; nas cidades, grids de energia, iluminação e transporte público; nas fábricas, robôs para manufatura, dispositivos para gerenciamento da cadeia de produção e sensores preditivos para manutenção. Tecnologias em fase de estudo e prototipação incluem veículos autônomos, robôs domésticos, pagamentos por voz e vídeos com altíssima resolução (8K).

De fato, todos esses são caminhos possíveis para lidar com a informação precisamente localizada ou especializada, mas ela também pode ser funcional a interesses escusos, levantando questões sobre privacidade e uso de dados pessoais. 
De modo geral, as TI são fundamentais para o alargamento dos contextos da globalização, permitindo que fluxos de capital e informação perpassem as fronteiras nacionais com maior facilidade e com a participação de mais agentes, de distintas origens (ARROYO, 2006, p. 178). Para isso, as redes técnicas tangíveis e intangíveis são elemento fundamental, que iremos detalhar a seguir.

\subsection{Transformações no macrossistema técnico para conectividade à Internet no território brasileiro}

No período técnico-científico-informacional, a informatização do território aprofundou-se a ponto de permitir o surgimento de novos objetos, como os aplicativos, e seu uso rapidamente capilarizou-se no cotidiano das pessoas. Já com a criação e a popularização da Internet, houve um novo salto qualitativo na rede de telecomunicações mundial, permitindo um inédito nível de interação entre lugares e agentes materialmente distantes. No entanto, o grau de modernização e sofisticação do meio geográfico hoje predominante, em parte verificado pela disponibilidade das redes técnicas e pela densidade informacional, manifesta-se de modo diferenciado no território brasileiro, promovendo seletividade espacial e autorizando diversos usos do território pelos agentes. Conforme Santos (2008, p. 25),

Em nossa época, o que é representativo do sistema de técnicas atual é a chegada da técnica da informação, por meio da cibernética, da informática, da eletrônica. Ela vai permitir duas grandes coisas: a primeira é que as diversas técnicas existentes passam a se comunicar entre elas. A técnica da informação assegura esse comércio, que antes não era possível. Por outro lado, ela tem um papel determinante sobre o uso do tempo, permitindo, em todos os lugares, a convergência dos momentos, assegurando a simultaneidade das ações e, por conseguinte, acelerando o processo histórico.

Fatores como as funcionalidades, hierarquias e posições das redes revelam pistas sobre a conectividade dos lugares e a seletividade espacial, permitindo melhor compreender os usos do território (HUERTAS, 2015, p. 46). 
Considerando as redes, inclusive as informacionais, como instrumentos analíticos e formas sociais articuladas a processos de mudança técnica e cultural, é preciso destacar que sua difusão é sempre social e territorialmente seletiva (RIBEIRO, 2000, p. 16-17). Ademais, a despeito dessa difusão, grandes parcelas dos territórios estão em condições de imobilismo (idem, p. 21), o que indica que a mobilidade é um atributo dos agentes sociais que se manifesta de forma relativa e não homogênea.

Certas condições são imprescindíveis para o surgimento e o notável crescimento da produção e do uso de software como serviço, nestas duas primeiras décadas do século XXI. Primeiro, a conformação de uma tecnosfera fundada, por um lado, na difusão das redes de acesso à Internet, especialmente por meio das conexões de tipo móvel. Por outro lado, essa tecnosfera se assenta em tecnologias modernas de armazenamento e interoperabilidade entre máquinas, entre as quais destacamos a computação em nuvem. Além disso, foi preciso a constituição de uma base normativo-institucional favorável à expansão da indústria de software e serviços em TI, num contexto em que se desenvolveram novos meios de contratação e regulação para o ramo, modificando-o radicalmente.

As redes de telecomunicação são elementos cruciais para a distribuição do software como serviço. Contrariamente a visões românticas que induzem ao determinismo tecnológico (DIAS, 2005; MATTELART, 2005), deve-se pontuar que as redes, ou o "espaço reticular", são por definição desigualmente disseminadas pelos territórios. Seus nós e suas linhas promovem, simultaneamente, conexão e exclusão (CASTILLO, 1999, p. 32), e a situação de histórica desigualdade social e econômica no Brasil impõe condições ainda mais particulares para a circulação de dados, a mobilidade dos agentes e a localização das firmas.

Musso (2004, p. 31) explica sua proposta do conceito de rede como uma "estrutura composta de elementos em interação", os nós, conectados entre si por caminhos ou ligações. Seria, ainda, "uma estrutura de interconexão instável no tempo", que contém em si a própria dinâmica da rede. Indo além, o autor sugere que a rede é "uma técnica maior de organização do espaço-tempo (...). Uma matriz espaço-temporal". Tal matriz técnica é capaz de criar um tempo mais curto por meio do transporte ou pelo intercâmbio de informações: "a rede de comunicação 
adiciona ao espaço-tempo físico um espaço ampliado e um tempo reduzido" (idem, p. 33). Já Ribeiro (2000, p. 16-17) propõe

\begin{abstract}
Pressionar a noção de rede por meio de dois movimentos analíticos complementares: o primeiro refere-se à dimensão societária dos projetos contemporâneos de modernização, e o segundo diz respeito à reflexão do poder, às formas de comando. Procuramos, por esta opção analítica, reduzir o acionamento da noção de rede como metáfora, ou seja, como uma nomeação dos fenômenos sociais que impede a indicação precisa de atividades sociais e econômicas ou que permite desconhecer a natureza mercantil da técnica e os interesses envolvidos em sua difusão, sempre social e territorialmente seletiva.
\end{abstract}

Benakouche (2005, p. 82) cita as ideias de Thomas P. Hughes para recordar que a técnica não é neutra, como muitas vezes se propaga: "num sistema técnico, ou sociotécnico, as relações raramente se estabelecem de forma natural, digamos, mas pelo contrário, são quase sempre permeadas por conflitos". Hughes destacava a dimensão política dos sistemas técnicos ao apontar a existência dos chamados "construtores do sistema" ("system builders"), questionando quem os controla e sobre quais bases (BENAKOUCHE, 2005, p. 84).

As empresas do ramo de telecomunicações historicamente usam o território brasileiro como recurso, em mono, duo ou oligopólios, conforme detalhado por Silva (2018, p. 16). As firmas que provêm o conteúdo da Internet reproduzem essas estratégias, assentadas numa base técnica que se modernizou, e produzem normas que implicam nos padrões de conduta dos consumidores, na produção e no uso do território. Nesse contexto, o capital corporativo nacional e estrangeiro inclui "uma infinidade grande de companhias, setores e organismos interessados em participar da infraestrutura, dos sistemas de movimento, do uso territorial de um país com dimensões continentais", como o Brasil.

Diversas modernizações estavam em curso no território brasileiro nas décadas de 1960 a 1980 (por exemplo, em transportes e agricultura). Como aponta Santos (2009, p. 255), “a geografia dos fluxos depende (...) da geografia dos fixos”, ou seja, o conteúdo que trafega pelas redes depende de sua configuração espacial. Segundo Dias (2005, p. 11-12), os fluxos gradualmente se tornaram mais espessos e acelerados, e as redes de comunicação e transporte, mais complexas. Isso resulta 
na ampliação da escala de atuação dos agentes que controlam esses fluxos.

Braudel (2009, p. 519) nos lembra que as pré-condições para a conformação do capitalismo dependem da circulação. A instalação e a modernização das redes técnicas que sustentam a economia baseada nas TI consistem num processo de adição de valor a certas porções do território, dado que elas dão suporte à circulação de bens tangíveis e intangíveis. Essa dinâmica simultaneamente alimenta e é condicionada por alterações na divisão territorial do trabalho e pela criação de especializações produtivas (SANTOS, 2005; ARROYO, 2015, p. 41).

Sendo uma condição para o desenvolvimento do atual modo de produção, a circulação nutre uma demanda interminável por mais velocidade nos fluxos de bens, pessoas, capital e informação (BLANCO, 2015, p. 15). As características dos processos produtivos colocam necessidades particulares para as redes e, no capitalismo, as condições de circulação são tão relevantes quanto as de produção. Por isso, quando as firmas desejam instalar-se nos lugares, emergem disputas e pressões por redes eficientes (ARROYO, 2015, p. 47). No contexto latinoamericano, algumas produções chegam a não ser viáveis por conta dos custos de transporte inclusos na produção (BLANCO, 2015, p. 20).

Conforme Dias (1996, p. 123), a implantação das redes-suporte de telecomunicações no Brasil foi acelerada, entre os anos 1960 e 1970, com a conclusão por volta de 1985 (com o lançamento de satélites brasileiros ${ }^{16}$ ). Já no caso das redes-serviço, nos anos 1980 houve expansão do acesso a redes de telefonia, com aporte de capital nacional e externo; no entanto, ainda permanecem grandes desigualdades regionais e um grau de integração muito desigual entre porções do território brasileiro. Ao mesmo tempo, se foi observando um

16 Satélites são objetos complexos, que exigem grandes círculos de cooperação em seu desenvolvimento e são financiados por agentes participantes do circuito superior da economia. Como parte da tecnosfera de conectividade, o Brasil lançou seu Satélite Geoestacionário de Defesa e Comunicações Estratégicas (SGDC) em 4 de maio de 2017, operado pela Telebras e com duas faixas de frequência. A banda Ka foi direcionada para ampliar a oferta de banda larga, segundo as necessidades do PNBL. Já a banda X é de uso exclusivamente militar. $\mathrm{O}$ dispositivo cobre todo o território nacional e parte do Oceano Atlântico e tem vida útil estimada em 18 anos. Foi um investimento de $\mathrm{R} \$ 2,1$ bilhões, em projeto dos ministérios da Defesa e da Ciência, Tecnologia, Inovações e Comunicações. A proposta é fornecer maior autonomia às comunicações civis e militares brasileiras, mas a fabricante foi a multinacional francesa Thales Alenia Space. Além disso, os satélites utilizados pelo Brasil são gerenciados por estações localizadas fora do país ou com controle por capital estrangeiro - e o mesmo ocorre com os 45 satélites para comunicação atualmente utilizados pelo Brasil, todos de companhias privadas (PESQUISA FAPESP, 2017, p. 12). 
"envelhecimento" acelerado de certos objetos técnicos, como os telefones fixos.

Assim se conforma um processo de exclusão social, associado a valorização econômica e espacial: a telemática tem o potencial de integrar o território, mas o que se vê é forte polarização em torno de São Paulo. Isso se relaciona, inclusive, à desconcentração industrial paulista, que incluiu empresas de telecomunicações e centros de processamento de dados, além de nós de redes como a Transdata em municípios além da capital. As redes eletrônicas viabilizam novas formas organizacionais de produção, e o modo como os fluxos de informação se impõem acaba sendo condição necessária ao movimento dos elementos materiais. Por isso, a capital paulista pode ser considerada uma metrópole informacional, substituindo a antiga metrópole industrial. A aceleração dos fluxos econômicos, por sua vez, gera novas interações espaciais e reafirma a importância estratégica do espaço geográfico (idem, p. 128-140).

Uma síntese de equipamentos presentes nos domicílios brasileiros, elaborada por Théry e Mello-Théry (2018, p. 308) a partir de dados do Censo 2010 (IBGE), evidencia a maior ocorrência de dispositivos como microcomputador, rádio e televisor exatamente na chamada Região Concentrada. De acordo com proposta de Santos e Ribeiro (1979), tal região compõe-se dos estados de Espírito Santo, Minas Gerais, Rio de Janeiro, São Paulo, Paraná, Rio Grande do Sul e Santa Catarina - correspondendo às regiões Sudeste e Sul, na concepção do IBGE. Ressalte-se, porém, que a difusão do meio técnico-científico-informacional não ocorre de forma homogênea nessa porção do território. A densidade informacional é maior, por exemplo, nas capitais dos estados, em relação ao interior.

A referida dinâmica de concentração se repete quanto à presença de agências bancárias, indústrias de transformação, serviços de informação e comunicação, operações de crédito, comércio varejista e atacadista (THÉRY; MELLO-THÉRY, 2018, p. 202-215), entre muitos outros fatores que poderíamos elencar. O Produto Interno Bruto e os salários também tendem a ser maiores na Região Concentrada, quando comparados às demais regiões (idem, p. 194-200).

A conexão à Internet, por sua vez, reproduz desigualdades regionais. Trata-se de uma questão de renda, instrução, localização e classe social, 
influenciando inclusive no tipo de conexão predominantemente utilizada. As últimas pesquisas do Cetic.br $(2019,2020)$ indicam que em 5 anos, de 2014 a 2019, o percentual de usuários da Internet que se conectam pelo celular saltou de 76\% para 99\% - aproximadamente 133,8 milhões de pessoas. O uso do computador caiu pela metade, de 80 para $42 \%$ (Gráfico 1.2). Ademais, os brasileiros utilizam aplicativos durante uma média de três horas diariamente, e a venda de smartphones tem oscilado entre 40 e 50 milhões de aparelhos por ano (CETIC.BR, 2019). No entanto, desigualdades fora do âmbito virtual se reproduzem quanto ao acesso à rede, conforme mostram as menores proporções registradas pelas pesquisas em áreas rurais e entre indivíduos mais velhos, com menor renda e escolaridade.

\section{Gráfico 1.2. Brasil. Dispositivo utilizado para acessar a Internet (2014-2019)*.}

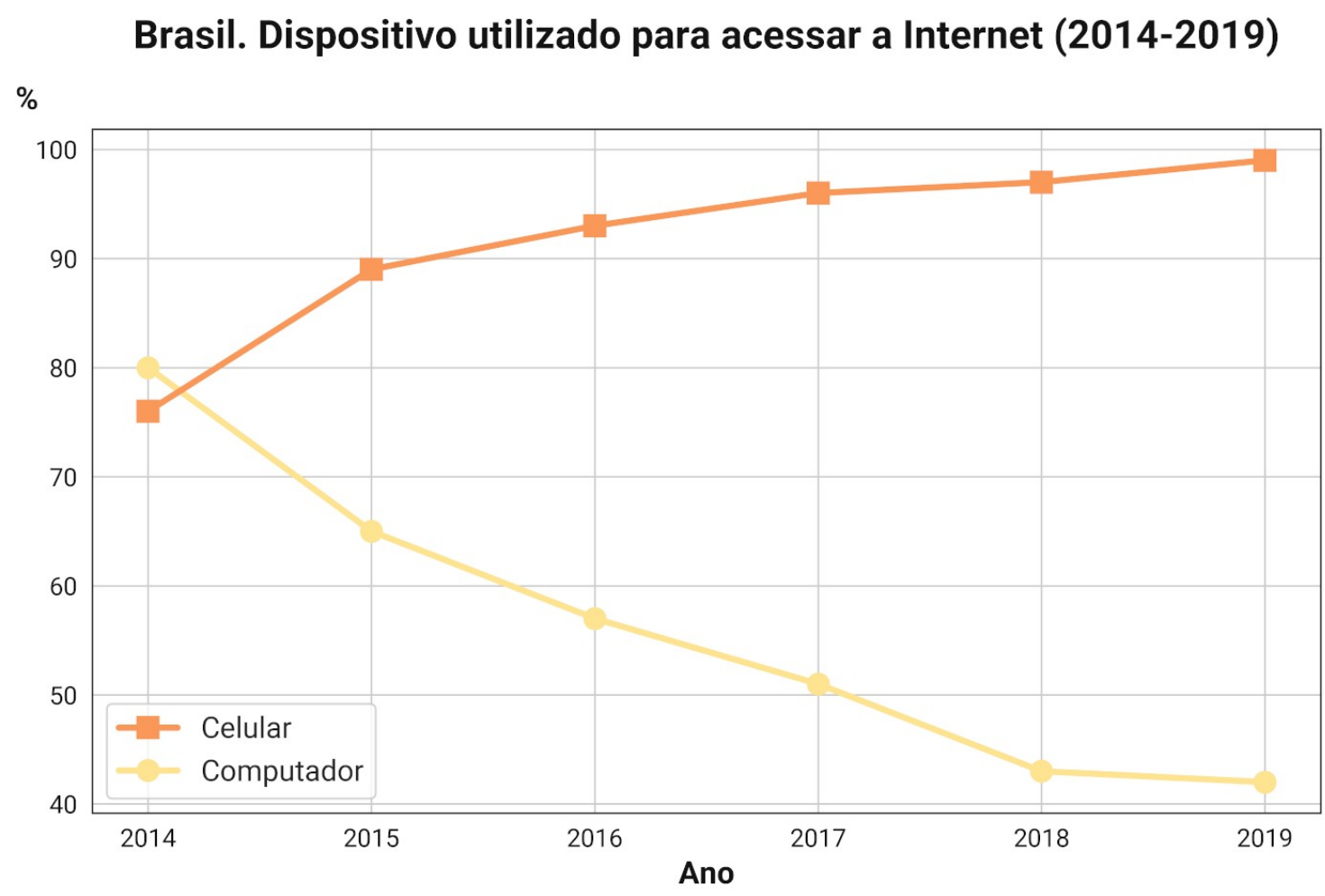

Fonte: Cetic.BR, 2020

* Percentual dos usuários de Internet que utilizaram o dispositivo em questão para acessar a rede.

Fonte: elaboração própria, a partir de Cetic.BR (2019). 
É importante ressaltar que, na América Latina, a adoção de tecnologias está condicionada por fatores como a heterogeneidade da estrutura produtiva, os altos índices de informalidade e precariedade da mão de obra e as restrições socioeconômicas ao acesso e à conectividade em uma infraestrutura digital já deficitária (CEPAL, 2020, p. 2). Em junho de 2020, em 44\% dos países latinoamericanos não se atingia uma velocidade de download de $25 \mathrm{Mbps}$ (Megabits por segundo), que permitisse realizar várias atividades online simultaneamente. Com menos de 5 Mbps, não é possível sustentar atividades como ensino e trabalho à distância.

Em 2019, existiam no Brasil 34,2 milhões de domicílios com acesso via banda larga fixa e 198,2 milhões de conexões do tipo banda larga móvel (tendo em vista que um indivíduo pode possuir mais de um aparelho com a conexão). Acompanhando essa tendência, observa-se que o número de smartphones em uso no Brasil cresceu 8,8\% de 2018 a 2019, e a tendência de ascensão também ocorreu com os computadores dos tipos notebook $(4,5 \%)$ e desktop (3,8\%). No entanto, $30 \%$ do total de 45.464 .599 domicílios não possuíam computador e acesso à Internet e, de 2016 a 2018, esse número oscilou entre 39 e 41\%. O Gráfico 1.3 apresenta o crescimento dos acessos fixos, e as tabelas 1.1 e 1.2 trazem a densidade de acessos por região. 
Gráfico 1.3. Brasil. Evolução dos acessos e densidade de banda larga fixa (20072020).

Brasil. Evolução dos acessos à Internet em conexão de banda larga fixa (2007-2020)

Acessos

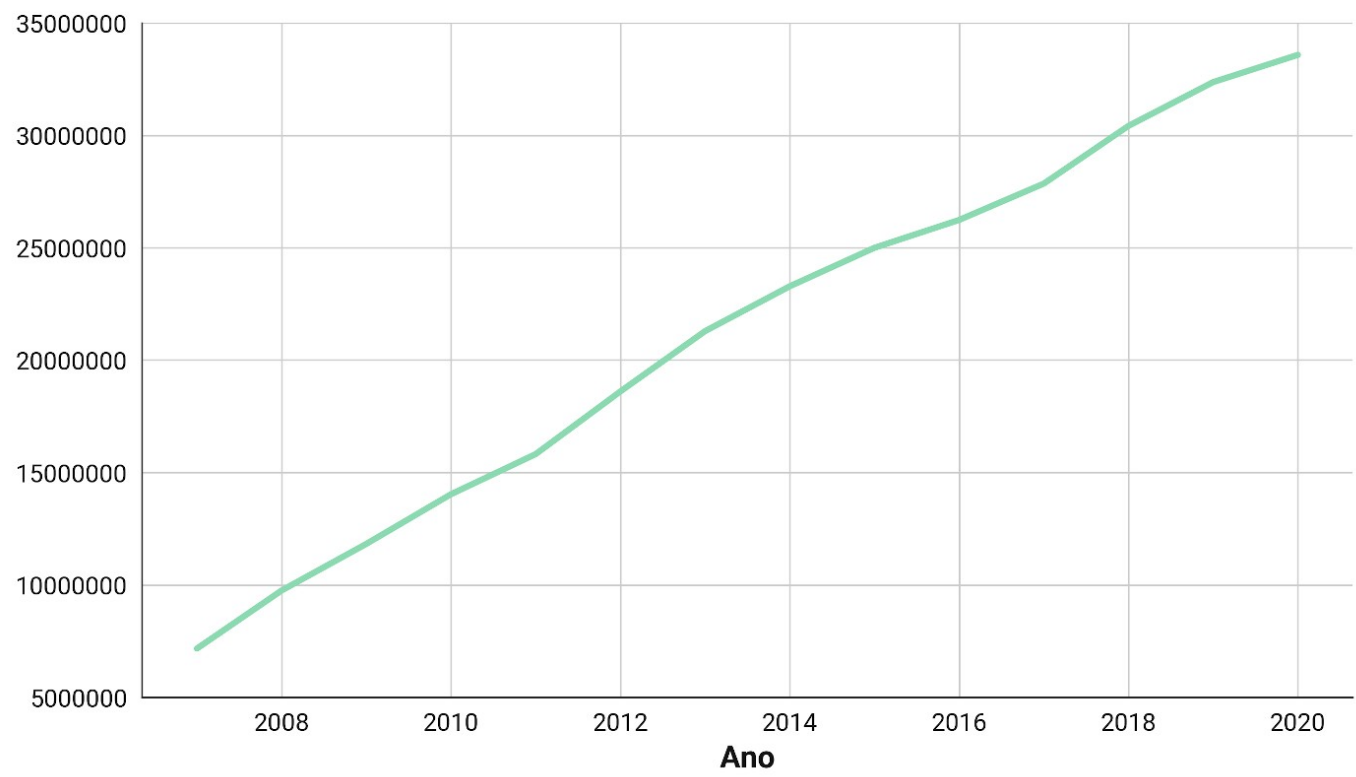

Fonte: Anatel, 2020. Elaboração própria.

Fonte: elaboração própria, a partir de Anatel (2020).

Tabela 1.1. Brasil. Densidade de banda larga fixa por região (2020).

\begin{tabular}{ll}
\hline Região & Densidade de banda larga fixa \\
\hline Brasil & 49.0 \\
Centro-Oeste & 48.8 \\
Nordeste & 26.9 \\
Norte & 25.6 \\
Sudeste & 61.7 \\
Sul & 62.3 \\
\hline
\end{tabular}

Fonte: elaboração própria, a partir de Anatel (2020). 
Tabela 1.2. Brasil. Densidade de banda larga móvel por região (2020).

\begin{tabular}{ll}
\hline Região & Densidade de conexões móveis \\
\hline Brasil & 95.7 \\
Centro-Oeste & 104.1 \\
Nordeste & 83.9 \\
Norte & 84.6 \\
Sudeste & 103.8 \\
Sul & 96.6
\end{tabular}

Fonte: elaboração própria, a partir de Anatel (2020).

Os dados apresentados referem-se aos acessos de banda larga fixa (Serviço de Comunicação Multimídia - SCM) e telefonia móvel (Serviço Móvel Pessoal - SMP), enviados pelas prestadoras dos serviços. Ressalte-se que a densidade é medida em acessos a cada 100 domicílios para a banda larga fixa, e a cada 100 habitantes, para a telefonia móvel. A tecnologia empregada no modelo fixo se divide principalmente em cabos de fibra óptica ${ }^{17}$ (39,9\% do todo), coaxiais ${ }^{18}$ $(28,2 \%)$ e metálicos $(24,3 \%)$. Quanto às empresas teleoperadoras, Claro e Vivo dominam, juntas, mais de 50\% dos mercados fixo e móvel.

Percebe-se que as conexões fixas mais do que dobraram na última década, mas que a disparidade entre regiões é muito alta - Sul e Sudeste possuem densidade uma vez maior que Norte e Nordeste. Deve-se pontuar que um dos grandes anéis de fibra óptica do território brasileiro está justamente no Nordeste (Figura 1.2), e que municípios dessa região e do Norte foram contemplados por ações planejadas no âmbito do Programa Nacional de Banda Larga do Governo Federal (entre 2010 e 2016, aproximadamente), com fins de democratizar o acesso a essa tecnologia. As desigualdades no acesso fixo persistem, mas podem ter sido compensadas pela maior capilarização dos acessos móveis, como exposto na Tabela

17 De acordo com Toledo Junior (2002, p. 140), fibra óptica (ou ótica) é "um elemento simples de transmissão óptica, caracterizado por um núcleo, por onde a luz é transmitida, e uma casca, que confina a luz no interior do núcleo. O confinamento é obtido com uma diferença de índices de refração entre a casca e o núcleo. É composta de material dielétrico, normalmente o vidro, tem a forma de um filamento cilíndrico e diâmetro comparável a um fio de cabelo".

18 Os fios de cobre, utilizados nos cabos coaxiais, podem ser chamados de "par trançado" porque eram entrelaçados com antigos fios de lâmpadas. São considerados um canal com baixa largura de banda, diferentemente da fibra ótica, que possui uma capacidade de envio de bits por segundo teoricamente infinita (NEGROPONTE, 1995, p. 28). 
1.2 .

Figura 1.2. Anéis de fibra óptica Nordeste e Sudeste, operados pela empresa

\section{Eletronet ${ }^{19}$.}

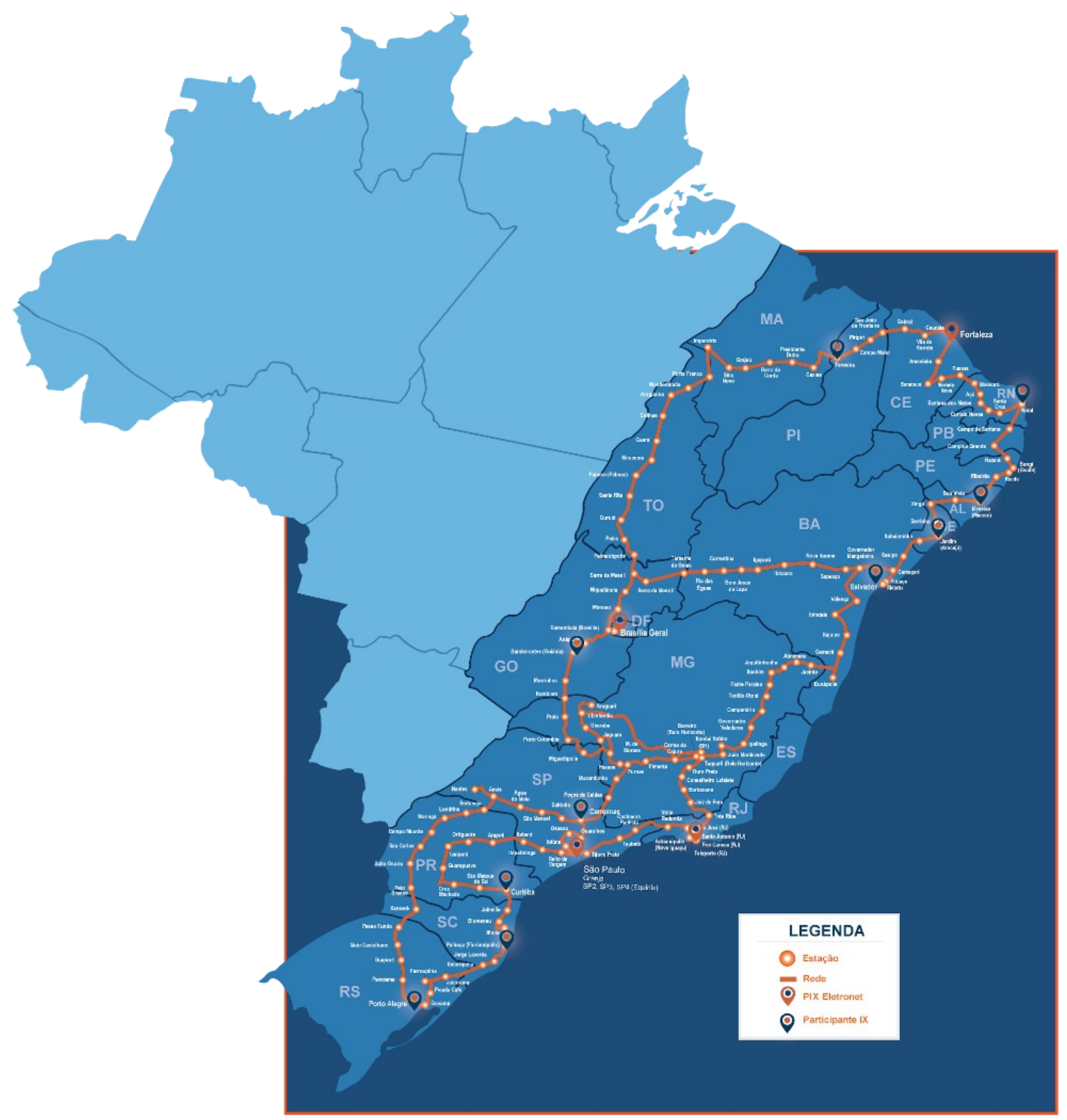

Fonte: Eletronet (2021).

19 A Eletronet, criada em 1999 pelo Governo Federal a fim de utilizar a rede de torres da Eletrobras para transmissão de dados, é detentora e operadora de uma rede de fibra óptica que perpassa 18 estados brasileiros, com mais de 17 mil km de extensão. Seu backbone utiliza cabos ópticos OPGW (optical ground wire) e a infraestrutura de linhas de transmissão de energia elétrica (ELETRONET, 2021). 
Os dados da Anatel (2020) mostram ainda que os planos de conexão móvel de tipos pré-pago e pós-pago estão a ponto de convergir em 2020, na casa dos 110 milhões de acessos. A tendência de convergência vem desde 2015, mas ficou mais próxima após o início da pandemia de Covid-19. No Brasil, a falta de acesso fixo (seja pela falta de oferta ou por razões econômicas) pode levar à opção pela conexão móvel, especialmente em uma situação que exige mais interações pela Internet do que antes das recomendações de distanciamento social. Também em 2015 passou a disseminar-se o uso das redes móveis $4 \mathrm{G}$ (hoje, 71,6\% do total de acessos), que permitem maiores velocidades de conexão móvel, com maior estabilidade e possibilidade de uso simultâneo sem sobrecarga.

Para a Cepal (2020, p. 2), conectividade significa o acesso a dispositivos informáticos e a serviços de banda larga com velocidade adequada. Distintos graus de conectividade podem implicar o direito à saúde, à educação e ao trabalho, ou levar ao aprofundamento de desigualdades socioeconômicas. Trata-se de uma condição necessária, ainda que não suficiente, para apropriar-se do valor gerado pelas tecnologias digitais. Sua capilarização e sua imensa diversidade de aplicações baseiam-se, em grande medida, na conexão entre usuários e dispositivos. Dessa forma, é imprescindível considerar a topologia de redes de Internet móvel e fixa, de servidores e data centers de grandes empresas dos ramos de SCS e da computação em nuvem.

Com a construção e o uso das chamadas "infovias" (redes por onde trafega a informação), novas formas de desempenhar diversas tarefas são incorporadas nos processos produtivos e na vida cotidiana. Tais mudanças técnicas são legitimadas e naturalizadas pela via da psicosfera, o que aos poucos vai remodelando todo o meio geográfico. Nesse âmbito, o software é um elemento fundamental, pois permite o manejo eletrônico de dados para automatização de funções simples ou complexas, impulsionando e facilitando o uso e a conectividade entre máquinas. Complexos processos computacionais simplificam tais funções e, por conseguinte, o produto software é mais propagandeado e cresce em popularidade, o que justifica o notável desenvolvimento econômico do setor na atualidade. 
No caso dos aplicativos que dependem da Internet para funcionar, a infraestrutura mais robusta é o backbone, a "espinha dorsal" ou o "core" da rede, por onde passa o tráfego de voz e dados. Aí, as operações realizadas são de transmissão, comutação, roteamento e gerenciamento desse tráfego - ou seja, determina-se o que será feito e para onde irão os dados. Do backbone saem redes secundárias, chamadas de backhaul, que distribuem o tráfego de forma mais capilar (CORDEIRO, 2009). Ambos os tipos de infraestrutura são complexos e dispendiosos para realizar consertos, manutenção e atualização, o que já impõe uma barreira à propriedade dessas redes. Apenas agentes com muito capital são capazes de realizar investimentos nesse ramo, tornando-o altamente centralizado e oligopolizado.

É raro conseguir obter-se um mapeamento do backbone de Internet em todo o território brasileiro, pois dados de localização de seus nós e linhas são considerados informação estratégica e usualmente pertencem às firmas teleoperadoras. A Figura 1.3 traz uma representação da topologia dessa rede e uma breve explicação sobre como funciona. 
Figura 1.3. Representação do backbone de Internet no Brasil (2010).

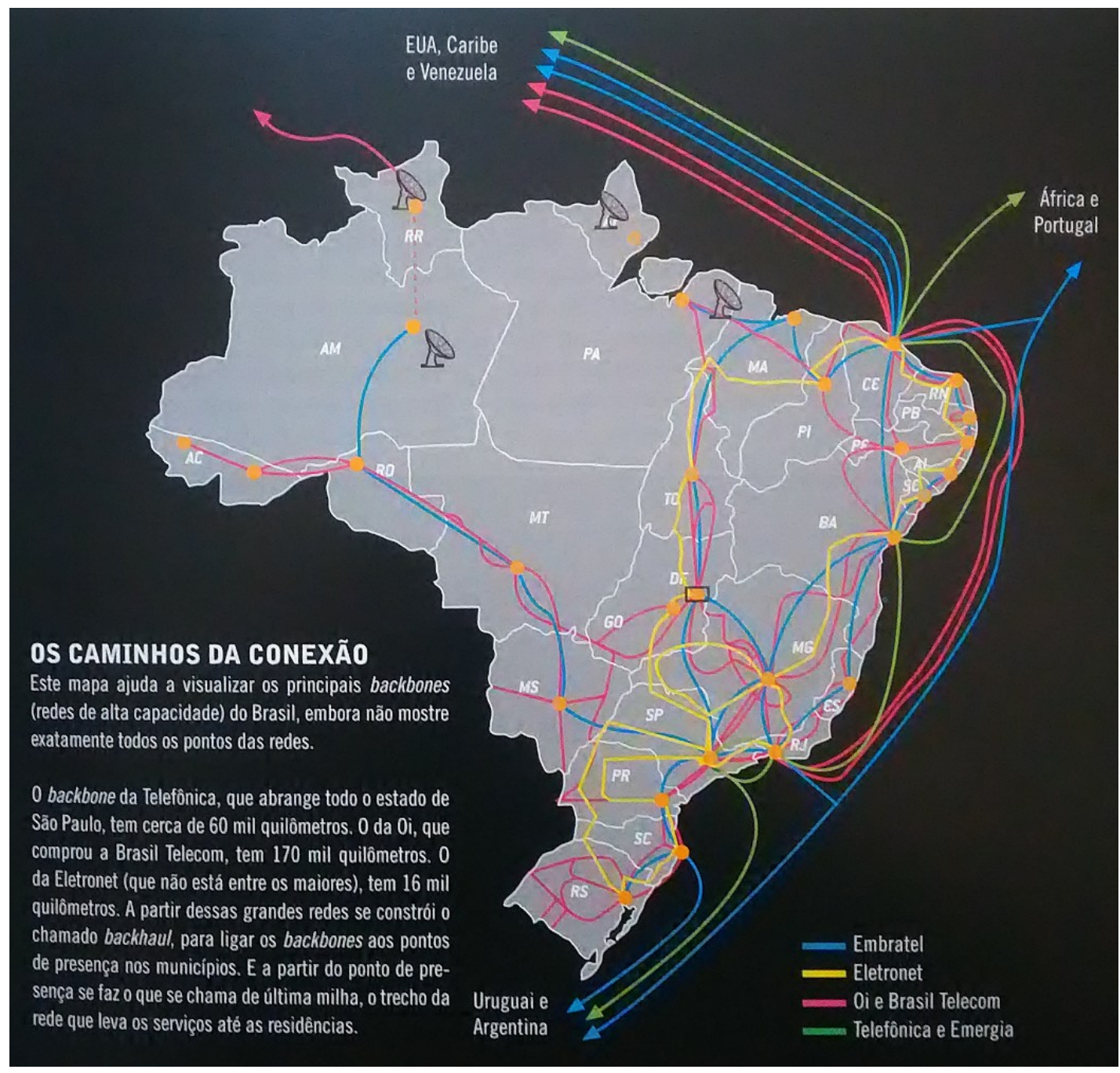

Fonte: Ribeiro e Cornils (2010).

Os cabos submarinos utilizados para telecomunicações (inclusive os cabos telegráficos) compuseram as forças catalisadoras da globalização e das redes corporativas globais (MALECKI; WEI, 2009, p. 360). Conforme o mapa abaixo, a maior concentração dos cabos para conexão via Internet ainda está no hemisfério Norte - como já acontecia desde a implantação dos cabos telegráficos -, entre a Europa e os Estados Unidos, e destes para países asiáticos (Figura 1.4). De fato, Malecki e Wei (2009, p. 275) observam uma mudança nessa centralidade justamente para a Ásia, por conta de maior demanda por capacidade de transmissão de dados. Mesmo em locais com menor demanda, os custos de conectividade vêm caindo vertiginosamente, tornando-os mais atrativos para a 
alocação de novos cabos.

Figura 1.4. Cabos submarinos para conexão à Internet (2021).

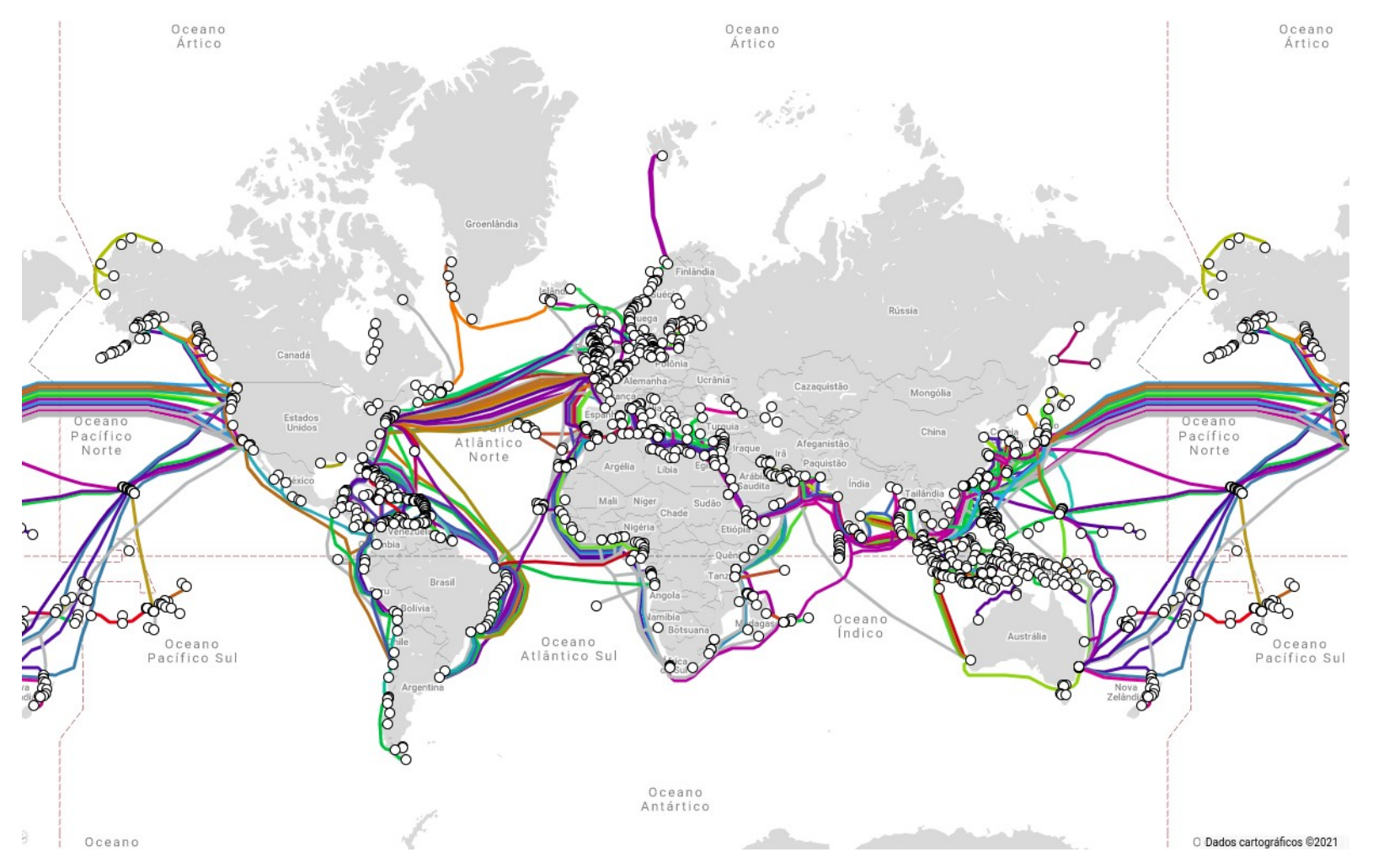

Fonte: Telegeography (2021).

A construção e a propriedade dos cabos submarinos, em geral, são realizadas por consórcios internacionais, com a participação de empresas de vários países e continentes. É o caso do projeto South Atlantic Cable System (SACS), que liga Angola a Fortaleza (CE) e é fruto de uma parceria entre Google (Estados Unidos), Antel (Uruguai), Angola Cables (Angola) e Algar Telecom (Brasil) (SANTANA, 2018). Além disso, corporações que tradicionalmente trabalhavam produzindo conteúdo para a Internet, tais como Facebook e Google, atualmente participam da construção de novas infraestruturas de acesso, entre elas os cabos submarinos. Dois exemplos sul-americanos são os projetos Tannat e Monet, que também envolvem a implantação de fixos como centros de processamento de dados (GOOGLE, 2015). Assim se verifica a articulação de uma série de equipamentos (cabos, servidores, antenas etc.) em um macrossistema técnico de 
comunicação em vias de controle por cada vez menos empresas.

Conforme notam Théry e Mello-Théry (2018, p. 293-294) a respeito dos sistemas de comunicação no território brasileiro, "fora aquele que acompanha o litoral, o principal eixo segue a estrada Brasília-Belém, indo direto para a Amazônia Oriental. Mais a oeste, outras linhas permitem ligações com a Amazônia Ocidental, seguindo as estradas construídas nos anos 1970, para Cuiabá e Porto Velho" e chegando à maioria das capitais de estados. Esses padrões de organização do espaço também se verificam no Mapa 1.1, a respeito das linhas de transmissão de energia elétrica ${ }^{20}$ e do registro de domínios de Internet (por exemplo, os endereços terminados em “.br"). É identificável também uma sobreposição com o grau de urbanização dos municípios (Mapa 1.2), que por sua vez dialoga justamente com a disponibilidade de redes de comunicação e transporte, ao longo do tempo.

\footnotetext{
20 As redes de energia elétrica funcionam como um indicador das dinâmicas do território, articulando porções consumidoras e porções produtoras de energia. Ocorre um diálogo envolvendo as demandas causadas, por exemplo, pela concentração populacional e por atividades econômicas; a disponibilidade de recursos naturais (no Brasil, vinculada sobretudo às usinas hidrelétricas); e a existência de recursos para a captação da energia. Note-se, contudo, que existe considerável deficit na interconexão entre as redes elétricas no território brasileiro, de modo que aproximadamente a metade do país depende de produção de energia local para atender a suas necessidades. $O$ eixo essencial dessas redes é o feixe de linhas de altatensão conectando a Usina Hidrelétrica de Itaipu (no Paraná) ao estado de São Paulo, ao passo que regiões como Nordeste, Norte e Centro-Oeste apresentam menor densidade de redes (THÉRY; MELLO-THÉRY, 2018, p. 291-293). Em São Paulo também é maior a variedade de outras fontes de energia, como gás natural e bagaço de cana-de-açúcar (idem, p. 96), o que está relacionado, por exemplo, à produção agrícola do estado e à produção de petróleo e gás na Bacia de Santos.
} 
Mapa 1.1. Brasil. Redes de energia elétrica e registro de domínios de Internet (2018).

Brasil. Redes de energia elétrica e registro de domínios de Internet (2018)

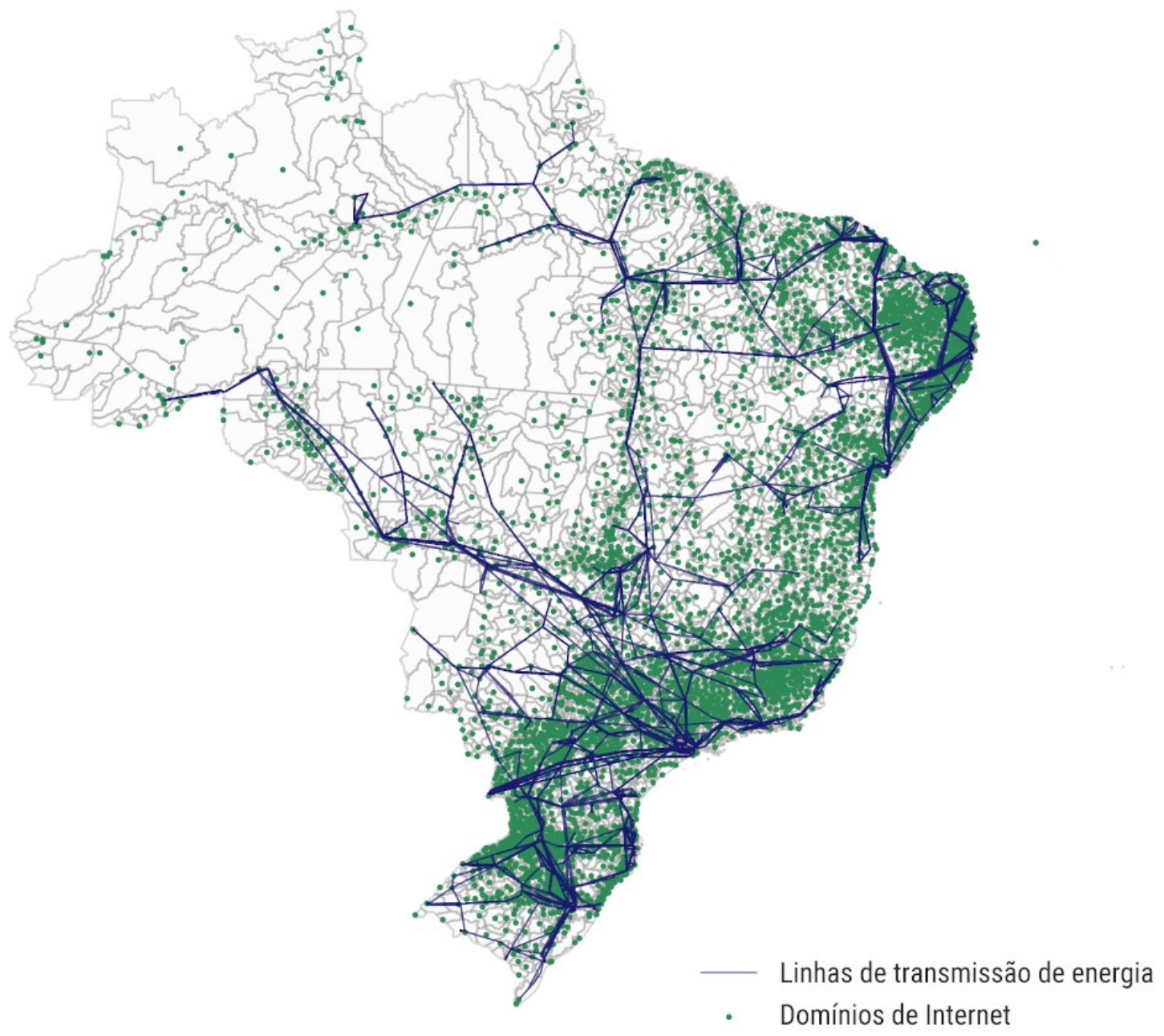

Fonte: IBGE, 2018.

Organização e elaboração: Melissa Steda.

Fonte: elaboração própria, a partir de IBGE (2018). 
Mapa 1.2. Brasil. Porcentagem de urbanização dos municípios (2010).

\section{Brasil. Porcentagem de urbanização dos municípios (2010)}

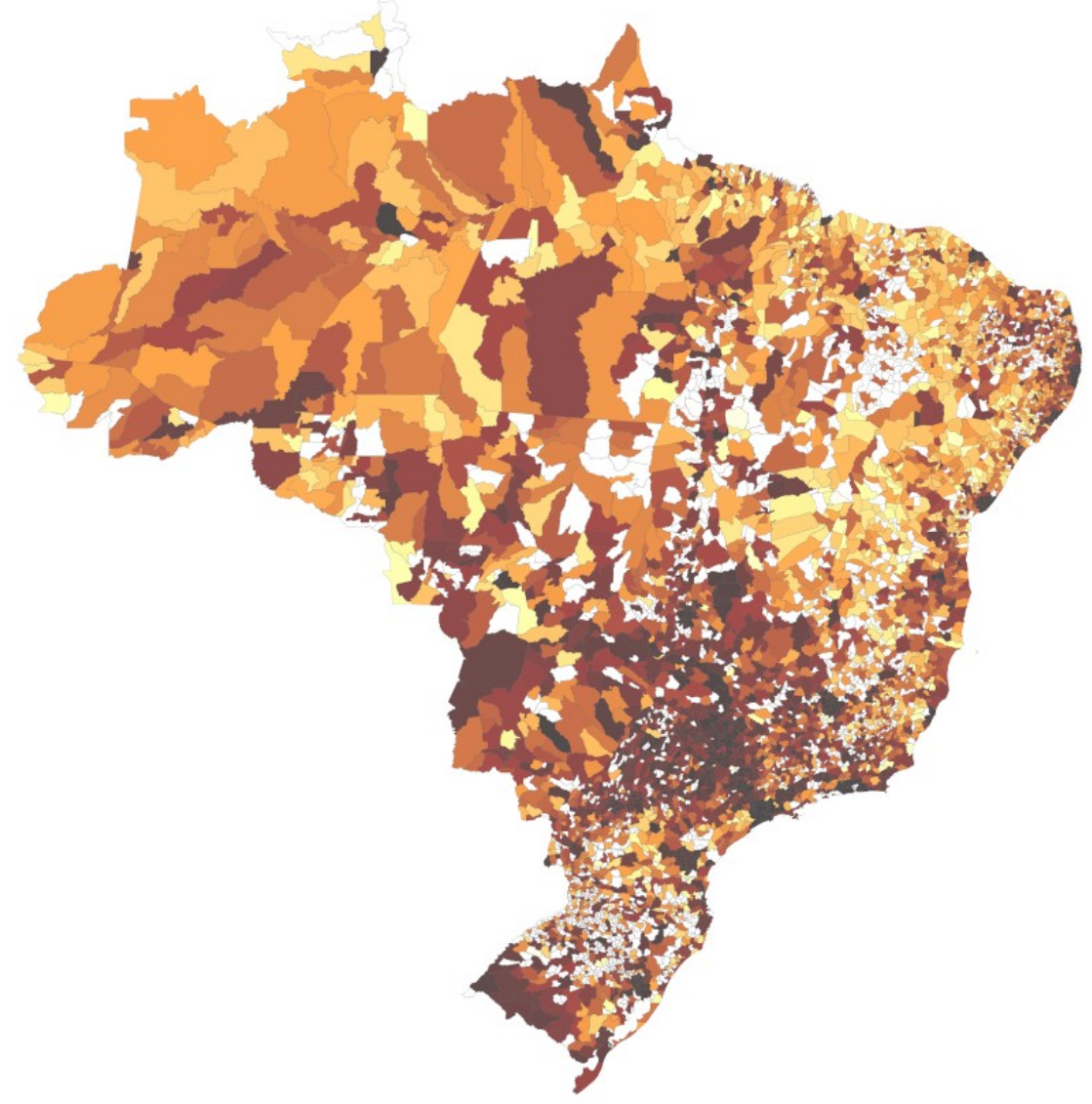

Fonte: elaboração própria, a partir de dados do Censo Demográfico 2010.

O software como serviço ascende em intrínseca relação com a conexão à Internet, tendo em vista que ela é um dos canais para o acesso dos clientes a esses produtos. No ano de 2023, estima-se que haverá 5,3 bilhões de usuários de Internet no mundo. Em 2019, eram 4,2 bilhões (RACONTEUR, 2020). A Internet assemelha-se a redes de energia ou telefonia na medida em que as consideramos como infraestruturas críticas, do ponto de vista de que são hoje imprescindíveis para que se ofertem uma série de serviços essenciais ao funcionamento sobretudo de áreas urbanas ou de áreas rurais mais integradas à dinâmica urbana. Por isso, tal rede é também um recurso estratégico, econômica e politicamente, mobilizando Estados e empresas na elaboração de planos de defesa e cibersegurança. Do mesmo modo, as 
corporações realizam grandes investimentos em segurança da informação, sendo os bancos alguns dos agentes mais preocupados com inovações nessa área. Isto pois a Internet representa um elemento de suporte à circulação não apenas de uma carga gigantesca de dados (o big data), como também das ordens para que o capital financeiro se realize, ao qual interessam variáveis como velocidade e segredo (por exemplo, quando se negociam grandes montantes de dinheiro). Ademais, conforme ressalta Israel (2019, p. 26-27),

Embora associadas quase exclusivamente ao projeto ARPANET ${ }^{21}$, as redes digitais surgiram como um fenômeno técnico através de diversas outras iniciativas que convergiram para a constituição da Internet como rede mundial, entrelaçada por cabos terrestres e submarinos. Herdeira do sistema de telefonia, a conectividade da Internet se consolidou a partir dos anos 1990 como um modelo de prestação de serviço privado, definindo o que está dentro e o que está fora das redes digitais a partir das relações de mercado.

A primeira mensagem enviada no âmbito da ARPANET foi da Universidade da Califórnia em Los Angeles até o Stanford Research Institute (atual SRI International), ambos nos Estados Unidos, em 29 de outubro de 1969. O projeto possuía generoso financiamento e recursos mais numerosos que outros países poderiam acessar. Esse foi considerado o primeiro nó da rede, com a transmissão de dados ocorrendo por meio da comutação de pacotes e da alocação dinâmica de recursos. É imprescindível recordar, no entanto, que o francês Louis Pouzin foi um pioneiro no desenho e na implementação da comutação de pacotes em redes de comunicação que levaram ao desenvolvimento da Internet ${ }^{22}$. Ele coordenou o projeto Cyclades, que influenciou a criação do protocolo TCP/IP e levaria à possibilidade de conexão entre diversas redes de computadores distintas (ISRAEL, 2019, p. 74; 93). Note-se, portanto, que há décadas a informatização do território contém flagrantes contornos geopolíticos e a história das mudanças técnicas e suas reverberações no meio geográfico dependem de múltiplos fatores associados.

21 “Criada em 1958, o objetivo dado à ARPA (Advanced Research Projects Agency) pelo Departamento de Defesa (DoD) [dos Estados Unidos], consistia justamente no desenvolvimento de pesquisas que resultassem em superioridade tecnológica militar face ao programa soviético, que lançara em 1957 o satélite Sputnik" (ISRAEL, 2019, p. 62).

22 o processo de troca de sinais e de comutação de pacotes entre máquinas constitui o chamado "handshaking" (aperto de mãos), quando se estabelece a comunicação por meio de protocolos detalhados (como o TCP/IP) (NEGROPONTE, 1995, p. 197). 
Tim Berners-Lee e Robert Cailliau desenvolveram a World Wide Web inicialmente na Organização Europeia para a Pesquisa Nuclear (CERN), para comunicação e análise de dados no CERN e em laboratórios de Física, e em 1993 permitiram o acesso público à rede para pessoas com acesso a um computador e uma rede telefônica (BYNUM, 2018, p. 338-339).

No entanto, o meio técnico-científico-informacional resulta de condições históricas, sociais, políticas, econômicas e territoriais específicas. Ainda que seja predominante, ele se realiza nos lugares de modo completamente diferenciado e é mediado pelas formações socioespaciais (SANTOS, 1997). Por exemplo: em 1972, existiam apenas 150 mil computadores no mundo, e operá-los exigia conhecimento altamente especializado (NEGROPONTE, 1995, p. 90). No caso do Brasil, Dias (1995, p. 156) aponta três fases no aumento da densidade de redes de informação e comunicação: nos anos 1960, quando a informática estava presente apenas em grandes empresas; nos anos 1970, quando começaram a se difundir os microcomputadores; e nos anos 1980, quando aumentou a capacidade de análise instantânea de dados.

Mesmo com a ideia da Internet como uma "rede mundial de computadores", frequentemente caracterizada pela comunicação via protocolo $\mathrm{TCP} / \mathrm{IP}^{23}$, existem tecnologias para sua administração baseadas em políticas locais ou em infraestruturas descentralizadas. A China, por exemplo, tem focado as estratégias de governança da Internet em seu território em padrões técnicos próprios, que geram questionamentos quanto às intenções de manter a rede funcionando com padrões técnicos globais mais abertos e interoperáveis (HOFFMANN et al., 2020, p. 240).

Esse tipo de reconfiguração dos elementos básicos da Internet, por um lado, atenua a concentração da rede em torno de instituições situadas nos países centrais, mas também pode contribuir para fragmentação dos protocolos,

23 O Transmission Control Protocol/Internet Protocol, traduzido como protocolo de controle de transmissão/protocolo da internet, é um padrão técnico para comutação de pacotes na Internet. Dele fazem parte os endereços IP, que funcionam como identificadores numéricos ou alfanuméricos de cada dispositivo conectado à rede, para que possam receber os pacotes comutados (KURBALIJA, 2016, p. 54-55). A governança do funcionamento do TCP/IP cabe à Internet Engineering Task Force (IETF), ou força-tarefa de engenharia para internet, uma "comunidade internacional aberta de desenvolvedores de recursos" para a rede (CABRAL et al., 2017, p. 141). 
arquiteturas, aplicações e dispositivos empregados na rede, processo que vem sendo chamado de "splinternet" - numa tradução livre, "internet estilhaçada" (idem, p. 256). Ressalte-se, no entanto, que há tempos existem tecnologias como as redes mesh, que funcionam com uma lógica distribuída baseada em roteadores sem fio (daí o nome "mesh", a respeito de sua arquitetura em malha) que promove uma espécie de "interconexão cooperativa", potencialmente muito útil em comunidades isoladas do restante da Internet ou que desejem apropriar-se tecnicamente da arquitetura da rede para fins de democratização e emancipação política (ISRAEL, 2019, p. 239-240).

Houve monopólios na indústria das redes de telecomunicação por cabos, chegando a controlar não só a rede-suporte, mas também seu conteúdo (NEGROPONTE, 1995, p. 79). É um exemplo de como as redes são portadoras de ordem em escala planetária, assim como podem ser vetores de desordem em escala local (DIAS, 1995, p. 154). Ressalte-se que, especialmente desde 2016, observou-se um deterioramento intencional da infraestrutura pública brasileira de informática, com demissões de funcionários especializados e o desmonte de empresas do ramo, como a Dataprev. Esse tipo de atitude, coordenada com interesses do capital privado no crescente mercado brasileiro de TI, vai na contramão de todas as evidências que mostram estarmos vivendo um período histórico em que a informação é recurso cada vez mais estratégico, inclusive para os Estados.

Iozzi (2006, p. 17) aponta três períodos na formação do macrossistema de telecomunicações brasileiro. $O$ primeiro, de meados do século XIX à década de 1960, corresponde à implantação das redes de telefonia, operadas por empresas privadas. No segundo período, entre os anos 1960 e o fim dos 1990, ocorreu a estatização das empresas e a formação do Sistema Brasileiro de Telecomunicações. Por fim, a partir de 1998, identifica-se um período de privatização e nova regulação do setor, ainda vigente. As firmas que agora controlam essas redes (e também as de telefonia móvel) selecionam pontos do território para ofertar seus serviços, prezando por maiores lucros e não pela universalização do acesso.

Anteriormente, o sistema Telebras possuía como fontes de financiamento recursos de geração própria, recursos de terceiros (via empréstimos 
e financiamentos), autofinanciamento e recursos fiscais do Fundo Nacional de Telecomunicações. Com a extinção desse fundo, mais as políticas de controle da inflação nos anos 1990 e menor captação de recursos de terceiros, decaiu o financiamento do sistema e foi teoricamente justificada uma desestatização, segundo interesses privatistas. Ele foi então reestruturado, passando de uma estrutura de polos em cada unidade da federação para a divisão do território brasileiro em áreas de concessão (IOZZI, 2006, p. 31; 56).

Note-se que a concessão implica satisfazer necessidades coletivas, diferentemente de um regime de autorização de serviços públicos. Na concessão, o regime jurídico de prestação do serviço é público, sendo que a empresa concessionária tem os mesmos encargos, obrigações e prerrogativas do poder público, conforme registrado em contrato entre essas partes. Isso pressupõe também obrigações de universalização e continuidade na prestação do serviço, com prazo de exploração determinado, diferentemente de um regime privado (IOZZI, 2006, p. 67).

A Lei Geral de Telecomunicações (LGT), aprovada em 1997, prevê os regimes público e privado de prestação de serviços. Valente $(2016$, p. 18) os descreve da seguinte maneira:

O primeiro, prestado sob concessão, possui metas de universalização, controle de tarifas, obrigações de qualidade, continuidade e reversibilidade dos bens (devolução da infraestrutura do sistema privatizado ao fim do contrato de concessão, para garantir a continuidade do serviço. Segundo a LGT, o regime público deve ser adotado para serviços considerados essenciais - desde aquela época, somente a telefonia fixa. 0 segundo traz bem menos obrigações. Prestado via autorização, libera operadoras para atuarem com muito mais liberdade no mercado e hoje disciplina as demais atividades do setor, como telefonia móvel e acesso à Internet.

Recorrentemente, as teleoperadoras pressionam o Estado para flexibilização da LGT, com argumentos relacionados à suposta falta de interesse da população na telefonia fixa, a incentivos públicos em áreas de baixa renda com menor interesse do mercado, e mesmo na interpretação do que são os bens reversíveis na telefonia, acima mencionados (e que, antes das privatizações nos 
anos 1990, pertenciam ao Sistema Telebras). Também existe tensão em torno dos recursos do Fundo de Universalização dos Serviços de Telecomunicações (FUST), liberados somente para uso em regime público, e do regime utilizado para prestação de serviços de acesso à Internet - já que o Marco Civil da Internet coloca o acesso à rede como essencial. Um marco regulatório ainda menos restritivo para as teles, com desonerações e menos obrigações, pode limitar a atuação do Estado e tornar-se ainda mais um empecilho para a democratização das comunicações e a universalização do acesso à Internet no Brasil (VALENTE, 2016, p. 18-19).

As sucessivas modernizações no território permitem visualizar as possibilidades para seu uso e a superposição de diversas divisões territoriais do trabalho, conforme detalhado por Schiaffino e Parserisas (2019, p. 6). Por exemplo, os antecedentes da telefonia celular datam de 1947, nos Estados Unidos, e a primeira geração (1G) de celulares comerciais é de 1973, com o Motorola DynaTac. A segunda geração $(2 \mathrm{G})$, nos anos 1990 , promoveria a mudança da telefonia celular analógica à digital, que levaria às seguintes gerações que utilizamos nos anos 2020 (3G, $4 \mathrm{G}$ e $5 \mathrm{G})$, cada uma delas com suas características técnicas particulares, como quanto à banda de radiofrequência utilizada ${ }^{24}$.

As estações rádio base (Mapa 1.3) são objetos bastante visíveis da tecnosfera da telefonia móvel, mas sua topologia é muito similar à de outras redes técnicas no Brasil. Evidentemente, há uma série de outros aparatos escondidos na paisagem, como os cabos de fibra óptica. Mas, sobretudo se considerarmos a Internet uma totalização do meio geográfico da globalização (ISRAEL, 2019), fica evidente que tal infraestrutura de conectividade possibilita somente a alguns agentes ter os benefícios potenciais da rede.

240 espectro eletromagnético é uma propriedade da luz que se divide em comprimentos (bandas) usados de forma diversificada. Daí se obtém as bandas utilizadas, por exemplo, pela telefonia celular. 
Mapa 1.3. Brasil. Estações rádio base (2018).

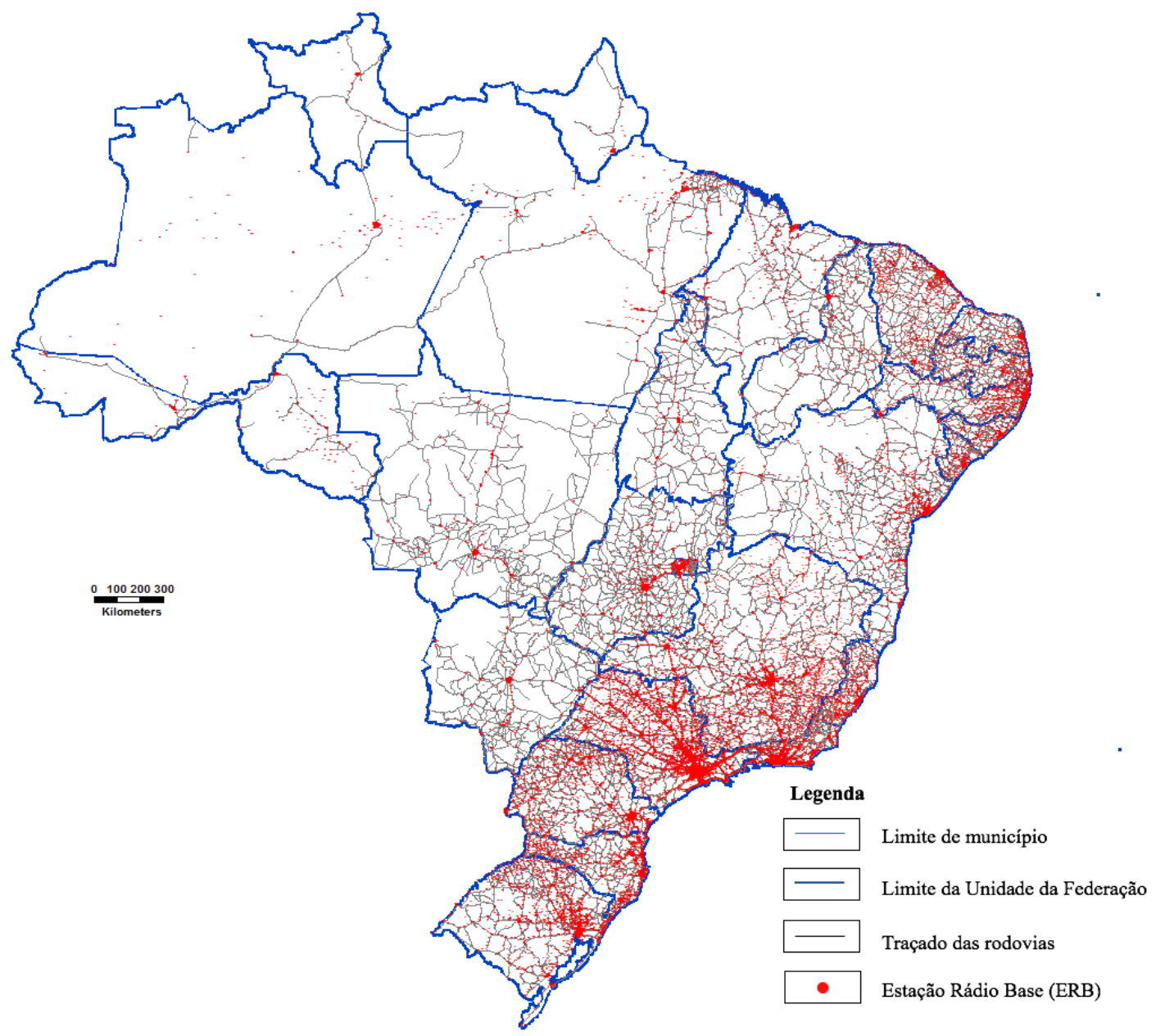

Fonte: Bertollo (2019, p. 172).

Para detalhar um aspecto da capilarização dos dispositivos de TI pelo território brasileiro no nível dos domicílios, trazemos a Tabela 1.3, com os dados mais recentes disponíveis sobre a presença de computador e conexão à Internet por área, região, renda familiar e classe social, em 2019. Em contrapartida, 30\% do total de 45.464.599 domicílios não possuem aqueles itens e, de 2016 a 2018, esse número oscilou de 39 a 41\%. 
Tabela 1.3. Brasil. Domicílios, por presença de computador e Internet (2019).

\begin{tabular}{|c|c|c|}
\hline \multicolumn{2}{|l|}{ TOTAL } & \multirow{2}{*}{$\begin{array}{r}26,527,609 \\
24,987,632\end{array}$} \\
\hline ÁREA & Urbana & \\
\hline & Rural & $1,539,977$ \\
\hline \multirow[t]{5}{*}{ REGIÃO } & Sudeste & $13,555,126$ \\
\hline & Nordeste & $5,197,792$ \\
\hline & Sul & $4,506,388$ \\
\hline & Norte & $1,374,702$ \\
\hline & Centro-Oeste & $1,893,601$ \\
\hline \multirow[t]{9}{*}{ RENDA FAMILIAR } & Até $1 \mathrm{SM}$ & $3,324,912$ \\
\hline & Mais de $1 \mathrm{SM}$ até $2 \mathrm{SM}$ & $5,762,963$ \\
\hline & Mais de 2 SM até 3 SM & $4,966,828$ \\
\hline & Mais de 3 SM até 5 SM & $5,096,330$ \\
\hline & Mais de $5 \mathrm{SM}$ até $10 \mathrm{SM}$ & $3,334,248$ \\
\hline & Mais de $10 \mathrm{SM}$ & $1,563,581$ \\
\hline & Não tem renda & 277,530 \\
\hline & Não sabe & $1,125,776$ \\
\hline & Não respondeu & $1,075,442$ \\
\hline \multirow[t]{4}{*}{ CLASSE SOCIAL } & $\mathrm{A}$ & 968,140 \\
\hline & B & $8,586,076$ \\
\hline & C & $13,820,394$ \\
\hline & $\mathrm{D}$ e $\mathrm{E}$ & $3,152,999$ \\
\hline
\end{tabular}

Fonte: elaboração própria, a partir de Cetic.BR (2019).

Vemos delinear-se uma situação de estagnação e aprofundamento das desigualdades regionais brasileiras em relação ao acesso à Internet. Vêm se sustentando os baixos índices de conectividade a banda larga fixa em áreas rurais (CETIC.BR, 2020), e em porções do território distantes dos centros mais dinâmicos da economia nacional, tais como o interior do estado do Amazonas, além da dificuldade do acesso, há quase monopólio de algumas operadoras de telefonia e o uso das redes é mais rarefeito (EUZÉBIO, 2011, p. 83; QUEIROZ, 2015, p. 222). 
Ao focarmo-nos no consumo dos dispositivos e na conectividade, verifica-se que o número de smartphones em uso no Brasil cresceu 8,8\% de 2018 a 2019, e a tendência de ascensão também ocorre com os computadores dos tipos notebook $(4,5 \%)$ e desktop $(3,8 \%)$. Por outro lado, as conexões de dados nos ambientes doméstico e corporativo se mantiveram estáveis. Já no âmbito da computação em nuvem, os incrementos foram mais expressivos: o mercado de software como serviço cresceu 48,7\% em relação a 2018 (ABES, 2020, p. 5), e mais de dois terços das empresas consideradas no estudo têm algum tipo de iniciativa em nuvem pública (ABES, 2020, p. 21). Esta modalidade de armazenamento de dados alcançou um valor de mercado estimado em US\$ 3,5 bilhões no Brasil em 2020, ou um aumento de $36,6 \%$ sobre o ano anterior (ABES, 2020, p. 22).

De acordo com folder informativo do CGI.br, em 2005, 68\% dos brasileiros residentes em áreas urbanas nunca haviam acessado a Internet; em 2006, havia 1 milhão de domínios .br registrados (contra 3,7 milhões em 2015), e somente $49 \%$ das empresas com acesso à Web possuíam um website. A rede era acessada em lan houses por metade dos usuários em 2007, o que denota que não era tão comum possuir computador em casa. Por outro lado, nessa época eram lançados o iPhone (2007), os primeiros celulares com sistema Android, pertencente à Google (2008) e o aplicativo para troca de mensagens WhatsApp (2009), que atingiria 700 milhões de usuários mensais no mundo em 2015. Também eram lançados o Youtube (2005) e o Twitter (2006), e o Netflix iniciava operações no Brasil (2011). Todas essas transformações na tecnosfera (Tabela 1.4), tanto nos bens tangíveis como nos intangíveis, são muito intensas, aceleradas e recentes. 
Tabela 1.4. Fatos e dados relevantes sobre a tecnosfera de conectividade à Internet no Brasil e políticas públicas relacionadas.

\begin{tabular}{ll}
\hline Ano & Ocorrência \\
\hline 2008 & Lançamento do programa Banda Larga nas Escolas \\
\hline 2009 & Início do programa Telecentros.br \\
\hline 2010 & Lançamento do Plano Nacional de Banda Larga \\
\hline 2011 & $\begin{array}{l}\text { 1.934 provedores de serviços de Internet atuavam no Brasil, e 87\% das empresas } \\
\text { possuíam websites com domínio .com.br; Facebook supera o número de usuários } \\
\text { do Orkut no país }\end{array}$ \\
\hline 2012 & Lei de Acesso à Informação \\
\hline & $\begin{array}{l}\text { Política de desoneração de smartphones; 23\% dos estabelecimentos de saúde com } \\
\text { conexão à Internet utilizavam prontuários completamente eletrônicos; emergem } \\
\text { escândalos internacionais de espionagem a diversos países pela Internet, } \\
\text { inclusive o Brasil (revelados principalmente por Edward Snowden) }\end{array}$ \\
\hline $\begin{array}{l}\text { 55\% da população brasileira era usuária da Internet; sanção do Marco Civil da } \\
\text { Internet; popularizam-se aplicativos de “economia compartilhada”, como Uber e }\end{array}$ \\
$\begin{array}{l}\text { Airbnb; o smartphone supera o computador como principal dispositivo de acesso } \\
\text { à Internet por usuários jovens (crianças e adolescentes); a proporção de } \\
\text { domicílios urbanos com Internet se equipara à daqueles com computador; a } \\
\text { proporção de domicílios com computador portátil (laptop ou notebook) supera a } \\
\text { daqueles com computador de mesa (desktop) }\end{array}$
\end{tabular}
Fonte: elaboração própria, com adaptação e acréscimos a folder informativo do CGI.br (2016).

As entidades participantes da governança da Internet, que influenciam em sua difusão pelo território e nos acontecimentos acima relatados, constituem o que Lévy (1994, p. 228) chamou de atores não-econômicos, mas que ainda estão sujeitas, em certa medida, à regulação pelo mercado. Um agente relevante nos círculos de cooperação envolvidos na conectividade brasileira é o Comitê Gestor da Internet no Brasil (CGI.br) ${ }^{25}$. Trata-se de um órgão multissetorial, não-regulador, criado em 1995. Participam dele representantes do governo, da academia, de empresas de qualquer porte, e da sociedade civil (organizada em entidades não-

25 Em meados dos anos 1990, definiu-se que, diferentemente da regulação da telefonia no Brasil (pela Agência Nacional de Telecomunicações - Anatel), a Internet receberia sugestões de desenvolvimento pelo CGI.br. A princípio um órgão de governança multiparticipativa mais técnico, a partir de 2003 passou a ter maior participação da sociedade civil (idem, p. 6-7). 12 dos 21 membros são não-governamentais, formando maioria - no entanto, este modelo por vezes é ameaçado por pressões antidemocráticas, a fim de garantir mais cadeiras do governo. Ainda assim, o CGI.br já foi capaz de produzir importantes orientações para um uso livre e democrático da Internet no Brasil, como um "decálogo de princípios" que provavelmente foi inspiração para o texto inicial do Marco Civil da Internet (lei federal de 2014 que estabeleceu direitos para uso da Internet no país) (ZANATTA, 2016, p. 13). 
governamentais ou sem fins lucrativos). Subdivisões técnicas do CGI.br são responsáveis por distribuir endereços IP e nomes de domínio, criar normas e princípios para o uso da Internet no Brasil, proteger a segurança dos usuários da Web e corrigir vulnerabilidades técnicas da rede. Outro importante papel do comitê é recomendar o investimento nos chamados Pontos de Troca de Tráfego (PTTs), que permitem aumentar o número de conexões entre redes no território e diminuir o tempo de espera dos usuários para o tráfego de dados (ZANATTA, 2016, p. 4).

Os Pontos de Troca de Tráfego ${ }^{26}$ são um serviço público importante para reduzir-se o consumo de banda internacional e otimizar o tráfego de dados nacional, tornando sua entrega mais eficiente (AFONSO, 2002). Esses ambientes de interconexões devem ser neutros e de utilização pública, com pontos de acesso abrigados em vários provedores. Nas regiões metropolitanas, são implementados os chamados PTTMetro (Metropolitan Internet Exchange Points), que devem ter como características neutralidade (independência de provedores comerciais de Internet), qualidade (com troca de tráfego eficiente), e uma única matriz de troca de tráfego regional. Dessa forma, é possível resolver balanços de tráfego localmente, sem recorrer a redes de terceiros, possivelmente distantes - o que permite diminuir a latência e o tempo de espera da troca de dados (ZANATTA, 2016, p. 8).

Usualmente, a troca de tráfego ou "peering" entre grandes redes ocorre sem custos, mas como nem todas as redes se conectam entre si, no roteamento de pacotes de dados são também utilizadas infraestruturas de terceiros (o chamado "trânsito"). Com os PTTs, é possível ocorrer o subsídio (por exemplo, com os recursos arrecadados pela alocação de domínios “.br” pelo NIC.br) ou rateio entre os usuários. Já o trânsito é um serviço comercial, geralmente envolvendo pagamento e acordos importantes para os Internet Service Providers (ISPs), pois a interconexão faz reduzir o tráfego Internet por eles carregado. Outros fatores técnicos que valem a menção são a melhoria da qualidade da transmissão de dados,

26 Os PTTs (ou IXPs, do inglês Internet Exchange Point) são um arranjo para troca de tráfego presente em dezenas de países e de especial relevância para os pequenos e médios provedores de Internet, providenciando grande redução de custos. Tais pontos permitem que redes que usam o protocolo Internet (Internet Protocol ou IP) "troquem tráfego de dados de forma eficiente em um ponto comum, um lugar físico onde duas ou mais redes se encontram" (GROSSMANN, 2015, p. 15). 
a resiliência e a menor latência (o "atraso" para a chegada de pacotes de dados de um ponto a outro). Tais características acabam atraindo empresas como a Netflix, que implantou redes de distribuição de conteúdos no Brasil (chamadas de CDNs), nos PTTs de São Paulo e Rio de Janeiro (GROSSMANN, 2015, p. 15-17). As conexões locais por meio de PTTs também auxiliam a reduzir custos para os agentes que usam a rede pois, do contrário, os valores são geralmente estabelecidos em dólares estadunidenses (AFONSO, 2002, p. 179-180).

Os provedores regionais de Internet, em contraste com as grandes teleoperadoras, têm dificuldade de acesso a linhas de financiamento que os permitam investir em redes de fibra óptica. Ademais, são custosas a mão de obra especializada e a obtenção de licenciamento urbano. Por vezes, porém, o vínculo entre Estado, indústria e academia acaba compensando esses gargalos. A empresa Padtec, originada em 2001 de um departamento do CPqD (que pertencia à Telebras) em Campinas (SP), tornou-se a maior fabricante de sistemas ópticos da América Latina. Com mais de 300 empregados, possuía em 2016 quatro escritórios no Brasil e um em Buenos Aires (Argentina) (CORDEIRO, 2016, p. 14-16).

É importante mencionar ainda a existência da Rede Nacional de Pesquisa (RNP), criada pelo então Ministério da Ciência e Tecnologia (MCT) em 1989 e ainda em operação. A partir de 2005, tem-se uma série de modernizações com o lançamento da chamada rede Ipê, primeira rede nacional de enlaces ópticos implementada na América Latina e considerada o "backbone acadêmico" do Brasil. Sua capacidade de transmissão de dados, hoje na escala dos Gigabytes por segundo (GB/s), veio de um acordo de cooperação entre a companhia Oi e a Agência Brasileira de Telecomunicações (Anatel). Tal infraestrutura possibilita não apenas o chamado tráfego de internet de produção (como o uso de correio eletrônico, navegação web e envio de arquivos), como também experimentações e o uso de serviços e aplicações mais avançados. Instituições de ensino e pesquisa em nível superior são alguns dos principais usuários da rede Ipê, mas a RNP oferece suporte (em termos de conectividade) a projetos mais amplos - por exemplo, com conexões de telemedicina com outros países da América Latina, ou com apoio a projetos de pesquisa e ao Portal de Periódicos da CAPES (RNP, 2010). 
É difícil imaginar a ciência moderna e a vida cotidiana sem o computador. Muitos problemas científicos fundamentais, da criação de novos medicamentos à simulação de mudanças climáticas, dependem dessas máquinas. Sistemas de computador pilotam aviões, auxiliam na criação de imagens médicas e lavam roupas (BYNUM, 2018, p. 339). Esses são exemplos das formas que o meio técnico-científico-informacional toma no período atual, ao passo que sustenta a difusão dos aplicativos.

O espaço se impõe pelas condições que oferece para a circulação (HUERTAS, 2015, p. 47), especialmente de dados, no século XXI. Ao se equipar o território com maior densidade de fluxos e fixos geográficos, abrem-se mais possibilidades para seu uso corporativo. Investimentos em seu aprimoramento e difusão e a produção de normas para sua utilização são compartilhados pelo Estado e pelas empresas, e os usuários acabam sendo signatários de um conjunto de regras estabelecidos pelos agentes hegemônicos, por meio de vários contratos e práticas (SILVA, 2018, p. 16).

A concentração das redes e atividades relacionadas à telemática em torno dos centros de gestão do território (São Paulo, Rio de Janeiro e Brasília) se relaciona ao oligopólio das telecomunicações no Brasil e configura um forte telecomando partindo desses lugares em direção a outros, especialmente pelo capital privado e corporativo, tanto nacional quanto estrangeiro. Como notado por Silva (2018, p. 28), a preparação técnica e normativa do território o torna apto a receber e emitir demandas da globalização e "reúne uma infinidade grande de companhias, setores e organismos interessados em participar da infraestrutura, dos sistemas de movimento, do uso territorial de um país com dimensões continentais, rico, diverso", porém extremamente desigual. Acaba sendo reiterada a condição de forte interligação entre os centros na rede urbana brasileira (CORRÊA, 2006, p. 306), em vez de haver disseminação de bens e serviços. 


\subsection{O advento da computação em nuvem como evento geográfico}

Uma das grandes revoluções trazidas pela computação é o fato de que ela permite executar operações em uma grande massa de dados num período de tempo aceitável e que, mesmo décadas após a invenção dos computadores, continua a aumentar em capacidade de processamento ${ }^{27}$. Ou seja, é um produto de rápida atualização, em vez de apenas tornar-se obsoleto e dar lugar a uma alternativa. Ele acompanha um incrível movimento: a quantidade de dados armazenada no mundo, entre todos os dispositivos e fontes disponíveis, cresce em torno de $23 \%$ ao ano, mais do que dobrando a cada 3 ou 4 anos.

Imensa parcela desses dados vem da Internet das Coisas, que consiste na conexão via Internet entre aparelhos e na tomada de decisões computacionais independentemente da interação com seres humanos, com registros das operações efetuadas e seus resultados. Portanto, estamos conhecendo também um grande aperfeiçoamento das tecnologias de inteligência artificial e aprendizado de máquina, todas as quais participam do universo da "big data" e só podem prosperar no meio técnico-científico-informacional.

Um computador é uma máquina ideal para processar tanta informação, por sua extrema rapidez ao realizar operações simples - portanto, um aparato central para a aceleração contemporânea. Especialmente no atual período, com a existência dos produtos "como serviço", vive-se um ápice de quantificação de diversos aspectos da vida humana, traduzindo-os em dados, cálculos, números e bits. É essa colossal massa de dados que tem sido chamada de "big data", exigindo o desenvolvimento de tecnologias ditas "não tradicionais", como a computação em nuvem, para seu armazenamento, manipulação e para acessá-los mais facilmente. De acordo com Bertollo (2019, p. 104),

A nuvem é composta de uma ampla rede de servidores remotos distribuídos pelo planeta que são conectados e funcionam como um

27 A medida de processamento de um computador em Hertz corresponde à quantidade de operações que ele pode executar por segundo. Por exemplo: um processador de $3 \mathrm{GHz}$ pode realizar 3 bilhões de operações simples por segundo. 
sistema único. Esses servidores armazenam e gerenciam dados, executam aplicativos e oferecem serviços de comunicação como chamadas de vídeo, e-mails, armazenamento de arquivos etc. Os arquivos são acessados on-line, por meio de um smartphone funcionando como um HD (hard disk) externo. Existem a nuvem pública, cujos serviços são gratuitos, a nuvem privada, que fornece serviços numa rede interna particular, a nuvem híbrida, que compartilha serviços entre nuvens públicas e particulares, e a nuvem de comunidade, que compartilha recursos apenas entre organizações como instituições governamentais.

Dodge e Kitchin (2007) utilizam termos aproximados, como “computação ubíqua" ou "pervasiva”, e Cabral et al. (2017, p. 69) destaca que "é importante e necessário ter conexão de internet e, dependendo do volume de informações, que a conectividade seja de alta velocidade", e que, nos pacotes básicos, os serviços que funcionam com armazenamento de dados em nuvem "são gratuitos, mas, para volumes maiores ou profissionais, são pagos” (idem, p. 188). Por sua vez, Kurbalija (2016, p. 86) coloca a nuvem como parte da "cesta de infraestrutura e padronização" da governança da Internet, e completa:

A computação em nuvem poderia ser descrita como a transferência dos dados dos discos rígidos no computador para servidores nas nuvens (isto é, grandes parques de servidores). A primeira onda de computação em nuvem começou com o uso dos servidores de correio online (Gmail, Yahoo!), aplicativos de mídia social (Facebook, Twitter) e aplicativos online (Wikis, blogs, Google Docs). Além dos aplicativos rotineiros, a computação em nuvem é extensivamente usada em software para negócios. Cada vez mais os ativos digitais estão sendo transferidos dos discos rígidos para a nuvem. Os principais atores da computação em nuvem são o Google, a Microsoft, a Apple, a Amazon e o Facebook, que têm ou planejam desenvolver grandes parques de servidores.

O software como serviço ao mesmo tempo depende da conexão à Internet, por ser o meio pelo qual os clientes contratam os serviços, mas também depende da estrutura da nuvem, pois as informações não permanecem no próprio computador do usuário. A nuvem pública usa a infraestrutura e os programas de um fornecedor de data center, como Google, Amazon, Oracle e Microsoft, sendo um serviço com características do circuito superior da economia urbana. Os servidores utilizados são sofisticados e conectados em rede, de modo mais avançado do que em arquiteturas como a intranet ou os protocolos de comunicação FTP (File Transfer Protocol) - que ainda existem, mas não mais predominam entre as 
conexões remotas.

A nuvem privada é exclusiva da empresa que a contrata e é gerenciada por seus funcionários ou prestadores de serviços. É o modelo mais adotado por organizações que precisam de um ambiente físico seguro ou que buscam segurança e privacidade para os dados armazenados e para a utilização de aplicativos ou transações, como as instituições financeiras. O modelo de nuvem híbrida é bastante utilizado pelo ramo de e-commerce: a nuvem pública é útil no caso de flutuações sazonais de tráfego de informações (por exemplo, durante períodos de promoções, que geram mais acessos), enquanto os dados dos clientes e de transações bancárias são administrados no modelo de nuvem privada.

Uma situação de solidariedade organizacional (SANTOS, 2009, p. 285; CASTILLO et al., 1997) entre grandes empresas do ramo de TI (neste caso, entre Google e Yahoo, com participações futuras de Amazon e Microsoft) possibilitou a criação dessa novidade fundamental na tecnosfera. Desde então, ocorreu uma série de modernizações irreversíveis em tecnologias de armazenamento e acesso a grandes bases de dados, com incrementos na conectividade e criação das chamadas máquinas virtuais, o que revolucionou especialmente o consumo produtivo de software.

A nuvem se origina de um sistema de arquivos distribuídos lançado em 2006, chamado Hadoop, fruto de estudos e esforços conjuntos da Google e da Yahoo $^{28}$. Segundo Harris (2013), muitas firmas de TI estadunidenses focadas em ferramentas de busca, tendo de lidar com bilhões de páginas web e com máquinas e funcionários insuficientes para processar os dados, observavam os mesmos problemas e já vinham trabalhando com métodos de computação distribuída.

A relevância do surgimento dessa tecnologia vem da necessidade de associação entre aquelas grandes firmas, para desenvolvimento de uma solução "disruptiva", como se diz no jargão empresarial. Ainda que num mercado de concorrência ferrenha, foi estratégia de sobrevivência realizar um movimento de cooperação para resolver seus problemas. A nuvem emerge, então, como um novo

28 Todo o processo, desde os primeiros debates teóricos sobre armazenamento de dados que desembocaram no sistema Hadoop, está documentado em papers redigidos na época pelas equipes de cientistas das empresas (DEAN; GHEMAWAT, 2004; FRANKLIN; HALEVY; MAIER, 2005; CHANG et al., 2006). 
paradigma tecnológico e como evento geográfico, que alterou os modelos de contratos e permitiu a existência e a ascensão dos aplicativos.

A estimativa é de que $49 \%$ dos dados armazenados no planeta estarão em ambientes virtuais do tipo nuvem pública até 2025, sendo que os gastos corporativos com essa tecnologia cresceram 47\% em 2020. As receitas dessa tecnologia de armazenamento vêm majoritariamente dos softwares como serviço, ultrapassando US\$ 150 bilhões em 2020. Tais tendências implicam em fatores como maiores demandas por metro quadrado de data centers ${ }^{29}$, um mercado dominado pelos Estados Unidos (38\% do total), pela China (10\%) e pelo Japão (7\%) (RACONTEUR, 2020).

De acordo com a Estratégia Geral de Tecnologia da Informação e Comunicação do IBGE (EGTI 2019-2020), o software como serviço é parte dos serviços de computação em nuvem e pode ser utilizado diretamente no navegador web:

Enquanto a tecnologia de cloud computing preocupa-se com a oferta de infraestrutura para armazenamento e processamento de informações, o SaaS disponibiliza software na rede através dos navegadores dos usuários / clientes. Uma mesma instância de software, disponível num servidor, é usada simultaneamente pelos clientes como se fosse uma aplicação web (IBGE, 2019, p. 21).

Trata-se de um serviço comercializado sob demanda, de modo que recursos para sua utilização são dispostos conforme a necessidade, em vez de por cópias para uso individual (IBGE, 2019, p. 21). Esta última forma de distribuição era mais tradicional para o chamado "software de prateleira", sendo que a formulação dos termos de uso do software como serviço veio alterar significativamente os contratos para sua utilização. O IBGE $(2019$, p. 21) aponta ainda que o SCS possibilita menores custos de instalação e manutenção para o usuário final, por se tratar de um serviço centralizado. Sua operação pode funcionar continuamente (todos os dias da semana, 24 horas por dia), o que permite satisfazer demandas e imposições do tempo acelerado da globalização, de modo já observado em outras

29 Data center é uma sala preparada para abrigar vários servidores, ou seja, computadores com alta capacidade de processamento. Por isso, deve possuir requisitos especiais: um sistema de ar condicionado suficiente para um local com centenas de computadores funcionando simultaneamente; um sistema antiincêndio; acesso controlado e normas de segurança; piso elevado para conter o cabeamento; e geradores de energia, para o caso de falhas na rede elétrica. 
redes técnicas:

Esse movimento de disponibilização de TI como serviço para satisfazer as necessidades das empresas já vem sendo praticado por grandes empresas como a IBM, Google e Microsoft, que oferecem seus serviços pagos através da cobrança de tarifas, no mesmo modelo das empresas de energia elétrica ou de telecomunicações (IBGE, 2019, p. 21).

As tecnologias denominadas big data proporcionam uma nova abordagem da informação: as análises não mais necessariamente são feitas a partir de dados armazenados estaticamente, mas sim a partir de fluxos de dados. Uma das vantagens dessa tendência é a capacidade de processar informações enquanto um evento ocorre - por exemplo, ao monitorar pacientes num hospital -, a fim de tomar decisões mais rápidas. É importante ressaltar que, ainda que muitos desses processos sejam automatizados, em geral o monitoramento e as decisões finais são tomadas por humanos, e não pelos computadores (DAVENPORT; BARTH; BEAN, 2012). Debates éticos em relação ao futuro da inteligência artificial são alimentados justamente pelo desenvolvimento desse tipo de tecnologia.

As TI são comumente tratadas como grandes novidades, mas possuem histórias longas de dependência do desenvolvimento de outros sistemas técnicos e de estudos científicos. A criação do termo "inteligência artificial”, por exemplo, é creditada ao cientista da computação John McCarthy, em 1955. Na ocasião, foi organizado um grupo de estudos sobre o assunto, a fim de "descobrir como fazer máquinas criarem linguagem, formarem abstrações e conceitos, resolverem tipos de problemas agora restritos a humanos e melhorarem a si mesmas". Ali também foram feitas comparações com uma rede de neurônios - um modelo similar às atuais redes neurais, algoritmos utilizados em aprendizado de máquina - e se observava que

A velocidade e a capacidade de memória dos computadores atuais podem ser insuficientes para simular muitas das funções do cérebro humano, mas o maior obstáculo não é a falta de capacidade computacional, e sim nossa inabilidade de escrever programas aproveitando tudo o que temos [atualmente] (MCCARTHY et al., 1955).

A própria ideia de que máquinas poderiam "pensar" já havia sido 
proposta por Alan Turing, que afirmava que "computadores digitais" deveriam poder executar as mesmas operações que uma pessoa é capaz de fazer. Esse "computador digital" deveria conter uma unidade de armazenamento, uma de execução e outra de controle (TURING, 1950, p. 436-437), o que se vê de modo muito similar nos data centers contemporâneos.

Hoje, inteligência artificial usualmente se refere ao direcionamento das tecnologias para a criação de dispositivos inteligentes, para finalidades recorrentemente utilizadas no modelo de negócio dos aplicativos, como a recomendação de produtos a consumidores. Desse modo, se vai além das máquinas que simplesmente executam tarefas com maior velocidade que os seres humanos ou sistemas técnicos pretéritos; as inteligências artificiais são capazes de encontrar padrões a partir de dados a elas alimentados e aprender comportamentos para aplicar a partir desses padrões, por meio de algoritmos escritos especialmente para essas finalidades. Daí vem a ideia de aprendizado de máquina (machine learning), na qual se extrai conhecimento dos dados para usos como deteç̧ão de padrões e anomalias, prevenção de fraudes bancárias, agrupamento de usuários de determinado serviço, previsão de vendas, assistentes virtuais em websites e chats (os chamados "bots"), entre muitas outras possibilidades. Em resumo, o aprendizado de máquina torna mais palpável a proposta das tecnologias de inteligência artificial.

A "virada" para o big data em termos de tecnologia computacional provoca, ainda, alterações na divisão do trabalho e nos processos produtivos. Ascendem ocupações como engenheiros e cientistas de dados; tecnologias mais tradicionais, como os bancos de dados relacionais, são aprimoradas para armazenar mais dados e permitir consultas milhares de vezes mais rápidas (DAVENPORT; BARTH; BEAN, 2012). Tudo isso, evidentemente, gera maiores necessidades de provisão de eletricidade, resfriamento, segurança e outros recursos para manutenção de computadores de alta performance. Tais recursos e suas redes não estão disponíveis de modo homogêneo nos territórios.

A maior parte das informações digitais é guardada em alguns tipos distintos de localidades. Os dispositivos pessoais que utilizamos cotidianamente 
são chamados "endpoints" (em tradução livre, "pontos finais"); infraestruturas como torres de celular e servidores institucionais pertencentes a entidades públicas ou privadas são chamados de "edges" (em tradução livre, "arestas"); e o "core" ("centro" ou "núcleo") são os tradicionais servidores e data centers da computação em nuvem (VOPSON, 2021). Tais tecnologias operam com os mesmos princípios: bits de informação podem ser armazenados em qualquer material que possua dois estados distintos e comutáveis. A informação digital é então guardada na forma de zero (0) ou um (1), os bits, no código binário. Oito bits correspondem a um byte, e o comprimento físico de um bit é de aproximadamente 30 nanômetros (bilionésimos de metro) (VOPSON, 2021). Ao passo que parece difícil compreender esse tipo de dimensão, manipular bits também requer a capacidade de controlar materiais na escala atômica, o que só é conseguido por agentes com um grau sofisticado de especialização.

Um exemplo de topologia de servidores são os da Fundação Wikimedia (entidade filantrópica operadora do projeto Wikipédia, entre outros), que situamse em clusters localizados em distintos continentes, são conectados entre si pela Internet e com diversas funções diferentes. A Wikimedia é uma das instituições mais relevantes dentre o movimento de software de código livre e aberto (em inglês, free, libre and open source software, ou FLOSS), mas os hardwares utilizados em seus data centers provém de firmas como Cisco e Dell (Figuras 1.5, 1.6 e 1.7). O grau de especialização envolvido na configuração e na administração de data centers resulta num tipo de produção restrito a corporações do ramo de TI. 
Figura 1.5. Representação da localização dos servidores da Fundação Wikimedia (2006).

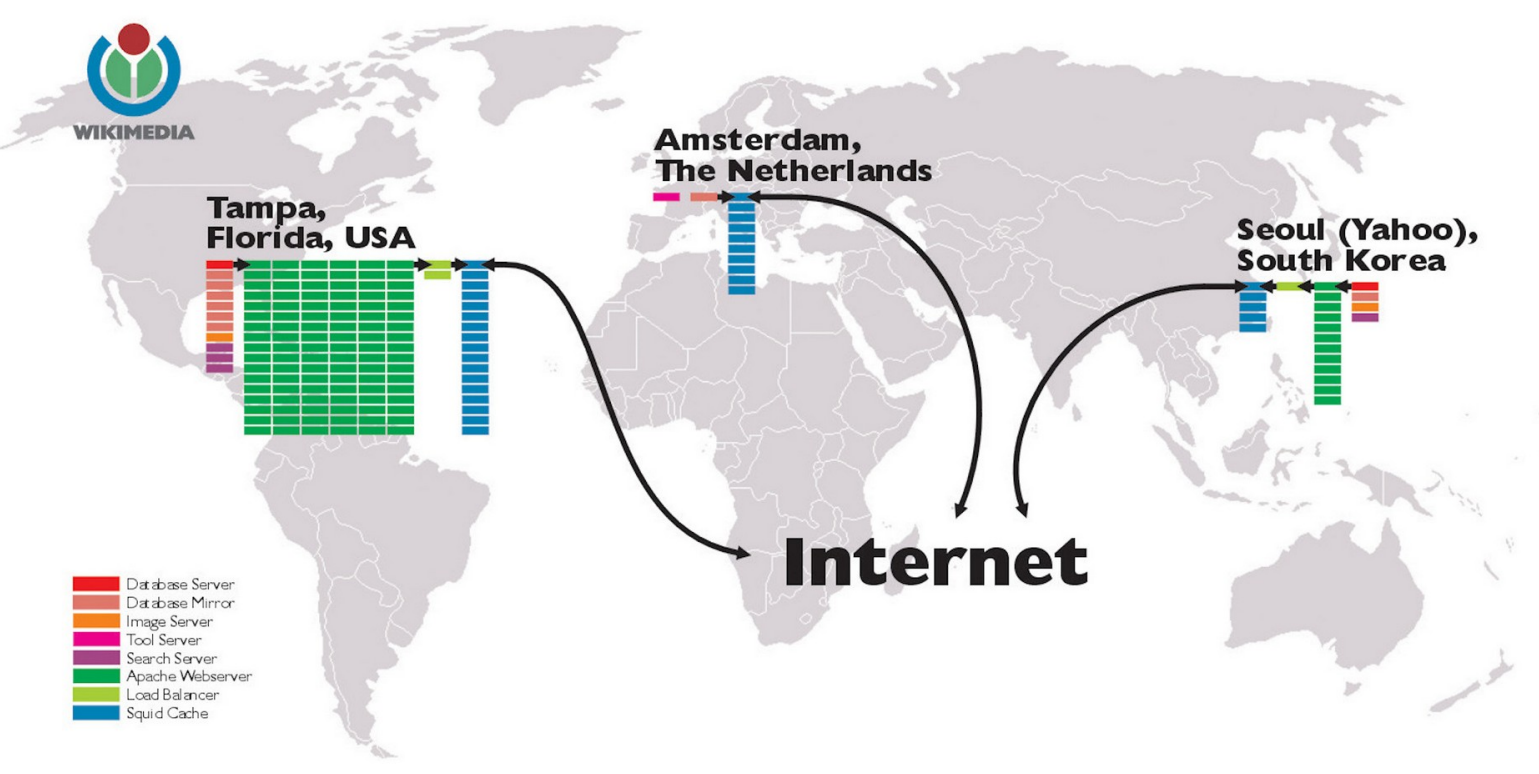

Fonte: Wikimedia, 2006. Disponível em:

<https://commons.wikimedia.org/wiki/File:Wikimedia_server_e.jpg>.

Figuras 1.6 e 1.7. Servidores da Fundação Wikimedia (2012).

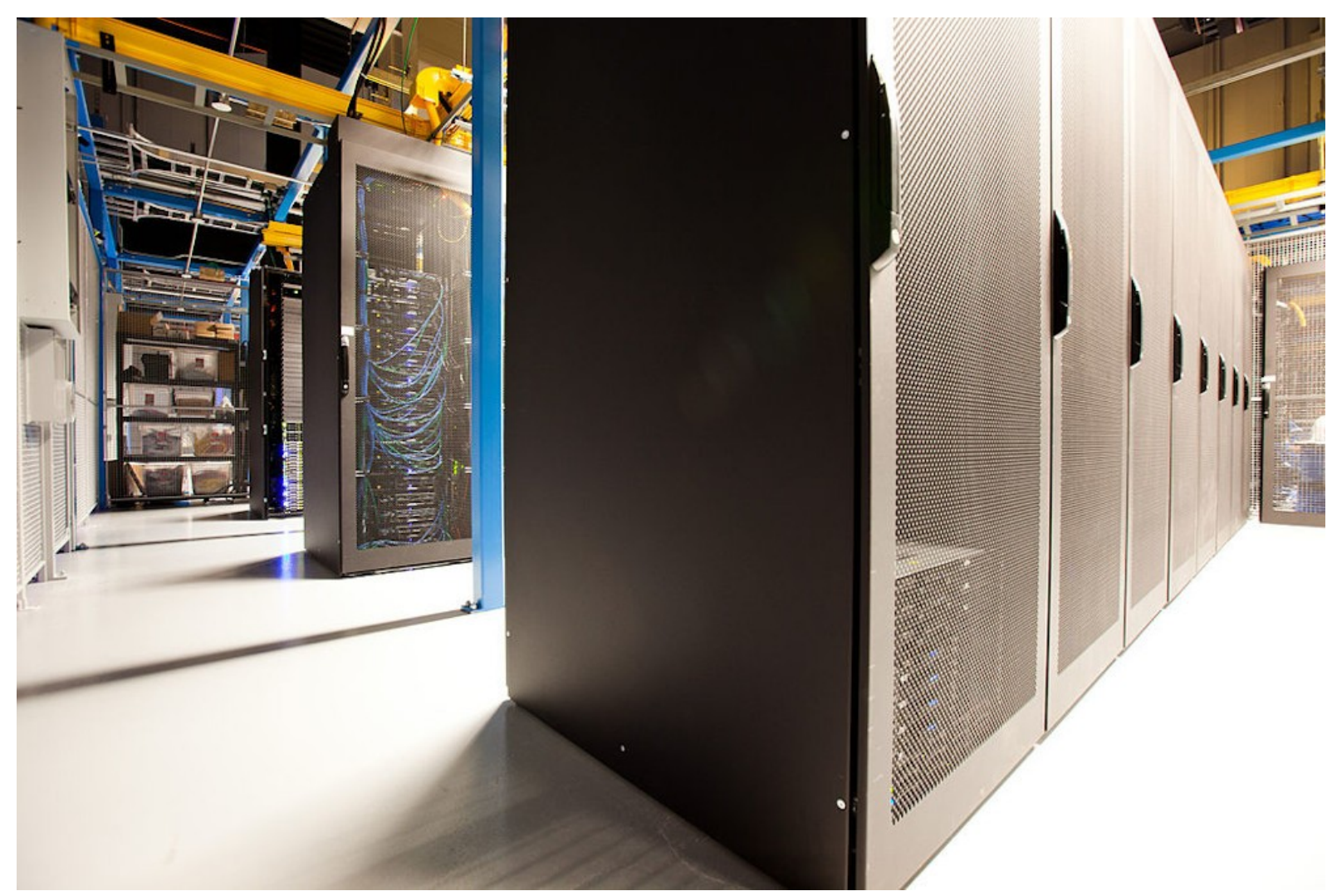




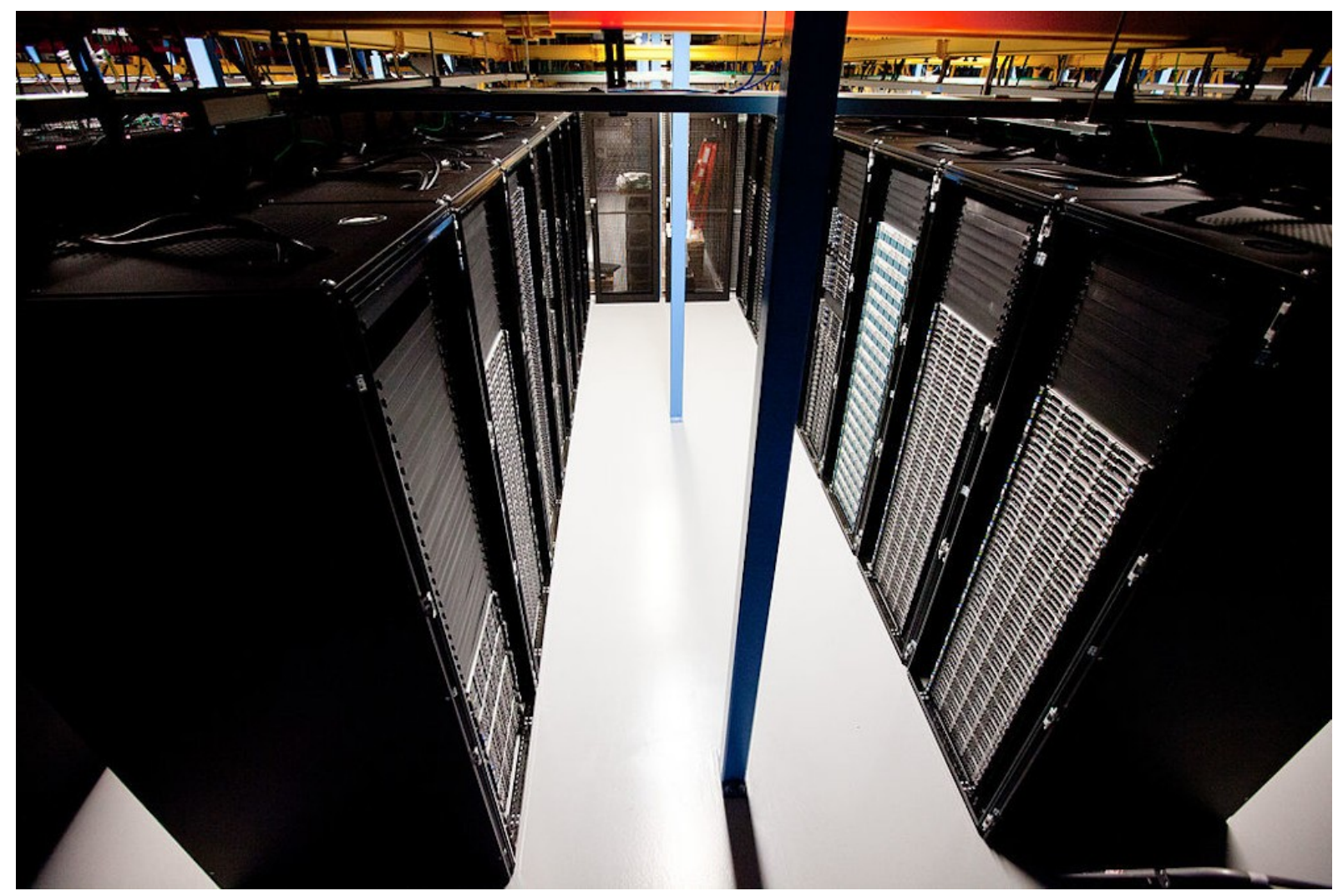

Fonte: Wikimedia (2012). Disponível em:

<https://commons.wikimedia.org/wiki/Category:Wikimedia_servers_in_2012>.

De acordo com o IBGE (2019, p. 22-23), tendo em vista que o usuário não precisa ter conhecimento profundo da plataforma na qual o software foi implantado, seu uso se torna mais simples e as conexões entre diferentes serviços também são facilitadas. Potencializa-se o aspecto da internet e das TI como "rede de redes". Ademais, são propiciadas formas modernas de armazenamento e manipulação de dados, conhecidos como "data lake" (lago de dados) ou "data mining" (mineração de dados). Tais estruturas não estavam disponíveis até o século XXI, consistindo numa novidade técnica que permite facilitar e centralizar o acesso a maior quantidade de dados (estruturados ou não) em um repositório, bem como seu processamento, análise e visualização.

A produção de software como serviço se inscreve em um ramo econômico considerado estratégico pelos Estados, intensivo em pesquisa, desenvolvimento e inovação; sua base de usuários individuais e empresariais cresce vertiginosamente, sobretudo por meio de dispositivos móveis ou da 
chamada Internet das Coisas. Com o desenvolvimento da computação em nuvem, o SCS se tornou a principal forma de distribuição e uso de softwares. Como os usuários não necessitam baixar e instalar programas de configuração, ou mesmo fazer cópias internas para diferentes máquinas, gastam menos tempo, armazenamento e largura de banda. O fornecedor deve oferecer um sistema com toda a estrutura necessária ao cliente (por exemplo, segurança e conectividade).

O software pode ser totalmente utilizado pela Internet, com um navegador Web, ou pode possuir uma instalação local (como no caso dos programas para backup ou antivírus). Não há necessidade de que o cliente tenha profissionais capacitados para manter esse sistema e o tempo de implementação é menor. Um valor é cobrado pelos serviços, geralmente correspondente a uma licença temporária de uso do programa (por exemplo, mensal ou anual), mas licenças vitalícias também são aplicadas. $O$ cliente pode adquirir licenças de outros produtos conforme sua necessidade, o que confere menor custo geral e o permite aplicar a verba em outros tipos de investimentos. No modelo tradicional de distribuição de tais produtos, o cliente paga pela licença de uso e também é responsável por sua instalação e manutenção.

As empresas produtoras de software como serviço são então capazes de atingir maior número de usuários, em comparação ao software com distribuição tradicional. Por outro lado, há custos significativos com salários (que, em TI, em geral não são baixos), publicidade para adquirir mais clientes e suporte para manter o produto atualizado. Os desenvolvedores concentram-se na atualização do software e não em sua infraestrutura, o que torna o desenvolvimento de sistemas de software mais rápido. O usuário, por sua vez, não administra características individuais da aplicação, somente configurações específicas.

Alguns modelos de cobrança de software como serviço são o valor recorrente (geralmente mensal) proporcional à quantidade de licenças utilizadas; o valor recorrente (usualmente mensal) proporcional ao uso (por exemplo, ao uso em disparos de mala direta ou e-mail marketing); propagandas, como no caso de banners em websites; e "freemium", que são os softwares tanto com versões gratuitas como pagas, sendo que estas apresentam mais funcionalidades. Por 
exemplo, uma firma de SCS que realiza marketing por e-mail em geral cobra pelo envio dos correios eletrônicos e por um limite de armazenamento em seus servidores, além de mensalidades por serviços adicionais.

A regulação de dados dos usuários é um tema sensível no universo do software como serviço e da computação em nuvem, sobretudo em momentos de migração de informações para servidores diferentes ou de atualização de algum dos serviços oferecidos, para evitar vazamentos. Além disso, é crucial ter acesso a um provedor de serviço de Internet com conexão veloz, estável e confiável, e ter cuidado com a compatibilidade e a conexão entre os diversos equipamentos que compõem a rede que dá suporte aos serviços oferecidos. No âmbito do licenciamento dos softwares, usualmente é feito um Acordo de Nível de Serviço (ANS, ou Service Level Agreement, em inglês), que é distinto dos chamados "web services", ainda que sistemas de SCS possam ofertar seus serviços por meio de uma plataforma automatizada de web services (por exemplo, Amazon Web Services AWS), sem interferência humana.

Isso mostra como as companhias que detém a capacidade de oferecer hospedagem em seus servidores tornam-se fundamentais para outros mercados relacionados. A Amazon possui o "negócio perfeito" neste momento do atual período histórico, pois congrega a principal plataforma de e-commerce no mundo, um próspero negócio de computação em nuvem (aumentando $32 \%$ ao ano) e crescentes habilidades de marketing (HOROWITZ, 2021).

Em geral, clientes acabam optando pelo uso de serviços como o AWS quando os dados são complexos ou volumosos demais para manejo numa infraestrutura tradicional. Os tipos de arquitetura de dados oferecidos pelas corporações da nuvem têm maior capacidade e performance, resultando em mais agilidade e flexibilidade. É mais rápido e econômico responder a demandas dos clientes, ou mesmo ativar ou desativar recursos, e os padrões de manutenção e segurança são certificados. Outra grande vantagem é poder contratar armazenamento sazonalmente, diminuindo os períodos em que uma empresa paga por armazenamento ocioso.

As corporações Amazon, Apple, Facebook e Google adquiriram centenas 
de outras empresas ao longo das últimas duas décadas (Figuras 1.8 a 1.11), seguindo um padrão similar. Em geral, elas primeiro se tornaram dominantes em seu negócio original (como buscas na Internet, para a Google, ou e-commerce, para a Amazon), para em seguida realizarem aquisições em novos setores. A maior parte dessas aquisições envolveu startups com patentes de alto valor ou engenheiros talentosos, que levaram ao desenvolvimento de produtos muito populares, como o iTunes (da Apple) e o Google Docs. Os críticos desse tipo de comportamento acusam as corporações de monopolizar o ramo de TI para enfraquecer seus competidores, pois as aquisições não teriam como objetivo maior as inovações tecnológicas, mas sim o controle do mercado - na chamada tática "copy, acquire, kill" ("copie, adquira e mate", em tradução livre) para eliminar competidores (ALCANTARA et al., 2021).

Figuras 1.8, 1.9, 1.10 e 1.11. Histórico de aquisições de outras empresas pelas corporações Apple, Amazon, Facebook e Google.
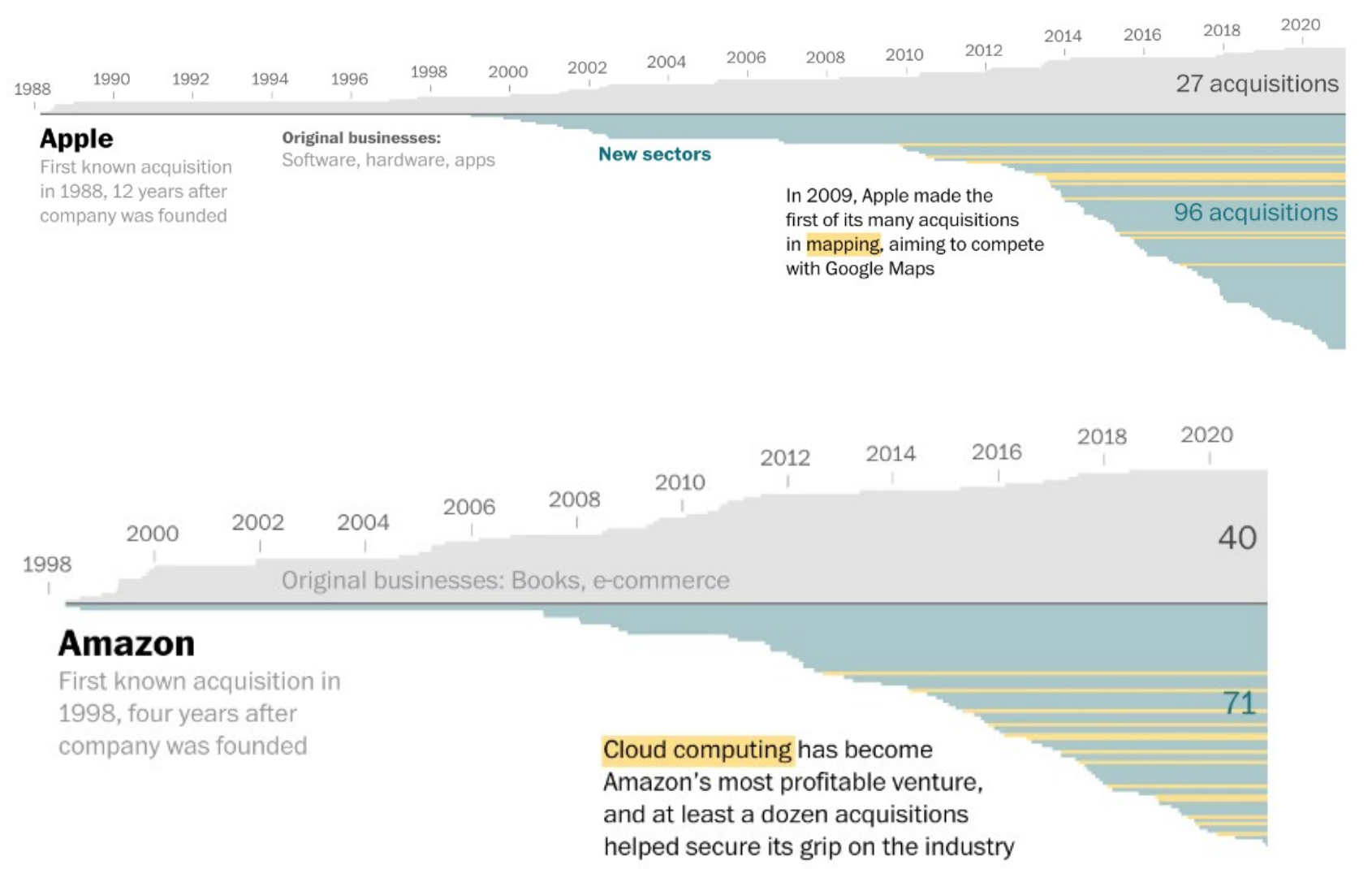

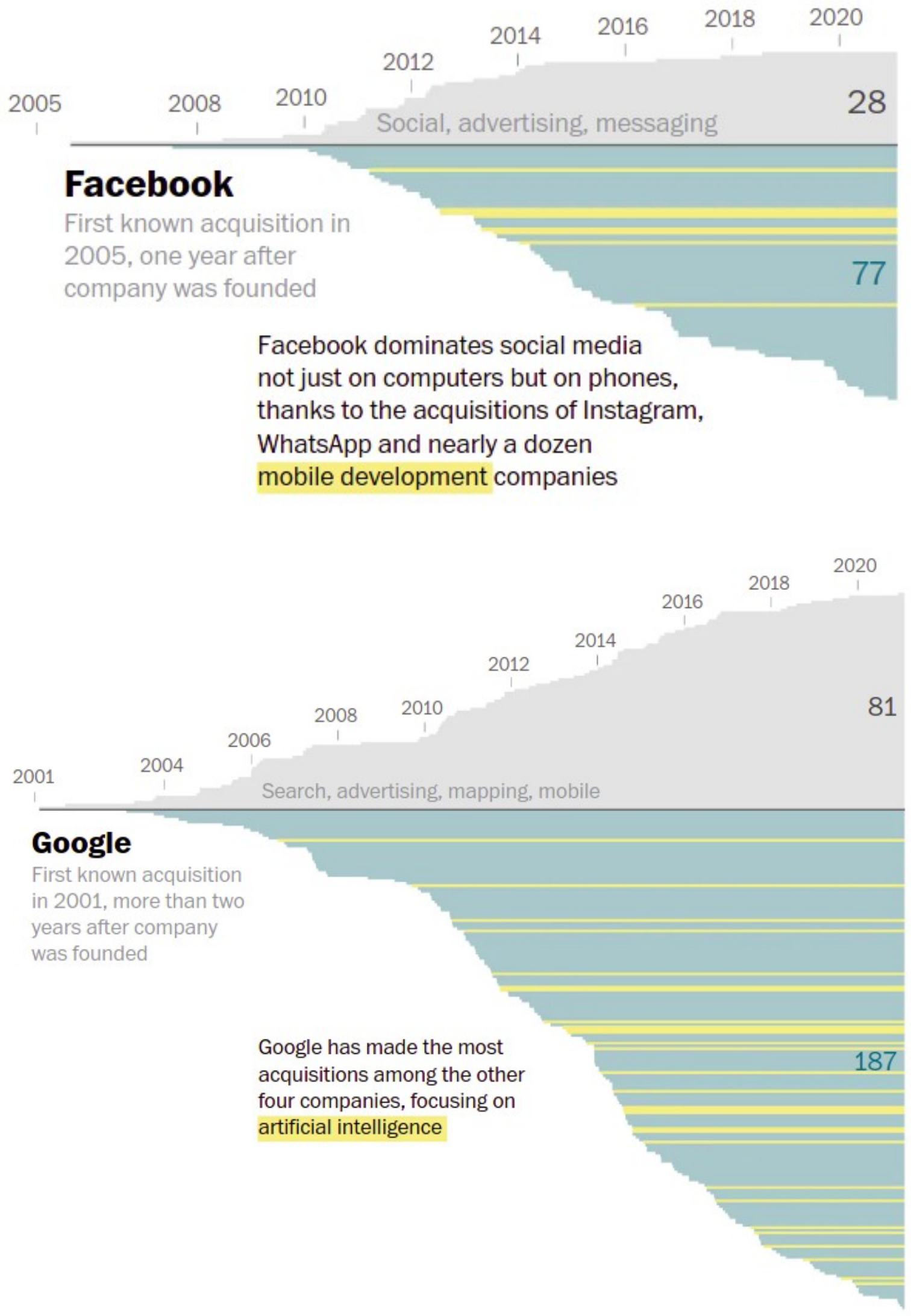

Fonte: Alcantara et al. (2021). 
Sobre o uso de estratégias corporativas agressivas das grandes para com as pequenas empresas, aponta Arroyo (2009, p. 481):

O poder de mudança tecnológica e de transformação institucional dos grandes grupos econômicos aumenta significativamente a partir da intensidade dos processos de fusão, aquisição e associação de empresas (...). Cada vez com maior frequência, desenvolvem-se formas múltiplas de associação entre empresas de diferentes países, incluindo acordos de subcontratação, investimentos cruzados, participação acionária minoritária, acordos de licenciamento, aquisições, entre outras.

É dessa forma que as corporações oligopólicas consolidam seu espaço de atuação para além das fronteiras nacionais, concentrando a concorrência mundial. As TI contribuem sobremaneira para esse quadro, já que viabilizam o desmembramento das etapas de produção em diferentes localidades, mas mantendo um monitoramento centralizado de cada uma delas (ARROYO, 2009, p. 481). Muitas das maiores fusões e aquisições de 2020 envolveram empresas do ramo de TI: computação em nuvem (Salesforce), hardware (AMD, NVIDIA), plataforma de colaboração para trabalho remoto (Slack), software (Facebook, Uber, Adobe) e outras que dão suporte a usuários de aplicativos, enviando mensagens durante seu uso (como a Twilio) (CAREY, 2020).

Ademais, as firmas da computação em nuvem se impõem na paisagem: por exemplo, em São Francisco (EUA) existem vários empreendimentos em diversos ramos operados ou patrocinados pela Oracle (como o estádio de beisebol Oracle Park), e a mais alta torre corporativa da cidade é conhecida como Salesforce Tower, por conta de sua construção ter sido capitaneada pela Salesforce. 0 edifício se tornou uma referência na paisagem local e no plano de renovação urbana no centro de São Francisco.

A topologia dos servidores da computação em nuvem reproduz a divisão internacional do trabalho tal qual ocorrido em outros períodos históricos, com distintas atividades econômicas. É uma tarefa custosa romper com esse padrão, sobretudo para os países periféricos, e o espaço geográfico sempre se impõe como condição para a distribuição ou o reforço da concentração das novas atividades econômicas e inovações tecnológicas. Não se encontram com facilidade os 
desenhos da topologia da nuvem, mas mapas mais genéricos são disponibilizados pelas empresas (Mapas 1.4 a 1.8) e nos permitem visualizar, de alguma forma, sua materialidade.

Mapa 1.4. Infraestrutura dos serviços Microsoft Azure.

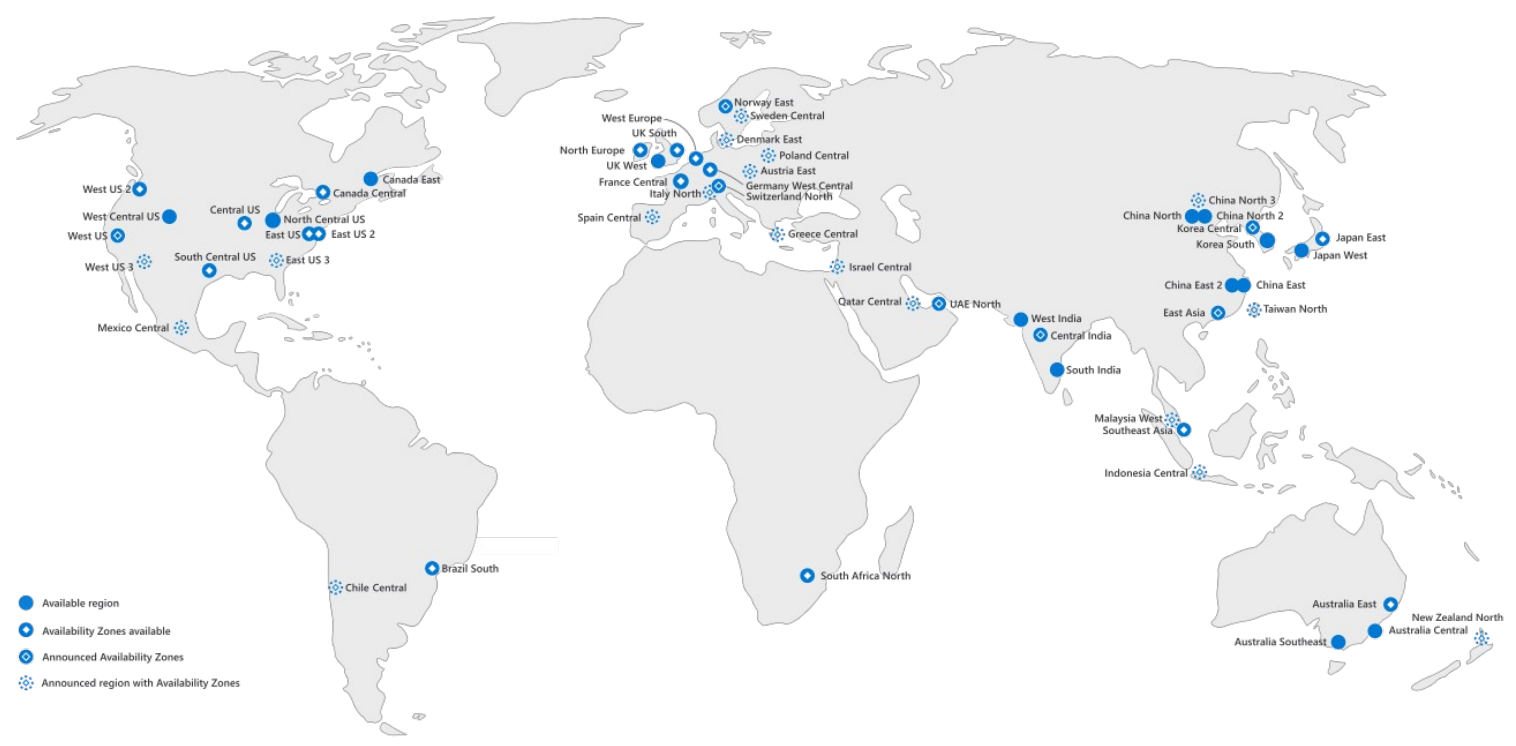

Fonte: Microsoft Azure, 2021. Disponível em: <https://azure.microsoft.com/en-us/globalinfrastructure/geographies/>.

Mapa 1.5. Infraestrutura dos serviços Oracle cloud.

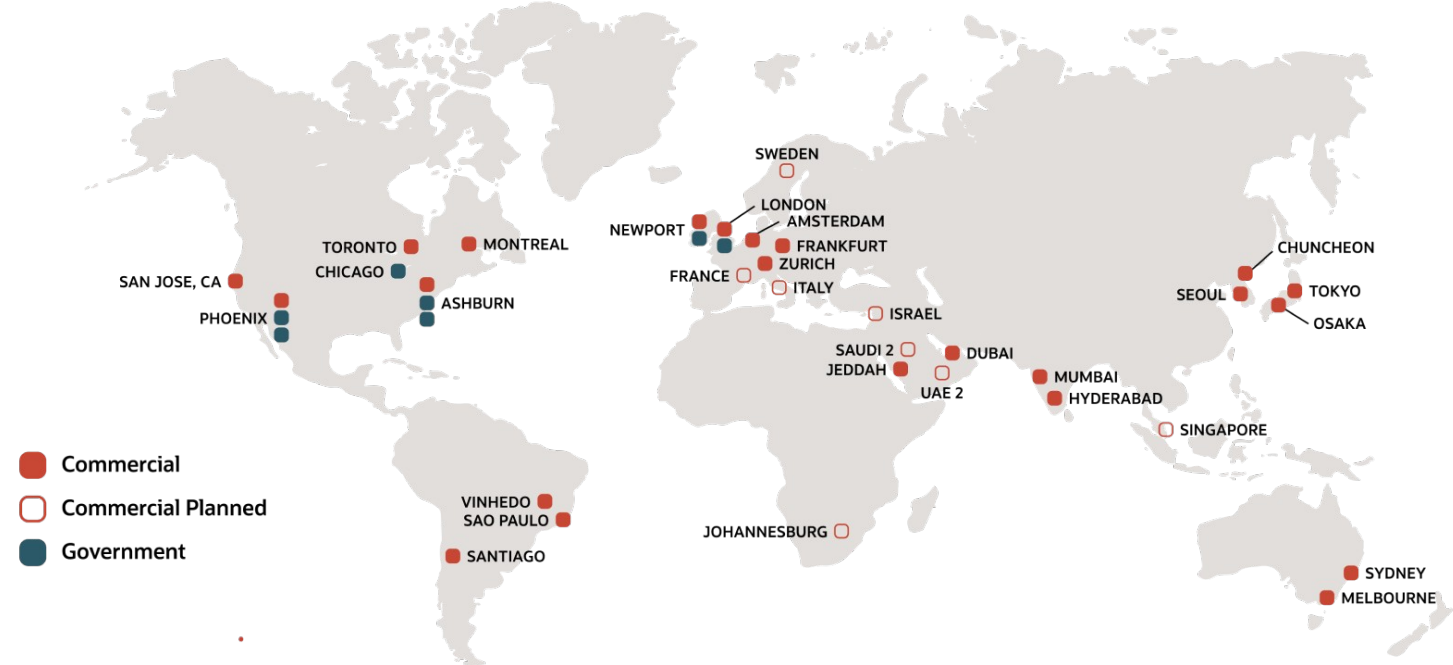

Fonte: Oracle, 2021. Disponível em: <https://www.oracle.com/cloud/architecture-andregions/>. 
Mapa 1.6. Infraestrutura dos serviços Google Cloud Services - regiões.

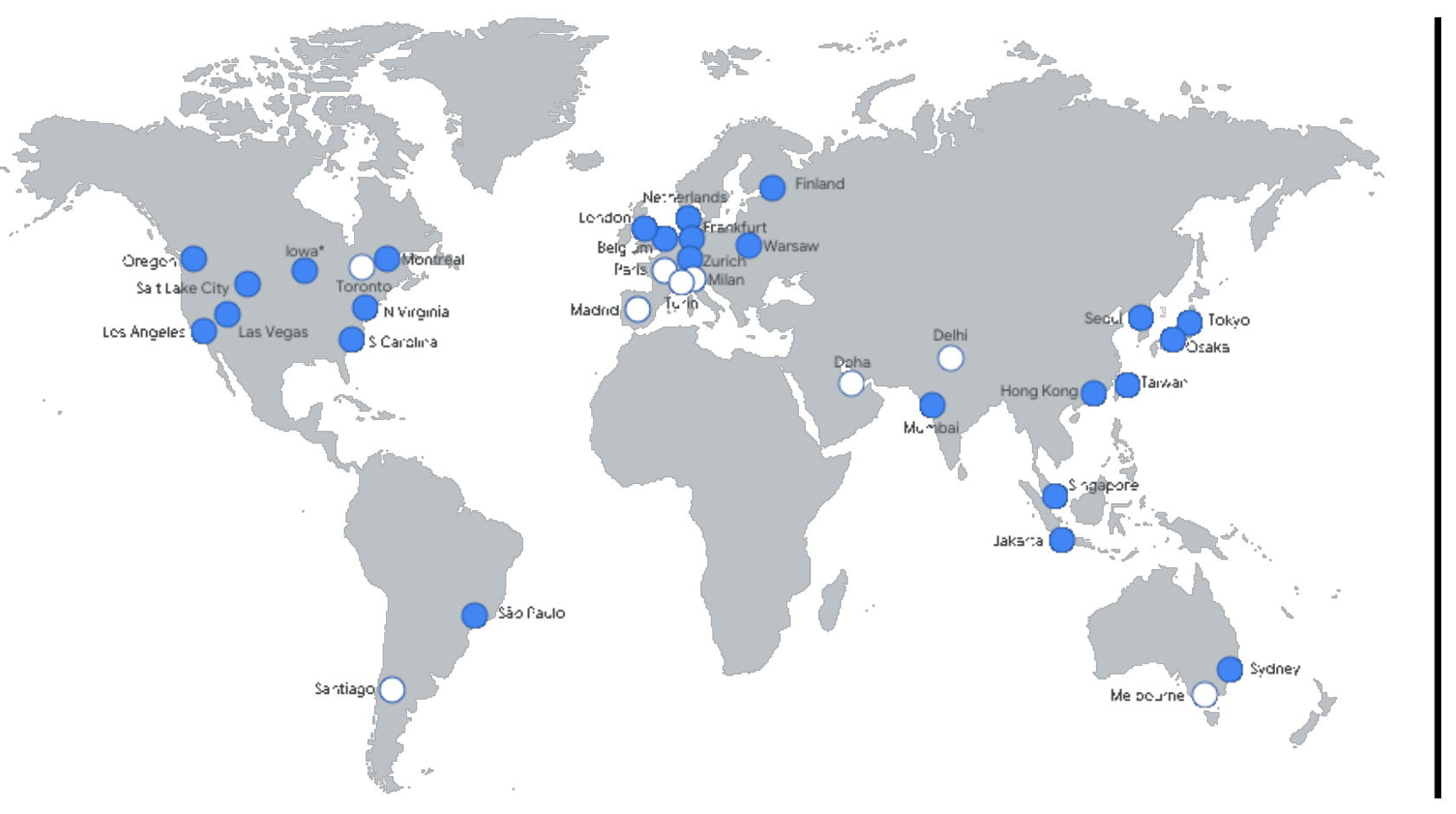

Fonte: Google Cloud, 2021. Disponível em: <https://cloud.google.com/about/locations>.

Mapa 1.7. Infraestrutura dos serviços Google Cloud Services - cabos submarinos.

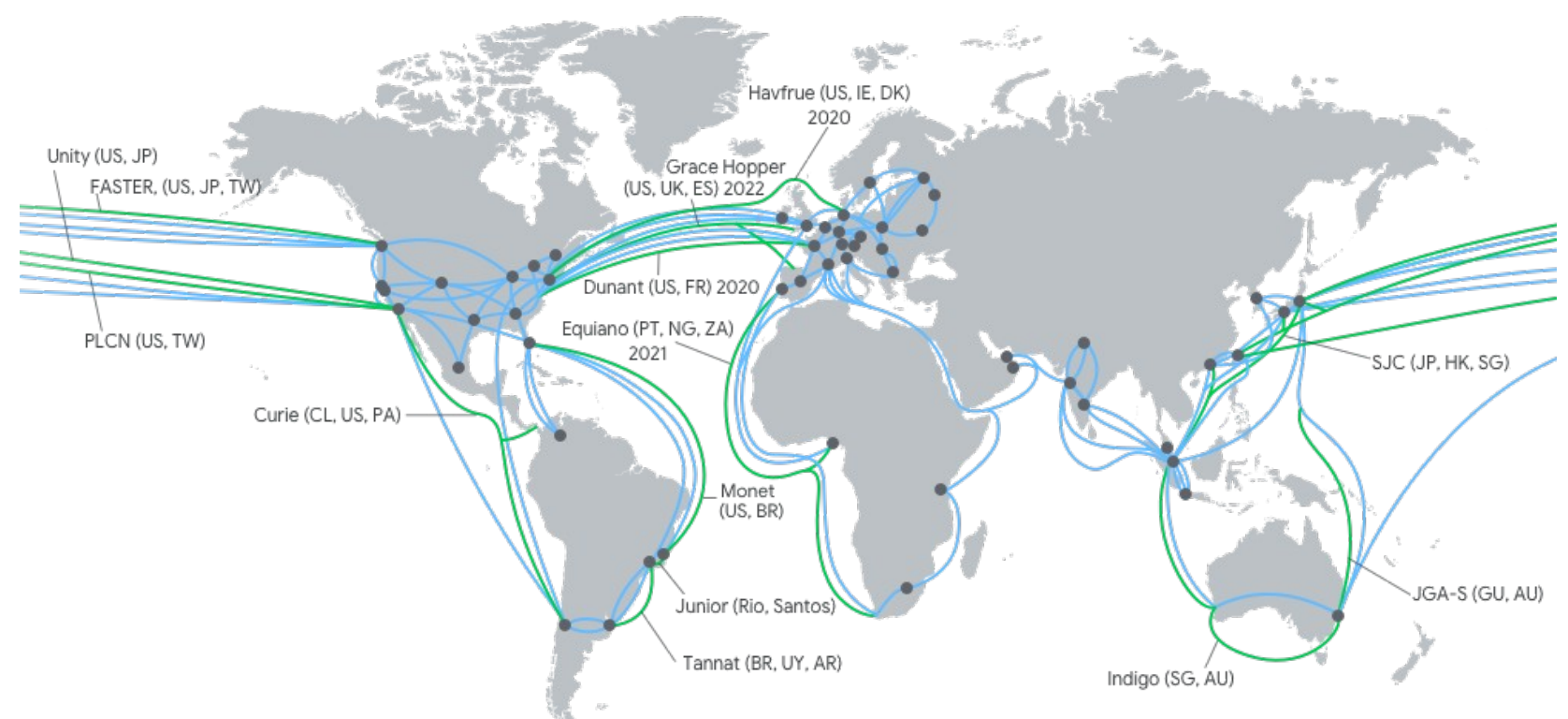

Fonte: Google Cloud, 2021. Disponível em: <https://cloud.google.com/about/locations>. 


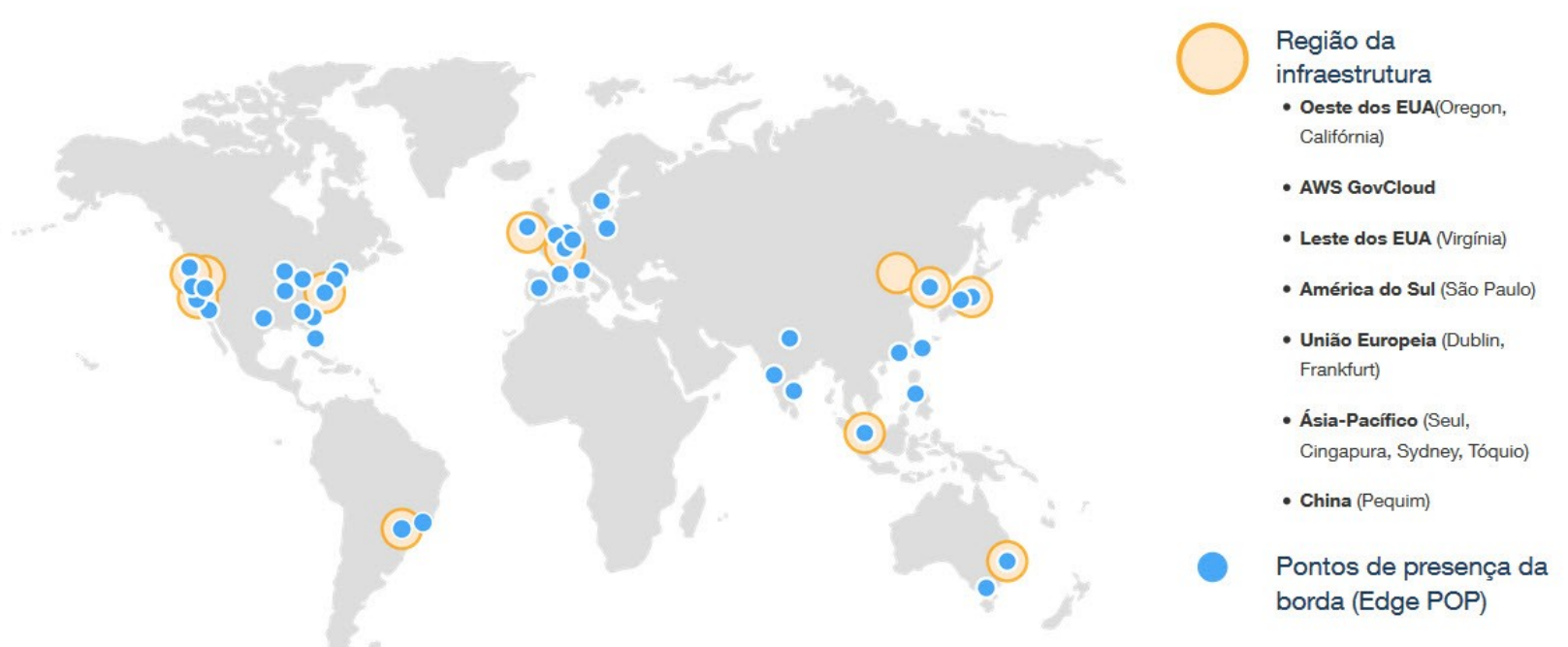

Fonte: EBS-IT Services, 2021. Disponível em:

<https://www.ebs-it.services/especialidades/amazon-web-services/>.

Essas firmas costumam chamar de "regiões" os perímetros de localização de seus data centers, sem especificar a localização exata. Um conjunto de duas ou mais regiões é denominado "geografia". Por exemplo, a região "West Europe" da Microsoft Azure está contida na geografia "Europe". Regiões, por sua vez, são agrupamentos de zonas, que se conectam a outras zonas na mesma região com alta velocidade e grande largura de banda, além de menores custos e latência. A fim de prevenir falhas, os provedores desses serviços recomendam se utilizem os serviços de mais de uma zona, a depender de fatores como disponibilidade, performance, custo e regulação local. Os pontos de presença da AWS (Edge POPs) servem para entregar conteúdo para os usuários finais em velocidades mais altas. Até abril de 2020, havia 216 pontos de presença em 84 cidades, de 42 países.

Em sua origem, a tecnologia da nuvem foi compartilhada, mas o que se vê nos mapas é que, mesmo estando recorrentemente presentes nas mesmas cidades ou regiões, as empresas optam por ter seus próprios servidores. Até certo ponto, vale a pena dividir a infraestrutura, mas a informação estratégica coloca condições para preferir manter os serviços proprietários. Mesmo com a modernização dos objetos e redes computacionais, reproduz-se, mais uma vez, a 
concentração de sua disponibilidade na Europa ocidental, nas costas leste e oeste dos Estados Unidos e no sudeste asiático.

No Brasil, todas as empresas retratadas nos mapas acima restringem sua área de atuação aos estados de São Paulo e Rio de Janeiro. A Oracle chegou a anunciar em 2018 a construção de infraestrutura em Belo Horizonte (MG), mas mapas mais recentes passaram a mostrar Vinhedo (SP) como uma nova localização de seus servidores. É notável, ainda, o movimento da Google para construção de cabos submarinos (Mapa 1.7), como o "Junior", entre Santos (SP) e Rio de Janeiro (RJ), o "Tannat" e o "Monet", que conectam o Brasil respectivamente à Argentina e ao Uruguai, e à Flórida, nos EUA. A empresa demonstra seu interesse em controlar diversos aspectos da tecnosfera, provavelmente na busca por maior velocidade e exclusividade na oferta de seus serviços. Daí provêm preocupações com o crescente risco de que as mesmas empresas administrem a rede e os dados que por ela trafegam, aprofundando a concentração do capital, e passando a ter controle sobre as operações de manejo e circulação das informações, levantando questionamentos quanto a cibervigilância.

Conforme Santos (1997, p. 19-20), as grandes empresas aportam nos lugares e trazem suas normas, extremamente rígidas e duplicadas, pois suas técnicas também são normas. A padronização técnica e normativa, tanto na produção quanto na comercialização de bens quanto na oferta de serviços, é um recurso funcional ao capitalismo que, no caso da indústria de software, vem da própria telemática. Esse tipo de norma também auxilia a evitar prejuízos advindos do emprego de tecnologias alternativas ou menos funcionais e garante "às empresas detentoras desse conhecimento tecnoprodutivo a manutenção de sua competitividade e de seu poder sobre a produção e o consumo e, portanto, sobre o mercado mundial" (WOLFF, 2005, p. 130).

Carr (2004, p. 33-35) observa que a padronização técnica é especialmente rápida nas $\mathrm{TI}$, devido à busca dos usuários por maior interconectividade e interoperabilidade entre os dispositivos informacionais. Os hardwares, por exemplo, foram se homogeneizando dos grandes computadores mainframe até os servidores e conexões via Internet, permitindo às empresas primeiro se 
conectarem internamente, depois entre firmas, e hoje em dia diretamente aos usuários. Assim se conseguem também preços mais baratos para comprar, atualizar e fazer a manutenção dos computadores.

Vê-se que a informática permite a interligação entre diversas técnicas e dispositivos que antes não se comunicavam, viabilizando a convergência dos momentos. Sem dúvida, observa-se um uso imperialista, desigual e combinado das técnicas (SANTOS, 2000, p. 52), com imposição das regras do mercado global, pela associação entre objetos modernos e atores hegemônicos (SANTOS, 2009, p. 240). Mas esse processo é dialético e as novas técnicas permitem também renovadas interações entre agentes contra-hegemônicos, levando, por exemplo, a outros usos dos aplicativos e do território. Por isso é preciso notar, com Silveira (2012, p. 214), que

A universalidade empírica é construída, sobretudo, pela solidariedade organizacional, isto é, pela interdependência das variáveis que determinam e dominam o período, mesmo quando não estão presentes nos lugares. Mas a universalidade empírica abriga, também, a solidariedade orgânica, isto é, a vida advinda da interdependência das variáveis no lugar. Daí as temporalidades, que são também visões do tempo que os agentes têm, pela sua situação existencial diversa, permitindo diversas interpretações do período.

Conforme Santos (2009, p. 144), "se consideramos o mundo como um conjunto de possibilidades, o evento é um veículo de uma ou algumas dessas possibilidades", sendo o lugar seu depositário final e obrigatório. Os eventos são portadores da ação presente, transformam as coisas e lhes conferem novas características. Eles estão sempre associados a um agente e não ocorrem de modo isolado, mas sim sistêmico, que determina sua duração (inscrita na totalidade característica de um certo momento) e amplitude. Já a escala de realização de um evento depende de uma combinação solidária de vetores de diferentes níveis hierárquicos (ibidem, p. 145-146; 149; 153; 160).

Nas regiões e nos lugares, o tempo empiricizado é condição de possibilidade, enquanto a "entidade geográfica preexistente" é condição de oportunidade (SANTOS, 2009, p. 165). Assim emergem os chamados espaços da racionalidade, produzidos e organizados sob a lógica do acontecer hierárquico e 
das técnicas informacionais, das verticalidades e razões globais, "que impõem uma ordem alheia, instrumental e pragmática ao funcionamento dos lugares". As crescentes solidariedades organizacionais que ali se configuram funcionam com o comando remoto das técnicas de produção, e acabam por atrair capitais e desenhar a hierarquia entre os lugares.

O acontecer hierárquico - um dos aconteceres solidários que definem os subespaços, regiões ou lugares - resulta de informações e ordens provenientes de um lugar mas que se realizam em outro, como trabalho. Nesse caso, a solidariedade entre agentes não depende da existência de contiguidade, e as relações que estabelecem podem ser pontuais, diferentemente do acontecer complementar (SANTOS, 2009, p. 166-167). A Região Concentrada, e sobretudo o estado de São Paulo, são os lugares por excelência desse tipo de acontecer, onde se encontram os espaços da racionalidade contemporânea $e$ as modernizações técnicas e informacionais dos sistemas de objetos e de ações (BERNARDES, 2011, p. 428-429).

As racionalidades de origens distantes acabam se tornando fundamento da definição e da existência de regiões sobre as quais se impõem arranjos e novas coesões organizacionais (SANTOS, 2009, p. 285). Assim se viabiliza a solidariedade organizacional, que é embasada pela técnica da informação (BERNARDES, 2011, p. 414) e pressupõe uma certa interdependência mecânica entre certos lugares e agentes, fruto de normas advindas dos interesses do mercado. Ela é "paralela à produção de uma racionalidade que não interessa à maior parte das empresas nem da população" (SANTOS; SILVEIRA, 2011, p. 307).

De acordo com Ribeiro (2015, p. 163), a ideia de evento corresponde a um "feixe de acontecimentos cujas duração, qualidade e extensão são tributárias de uma estrutura organizacional de ordem material e normativa realizada e reproduzida distintamente segundo os lugares". Dessa forma, requerem "materialidades, ações, normas, informações, fixos e fluxos", conforme se observa quando da constituição e do crescente uso dos aplicativos e da computação em nuvem.

Mais além, conforma-se uma situação geográfica, ou "um complexo de forças em ação presente, organizada segundo feixes de variáveis que se juntam 
numa combinação única e inédita num dado momento e num dado subespaço", redefinindo a vida de relações local e sua relação com o mundo (CATAIA; RIBEIRO, 2015, p. 18). No caso da computação em nuvem, houve um reordenamento das materialidades, na medida em que os vetores de verticalidades vindas das corporações globais e resultantes de sua solidariedade aportaram nos lugares, por meio de novas técnicas e regulações. Conformaram-se as condições propostas por Silveira (1999, p. 26-27), numa nova situação geográfica que alterou a divisão territorial do trabalho e permitiu direcionar a flecha do tempo a novos futuros possíveis, ao passo que dialogou com estruturas historicamente herdadas - no caso, a história de informatização do território brasileiro.

Todos esses elementos, em conjunto com ações efetuadas pelos agentes que interagem com eles, constituem um meio geográfico técnico-científicoinformacional (SANTOS, 2009), característico do período histórico da globalização. É incontestável que uma técnica planetária se estabeleceu, baseada essencialmente na informação e apropriada por um conjunto de firmas e agentes globais. Todo esse sistema possui uma carga ideológica que legitima o discurso da globalização como fábula (SANTOS, 2008) e usa uma base normativo-institucional que também é cada vez mais padronizada globalmente (SILVEIRA, 2012, p. 210-211).

Para que se configurassem essas condições no Brasil, houve a atuação tanto do Estado quanto do mercado, em diálogo com condições territoriais relacionadas ao desenvolvimento prévio de indústrias como as de hardware e software tradicionais, desde a segunda metade do século XX. Acompanhando essa dinâmica, os agentes também promovem a formação de mão de obra especializada e a difusão de uma psicosfera que, associadamente, estimulam os consumos produtivo e consumptivo dos aplicativos, resultando em novos usos do território sejam eles hegemônicos ou alternativos, conforme explicaremos nas partes 2 e 3 deste trabalho. 


\section{Capitulo 2. Produzindo software como serviço: um bem intangivel no mundo globalizado}

O desenvolvimento das tecnologias da informação e comunicação, com o processo de digitalização do território, levaram ao atual estado de convergência entre a informática, o audiovisual e as telecomunicações, conforme explicam Retegui e Perea (2012). A partir dessas modernizações, Schiaffino e Parserisas (2019, p. 9) apontam a descoberta de novas formas de organização do circuito superior da economia urbana - por exemplo, novos modos de difusão das finanças na sociedade e no território. Os investimentos corporativos para difusão de aplicativos e de objetos técnicos como os smartphones, junto aos novos produtos financeiros oferecidos por bancos e outras instituições, são exemplos dessa dinâmica, da qual emergem novos agentes, como as fintechs.

No universo do uso dos aplicativos, o próprio usuário cria trabalho, por meio de mecanismos como os de rastreamento e avaliação das compras e serviços utilizados. Geram-se novas necessidades de consumo, que impulsionam o espalhamento de uma psicosfera a ele associado. Também emergem desafios legais, relacionados a uma transformação acelerada da divisão territorial do trabalho. Nesse âmbito, os motoristas (seja de carros, motocicletas ou bicicletas) vinculados aos aplicativos de entregas são parte fundamental da rede e suportam essas atividades. Todos os fatores listados ajudam a evidenciar a importância do espaço geográfico na economia dos aplicativos.

De acordo com Cabral et al. (2017, p. 238), software é um "programa de computador organizado em instruções em sequência, que são executadas pelos processadores". Uma metáfora tradicionalmente utilizada é a das receitas de bolo, por seu desenho do tipo "input - output". Tendo em vista que o hardware é o componente físico do computador, o software é o programa que o faz funcionar, executando algoritmos.

Já o software como serviço é um tipo de programa de computador geralmente de baixo custo, no qual o consumidor (seja uma pessoa ou uma 
empresa) tem acesso à licença de um serviço online, efetuando ou não um pagamento por ela. Não é o mesmo que um serviço em TI: este diz respeito a todo o ciclo de desenvolvimento de sistemas de informação - definição, desenho, desenvolvimento, implementação e operação -, para criar e oferecer serviços para todo o negócio (ANATEL, 2009).

Silveira $(2009$, p. 31$)$ explica que aplicativos de todo o mundo podem interagir entre si pela Internet, o que permite distribuir também mundialmente o trabalho envolvido em sua produção. $O$ aumento nas jornadas é potencializado por diferenças de fuso-horário, amplificando a produtividade. Trata-se de uma faceta dos chamados impérios da informação e do dinheiro, características da globalização. Daí forma-se um contexto global no qual as fronteiras são porosas para o dinheiro e para a informação, inclusive enfraquecendo e transformando a natureza dos Estados Nacionais (SANTOS, 1997, p. 16-17). Conforme discute Silveira (2015, p. 12), as TI são tecnologias da inteligência, que "podem ampliar, restringir, moldar e limitar nosso modo de comunicar, interagir, redigir e organizar informações":

As tecnologias de informação e comunicação integram o cotidiano de nossas sociedades. Utilizamos computadores, roteadores, servidores, celulares, softwares e aplicativos que facilitam nossa vida, aumentam nossa produtividade, melhoram nossa capacidade de interagir em grupo e são capazes de converter qualquer produção imaterial em bits, em sequências numéricas de zeros e uns. Nosso senso comum indica que essas tecnologias são produtos que simplesmente compramos e usamos. Elas precisariam apenas funcionar bem. Não deveríamos fazer nenhuma avaliação crítica para além de suas qualidades fartamente divulgadas pelo marketing das empresas que as desenvolvem. Assim como não precisamos saber como funciona o sistema de freios hidráulicos de um veículo para poder dirigi-lo, muitos dizem que pouco importa o que os softwares contêm e de que forma foram escritos (SILVEIRA, 2015, p. 12).

De acordo com o mais recente relatório anual da ABES (2020), em parceria com a consultoria IDC, o mercado de TI expandiu-se $10,5 \%$ no Brasil em 2019, acima da média de crescimento mundial. Dentro desse ramo da economia, foi justamente o software que registrou crescimento mais acentuado em 2019, de 16\% em relação ao ano anterior. Os softwares e serviços para exportação aumentaram 
29\% no mesmo período, e a movimentação de capital foi de $\mathrm{R} \$ 161,7$ bilhões (US\$ 44,3 bilhões), se considerados os mercados de software, serviços e hardware, e as exportações do segmento. 0 estudo destaca, ainda, que o "Brasil representa 1,8\% do mercado mundial de TI e 40,7\% do mercado da América Latina. Os investimentos neste segmento foram na ordem de 2,3\% do PIB" (ABES, 2020).

No entanto, deve-se ressaltar que na escala global a indústria de software é dominada por empresas multinacionais, não apenas em termos de produtos para consumidores comuns (tais como Windows e Office, da Microsoft), mas também em segmentos bastante específicos, como aviônica ou exploração de óleo e gás. Estes requerem investimento muito alto em pesquisa de mercado, inovação tecnológica, marketing etc., antes de qualquer venda, e o risco de falha é igualmente alto (SOFTEX, 2002, p. 27). No mundo, o maior produtor de software são os Estados Unidos, com $46,1 \%$ do mercado, enquanto o Brasil responde por apenas $1,9 \%$ (ABES, 2019).

Bens intangíveis (como os softwares) ou mesmo serviços podem ser considerados mercadorias, tendo em vista que, "no capitalismo, o produto do trabalho assume a forma de mercadoria" (BRUSCHI et al., 2016, p. 37). Especificamente, a atividade de programação de computadores possui um escopo que cria valores de uso, ou trabalho concreto útil (idem, p. 48). Note-se que a produção incorpora não apenas o processo propriamente produtivo, mas também outros como financiamento, suprimento de insumos, distribuição e marketing, cada qual com seus conhecimentos específicos necessários (POSSAS, 2006, p. 35).

As tecnologias, de modo genérico, estão presentes em diversas etapas da cadeia de produção em uma firma. Dowbor (2020, p. 29) nota que "não se trata apenas da robótica, que penetra de forma acelerada em inúmeros setores, mas também do pequeno agricultor que usa inseminação artificial e análise de solos, do médico que se apoia em redes de laboratórios e de cirurgia acompanhada à distância". Mais exemplos são dados por Bienaymé (1994, p. 72):

- Infraestrutura da firma: tecnologias dos sistemas de informação; tecnologias para planificação e orçamento; automação de tarefas de escritório. 
- Gestão de recursos humanos: tecnologias para formação de profissionais.

- Desenvolvimento tecnológico: tecnologias de produtos e pilotos; desenvolvimento de algoritmos; design assistido.

- Cadeia de suprimentos: tecnologias de transporte e comunicação.

- Logística interna: tecnologias de transporte; manutenção; estoque e conservação; testes.

- Produção: tecnologias de materiais; ferramentas; embalagens; funcionamento dos edifícios.

- Logística externa: tecnologias de transporte; sistemas de manutenção, condicionamento, comunicação e informação.

- Comercialização, venda e prestação de serviços: tecnologias de comunicação e informação; testes e diagnósticos; meios de comunicação, áudio e vídeo.

Dowbor (2020, p. 177) observa ainda que, "enquanto a própria produção de bens materiais é cada vez mais densa em tecnologia, o conjunto do processo, o financiamento, a comercialização e a distribuição, além dos controles e da gestão, passam a ser essencialmente intangíveis". Não apenas os algoritmos, como também tecnologias como os sinais magnéticos, mais amplamente utilizados antes dos softwares, autorizam o funcionamento de uma nova lógica econômica, mais reprodutível e comunicável.

Conforme revela sua própria denominação, o software como serviço é distribuído via contratos de prestação de serviços. Sua relevância vem tanto da imensa capilaridade de seu uso (inclusive para geração de renda, como no caso dos entregadores) quanto pelo fato de que seu funcionamento é atrelado à conectividade, ou seja, à disponibilidade de redes telemáticas e dispositivos informacionais (por exemplo, aqueles que funcionam por meio de chips e têm a possibilidade de conexão à Internet, como computadores e telefones celulares).

As condições técnicas e normativas a que nos referimos no Capítulo 1 deste trabalho possibilitaram o desenvolvimento de diversas soluções "as a service", que são embasadas pela existência da computação em nuvem: software 
como serviço, plataforma como serviço, infraestrutura como serviço, entre outras (Figura 2.1). A diferença entre elas é o grau de comando e customização a cargo do cliente ou da companhia que oferece a tecnologia. Quando se contrata a infraestrutura ou a plataforma como serviço, trata-se de firmar um contrato de acesso a máquinas virtuais e outras tecnologias (por exemplo, sistemas de segurança da informação), com fins de desenvolver seu próprio software. No caso do SCS, o programa já está pronto, e o cliente não se preocupa com a infraestrutura mobilizada para armazenar os dados ou executar o algoritmo.

Figura 2.1. Esquema explicativo de software, plataforma e infraestrutura como serviço.

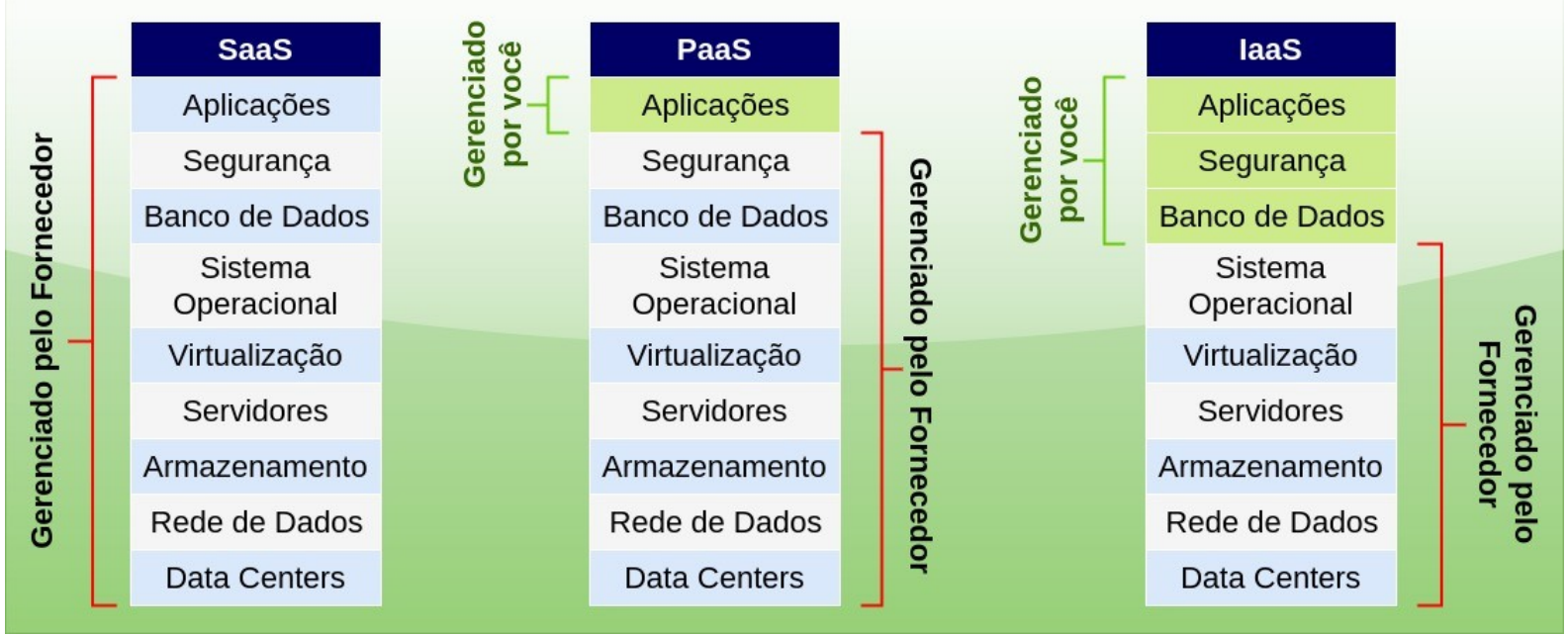

Fonte: Barbosa et al., 2017.

No caso do software como serviço, a instalação, a configuração e a execução do aplicativo são feitos pelo provedor de serviços. Alguns exemplos são os aplicativos da suíte Google Workspace (que inclui Google Docs, Drive, Calendar, Tasks, Sites, Analytics e outros) e o Microsoft Office 365 (que permite ao usuário subscrever-se para ter acesso a produtos como Word, Excel, Power Point e Outlook) pela Internet. Já na plataforma como serviço, o cliente gerencia seu aplicativo, mas no pacote do fornecedor incluem-se o sistema operacional, ferramentas para bancos de dados, um ambiente de execução para linguagens de programação e hospedagem em um servidor. Alguns exemplos de empresas que oferecem esses 
recursos são AWS Elastic Beanstalk, Heroku, Google App Engine, Apache Stratos e Windows Azure.

Por fim, o usuário que contrata a infraestrutura como serviço fica responsável por gerenciar não apenas seu aplicativo, como também fatores como o banco de dados correspondente e a segurança do programa, enquanto o fornecedor disponibiliza máquinas físicas ou virtuais, redes ou até infraestrutura de energia elétrica. É o caso de Google Compute Engine, Amazon EC2, Rackspace e, novamente, Windows Azure. Neste caso, o usuário possui maior controle de todo o processo. Contudo, nota-se que várias firmas (Google, Amazon, Windows) atuam em todas as escalas das ferramentas "como serviço".

Um caso especial é o das aplicações web, que são executadas diretamente no navegador e processadas em um servidor remoto, como as plataformas de e-commerce e redes sociais. Elas oferecem maior grau de interatividade com o usuário do que um site comum, apesar da comunicação também ser feita via protocolo HTTP (Hypertext Transfer Protocol). Novamente, entre as empresas detentoras das tecnologias de aplicações web mais populares encontram-se Google, Amazon, Windows e outras, como Facebook. Silveira (2015, p. 12) afirma que as próprias licenças de uso - com as quais concordamos no ato de acesso ou cadastro nessas plataformas - são uma ferramenta de poder, de modo que

As grandes corporações de tecnologia, cada vez mais empresas de entretenimento e relacionamento digitais, buscam o controle de nossas opções cotidianas, e nisso reside o seu negócio. Controlar e enredar o maior número de pessoas em suas teias de controle é o principal caminho do capitalismo cognitivo.

Uma alternativa crescente - porém também utilizada em larga escala pelas corporações de TI - é o software de código aberto (open source). Conhecido no Brasil como software livre, ele pressupõe que o código-fonte seja distribuído com o próprio programa, ou que seja disponibilizado com custo menor ou igual ao de distribuição. Sua modificação e difusão devem ser possíveis gratuitamente, sem necessidade de pagamento por direitos autorais. O código-fonte corresponde às instruções necessárias para que um programa funcione. No caso dos softwares 
livres, qualquer usuário pode fazer download do código fonte e eventualmente aperfeiçoá-lo. Afonso (2002, p. 182-183) observa que a maior parte dos servidores já opera com sistemas operacionais e programas de código aberto, e defende seu uso em instituições públicas, pois são potencialmente mais seguros (técnicos podem inspecionar o código e resolver falhas) e há maior facilidade de lidar com ações legais no caso de problemas. As versões mais popularizadas e padronizadas dos softwares são parte do impulso aos programas de código aberto (CARR, 2004, p. 50).

Para além das mudanças tecnológicas, as bases normativo-institucionais envolvidas na produção de aplicativos se constituem de regulação nacional e internacional em constante atualização, incluindo a participação de instituições de governança. Elas perpassam mudanças nos contratos de serviços, em consequência do surgimento do modelo em nuvem e das tecnologias "as a service". Isso trouxe consequências do ponto de vista da atuação das grandes empresas - já que o próprio modelo "como serviço" nasceu delas -, da divisão territorial do trabalho (com flexibilização, precarização e novas relações de trabalho) e do consumo, seja produtivo ou consumptivo. As alterações regulatórias tiveram como consequência, inclusive, levantes contra-hegemônicos de grupos como os trabalhadores dos ramos de TI e de entregas via plataformas eletrônicas. Ademais, a conformação de tais bases fomenta a criação e a execução de políticas públicas orientadas a incluir e priorizar a tecnologia da nuvem, seja para sua utilização como forma de armazenamento e acesso a dados, seja para formação de mão de obra especializada.

\subsection{Novos contratos, novas interações espaciais: tipologia e topologia dos agentes produtores de software como serviço no Brasil}

Quando começaram a ser escritos, nos anos 1950, os primeiros programas de computador eram simples e podiam ter algumas centenas de linhas de código. Isso permitia que fossem desenvolvidos e compartilhados dentro da 
própria empresa que necessitava automatizar alguma tarefa. Porém, à medida que se complexificaram (chegando aos milhares ou milhões de linhas de código), surgiram as chamadas "software houses", já intensamente nos anos 1960. Esses lugares especializados puderam captar economias de escala inerentes ao ramo de desenvolvimento de software, enquanto as firmas que compravam seus produtos mantinham pessoal apenas para manutenção, refino e solução de problemas com os programas (CARR, 2004, p. 44).

As software houses, junto à popularização dos computadores pessoais entre as décadas de 1970 e 1980 possibilitaram que programas mais sofisticados ficassem mais baratos e chegassem a um maior número de consumidores (notoriamente, outras empresas). Nesse processo, as firmas puderam comprar muito mais máquinas, empregados não-técnicos eram capazes de operá-las pela primeira vez, e a comunicação entre firmas e pessoas foi se tornando cada vez mais importante para os negócios. Por isso, foi absolutamente necessário tornar os softwares mais simples e padronizados, ampliando a base de usuários e gerando pressão pela substituição de programas proprietários por outros compartilháveis (CARR, 2004, p. 45).

Foi aí, também, que aumentou a necessidade de hardware mais sofisticado e homogeneizado, e as tarefas a automatizar foram ficando mais especializadas. Ao final dos anos 1980, as empresas não mais compravam simples programas para escrever textos ou planilhas, mas sim softwares distintos para funções como contabilidade, administração de bancos de dados e recursos humanos, design gráfico, entre outros. O ERP (Enterprise Resource Planning, ou Sistema de Gestão Empresarial) da alemã SAP foi um dos mais utilizados nos anos 1990, integrando módulos que executavam diversas funções (CARR, 2004, p. 46).

Notam-se, daí, dois pontos de destaque: primeiro, a intrínseca relação entre o desenvolvimento de hardware e de software - ambos parte da tecnosfera, porém com funções distintas, ainda que evidentemente associadas. 0 código dita a ação a ser executada mecanicamente pelo processador. O segundo ponto é a contínua pressão por melhorias nos programas, sobretudo para os usuários mais avançados. Isso gera competitividade entre firmas e reverbera no processo 
produtivo, na força de trabalho e em sua localização, já que se buscam espaços onde será possível produzir programas mais avançados - o que depende de acesso a mão de obra e insumos.

Os dados da antiga Secretaria Especial de Informática (SEI), organizados por Piragibe (1985) mostram que na década de 1980, quando o uso de computadores começava a se popularizar, os ramos de serviços e bancário correspondiam a mais de $40 \%$ do mercado consumidor, seguidos de diversos ramos industriais (Tabela 2.1).

Tabela 2.1. Brasil. Os 10 maiores mercados de computadores (1981).

\begin{tabular}{lll}
\hline Atividades & \% & \% acumulada \\
\hline Bureau de serviços & 20,7 & 20,7 \\
Bancos comerciais & 20,5 & 41,2 \\
Metalurgia e siderurgia & 6,0 & 47,2 \\
Comércio em geral & 4,3 & 51,5 \\
Ensino & 3,9 & 55,4 \\
Utilidade pública (telefone/água) & 3,6 & 59,0 \\
Construção civil e engenharia & 2,7 & 61,7 \\
Produtos alimentícios & 2,5 & 64,2 \\
Extração de minerais & 2,4 & 66,6 \\
Química & 2,3 & 68,9 \\
\hline
\end{tabular}

Fonte: Piragibe (1985, p. 186).

Evidentemente, em quarenta anos esse cenário mudou muito. A Associação Brasileira das Empresas de Software (ABES) organiza seus aproximadamente 2 mil associados em mercados, serviços e soluções onde atuam, que mostram a disseminação dos programas de computador pelos mais variados ramos produtivos (Quadro 2.1). É notória a pervasividade dos softwares, e observase como se tornaram mais específicos, o que é expresso sobretudo nas "soluções", ou finalidades mais restritas de cada produto. 
Quadro 2.1. Mercados, serviços e soluções oferecidos em software.

\begin{tabular}{|c|c|c|}
\hline Mercados & Serviços & Soluções \\
\hline $\begin{array}{l}\text { Agroindústria; } \\
\text { comércio; } \\
\text { construção civil; } \\
\text { educação; energia; } \\
\text { finanças; governo; } \\
\text { manufatura; } \\
\text { mineração; saúde; } \\
\text { serviços; } \\
\text { telecomunicação; } \\
\text { transporte. }\end{array}$ & $\begin{array}{l}\text { Consultoria; } \\
\text { desenvolvimento sob } \\
\text { encomenda; Electronic } \\
\text { Data Interchange (EDI ou } \\
\text { troca eletrônica de dados); } \\
\text { integração; operação de } \\
\text { serviços web (SaaS, IaaS); } \\
\text { outsourcing; portais web } \\
\text { (mídia, conteúdo etc.); } \\
\text { processamento de dados; } \\
\text { suporte e manutenção; } \\
\text { treinamento. }\end{array}$ & $\begin{array}{l}\text { Áudio e vídeo; automação de processos; } \\
\text { banco de dados; Business Intelligence (BI); } \\
\text { Customer Relationship Manager (CRM); } \\
\text { desenho gráfico; engenharia (CAD, CAM, } \\
\text { CAE etc.); ERP; ferramentas de busca; } \\
\text { ferramentas de desenvolvimento; } \\
\text { ferramentas de qualidade; games; } \\
\text { gerenciamento de redes e ambientes; } \\
\text { gestão de aprendizado (e-learning); gestão } \\
\text { de projetos; inteligência artificial; } \\
\text { manufatura (CNC, PCP, MRP etc.); } \\
\text { mensageria; mobilidade; multimídia; } \\
\text { negociação eletrônica; portais } \\
\text { corporativos; produção e gestão de } \\
\text { conteúdo; segurança; sistema operacional; } \\
\text { suítes de escritório; web aplicativos; web } \\
\text { marketing. }\end{array}$ \\
\hline
\end{tabular}

Fonte: elaboração própria, a partir de ABES (2021).

As empresas que produzem SCS podem criar, desenvolver, hospedar e atualizar seus produtos a partir de apenas uma localidade, usando conexões remotas em nuvem e sem terem de arcar com custos de logística. Para o lado do consumidor, por sua vez, o produto (ou uma subscrição a um serviço, tal como o aplicativo musical Spotify) fica acessível por meio de qualquer dispositivo conectado à Internet, com um navegador web e algumas diretrizes combinadas com o fornecedor do serviço. É também um sistema mais simples e rápido para oferecer suporte técnico e desenvolvimento colaborativo entre desenvolvedores que não estejam fisicamente próximos (AMARESAN, 2020). Em 2010, tratava-se de um segmento pequeno e em rápido crescimento, com as características de uma indústria emergente, aproximando-se do mainstream nos mercados globais (MÄKILA et al., 2010, p. 123); nos anos 2020, esse cenário definitivamente se consolidou.

Um aplicativo, portanto, pode ser considerado um programa de computador desenhado para processar dados eletronicamente, facilitando e 
reduzindo o tempo de execução de uma tarefa pelo usuário (UFPA, 2019); simplesmente, um programa de computador (ABA, 2006); ou um software, disponível numa loja virtual (como a Play Store da Google ou a App Store da Apple) para instalação em um meio eletrônico de comunicação (smartphone, aparelho de televisão, tablet, computador etc.) e para executar tarefas específicas (EAQ, 2017).

Na Classificação Nacional de Atividades Econômicas (CNAE), gerida pelo IBGE, são listadas três subclasses que abarcam a produção de aplicativos: os programas de computador sob encomenda (também chamados de "software de prateleira", subclasse 62.01-5/01), os customizáveis (ou "softwares personalizados", subclasse 62.02-3/00) e os não customizáveis (subclasse 62.031/00). Adicionamos ainda as empresas da subclasse 74.90-1/04 que continham na razão social os termos "software", "app", "aplicativo" e "informática”, pois identificamos que muitas firmas que produzem aplicativos consideram que executam atividades de intermediação, como é o caso das plataformas da dita "economia do compartilhamento". Essa separação gera alguns embates jurídicos. De acordo com Nasrallah (2017),

O Supremo Tribunal Federal - STF e o Superior Tribunal de Justiça - STJ assentaram o entendimento no sentido de que (i) os programas de computadores desenvolvidos para clientes de forma personalizada são serviços e geram incidência de tributo do ISS e são chamados de softwares personalizados, por outro lado, (ii) os programas de computadores produzidos em larga escala, chamados de softwares de prateleira, caracterizam-se mercadoria sujeitos à incidência de ICMS.

A tributação dos softwares ficou cada vez mais nebulosa, pois os produtores gradualmente passaram a oferecer mais opções de personalização. Ainda assim, considera-se que, nos programas customizáveis, são feitos menos ajustes para atender às particularidades dos clientes, em relação ao produto sob encomenda. Então, ainda que sejam fruto de obra intelectual do desenvolvedor, podem ser considerados mercadorias, em vez de prestação de serviço. No entanto, atividades adicionais de personalização, testes, documentação etc. podem ser classificadas como prestação de serviços profissionais.

Já o tipo de licenciamento dos aplicativos é considerado temporário não 
exclusivo, de modo que engloba serviços de manutenção, atualização e suporte técnico administrados pelo fornecedor por via remota, sem necessidade de cessão ou comercialização de uma licença. Por isso, ainda que não seja software personalizado, tampouco se caracteriza como programa de prateleira. Os programas customizáveis são aqueles em que os clientes podem especificar funções, módulos, relatórios e testes. Já os sob encomenda incluem projetos e modelagem de bancos de dados sob demanda, além do treinamento para seu uso, implementação ou administração.

Numa análise dos dados do CNPJ disponibilizados pela Receita Federal do Brasi $^{30}$, pudemos identificar um universo de 50.188 empresas que informaram exercer atividades sob os códigos CNAE selecionados para nossa análise. Desse total, também realizamos uma consulta apenas pelas empresas que continham os termos "app" ou "aplicativo" na razão social, às quais chamamos "empresas produtoras de aplicativos", por explicitamente haverem reportado que trabalham com esse produto. Elas são um total de 533. As Tabelas 2.2 e 2.3 e os Gráficos 2.1 e 2.2 reproduzem a quantidade de empresas por código CNAE.

30 A base de dados contempla registros do CNPJ de 1966 a 2020, mas realizamos uma seleção apenas das empresas que constavam como ativas à época da extração dos dados, em agosto de 2020. 
Tabela 2.2. Brasil. Empresas produtoras de software por código CNAE fiscal informado (2020).

Código CNAE fiscal Quantidade de empresas

Porcentagem do total

62.01-5/01 (Desenvolvimento de

programas de computador sob

29.673

59,0

encomenda)

62.02-3/00 (Desenvolvimento e

licenciamento de programas de

10.140

20,0

computador customizáveis)

62.03-1/00 (Desenvolvimento e

licenciamento de programas de

9.214

18,0

computador não customizáveis)

74.90-1/04 (Atividades de

intermediação e agenciamento de

serviços e negócios em geral, exceto

1.161

2,0

imobiliários)

Fonte: elaboração própria, a partir de dados da Receita Federal do Brasil (2020).

Gráfico 2.1. Brasil. Empresas produtoras de software, segundo código CNAE fiscal.

Brasil. Empresas produtoras de software por código CNAE fiscal (2020)

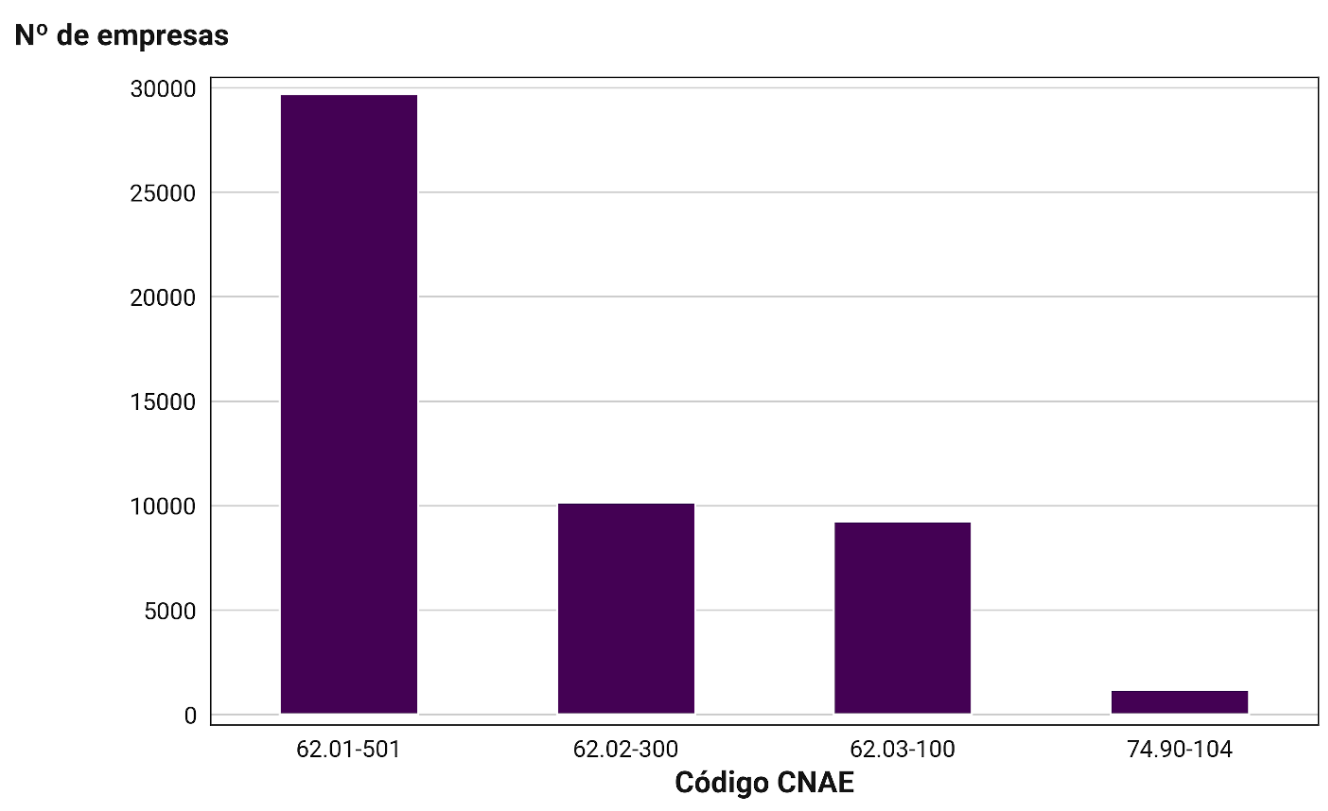

Fonte: Receita Federal do Brasil, 2020. Elaboração própria.

Fonte: elaboração própria, a partir de dados da Receita Federal do Brasil (2020). 
Tabela 2.3. Brasil. Empresas produtoras de aplicativos por código CNAE fiscal informado (2020).

Código CNAE fiscal Quantidade de empresas

Porcentagem do total

62.01-5/01 (Desenvolvimento de

programas de computador sob

encomenda)

62.02-3/00 (Desenvolvimento e

licenciamento de programas de

computador customizáveis)

62.03-1/00 (Desenvolvimento e

licenciamento de programas de

computador não customizáveis)

74.90-1/04 (Atividades de

intermediação e agenciamento de

serviços e negócios em geral, exceto

imobiliários)

Fonte: elaboração própria, a partir de dados da Receita Federal do Brasil, 2020.

Gráfico 2.2. Brasil. Empresas produtoras de aplicativos, segundo código CNAE fiscal.

Brasil. Empresas produtoras de aplicativos por código CNAE fiscal (2020)

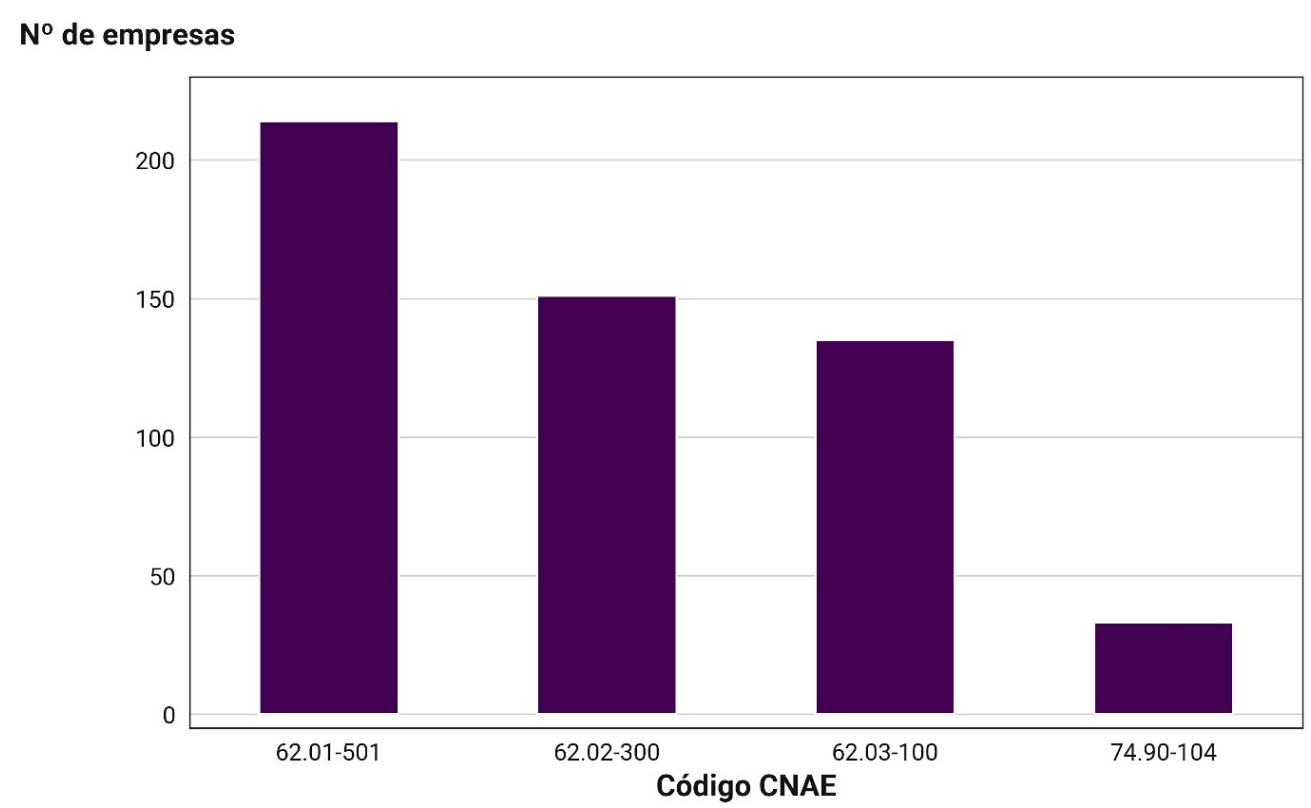

Fonte: Receita Federal do Brasil, 2020. Elaboração própria.

Fonte: elaboração própria, a partir de dados da Receita Federal do Brasil (2020). 
Como se vê nos dados, os aplicativos por encomenda são mais da metade dos tipos de software. Isso pode ser uma expressão da alta pervasividade das TI em outras áreas, de modo que cada vez mais usuários visam automatizar tarefas usando aplicativos especificamente desenhados para aquela finalidade. Quando feita a seleção por ano de início de atividade (Gráficos 2.3 e 2.4 e Tabelas 1 e 2 anexas), fica notável um incremento mais significativo coincidente com o surgimento da computação em nuvem, e com outros fatores de ordem normativa, que mencionaremos em seguida.

Gráfico 2.3. Brasil. Empresas produtoras de software por ano de início de atividade (1990-2019).

Brasil. Empresas produtoras de software por ano de criação

$\mathrm{N}^{\circ}$ de empresas

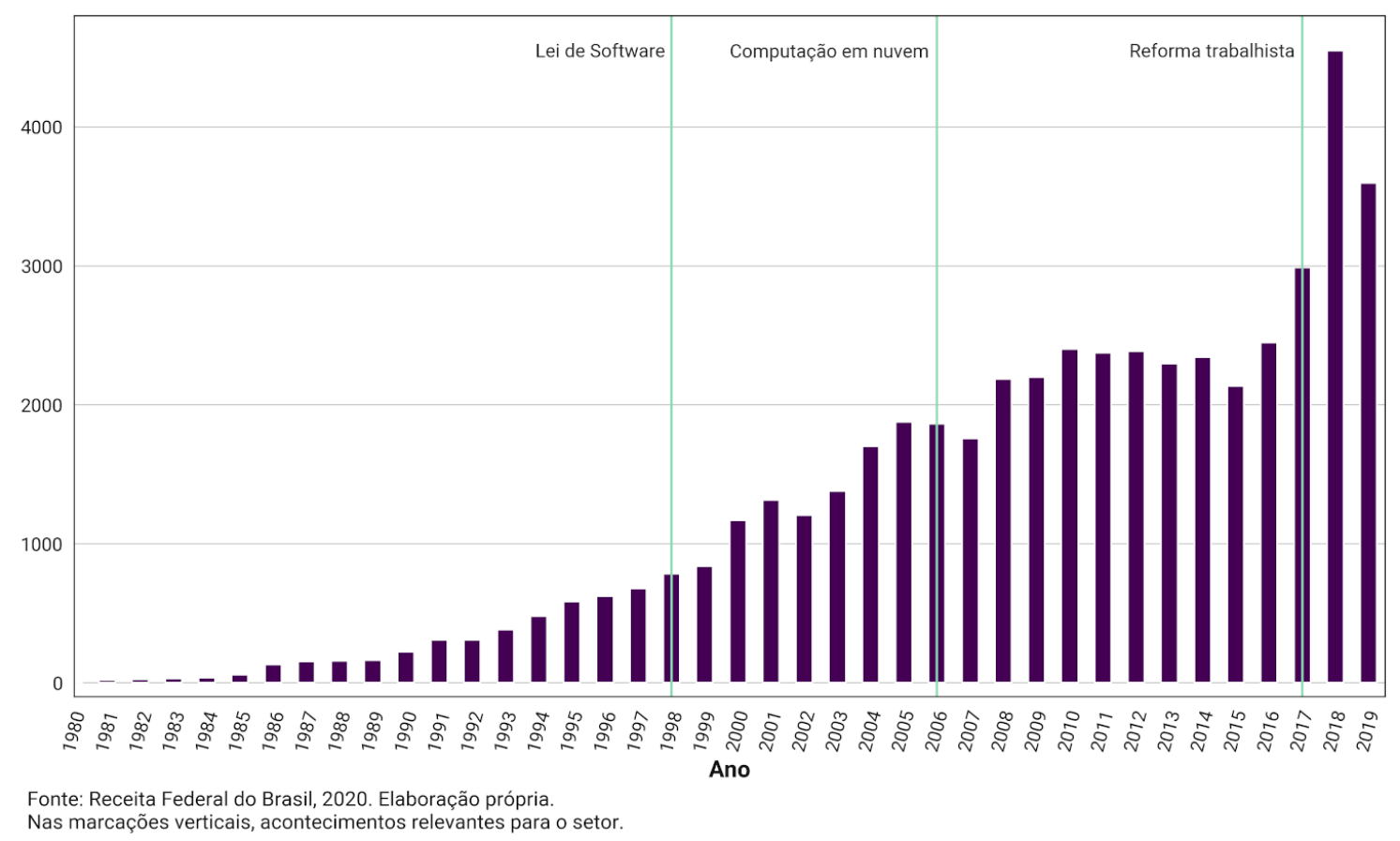

Fonte: elaboração própria, a partir de dados da Receita Federal do Brasil (2020). 
Gráfico 2.4. Brasil. Empresas produtoras de aplicativos por ano de início de atividade (1986-2019).

Brasil. Empresas produtoras de aplicativos por ano de criação

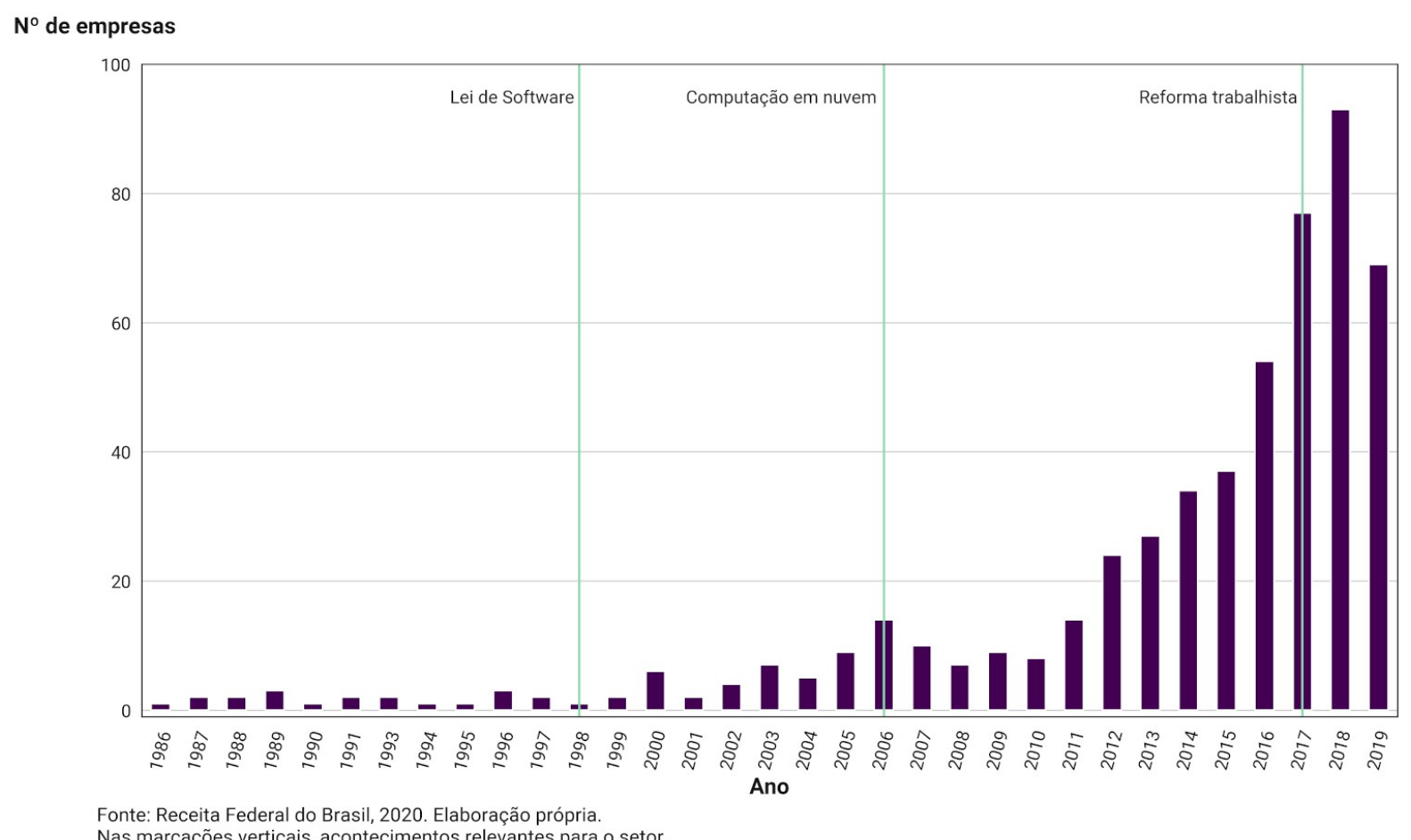

Fonte: elaboração própria, a partir de dados da Receita Federal do Brasil (2020).

Partindo do levantamento de Steda (2015, p. 47), pode-se inferir que alguns elementos constituintes da base normativo-institucional da produção de software influenciaram o início das operações de empresas do ramo. Um primeiro crescimento mais significativo é notado no início dos anos 2000, pouco depois da sanção da segunda versão chamada Lei do Software (Lei n. 9.609; a primeira versão era de 1988), com a finalidade de proteger a propriedade intelectual do software e regular sua comercialização no Brasil. Outros fatores que não se pode deixar de destacar são o surgimento da computação em nuvem, em 2006, e a flexibilização de normas trabalhistas no país, em 2017. Ambos conformaram novas condições de contratação de mão de obra no ramo de software, em muitos casos precarizada.

Nas décadas de 2000 e 2010, foram intensificadas as políticas públicas federais voltadas a incentivos fiscais e à inovação no segmento de TI, com dois importantes marcos regulatórios: a Lei da Inovação (Lei n. 10.973/2004) e a Lei do 
Bem (Lei n. 11.196/2005). A primeira reduzia alíquotas de PIS/Pasep (Programa Integração Social/Programa de Formação do Patrimônio do Servidor Público) e Cofins (Contribuição para o Financiamento da Seguridade Social), e a segunda instituiu o Regime Especial de Tributação para a Plataforma de Exportação de Serviços de Tecnologia da Informação (REPES), o Regime Especial de Aquisição de Bens de Capital para Empresas Exportadoras (RECAP) e o Programa de Inclusão Digital. Mais espeficiamente, a Lei n. 11.452/2007 extinguiu a incidência da CIDE (Contribuição sobre Intervenção no Domínio Econômico) de 10\% nas operações com programas de computador, e a Lei n. 12.546/2011 promoveu a desoneração da folha de pagamento para empresas de TI.

Outros fatores, no mesmo período, foram políticas industriais focadas em inovação e exportações em TI (como a PITCE - Política Industrial, Tecnológica e de Comércio Exterior, em vigor de 2004 a 2008), e na preferência em licitações da administração pública federal para aquisição de programas de computador. Políticas de ciência, tecnologia e desenvolvimento produtivo (como o Plano Nacional de Ciência, Tecnologia e Inovação e o Programa TI Maior) tiveram estratégias particulares para fomento à produção e à exportação de software e serviços em TI, identificando diversas áreas em que essas tecnologias poderiam ser aplicadas. Estímulos estatais são particularmente importantes para as empresas de menor porte, que são hoje a imensa maioria do mercado brasileiro de software (Tabelas 2.4 e 2.5 e Gráficos 2.5 e 2.6).

Tabela 2.4. Brasil. Empresas produtoras de software por porte (2020).

\begin{tabular}{lrr}
\hline Porte & Quantidade de empresas & Porcentagem do total (\%) \\
\hline Microempresa & 35.137 & 70,0 \\
Pequeno porte & 10.069 & 20,0 \\
Demais portes & 4.982 & 10,0 \\
\hline Fonte: elaboração própria, a partir de dados da Receita Federal do Brasil (2020).
\end{tabular}

Fonte: elaboração própria, a partir de dados da Receita Federal do Brasil (2020). 
Gráfico 2.5. Brasil. Empresas produtoras de software por porte (2020).

Brasil. Empresas produtoras de software por porte (2020)

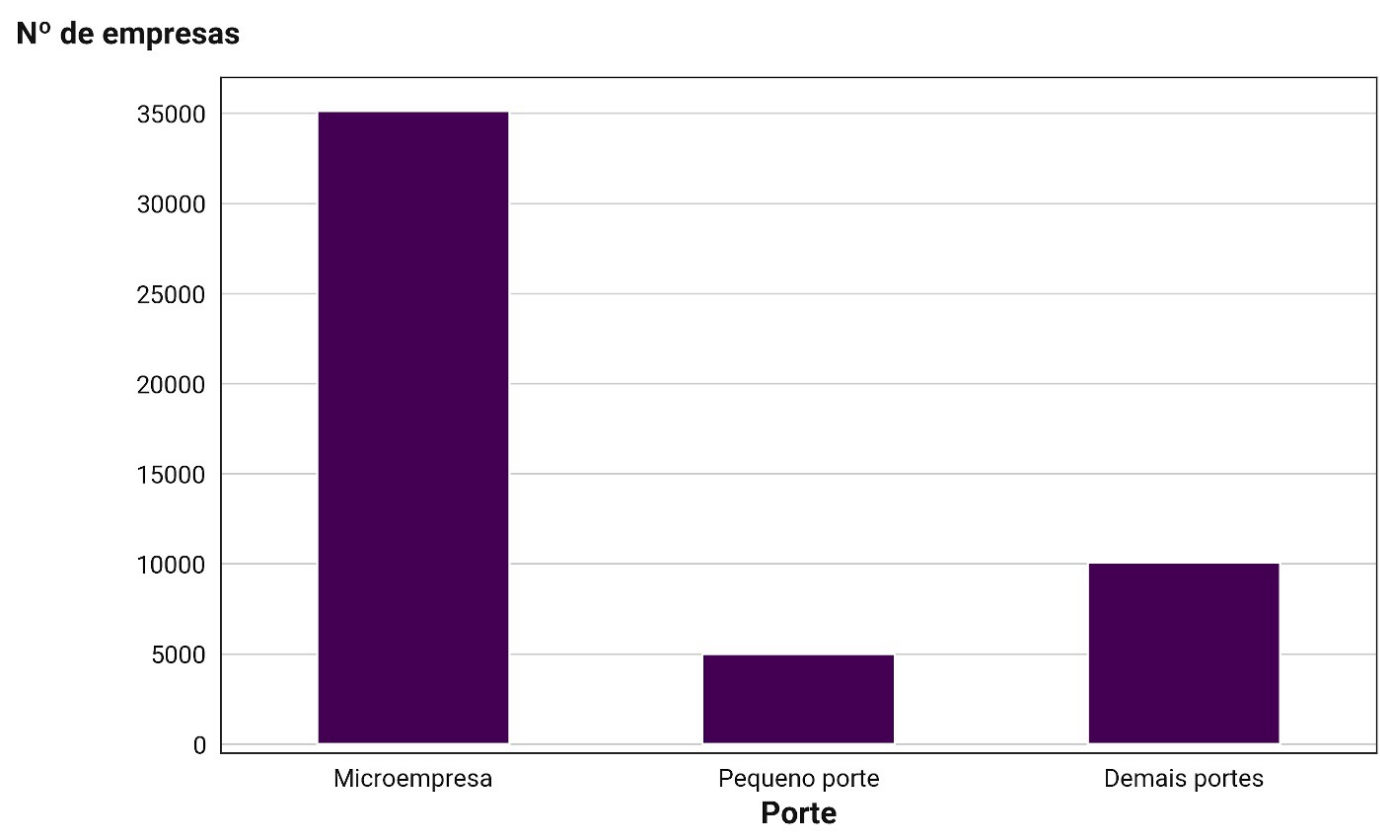

Fonte: Receita Federal do Brasil, 2020. Elaboração própria.

Fonte: elaboração própria, a partir de dados da Receita Federal do Brasil (2020).

Tabela 2.5. Brasil. Empresas produtoras de aplicativos por porte (2020).

\begin{tabular}{lrr}
\hline Porte & Quantidade de empresas & Porcentagem do total (\%) \\
\hline Microempresa & 323 & 61,0 \\
Pequeno porte & 127 & 24,0 \\
Demais portes & 83 & 16,0 \\
\hline
\end{tabular}

Fonte: elaboração própria, a partir de dados da Receita Federal do Brasil (2020). 
Gráfico 2.6. Brasil. Empresas produtoras de aplicativos por porte (2020).

Brasil. Empresas produtoras de aplicativos por porte (2020)

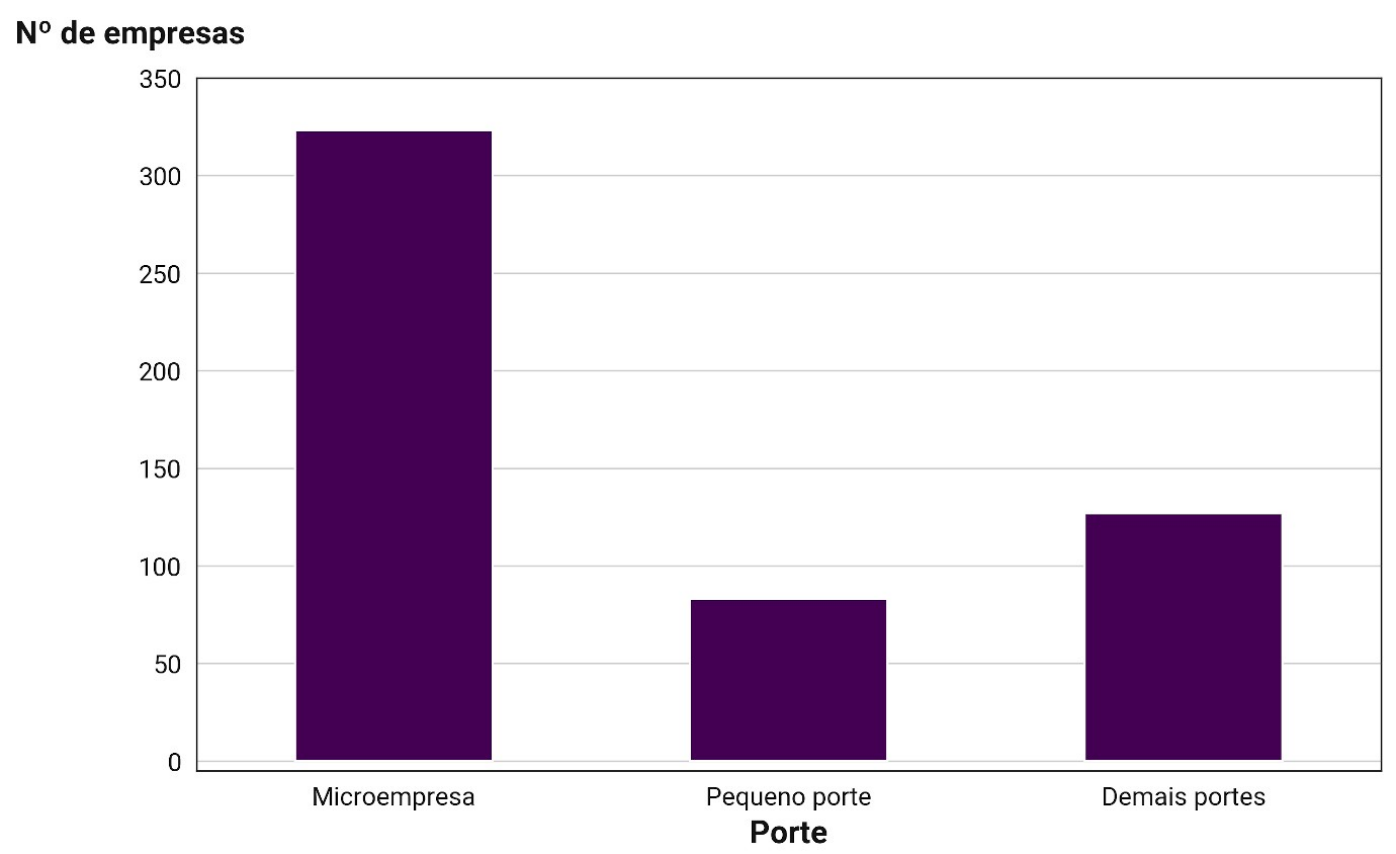

Fonte: Receita Federal do Brasil, 2020. Elaboração própria.

Fonte: elaboração própria, a partir de dados da Receita Federal do Brasil (2020).

Diversos agentes, nacionais e estrangeiros, compõem a indústria de software no Brasil: empresas de diferentes tamanhos, estratégias, modalidades da produção. Conforme mostram as tabelas 2.6 e 2.7 e os gráficos 2.7 e 2.8 , a produção de aplicativos é afetada pela forte concentração regional de indústrias de tecnologia no Sudeste do Brasil (especialmente no estado de São Paulo), associada a condições como maiores redes de conectividade e disponibilidade de mão de obra especializada. Além disso, durante o processo de concentração e centralização de capital, o poder dos grandes grupos econômicos tende a aumentar, bem como sua capacidade de criar as normas que regulam os usos do território e o gerenciamento das redes (ARROYO, 2015, p. 48).

Toledo Junior (2003, p. 94) já alertava que a configuração espacial das ações das firmas de tecnologia deveria ser considerada não apenas em seus aspectos materiais, mas também quanto aos serviços e possibilidades que oferecem. Por se tratar de um ramo altamente inovativo, as normas para TI não 
são sequer capazes de acompanhar o movimento do lançamento de novos produtos e serviços, que podem ser inclusive vetores de desordem nos lugares - como é o caso, por exemplo, dos ramos de hospedagem ou viagens em cidades onde a plataforma Airbnb começa a atuar.

A regionalização proposta por Santos e Silveira (2011) nos pareceu mais adequada para classificar e representar graficamente a distribuição das empresas de software no Brasil. Nota-se que, a despeito do alarde sobre o quão inclusivas e disseminadas as TI podem ser num mundo conectado, ainda há diversos constrangimentos que tensionam sua dispersão pelo território e as mantém na Região Concentrada, como uma força centrípeta - provavelmente, vinculada à densidade informacional e às condições socioeconômicas dessa porção do território, mais propensas a oferecer atrativos ao ramo de software. Além disso, as profissões requeridas para operar nesse segmento demandam certo grau de especialização, mais seletivo e mais relacionado à topologia da rede urbana brasileira, com concentração nas metrópoles.

Tabela 2.6. Brasil. Empresas produtoras de software por região (2020).

\begin{tabular}{lrr}
\hline Região & Quantidade de empresas & Porcentagem do total (\%) \\
\hline Concentrada & 42.546 & 84,8 \\
Nordeste & 3.955 & 7,9 \\
Centro-Oeste & 2.957 & 5,9 \\
Amazônia & 730 & 1,5 \\
\hline Fonte: elaboração própria, a partir de dados da & Receita & Federal do Brasil (2020). \\
Regionalização: Santos e Silveira (2011). & &
\end{tabular}


Gráfico 2.7. Brasil. Empresas produtoras de software por região (2020).

Brasil. Empresas produtoras de software por região (2020)

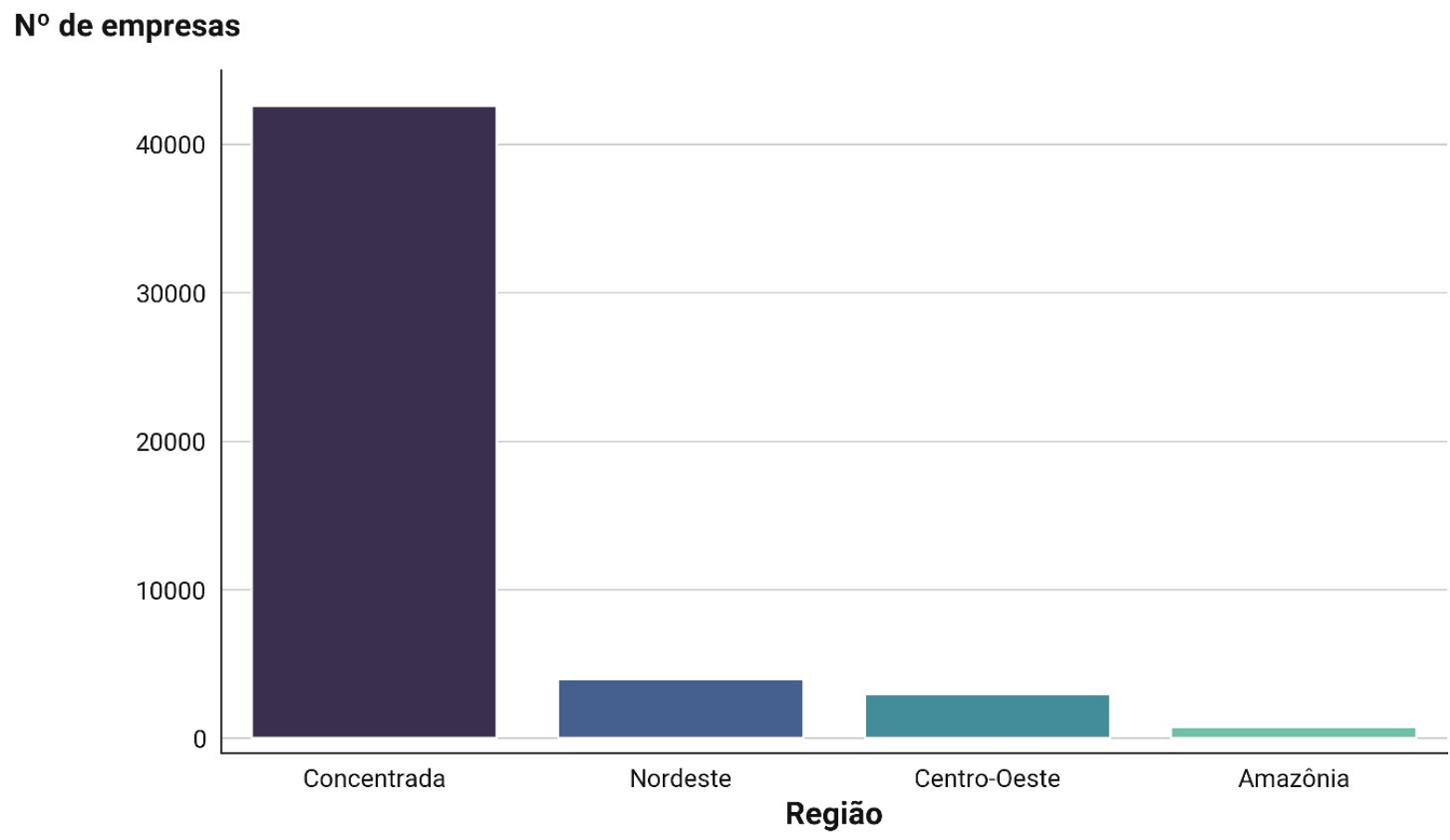

Fonte: Receita Federal, 2020. Elaboração própria.

Fonte: elaboração própria, a partir de dados da Receita Federal do Brasil (2020).

Tabela 2.7. Brasil. Empresas produtoras de aplicativos por região (2020).

\begin{tabular}{lrr}
\hline Região & Quantidade de empresas & Porcentagem do total (\%) \\
\hline Concentrada & 435 & 81,6 \\
Nordeste & 51 & 9,6 \\
Centro-Oeste & 40 & 7,5 \\
Amazônia & 7 & 1,3 \\
\hline Fonte: elaboração própria, a partir de dados da & Receita & Federal do Brasil (2020).
\end{tabular}

Regionalização: Santos e Silveira (2011). 
Gráfico 2.8. Brasil. Empresas produtoras de aplicativos por região (2020).

\section{Brasil. Empresas produtoras de aplicativos por região (2020)}

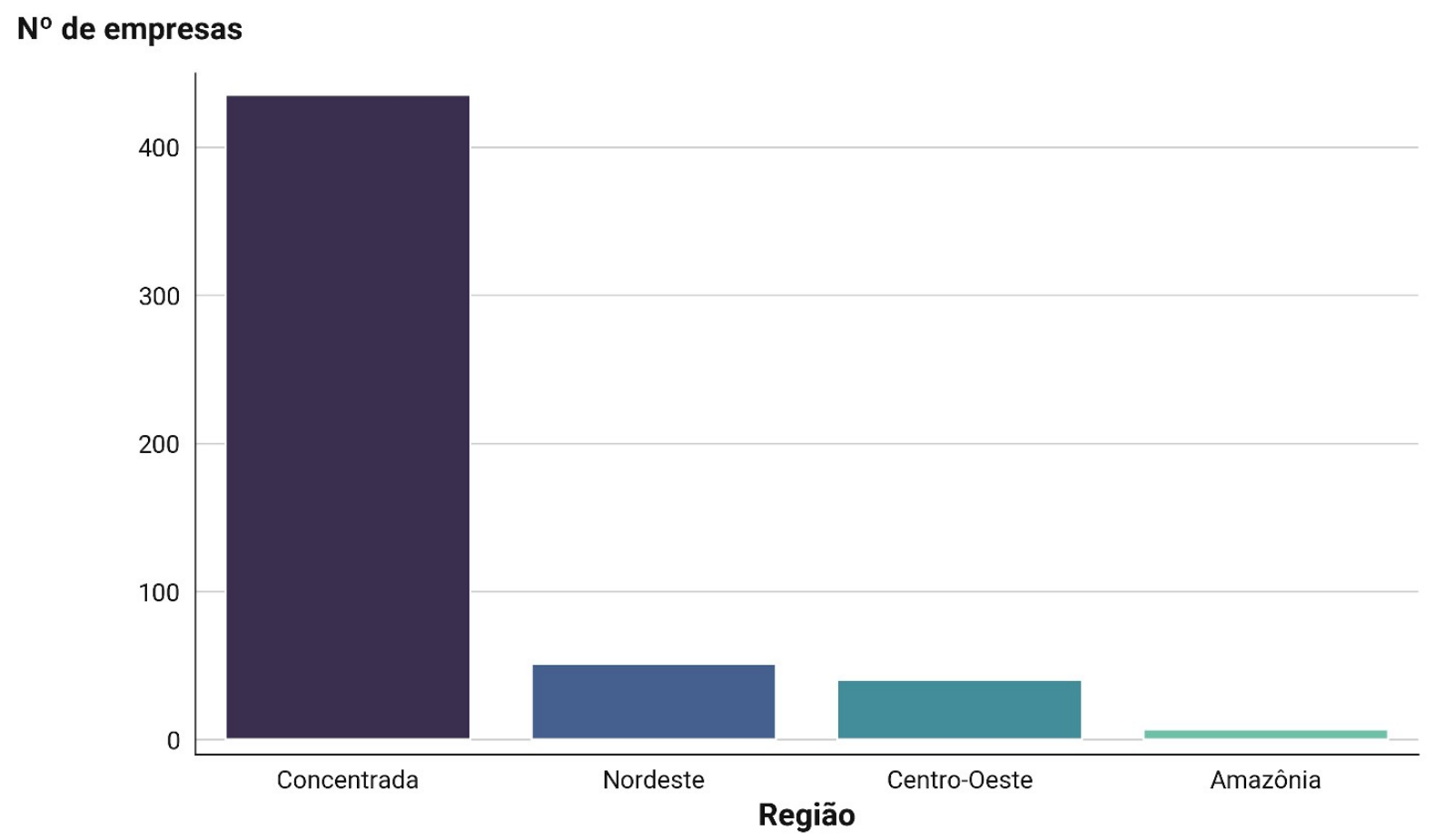

Fonte: Receita Federal, 2020. Elaboração própria.

Fonte: elaboração própria, a partir de dados da Receita Federal do Brasil (2020).

As empresas produtoras de software de alto valor agregado, comumente multinacionais, costumam atuar na área de consultoria de sistemas, e as firmas voltadas ao software de baixo valor agregado, ao contrário, trabalham com tarefas mais simples (como geração de códigos ou manutenção de programas), com competição acirrada entre empresas locais, baseada em preço e na interação com os clientes. Nos mapas 2.1 e 2.2 apresentamos, respectivamente, a distribuição regional de empresas produtoras de software e de aplicativos no território brasileiro. O que pode-se notar preliminarmente é a predominância dos centros de gestão do território (estados de São Paulo, Rio de Janeiro e o Distrito Federal) (CORRÊA, 1996) e maior número de estabelecimentos em estados que contam com mais investimentos em parques tecnológicos, tais como Minas Gerais, Pernambuco e os estados da região Sul.

Os gráficos 2.9 a 2.12 e as tabelas 3 e 4 (anexas) detalham os números por 
estado. Para melhor visualização dos dados, os gráficos 2.10 e 2.12 não mostram o estado de São Paulo, onde se localiza a maioria (24.267, ou 48\%) das empresas (ver tabela 3, anexa). Os dados mostram ainda que serviços avançados, como os de intermediação (subclasse CNAE 74.90-1/04), são concentrados em São Paulo - três vezes mais que o segundo colocado, Minas Gerais.

Mapa 2.1. Brasil. Empresas produtoras de software por estado e região (2020).

Brasil. Empresas produtoras de software por unidade da federação e região (2020).

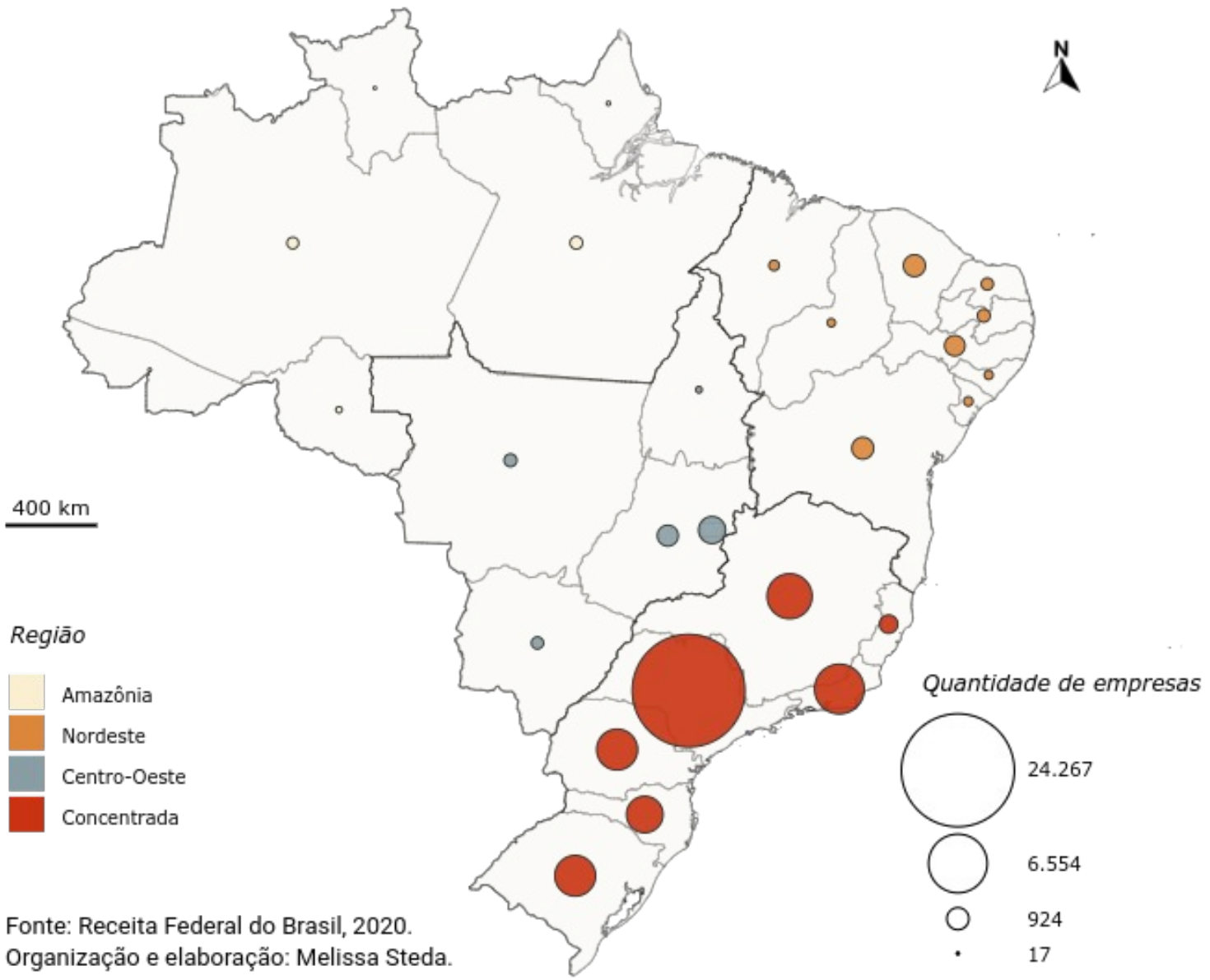

Fonte: elaboração própria, a partir de dados da Receita Federal do Brasil (2020). 
Gráfico 2.9. Brasil. Empresas produtoras de software por unidade da federação (2020).

Brasil. Empresas produtoras de software por unidade da federação (2020)

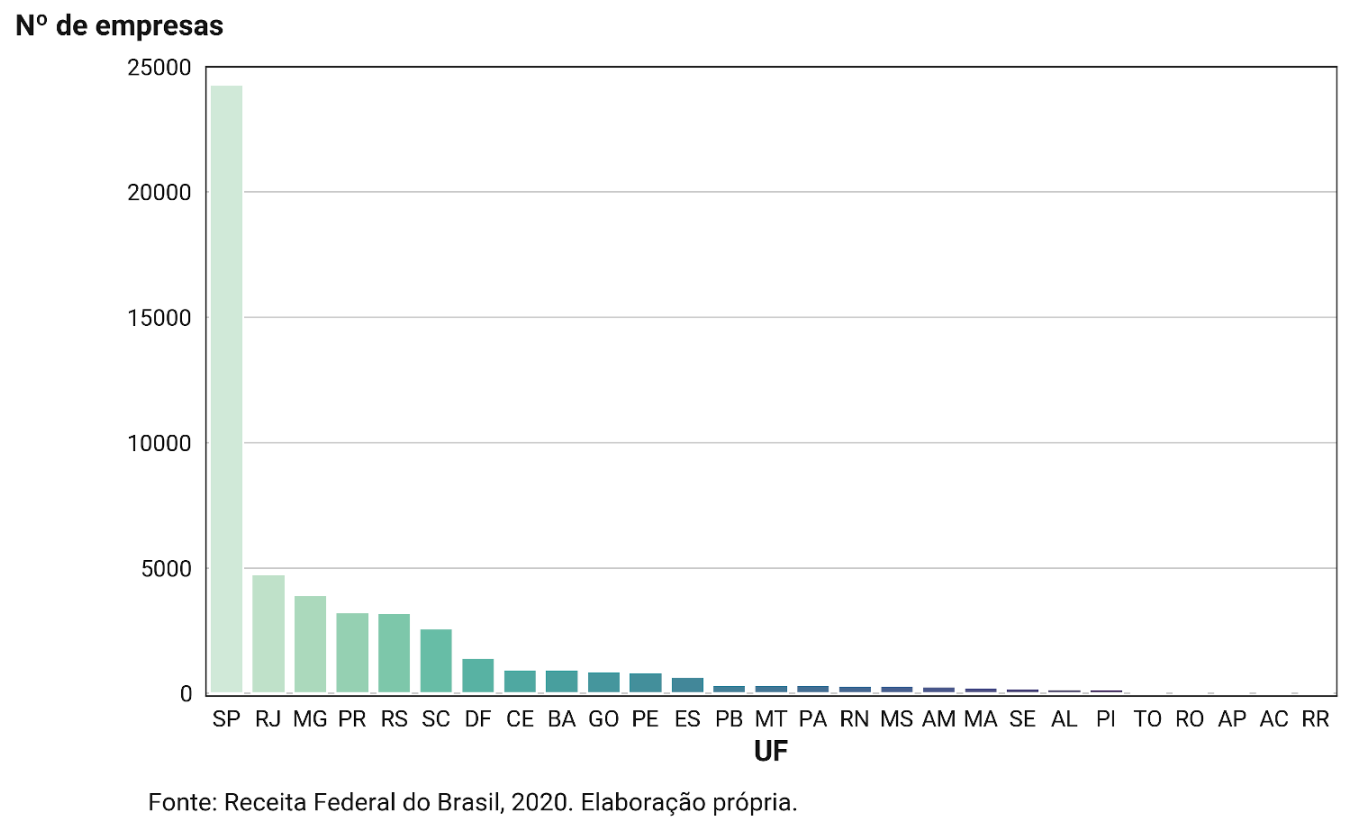

Fonte: elaboração própria, a partir de dados da Receita Federal do Brasil (2020).

Gráfico 2.10. Brasil. Empresas produtoras de software por unidade da federação, excluindo-se São Paulo (2020).

Brasil. Empresas produtoras de software por unidade da federação, excluindo-se SP (2020) $\mathbf{N}^{\circ}$ de empresas

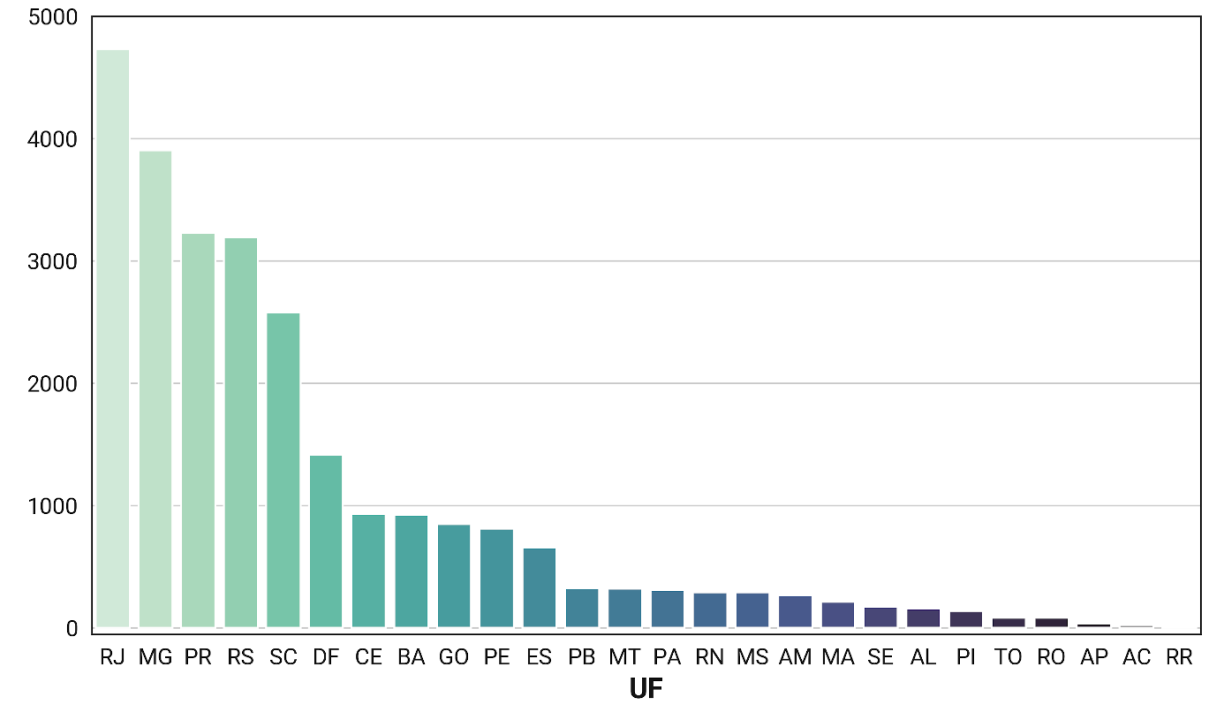

Fonte: Receita Federal do Brasil, 2020. Elaboração própria.

Fonte: elaboração própria, a partir de dados da Receita Federal do Brasil (2020). 
Mapa 2.2. Empresas produtoras de aplicativos por estado (2020).

Brasil. Empresas produtoras de aplicativos por unidade da federação e região (2020).

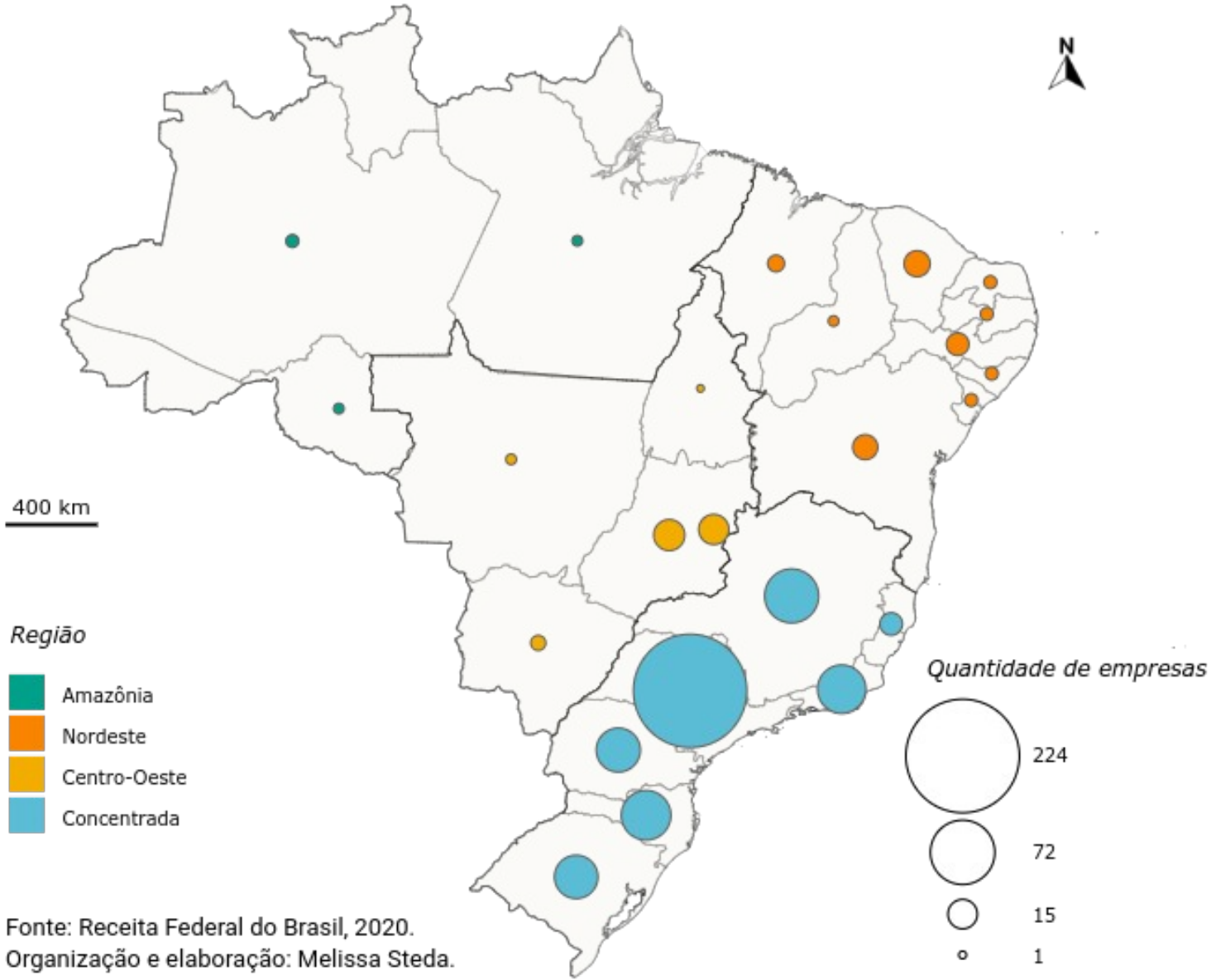

Fonte: elaboração própria, a partir de dados da Receita Federal do Brasil (2020). 
Gráfico 2.11. Brasil. Empresas produtoras de aplicativos por unidade da federação (2020).

Brasil. Empresas produtoras de aplicativos por unidade da federação (2020)

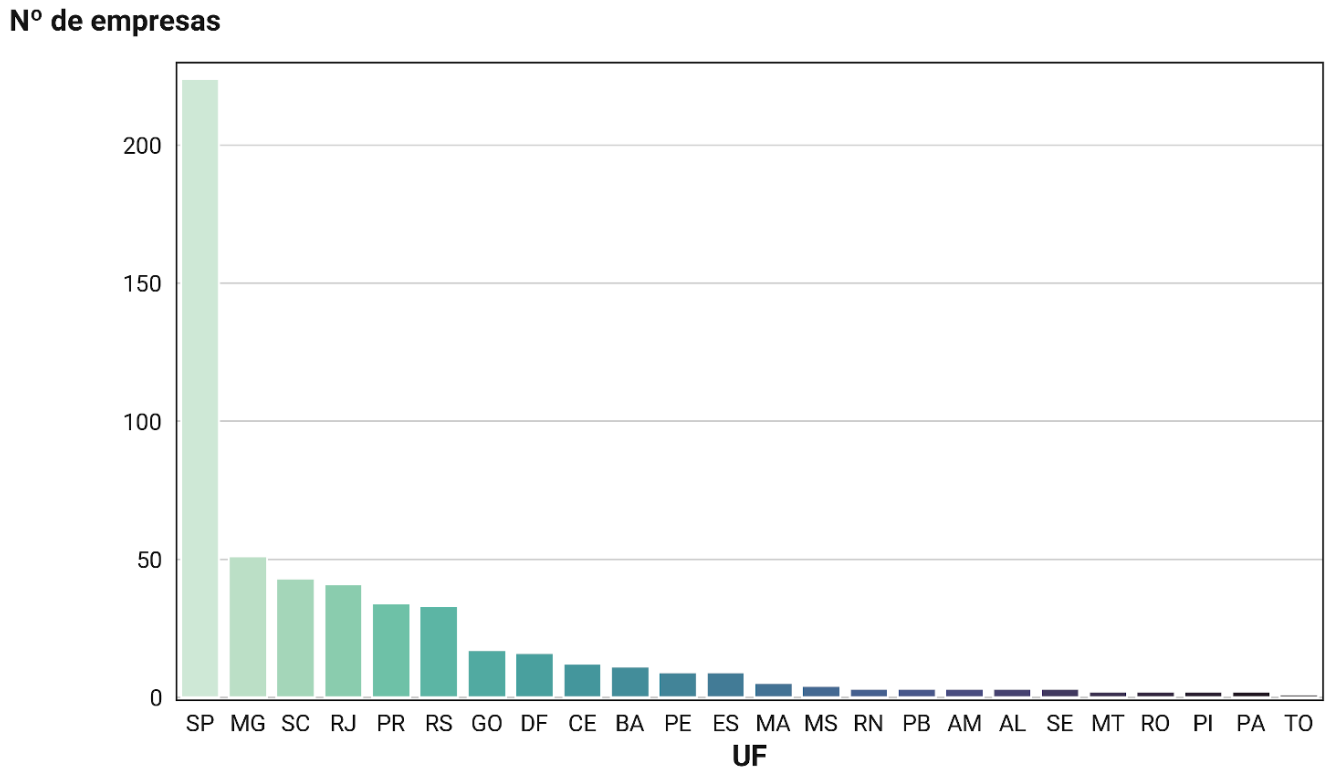

Fonte: Receita Federal do Brasil, 2020. Elaboração própria.

Fonte: elaboração própria, a partir de dados da Receita Federal do Brasil (2020).

Gráfico 2.12. Brasil. Empresas produtoras de aplicativos por unidade da federação, excluindo-se São Paulo (2020).

Brasil. Empresas produtoras de aplicativos por unidade da federação, excluindo-se SP (2020) $N^{\circ}$ de empresas

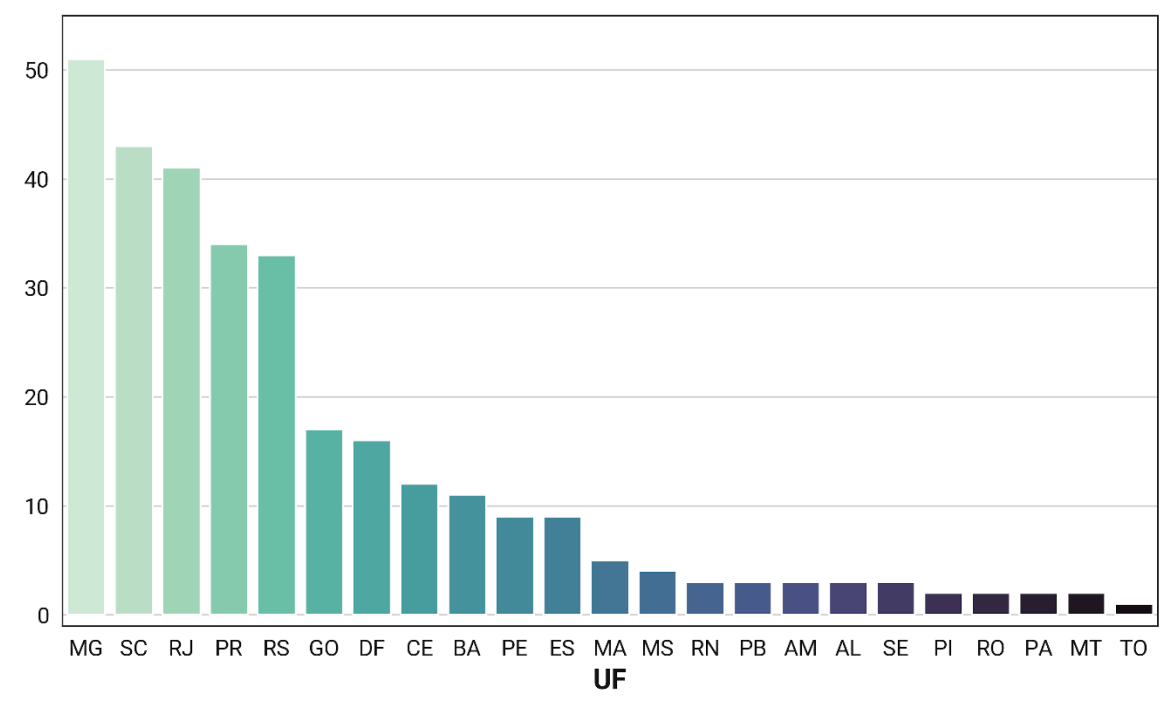

Fonte: Receita Federal do Brasil, 2020. Elaboração própria.

Fonte: elaboração própria, a partir de dados da Receita Federal do Brasil(2020). 
Nos dados de produção de aplicativos por unidade da federação, verifica-se que os seis primeiros estados, todos situados na região Concentrada, são responsáveis por $80 \%$ da produção - uma ligeira queda em relação à produção de software, que mostra que os mesmos estados concentram $83 \%$ das firmas. É nessa porção do território brasileiro que existe maior disponibilidade de redes de conectividade e mão de obra especializada, e também onde tradicionalmente se instalam corporações nacionais e internacionais.

Existem três modelos de produção predominantes no ramo de software, em função do tipo de produto. Eles eram abertamente inspirados na indústria mais tradicional, mas vêm se flexibilizando gradualmente (TENÓRIO; VALLE, 2012, p. 76):

- Produção job-shop: desenvolvimento de produtos individualizados, com projetos únicos para suprir uma necessidade específica do cliente. Portanto, cada projeto deve possuir componentes, ferramentas e regras próprios; a mão-de-obra deve ser altamente qualificada e especializada em tipos de sistemas, e não é facilmente intercambiável. Equipes de trabalho podem ser feitas e desfeitas em função de cada projeto.

- Fábricas flexíveis de projeto e produção de softwares: para fabricar produtos semi-padronizados, derivados de produtos semi-prontos já em estoque. Estes devem ser adaptados, finalizados e configurados para as necessidades específicas de cada cliente.

- Fábricas convencionais de projeto e produção de softwares: lembram, em certo grau, as fábricas fordistas. Os produtos são totalmente padronizados e seus componentes são intercambiáveis. A normalização de procedimentos e métodos de produção permite uma estratégia de economia de escala.

Além disso, segundo a Nomenclatura Brasileira de Serviços (NBS), o SCS pode ser classificado na subposição 1.1506.21.00 - Serviços de hospedagem de aplicativos e programas software como serviço (SaaS), que "inclui o fornecimento de acesso a aplicativos, programas e bancos de dados (...) hospedados em um ambiente centralizado na Internet ('nuvem'), onde todos os clientes podem utilizar 
a mesma solicitação (ambiente multi-inquilino)", com pagamentos mensais ou anuais, sob demanda. Já os aplicativos chamados não personalizados ou customizados são classificados na subposição 1.1502.10 (NBS, 2021).

Carr (2004, p. 54-55) anunciou que os aplicativos passariam a ser disponibilizados como uma grade de opções para uso via Internet de banda larga, numa plataforma com acesso de acordo com o uso. À época, a hoje gigante da computação em nuvem Salesforce já ofertava aplicações web para relacionamento com consumidores com a uma taxa mensal baixa. Seu slogan, "Sucesso, não software", já vislumbrava também um futuro em que importa mais estar a par das maiores inovações do que necessariamente produzir software da mesma maneira que antes.

Um exemplo nacional é a Totvs, uma das maiores empresas brasileiras de TI, criada em 1989 pelo fundador da antiga Microsiga, Laércio Cosentino. Ela incorporou mais de 20 fabricantes nacionais de software e sua expansão se deu principalmente por causa de programas para ERP. Em 2015, a Totvs comprou a Bematech, produtora de hardware e softwares para automação comercial, e no ano seguinte, sua receita chegou a $\mathrm{R} \$ 2,2$ bilhões. A corporação possui sede em São Paulo, 4 filiais no Brasil, 52 franquias e 7 unidades em países da América Latina, em 2017; os funcionários somavam, na época, 7.388, sendo 4.070 com curso superior, 941 pós-graduados com especializações, e 56 mestres e doutores. O investimento em pesquisa e desenvolvimento (P\&D) chegava a $\mathrm{R} \$ 1,2$ bilhão no mesmo ano, buscando criar plataformas para inteligência artificial, Internet das Coisas, computação em nuvem e big data. 2.105 funcionários atuam nessa área, em unidades em São Paulo, Rio de Janeiro, Joinville, Belo Horizonte e Porto Alegre, além do Totvs Labs em Mountain View, no Vale do Silício (Califórnia, Estados Unidos) (ZAPAROLLI, 2017, p. 75-76).

Um caso de plataforma criada para aprimorar serviços já oferecidos a clientes é o Fluig, para colaboração, processos e gestão de conteúdo. A Carol é uma plataforma de inteligência artificial para negócios, e outros produtos foram desenvolvidos para agroindústria, recursos humanos e automação comercial, em parceria com laboratórios de universidades e aplicação de testes automatizados, 
para reduzir o tempo de trabalho. Já no ramo de varejo, a loja-laboratório Omnistory, no Shopping Villa Lobos (zona oeste de São Paulo/SP) utiliza programas da Totvs para unir vendas físicas e por comércio eletrônico tanto pelo navegador Web quanto por aplicativos, utilizando ferramentas como os chatbots ("robôs de chat" que servem como assistentes virtuais para troca de mensagens entre clientes e empresas). Na loja física, uma câmera conectada à plataforma Carol reconhece o cliente, acessa seu perfil e histórico de compras e realiza sugestões e ofertas individualizadas em displays digitais; a compra é concluída em um ponto de venda móvel instalado em smartphones dos vendedores, o que dispensa a necessidade de caixas. Toda a gestão de estoques, crédito, fluxo de caixa e recolhimento fiscal é feita pelo ERP da Totvs (ZAPAROLLI, 2017, p. 77) - um exemplo de programa que sofreu modernizações, ainda que continue sendo da alçada da gestão de recursos, denotando o consumo produtivo de softwares.

Um ramo no qual os aplicativos têm se popularizado muito, e no qual o território tem especial relevância é o de transporte. Além das plataformas que se denominam "intermediadoras de caronas", como Uber, 99 e Cabify, no transporte rodoviário de passageiros se conformou um nicho que funciona no limite da regulação. Alguns exemplos são Clickbus, 4Bus, Aguiaflex, WeMobi, Outlet de Passagens e Guichê Virtual, oferecidos tanto como aplicativo instalável no celular quanto via navegador web.

Mais intrigante é o caso do aplicativo Buser, que permite comprar passagens de ônibus cujas viagens partem de locais alternativos aos terminais rodoviários. Investigando seus dados por meio do CNPJ, pode-se verificar que suas atividades são listadas com os códigos CNAE 62.03-1/00 (desenvolvimento de programas de computador não-customizáveis) e 74.90-1/04 (atividades de intermediação). Mas a empresa também possui uma holding sediada nos Estados Unidos, num endereço no estado de Delaware - conhecido por oferecer vantagens fiscais às firmas que ali se alocam - compartilhado com milhares de outras companhias (WAYNE, 2012).

Em ramos tradicionais da economia que estão sofrendo grandes mudanças por conta dos aplicativos, como transporte e hospedagem, observa-se 
que empresas grandes e pequenas se aproveitam do fato de que a regulação não acompanha as transformações tecnológicas. Estas, por sua vez, são muito mais rápidas do que no passado, quando já se acumulavam novos objetos técnicos e ações mediadas pelas TI, como o emprego de automação e Sistemas de Posicionamento Global (GPS) nos veículos ou vendas pela Internet.

No início da década de 2000 , Silveira (2000, p. 122) já revelava a importância das normas para a circulação de dados, bens e dinheiro. Sendo produtoras de unicidades, elas "participam ativamente no processo direto da produção, com imperativos técnicos, econômicos, administrativos e financeiros, e no processo não-direto da produção, através sobretudo de imperativos políticos". E acrescenta:

Hoje, mais do que antes, a produção especializada e moderna, assim como a circulação veloz de objetos, dados, ideias [e] dinheiro em suas diversas formas somente pode ser feita a partir de regulações. É também assim que o território se especializa e o seu próprio uso e funcionamento é prescrito através de normas (SILVEIRA, 2000, p. 122).

Ainda que o uso de software seja mais facilmente notado em áreas de maior densidade urbana - com maior disponibilidade de redes técnicas -, trata-se de um produto que media atividades no campo e na cidade, compreendendo, portanto, a totalidade do espaço geográfico. Todo o território brasileiro usa, potencialmente e de diversas maneiras, o software como serviço; a especificidade do campo diz respeito sobretudo à agricultura científica, modernizada. A partir disso, podemos supor que o território brasileiro está informatizado, porém de forma heterogênea, em função de uma forte seletividade espacial, sobretudo do ponto de vista da tecnosfera. Nesse sentido, o produto software como serviço circula pelas infovias que estão distribuídas de modo desigual pelo território e conforma uma divisão territorial do trabalho a partir da nova economia digital.

No território brasileiro, não é raro encontrar, em pequenas e grandes cidades e nos dois circuitos da economia urbana (SANTOS, 2004), os serviços de informática, muito difundidos espacialmente. Já o segmento de software-produto parece ser mais restrito, possivelmente dominado por firmas multinacionais 
(SOFTEX, 2002, p. 27), tanto no caso de produtos amplamente consumidos (como o sistema operacional Windows e o pacote Office, ambos da estadunidense Microsoft) como em segmentos mais específicos da economia, provavelmente por requerer altos investimentos pré-venda em inovação tecnológica, marketing e pesquisa de mercado. Por outro lado, no Brasil empresas do varejo têm feito aquisições ou lançamentos de empresas dos chamados "serviços de informação", como é o caso do Magazine Luiza com o Luizalabs, criado para o desenvolvimento de novos produtos e serviços digitais.

Cada lugar é alvo de sucessivas e simultâneas divisões do trabalho ao longo do tempo, diretamente ligadas aos fluxos e aos circuitos de produção. Assim é que se formam solidariedades entre elementos herdados e novos, assinalando diversas combinações técnicas e sociais do trabalho a cada momento histórico (SANTOS; SILVEIRA, 2011, p. 144). A tecnosfera se apresenta no Brasil com uma Região Concentrada, somada a pontos e manchas; já a psicosfera característica do atual período histórico é mais generalizada, porém encontra resistências baseadas em modos regionais de viver, diante dos novos padrões de comportamento trazidos pela globalização (SANTOS; SILVEIRA, 2011, p. 103). Esses fatores se associam à concentração industrial na porção centro-sul do Brasil, que leva à concentração das mudanças tecnológicas (SPOSITO, 2019, p. 44), como mostram os dados sobre a produção de aplicativos. Pode-se notar, por exemplo, que a maior presença de empresas produtoras de software e aplicativos se sobrepõe à densidade populacional (Mapas 2.3 e 2.4) e às cidades mais influentes na rede urbana brasileira (Mapa 2.5). 
Mapa 2.3. Brasil. Municípios com empresas produtoras de software e densidade populacional (2020).

Brasil. Municípios com empresas produtoras de software e densidade populacional por unidade da federação (2020)

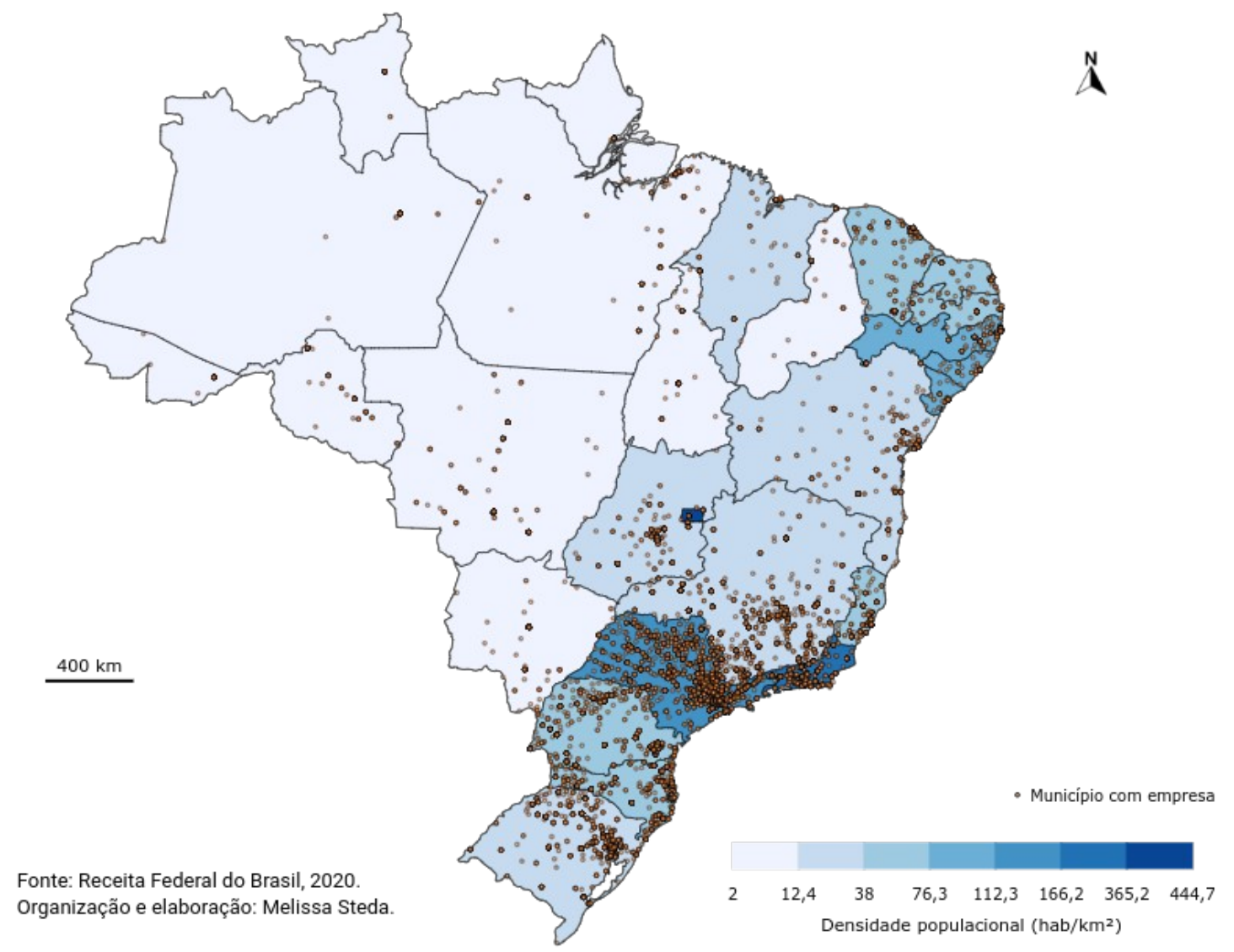

Fonte: elaboração própria, a partir de dados da Receita Federal do Brasil (2020). 
Mapa 2.4. Brasil. Municípios com empresas produtoras de aplicativos e densidade populacional (2020).

Brasil. Municípios com empresas produtoras de aplicativos e densidade populacional por unidade da federação (2020)

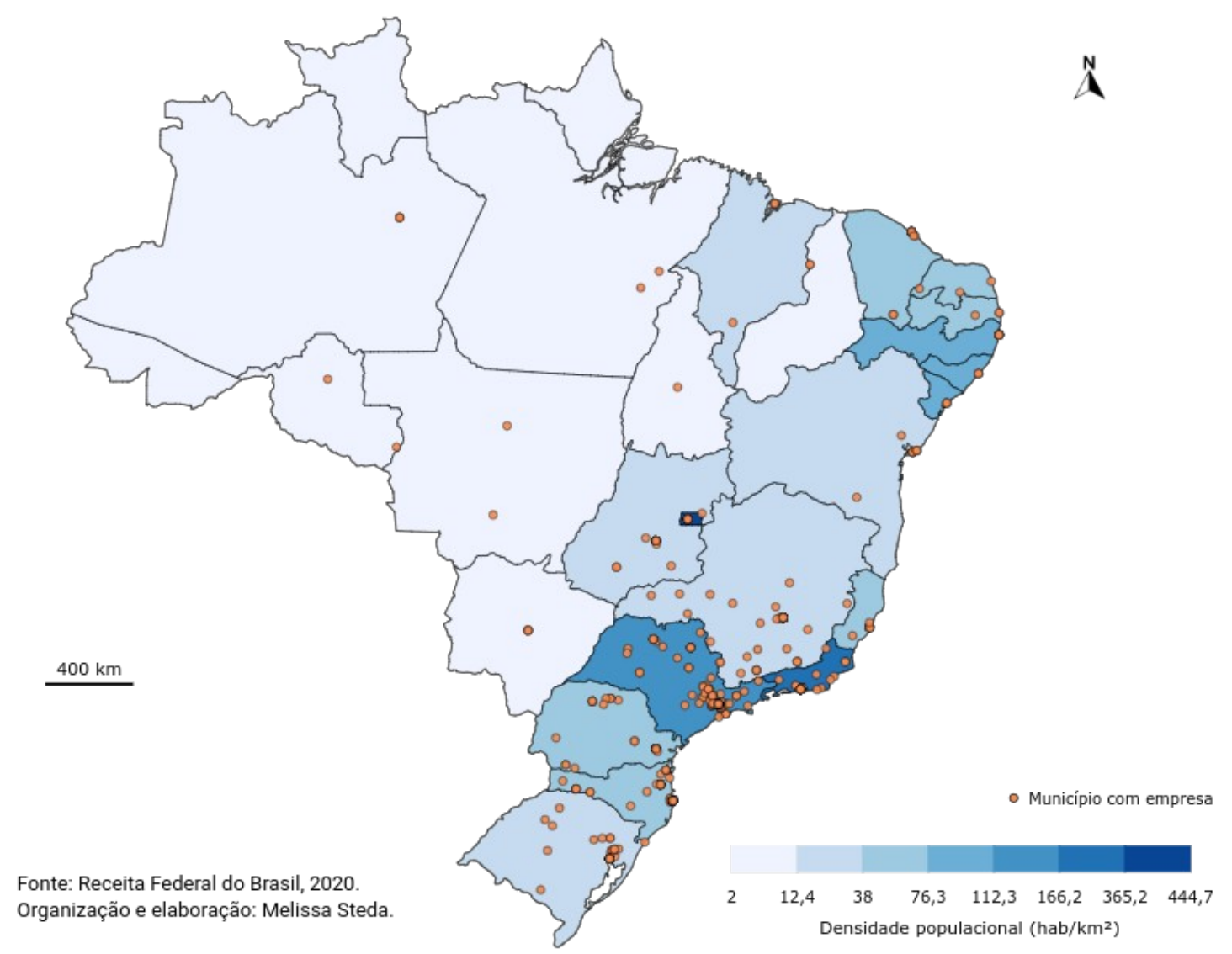

Fonte: elaboração própria, a partir de dados da Receita Federal do Brasil (2020). 
Mapa 2.5. Regiões de Influência das Cidades ${ }^{31}$.

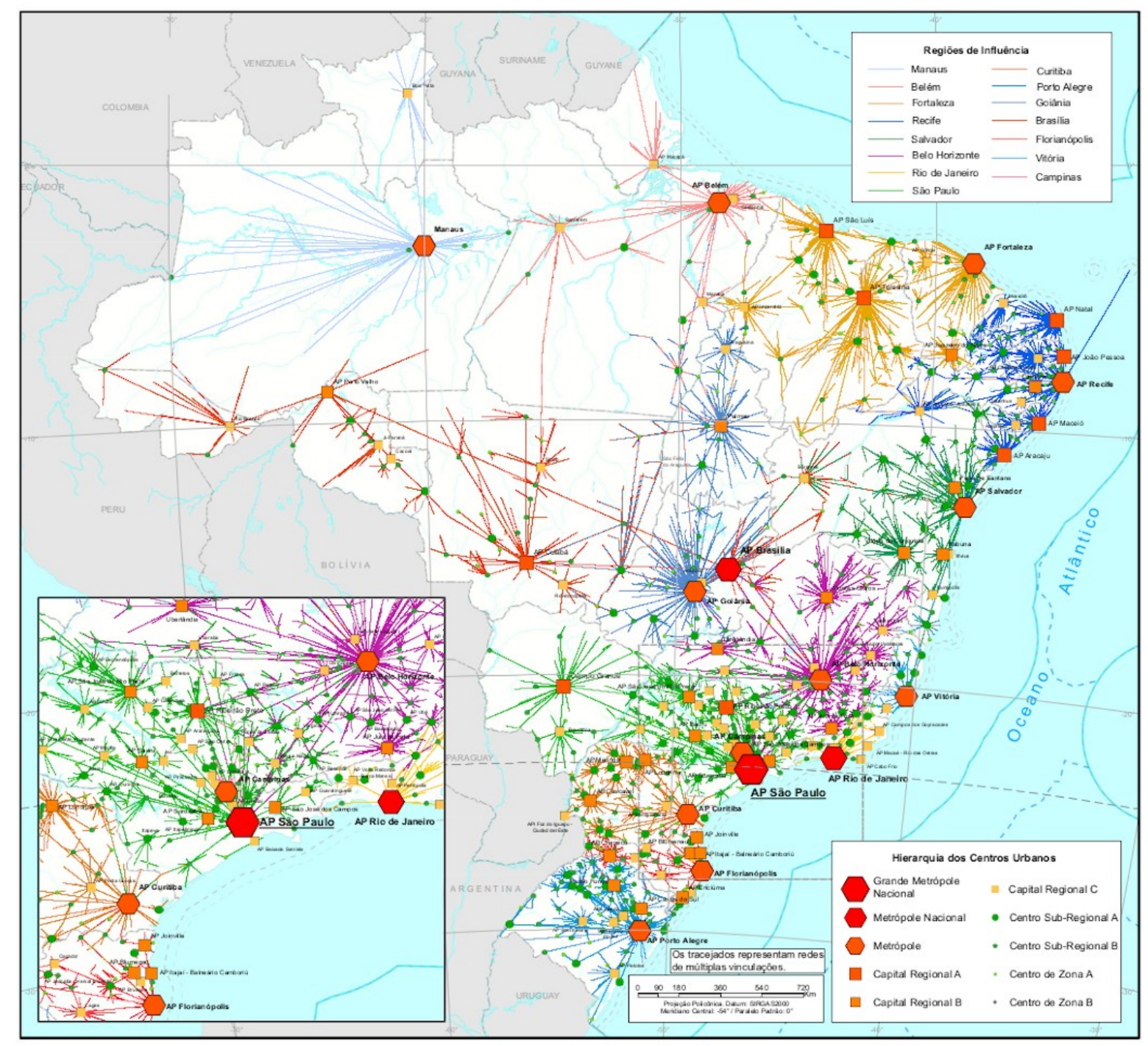

Fonte: IBGE (2020).

A cartografia que apresentamos reforça a divisão territorial do trabalho pretérita, que se aprofunda e se perpetua mesmo diante das transformações no espaço geográfico e continua sendo ditada pelas forças do mercado. Esse processo é visualizado ainda mais claramente nas empresas classificadas como produtoras somente de aplicativos. Entre os nexos territoriais que explicam a localização das firmas, como o grande número delas na região Concentrada, não há apenas a

31 A hierarquia e a região de influência das cidades são estabelecidas considerando funções de comando em atividades tanto empresariais quanto de gestão pública e a capacidade de suprir bens e serviços para outras cidades, gerando ligações por conta da atuação de instituições públicas e privadas presentes nos centros urbanos. "No nível mais alto da hierarquia urbana encontram-se as 15 Metrópoles com suas respectivas regiões de influência (Redes de primeiro nível)” (IBGE, 2020). 
densidade demográfica, mas também fatores como a disponibilidade da tecnosfera e a concentração de empresas de outros ramos, por sua vez condicionada por razões econômicas, sociais e históricas.

A existência de outras empresas do ramo de TI permite que se forneçam mutuamente serviços de software, tais como armazenamento, segurança, infraestrutura, suporte etc., compondo-se círculos de cooperação no território que intensificam seu uso corporativo. Ademais, metrópoles como São Paulo têm uma função centralizadora de fluxos e investimentos financeiros e informacionais que a torna ainda mais atrativa ao capital. Indo além no tema das concentrações e sobreposições de fatores, os mapas 2.6 a 2.16 mostram uma forte conexão entre a topologia das empresas produtoras de softwares e aplicativos, aglomerações produtivas e capitais de estado. Nos detalhes, destacamos cada região, segundo Santos e Silveira (2011).

Mapa 2.6. Brasil. Empresas produtoras de software e capitais de estado (2020).

Brasil. Empresas produtoras de software por região (2020)

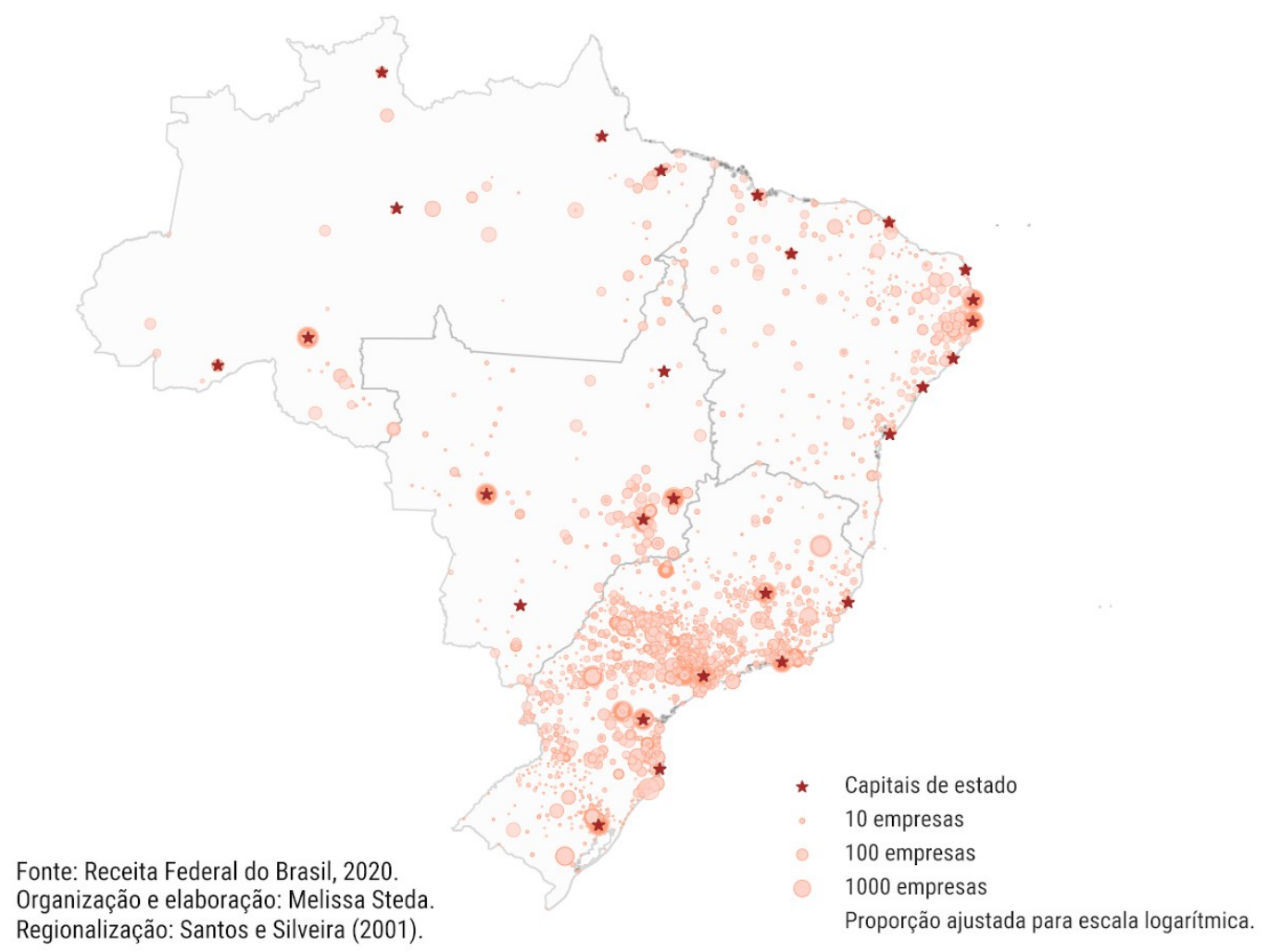

Fonte: elaboração própria, a partir de dados da Receita Federal do Brasil (2020). 
Mapa 2.7. Brasil. Empresas produtoras de software e aglomerações produtivas (2020).

Brasil. Empresas e aglomerações produtoras de software por região (2020)

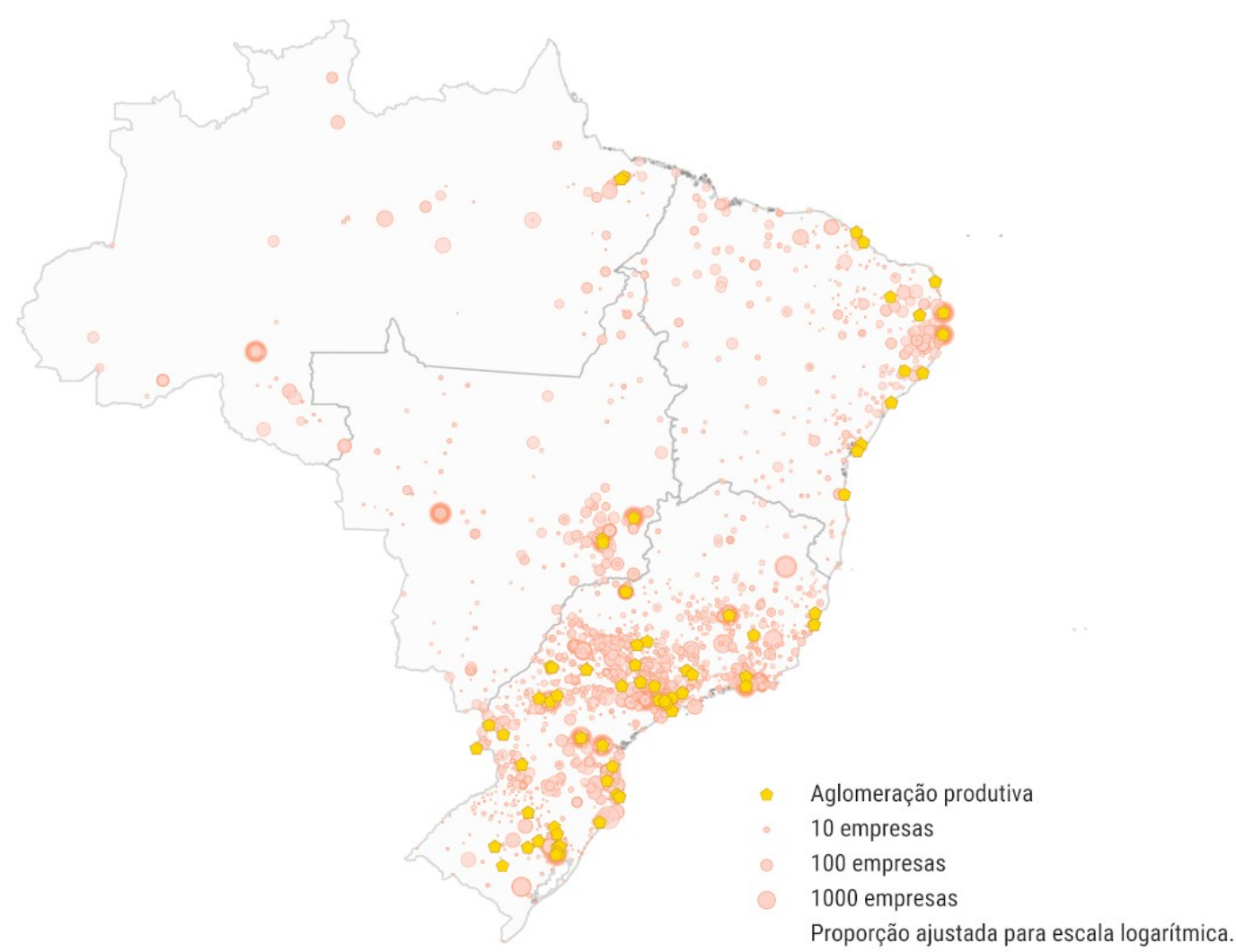

Fontes: Receita Federal do Brasil, 2020; Observatório Brasileiro de APLs (2021); Steda (2015).

Organização e elaboração: Melissa Steda.

Regionalização: Santos e Silveira (2001).

Fonte: elaboração própria, a partir de dados da Receita Federal do Brasil (2020), Observatório Brasileiro de APLs (2021) e Steda (2015). 
Mapa 2.8. Brasil. Empresas produtoras de aplicativos, aglomerações produtivas e capitais de estado (2020).

Brasil. Empresas produtoras de aplicativos por região e município (2020)

Fonte: Receita Federal do Brasil, 2020.

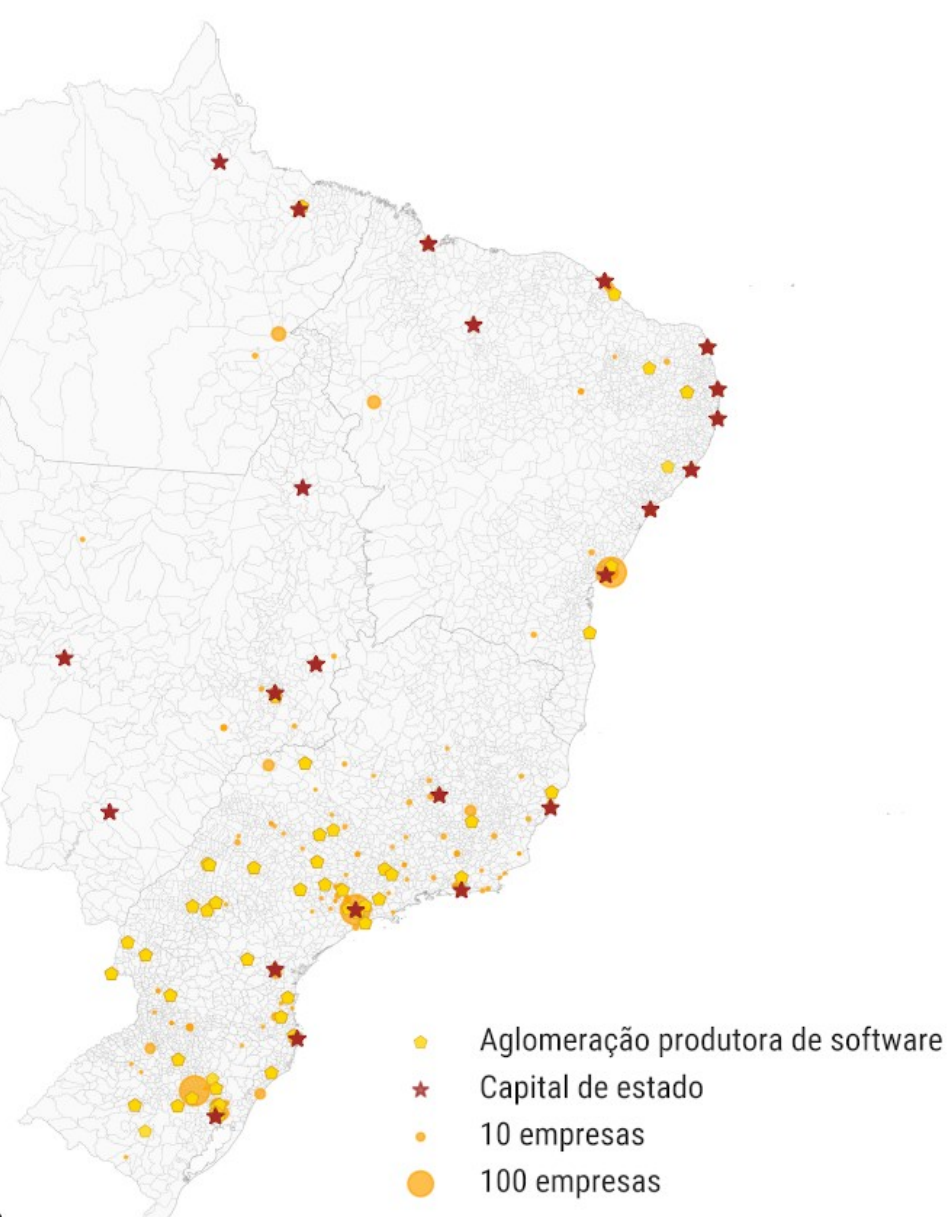

Organização e elaboração: Melissa Steda.

Regionalização: Santos e Silveira (2001).

Fonte: elaboração própria, a partir de dados da Receita Federal do Brasil (2020). 
Mapa 2.9. Região Concentrada. Empresas produtoras de software, aglomerações produtivas e capitais de estado (2020).

Região Concentrada. Municípios com empresas produtoras de software (2020)

Fontes: Receita Federal do Brasil, 2020; Observatório Brasileiro de APLs (2021); Steda (2015).

Organização e elaboração: Melissa Steda.

Fonte: elaboração própria, a partir de dados da Receita Federal do Brasil (2020). 
Mapa 2.10. Região Concentrada. Empresas produtoras de aplicativos, aglomerações produtivas e capitais de estado (2020).

Região Concentrada. Empresas produtoras de aplicativos por município (2020)

Fontes: Receita Federal do Brasil, 2020; Observatório Brasileiro de APLs (2021); Steda (2015). Organização e elaboração: Melissa Steda.

Fonte: elaboração própria, a partir de dados da Receita Federal do Brasil (2020). 
Mapa 2.11. Região Nordeste. Empresas produtoras de software, aglomerações produtivas e capitais de estado (2020).

Região Nordeste. Municípios com empresas produtoras de software (2020)

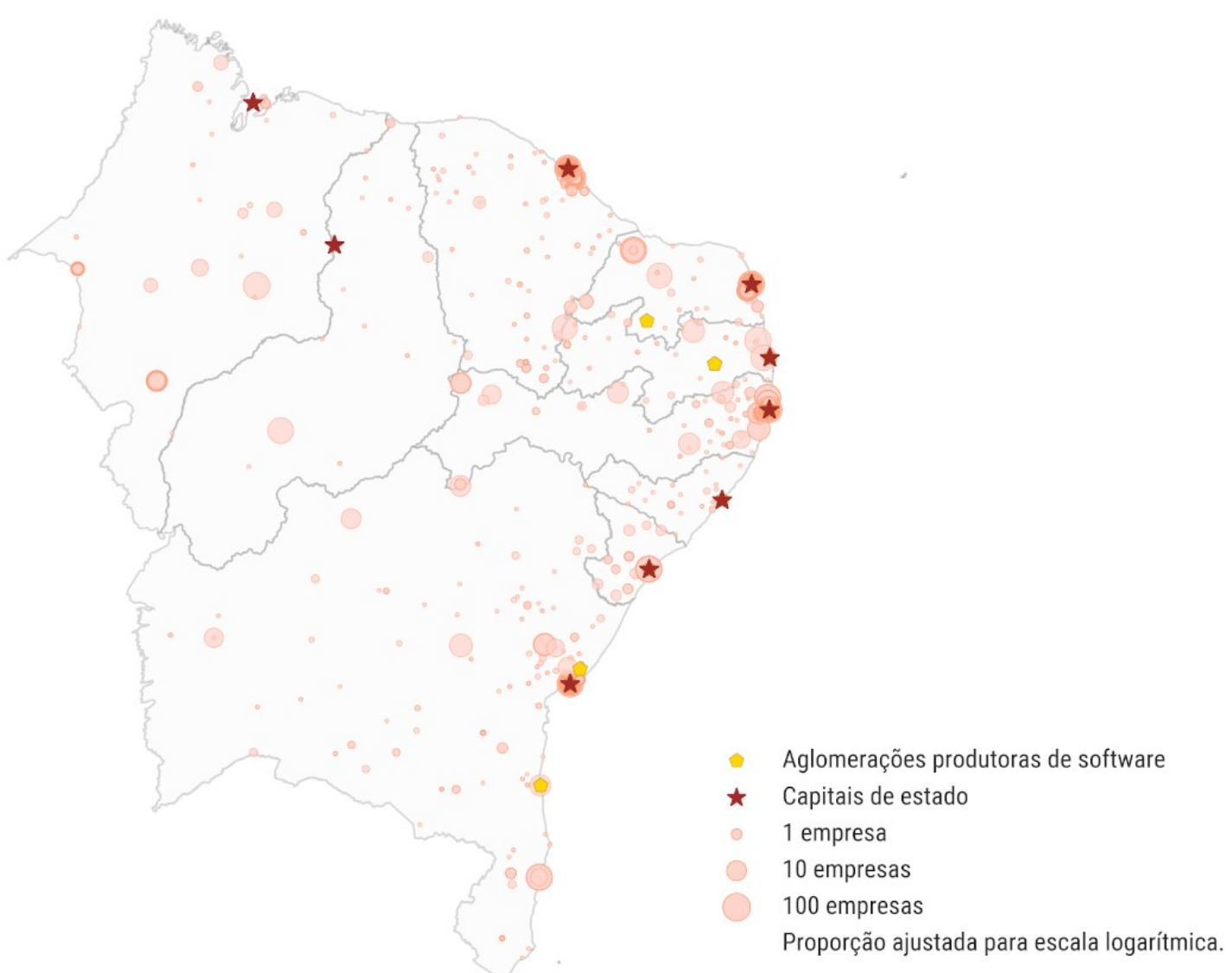

Fontes: Receita Federal do Brasil, 2020; Observatório Brasileiro de APLs (2021); Steda (2015).

Organização e elaboração: Melissa Steda.

Fonte: elaboração própria, a partir de dados da Receita Federal do Brasil (2020). 
Mapa 2.12. Região Nordeste. Empresas produtoras de aplicativos, aglomerações produtivas e capitais de estado (2020).

\section{Região Nordeste. Empresas produtoras de aplicativos por município (2020)}

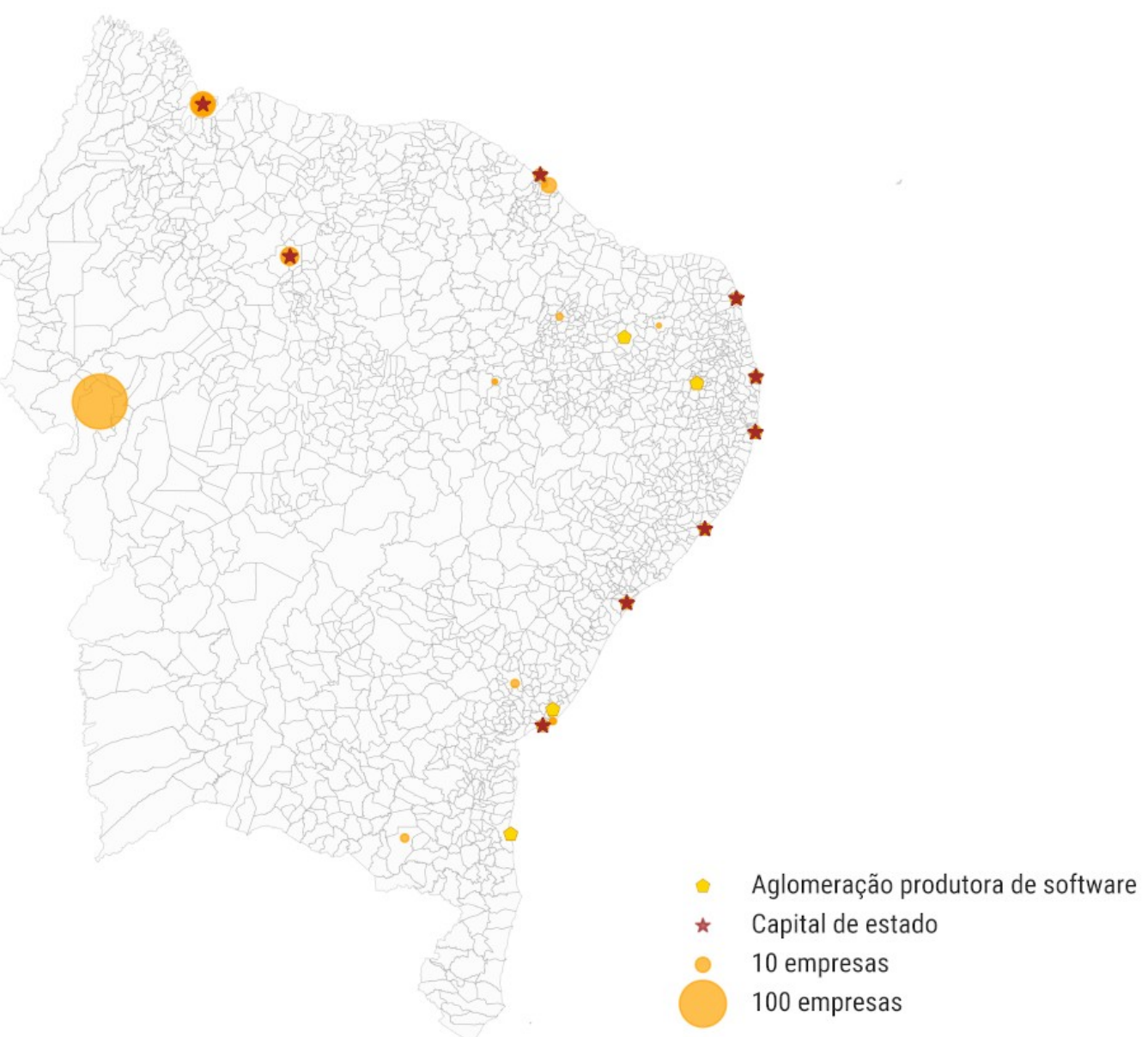

Fontes: Receita Federal do Brasil, 2020; Observatório Brasileiro de APLs (2021); Steda (2015). Organização e elaboração: Melissa Steda.

Fonte: elaboração própria, a partir de dados da Receita Federal do Brasil (2020). 
Mapa 2.13. Região Centro-Oeste. Empresas produtoras de software, aglomerações produtivas e capitais de estado (2020).

Região Centro-0este. Municípios com empresas produtoras de software (2020)

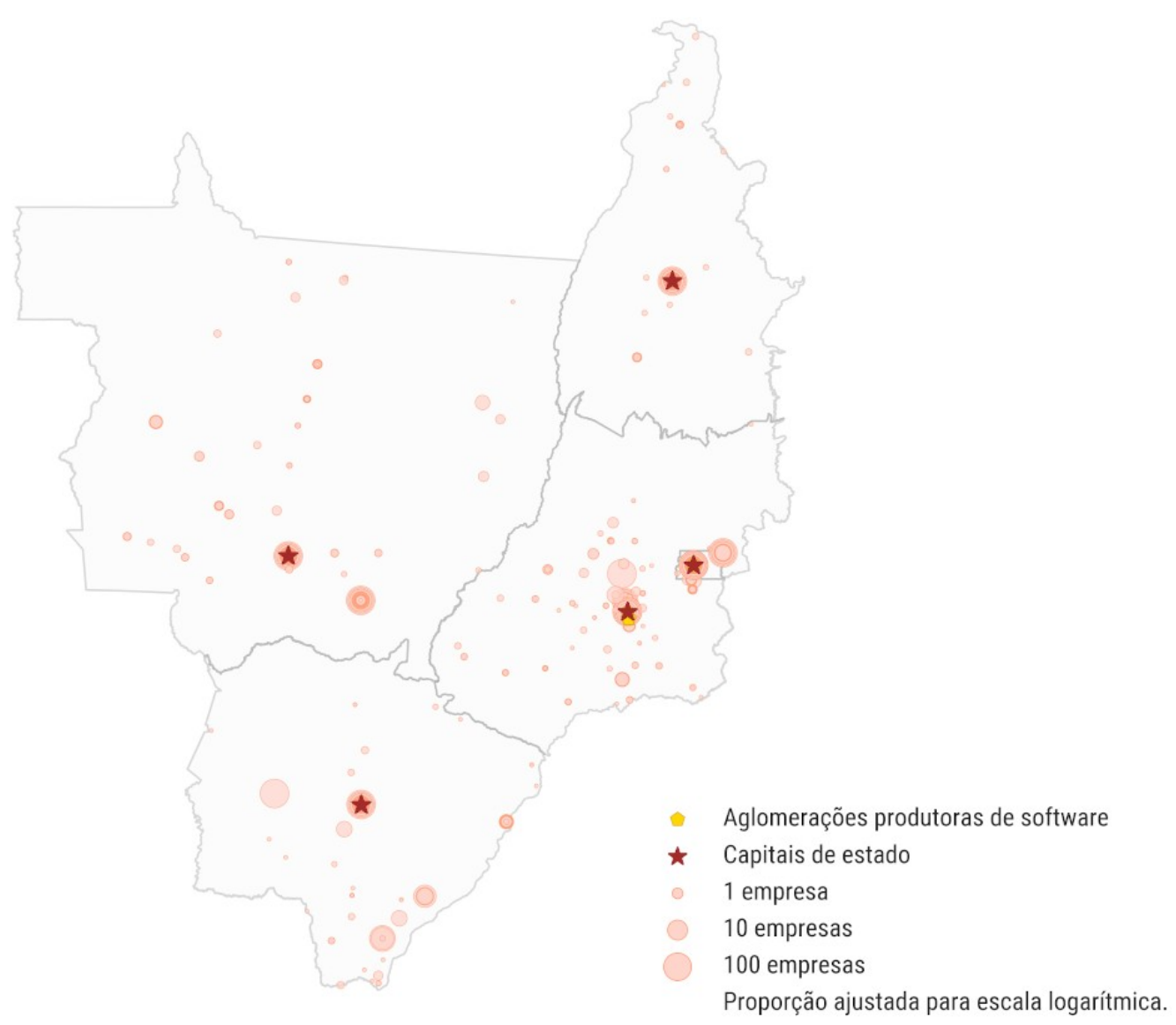

Fontes: Receita Federal do Brasil, 2020; Observatório Brasileiro de APLs (2021); Steda (2015).

Organização e elaboração: Melissa Steda.

Fonte: elaboração própria, a partir de dados da Receita Federal do Brasil (2020). 
Mapa 2.14. Região Centro-Oeste. Empresas produtoras de aplicativos, aglomerações produtivas e capitais de estado (2020).

Região Centro-0este. Empresas produtoras de aplicativos por município (2020)

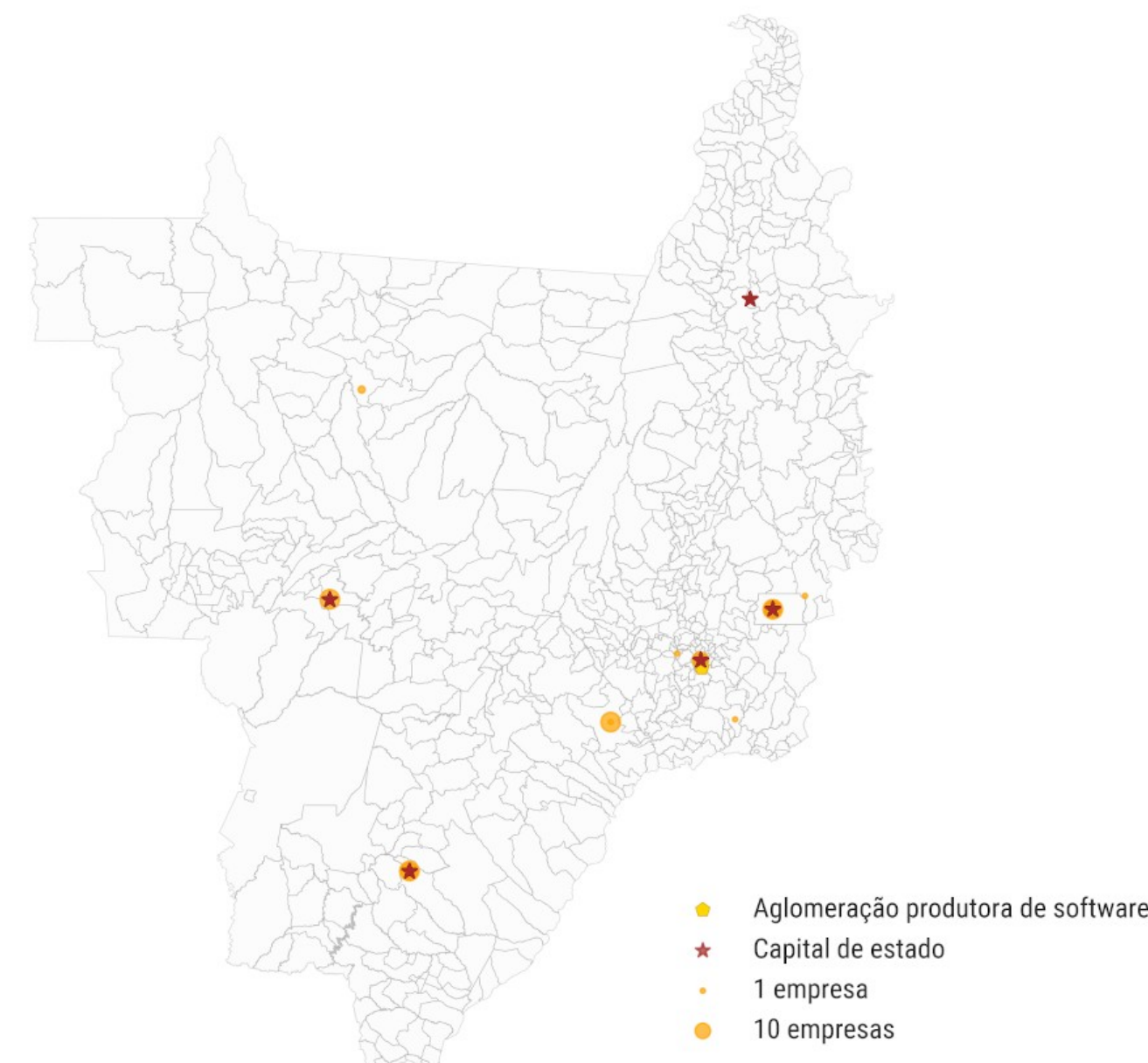

Fontes: Receita Federal do Brasil, 2020; Observatório Brasileiro de APLs (2021); Steda (2015). Organização e elaboração: Melissa Steda.

Fonte: elaboração própria, a partir de dados da Receita Federal do Brasil (2020). 
Mapa 2.15. Região Amazônia. Empresas produtoras de software, aglomerações produtivas e capitais de estado (2020).

Região Amazônia. Municípios com empresas produtoras de software (2020)

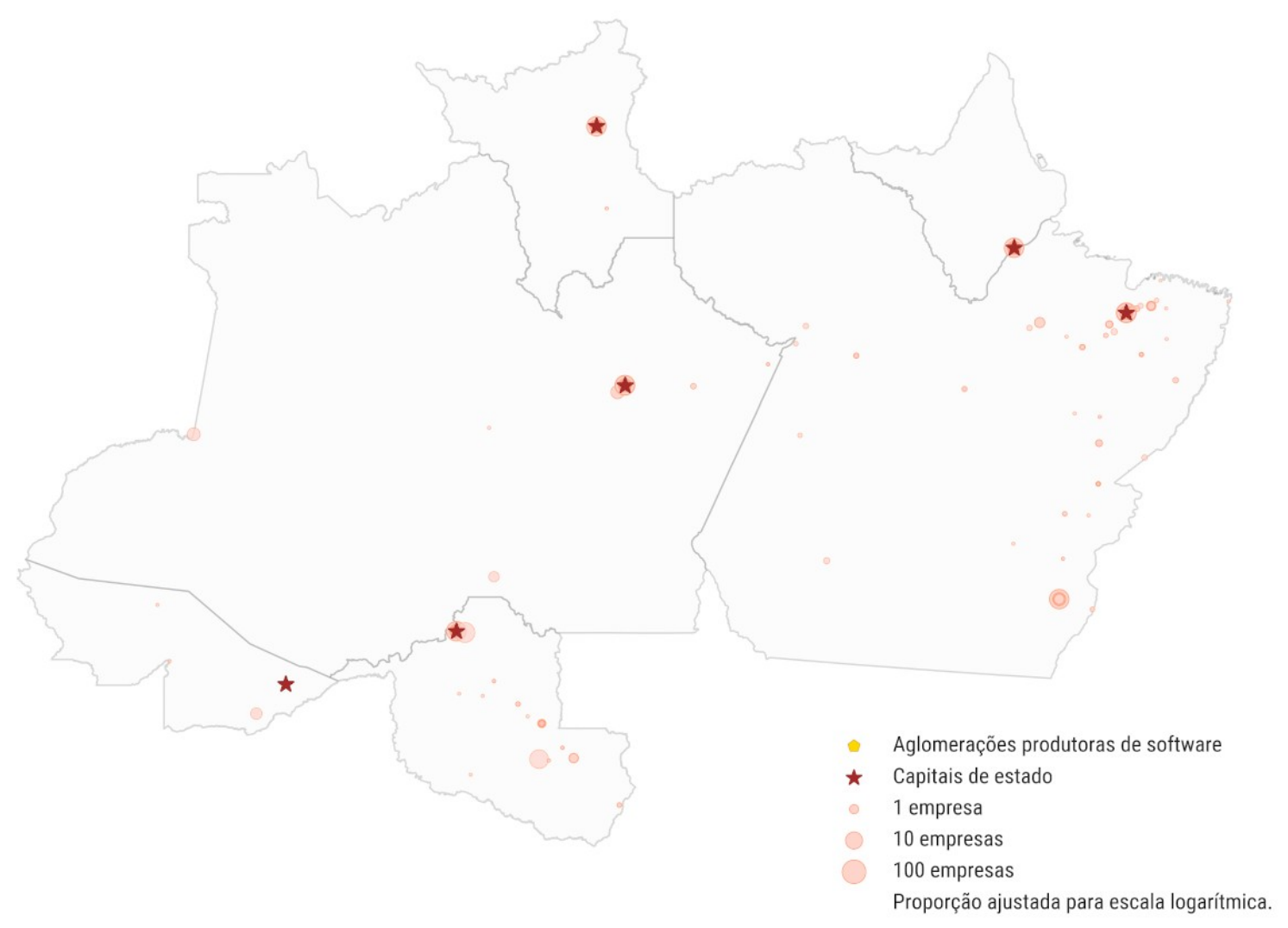

Fontes: Receita Federal do Brasil, 2020; Observatório Brasileiro de APLs (2021); Steda (2015).

Organização e elaboração: Melissa Steda.

Fonte: elaboração própria, a partir de dados da Receita Federal do Brasil (2020). 
Mapa 2.16. Região Amazônia. Empresas produtoras de aplicativos, aglomerações produtivas e capitais de estado (2020).

Região Amazônia. Empresas produtoras de aplicativos por município (2020)

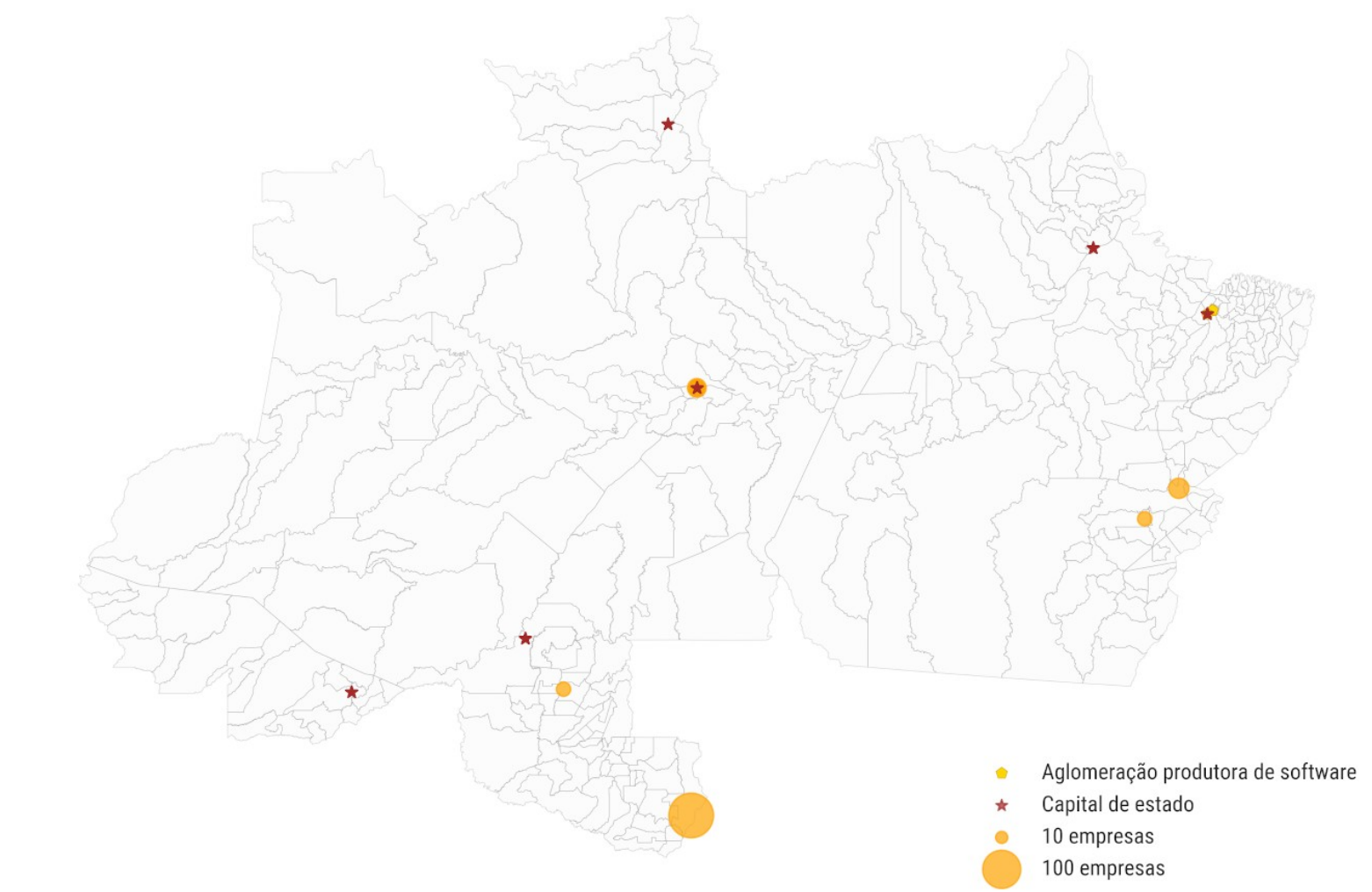

Fontes: Receita Federal do Brasil, 2020; Observatório Brasileiro de APLs (2021); Steda (2015).

Organização e elaboração: Melissa Steda.

Fonte: elaboração própria, a partir de dados da Receita Federal do Brasil (2020).

Utilizou-se a escala logarítmica para amenizar o efeito da concentração no estado de São Paulo ${ }^{32}$, que dificultaria a visualização nos mapas. Esse estado também se destaca por causa da quantidade de municípios, que interfere na contagem de empresas. Pode-se verificar que uma mancha delas povoa a região Concentrada desde a porção norte do Rio Grande do Sul até o sul de Minas Gerais, com uma extensão para o Distrito Federal. Destaca-se a concentração em torno dos

32 De acordo com a Agência Paulista de Promoção de Investimentos e Competitividade (INVESTSP, 2021), “a indústria paulista de fabricação de equipamentos de informática e periféricos concentra, de acordo com o Instituto Brasileiro de Geografia e Estatística (IBGE), 40\% do pessoal ocupado e 40\% do valor de transformação industrial (VTI) do segmento no país (...). Em relação às atividades de serviços de tecnologia da informação e comunicação, segundo o Ministério do Trabalho e Emprego (MTE), São Paulo abriga 32\% das unidades locais do país, respondendo por $44 \%$ do total dos vínculos empregatícios nacionais do setor, concentrados nas Regiões Metropolitanas de São Paulo (RMSP) e Campinas, com 72\% e 4\% dos empregos, respectivamente (2012)". 
centros de gestão do território (São Paulo/SP, Rio de Janeiro/RJ e Brasília/DF). Uma segunda mancha ocorre em torno das capitais do Nordeste ao longo da costa atlântica. Esse padrão se repete com as empresas explicitamente identificadas como produtoras de aplicativos, conforme mostra a cartografia.

Uma correlação forte se desenha com as aglomerações produtivas, especialmente nas regiões Concentrada e Nordeste. Alguns polos tecnológicos e Arranjos Produtivos Locais (APLs) ${ }^{33}$ produtores de TI (ver tabela anexa 6) que se destacam são o Porto Digital (em Recife/PE), Santa Rita do Sapucaí e Uberlândia (MG), Mossoró e Angicos (RN), Oeste Catarinense (SC), Passo Fundo e Pelotas (RS). Grande parte da produção de software se encontra ainda nos parques tecnológicos, que por sua vez estão comumente localizados em universidades nas capitais de estado ou regiões metropolitanas, como ocorre em Porto Alegre (RS), Uberlândia $(\mathrm{MG})$, João Pessoa e Campina Grande (PB), Curitiba (PR), Florianópolis (SC), Campinas e São José dos Campos (SP).

Não necessariamente coincidindo com os polos de tecnologia, nota-se um padrão de grande concentração de empresas - especialmente as produtoras de aplicativos - em função da agricultura científica globalizada e da presença de cursos superiores em tecnologias da informação e agronegócio, incluindo campi de instituições públicas de ensino, como Institutos Federais e universidades federais e estaduais. Observando nos mapas e nos dados disponibilizados pela Receita Federal, os casos mais evidentes são os de Balsas (MA), Vilhena (RO), Jataí (GO), Rondonópolis (MT) e Marabá (PA). Por outro lado, os dados também indicam que um terço dos estados não participa com números significativos da produção nacional de software (ver tabelas anexas 3 e 4). Todos eles estão situados nas regiões Amazônia e Nordeste, com exceção do Tocantins (na região Centro-Oeste).

A localização das atividades intensivas em informação gera especializações produtivas muito interessantes ao capital global. Como aponta Santos (2009, p. 241), "as possibilidades, técnicas e organizacionais, de transferir à

33 Em definição do Ministério da Economia, "Arranjos Produtivos Locais (APLs) são aglomerações de empresas e empreendimentos, localizados em um mesmo território, que apresentam especialização produtiva, algum tipo de governança e mantêm vínculos de articulação, interação, cooperação e aprendizagem entre si e com outros atores locais, tais como: governo, associações empresariais, instituições de crédito, ensino e pesquisa" (BRASIL, 2021). 
distância produtos e ordens, fazem com que essas especializações produtivas sejam solidárias no nível mundial", em função de fatores como a fluidez das redes e a flexibilidade das regulações. Além disso, nos países subdesenvolvidos, as grandes empresas usualmente optam por "instalar-se nas regiões metropolitanas onde, ao lado das infraestruturas econômicas e sociais, das economias de escala e das facilidades de comunicação à distância e interpessoal, [onde] a presença de uma mão-de-obra barata é um encorajamento a mais" (SANTOS, 2008, p. 168).

A modernização tecnológica gera efeitos de especialização e seletividade espacial, de modo que os subespaços mais especializados tornam-se os polos da dinâmica produtiva, enquanto os demais são mais receptores de vetores modernizantes (SANTOS, 2008, p. 257). É exatamente essa dinâmica que se expressa na cartografia apresentada, de modo que concentram-se nas regiões Sudeste e Sul do Brasil "a urbanização, a cientifização da agricultura, a presença de centros de pesquisa e ensino superior, a maior densidade de rodovias, ferrovias e bases materiais das telecomunicações e da teledetecção" (idem), espalhando-se com mais intensidade o meio técnico-científico-informacional do que em outras porções do território, com o apoio de uma psicosfera correspondente.

\subsection{Mudanças socioespaciais na composição da mão de obra no ramo de aplicativos}

Uma tremenda alteração acarretada pelo advento da computação em nuvem foi regulatória, nos modelos de contratação de serviços e de mão de obra em TI. Eles passaram a ser muito mais flexíveis e quase que instantâneos, dependendo da Internet e da nuvem para que os clientes pudessem adquiri-los. Tal modelo trouxe acentuação de certos modos de precarização no trabalho e constitui-se num fator que participa diretamente da aceleração contemporânea.

Segundo a Pesquisa Nacional por Amostra de Domicílios (PNAD) do IBGE de 2019, 17\% dos 23,8 milhões de trabalhadores autônomos no Brasil declararam os 
aplicativos como principal fonte de renda, ou 3,8 milhões de pessoas. De acordo com dados de pesquisa do Instituto Locomotiva, cerca de 17 milhões de brasileiros utilizam os aplicativos para obter alguma renda, incluindo pessoas que trabalham em outras áreas e buscam um complemento com estes serviços.

Conforme apontado por Arroyo (2006, p. 181), “a uma base material adequada para aumentar a fluidez territorial, soma-se uma base normativa que facilita a porosidade do território a partir de regulações flexíveis. A expressão mais acabada desse processo é a configuração do meio técnico-científicoinformacional". No território normado, que vai assimilando as demandas corporativas, se intensifica não apenas a tensão entre público e privado, mas também aquela entre o externo e o interno (ARROYO, 2000, p. 118). Silveira (1997, p. 41) observa, inclusive, que as normas são híbridas e podem ser simultaneamente técnicas, organizacionais e políticas, ou mesmo globais, nacionais ou locais constituindo uma "neo-regulação", e não a ausência do Estado.

As normas que regulam o uso do território são funcionais à competitividade, na medida em que compreendem "diferenças nas legislações nacionais, nas medidas de apoio governamental referentes a produção, investimento, subsídios à pesquisa e ao desenvolvimento etc.". A isso se somam outros fatores, como os instrumentos estatais de política tecnológica (ARROYO, 2009, p. 482). Nexos históricos entre Estado, mercado e território se reinventam e reverberam na complicada regulação do setor. Além disso, uma série de políticas públicas no Brasil mostram o aprofundamento dos vínculos entre os interesses do Estado e do mercado. O Projeto TI Maior já mencionava a computação em nuvem; programas para capacitação de mão de obra, como o Brasil Mais Digital (antigo Brasil Mais TI) têm participação de empresas como Microsoft, Totvs, Accenture e Deloitte. Sobretudo desde os anos 1980, houve uma migração do foco dessas políticas, do hardware para o software (e, mais recentemente, incluindo os serviços em TI).

A respeito de inovações tecnológicas, Possas (2006, p. 33-34) nota que estas devem ter como atributos apropriabilidade, cumulatividade e oportunidade. Eles se complementam entre si e são fundamentais em tecnologias complexas 
(como nas TI), em que são necessários conhecimentos técnicos com uma curva de aprendizado não-instantânea. Daí a pertinência de se encontrar mão de obra especializada, acostumada à prática com o novo dispositivo ou método, e acompanhando as mudanças regulatórias.

Citando Savy e Veltz (1993), Santos (2009, p. 205) afirma que "o novo espaço das corporações é o mundo" - frase especialmente apropriada quando se investigam as estratégias das empresas de tecnologia. A natureza dos produtos de TI (marcada, por exemplo, pelo grande número de bens intangíveis e pelo alto uso de trabalho remoto), em muitos casos, possibilita as condições ideais para a existência de um imenso mercado global. Ressalte-se, entretanto, que cada mercado nacional de software possui aspectos próprios que variam histórica e espacialmente conforme as (também dinâmicas) condições normativas e de conectividade oferecidas por aquele dado território.

Esse processo se vincula à difusão do meio técnico-científicoinformacional: a expansão das redes técnicas e atualizações na "geografia dos fluxos" (neste caso, de informação) estão em sua essência, gerando novas possibilidades de conhecimento sobre o planeta e de comunicação entre os lugares, tudo por meio da informação (ALBAGLI, 2017, p. 34). Isso é especialmente relevante ao investigar-se o software, um produto intangível rapidamente distribuído pela Internet, em oposição à logística tradicional dos bens tangíveis, por meio das redes não-virtuais.

Num sentido técnico, os programas de computador permitem a interoperabilidade entre diferentes objetos, desde que estejam equipados com um chip. Esse atributo tem enormes implicações para uma gama de situações, dos processos produtivos à vida cotidiana. Bruner (2014) chega a afirmar que

Toda empresa é uma empresa de software. O software está se tornando um componente essencial das grandes máquinas, tanto para quem as constrói quanto para seus usuários. Qualquer empresa que possua tais máquinas quer tirar o máximo proveito delas, pela otimização de suas operações com os softwares, e qualquer empresa que constrói essas máquinas deve aprimorá-las com camadas de software para que seja competitiva. Como consequência, uma startup de software com uma tecnologia promissora pode facilmente ser comprada tanto por uma grande 
firma industrial quanto por uma empresa de software do Vale do Silício. Isso tem um importante impacto organizacional, cultural e nas habilidades [dos trabalhadores] (tradução nossa).

Atualmente, as megaempresas que controlam o ramo de aplicativos especialmente Alphabet Inc. (o conglomerado ao qual pertence a Google), Amazon, Apple, Facebook e Microsoft - são responsáveis pelos maiores valores negociados no mercado de capitais mundial. Os modelos de produção de larga escala por elas adotados demandam alto grau de racionalização, pois buscam grande produtividade a custos baixos. Isso leva a um controle estrito da produção e requer maior especialização dos trabalhadores a cada estágio da fabricação do programa, com ocupações que vão de desenhistas a gerentes (Quadro 2.2, com mais detalhes na tabela anexa 5).

Em mais um exemplo de cooperação entre as referidas corporações, a GV (antiga Google Ventures, braço de investimentos da Alphabet Inc.) investiu 258 milhões de dólares na Uber, em 2014 - valor que correspondia a 86\% do orçamento anual de US\$ 300 milhões da empresa, na época. Já o Airbnb possuía, em 2015, valor de mercado superior ao da rede de hotéis Hyatt (mais de 10 bilhões de dólares), antes mesmo de realizar uma oferta pública de ações (Initial Public Offering, ou IPO) no mercado estadunidense (ROCKMANN, 2015, p. 19). Em 2021, ambas as empresas ampliaram seus mercados de atuação, sendo que a Uber Eats (para entrega de refeições) corresponde a mais de $60 \%$ do total dos negócios da firma, enquanto o Airbnb passou a permitir aos usuários cadastrados a oferta de "experiências" (por exemplo, passeios pela cidade), e não apenas de estadias. 
Quadro 2.2. Famílias ocupacionais que desempenham atividades relacionadas com as tecnologias da informação e comunicação, segundo a Classificação Brasileira de Ocupações (CBO).

\section{Código CBO Família ocupacional}

$1236 \quad$ Diretores de serviços de informática

1425 Gerentes de tecnologia da informação

$2021 \quad$ Engenheiros mecatrônicos

2122 Engenheiros em computação

$2123 \quad$ Especialistas em informática

2124 Analistas de sistemas computacionais

2032 Pesquisadores de engenharia e tecnologia

2143 Engenheiros eletroeletrônicos e afins

2612 Profissionais da informação

3001 Técnicos em mecatrônica

3003 Técnicos em eletromecânica

3132 Técnicos em eletrônica

3171 Técnicos em programação

3187 Desenhistas projetistas de eletrônica

3722 Técnicos em operação de máquinas de transmissão de dados

9502 Supervisores de manutenção eletroeletrônica veicular

9531

Eletricistas-eletrônicos de manutenção veicular (aérea, terrestre e naval)

Fonte: Softex (2016), que considerou “o conjunto de atividades realizadas por profissionais pertencentes a 596 famílias ocupacionais listadas na Classificação Brasileira de Ocupações (CBO). Dezessete foram selecionadas por apresentar atividades diretamente relacionadas com o desenvolvimento de produtos ou a prestação de serviços de TIC". Elaboração própria. 
De acordo com o relatório do Fórum Econômico Mundial WEF Future of Jobs (2018), a ocupação mais emergente no Brasil é a de desenvolvedores e analistas de softwares e aplicativos. Na indústria de tecnologias da informação e comunicação, são listados três fatores determinantes para decisões das empresas sobre a localização da força de trabalho: primeiro, a "disponibilidade de talentos"; em seguida, os custos de mão de obra; e, por fim, a localização da matriz da organização (WEF, 2018, p. 72). Os agentes e suas ações no espaço geográfico nos dizem muito sobre a divisão do trabalho, conforme observado por Silveira (2012, p. 217-218): "é importante indagar sobre o conteúdo técnico do trabalho e do lugar, quem comanda e quem impõe os parâmetros de valor", especialmente diante da ascensão do capitalismo de plataforma.

A "disponibilidade de talentos" mencionada pelo Fórum Econômico Mundial pode ser entendida como o suprimento de mão de obra especializada. No caso da produção de software, significa pessoas com formação ou habilidades sobretudo nas áreas das chamadas "STEM" (do inglês, Ciência, Tecnologia, Engenharia e Matemática). Segundo Landivar (2013, p. 6), o desenvolvimento de software emprega $12 \%$ de todos os trabalhadores das áreas "STEM", ou a maior parcela deles. Entretanto, de acordo com a Softex (2002), o Brasil possui um deficit de longa duração em termos de trabalhadores especializados no ramo de TI.

Por outro lado, segundo os dados da Demografia das Empresas e Estatísticas de Empreendedorismo do IBGE (2018), a quantidade de empresas de TI vem crescendo desde 2006 (gráfico 2.13), e tanto o pessoal ocupado (gráfico 2.14) quanto os salários médios mensais (gráfico 2.15) dobraram, no período de doze anos. Porém, ao passo que aumentou a quantidade de trabalhadores entre 2017 e 2018 - após a recente reforma trabalhista no Brasil -, os salários se mantiveram estáveis. 
Gráfico 2.13. Brasil. Número de empresas do ramo de TI (2006-2018).

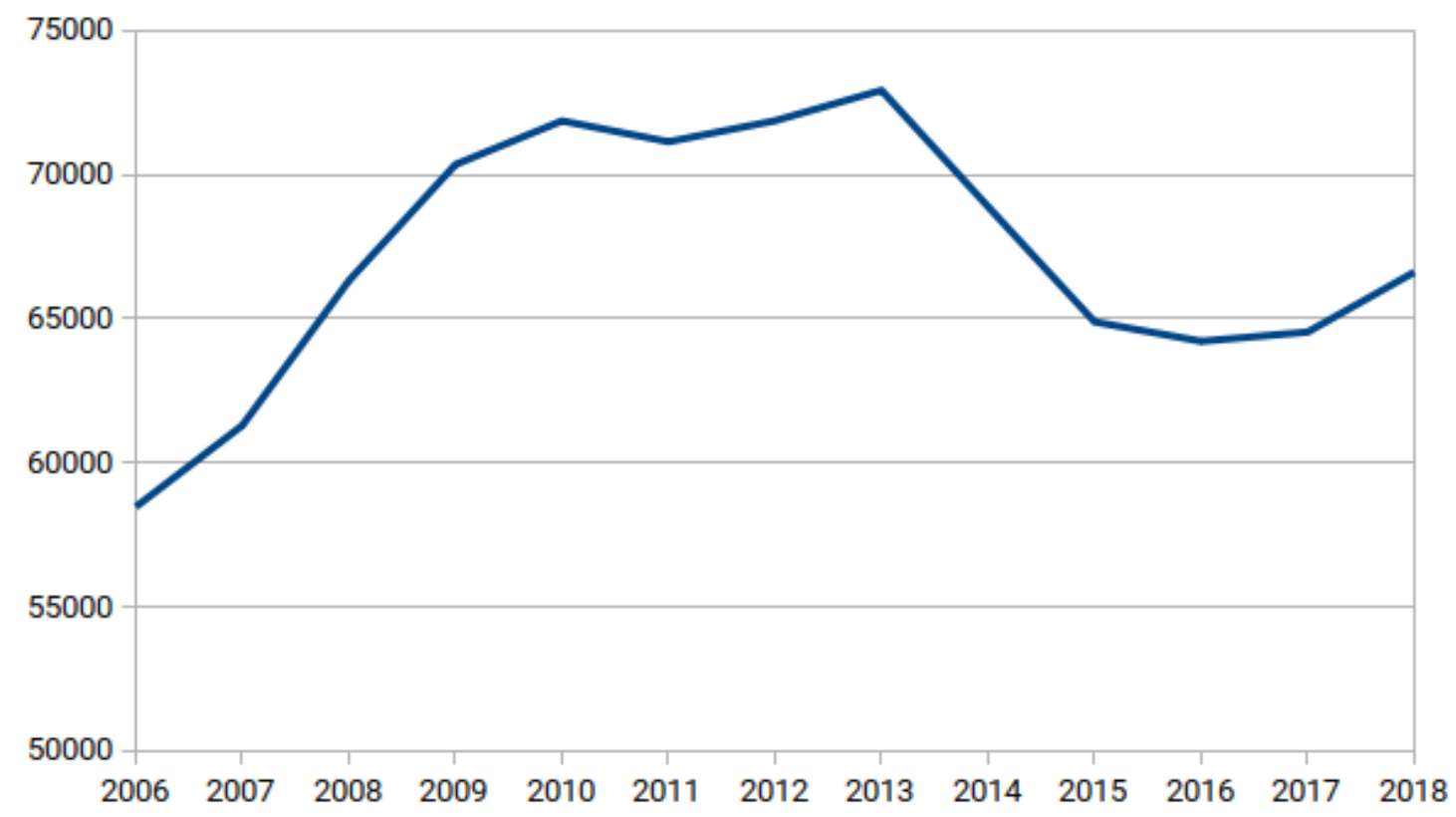

Fonte: elaboração própria, a partir de IBGE (2018).

Gráfico 2.14. Brasil. Pessoal ocupado total no ramo de TI (2006-2018).

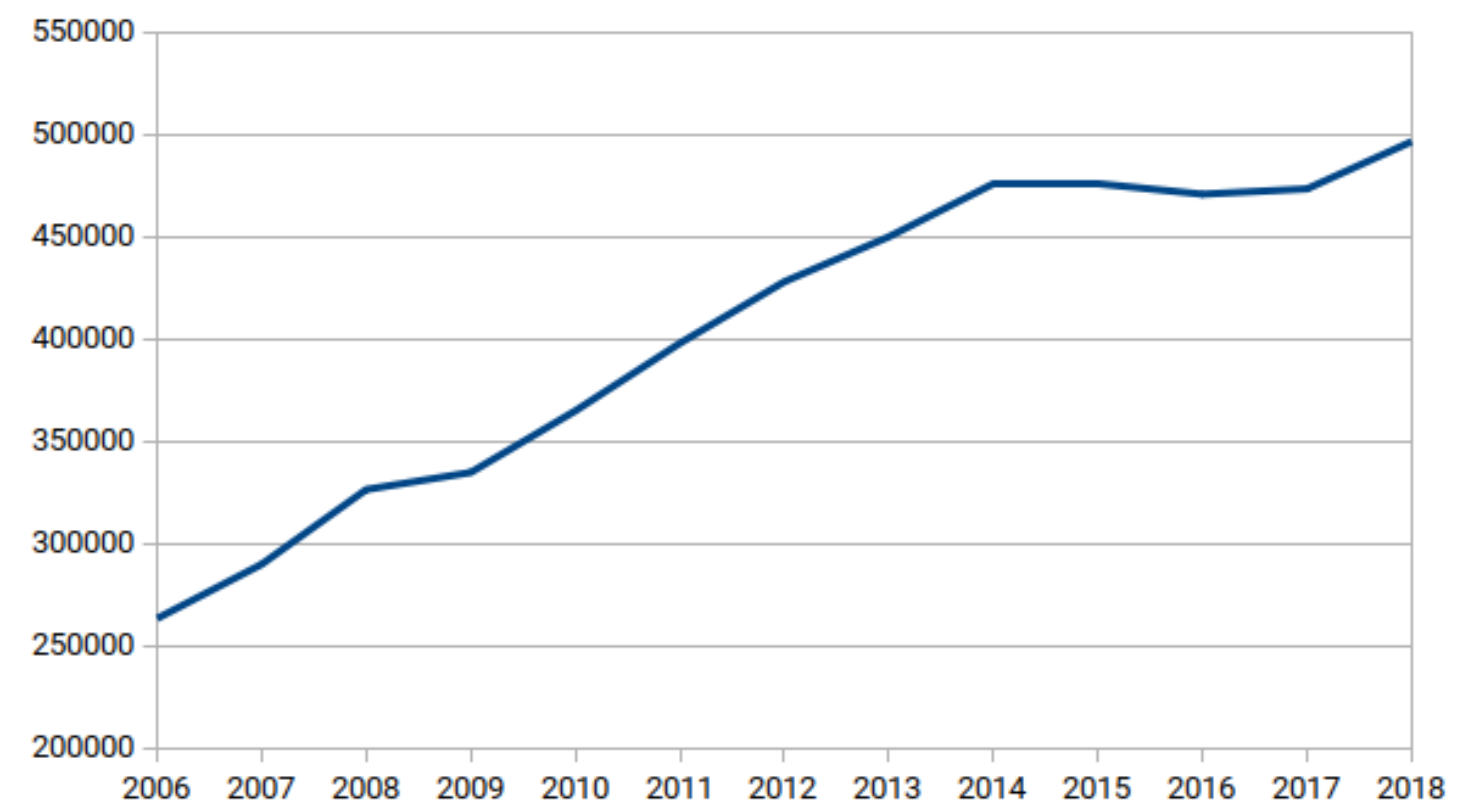

Fonte: elaboração própria, a partir de IBGE (2018). 
Gráfico 2.15. Brasil. Salário médio mensal, em reais, no ramo de TI (2006-2018).

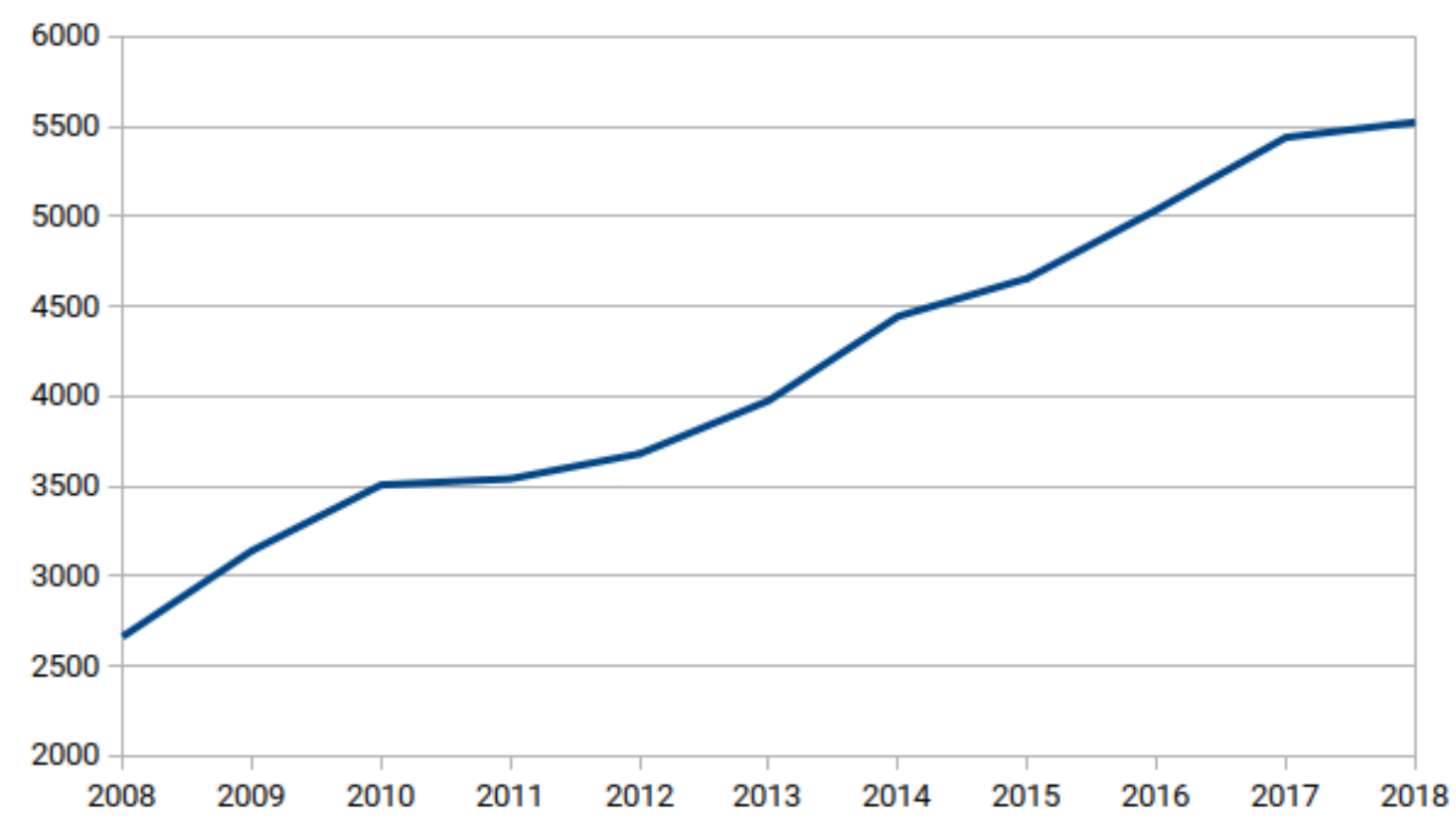

Fonte: elaboração própria, a partir de IBGE (2018).

Ainda assim, especificamente quanto ao software como serviço, os brasileiros representam menos de 3,5\% do total de desenvolvedores de aplicativos para Android, enquanto mais de um quinto deles está localizado nos Estados Unidos (tabela 2.8), reforçando a concentração já existente em relação às empresas e ao capital nesse ramo.

Tabela 2.8. Distribuição de desenvolvedores de aplicativos para Android no primeiro trimestre de 2018 , por país.

\begin{tabular}{lc}
\hline País & \% do total \\
\hline Estados Unidos & 21,23 \\
Índia & 5,72 \\
Alemanha & 5,65 \\
Reino Unido & 5,33 \\
Coréia do Sul & 3,70 \\
Espanha & 3,49 \\
Brasil & 3,47 \\
França & 3,38 \\
Canadá & 3,18 \\
Rússia & 3,00 \\
\hline
\end{tabular}

Fonte: elaboração própria, a partir de Statista (2018). 
Com a popularização da computação em nuvem, grande parte dos contratos de trabalho em desenvolvimento de software, que levavam meses para serem firmados, passou a depender apenas da Internet e do armazenamento remoto para que os clientes pudessem acessá-los e para recrutar funcionários. Esse modelo trouxe consigo a acentuação de certos modos de precarização no trabalho. Os trabalhadores autônomos são parcela cada vez maior da força de trabalho em TI, levados a competir por tarefas como freelancers, de modo precário e mal pago. Nos estudos das "geografias digitais" (ASH et al., 2016) e do trabalho digital, são considerados parte do chamado "infoproletariado" (ANTUNES; BRAGA, 2009), do "novo proletariado de serviços" (ANTUNES, 2020), ou ainda do "ciberproletariado" (DYER-WITHEFORD, 2015).

Tais trabalhadores estão sob a pressão da ideologia da "uberização", um novo estágio de organização, controle e gerenciamento do labor que se baseia na transformação do empregado em um "empreendedor de si mesmo" (ABÍLIO, 2020). Essa tendência alcança as mais diversas ocupações, qualificações e níveis de renda, num processo carregado de insegurança e que classifica os direitos dos trabalhadores como encargos, ainda que se difunda uma psicosfera de flexibilidade e independência ${ }^{34}$.

Abílio (2020, p. 14) aponta que a uberização se assenta em décadas de aniquilação de direitos, de desenvolvimento tecnológico e de liberalização dos fluxos produtivos e de investimento. A especificidade do âmbito das plataformas digitais vem do gerenciamento obscuro dos dados dos trabalhadores por meio de algoritmos, permitindo inclusive a previsão e a indução de seus comportamentos. A autora ainda ressalta que "desprotegidos socialmente, estes [trabalhadores] arcam com riscos e custos de sua atividade, vivem na incerteza sobre sua própria remuneração e carga de trabalho e estão subordinados, sob novas lógicas, a empresas que têm alto poder de monopolização e centralização" (idem).

É muito raro encontrar os trabalhadores da indústria de aplicativos organizados em entidades como os sindicatos, tendo em vista que - mesmo com

34 É importante frisar que, "apesar da visibilidade conferida pela empresa Uber, a uberização não está restrita nem ao setor de transportes nem às plataformas digitais. A perspectiva aqui apresentada vem sendo construída desde 2007, quando termos como crowdsourcing, sharing economy, gig economy ainda não haviam sido formulados" (ABÍLIO, 2020, p. 15). 
tanto alarde sobre um suposto mundo interconectado como nunca e repleto de possibilidades de comunicação - a economia de plataforma dificulta o contato entre colegas de função e com seus superiores. Ainda assim, é possível encontrar exemplos de solidariedade de classe e usos alternativos para as tecnologias, como foi o "Breque dos Apps", paralisação de entregadores organizada em diversas datas e locais durante a pandemia de Covid-19.

Os motoristas são responsáveis por adquirir ou alugar os veículos para trabalhar, além de custear manutenção, seguros, limpeza e multas, enquanto as empresas lucram com taxas entre $20 \%$ e $40 \%$ do que recebem os entregadores, aprofundando a pobreza na economia urbana. As figuras 2.2, 2.3 e 2.4 trazem registros da feira Expo Uber, promovida pela empresa em Santiago (Chile) em 2017, onde pessoas interessadas podiam se registrar como motoristas e entregadores, além de acessar serviços como compra, aluguel e seguro de veículos. Entre as palestras agendadas, havia discursos críticos à regulação do setor, como se isto representasse uma ameaça aos próprios trabalhadores.

Figura 2.2. Apresentação sobre regulação de aplicativos em feira promovida pela Uber (2017).

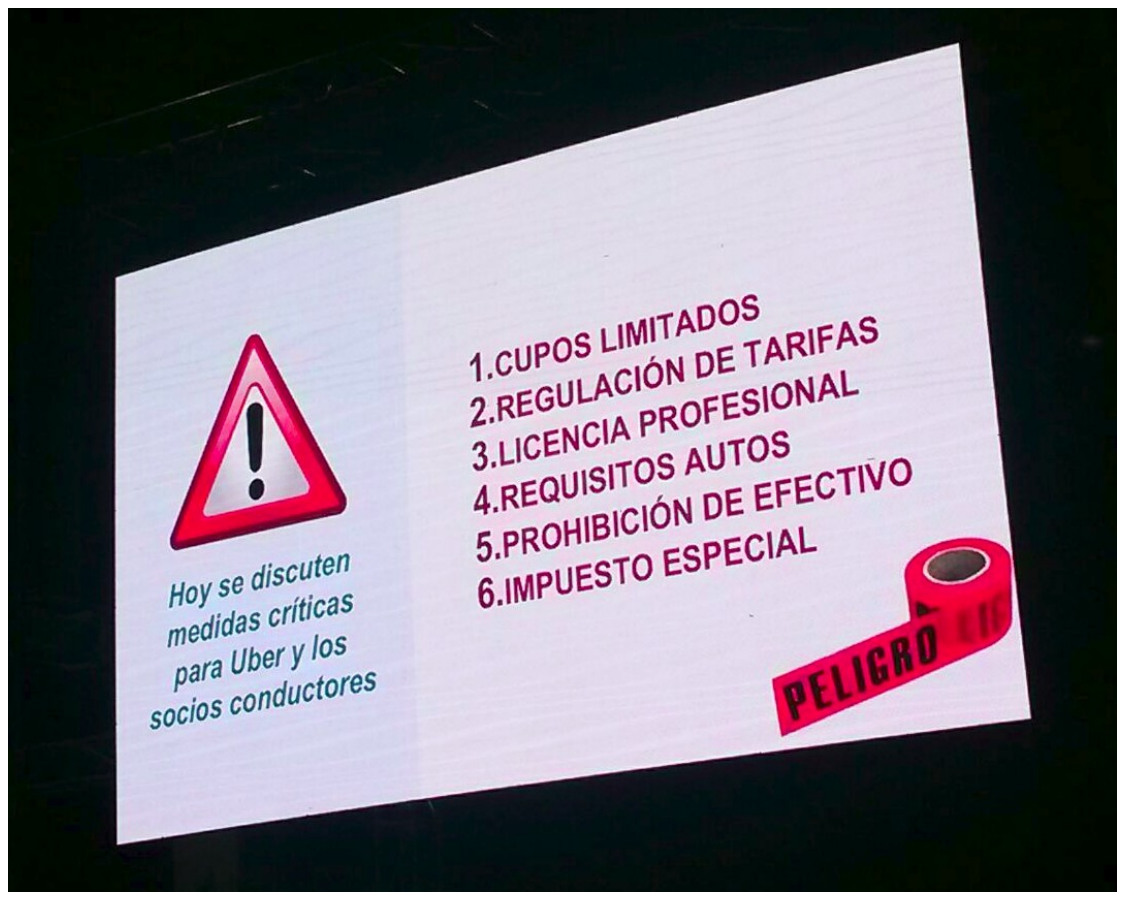

Fonte: autoria própria. 
Figura 2.3. Fabricantes de automóveis presentes em feira promovida pela Uber (2017).

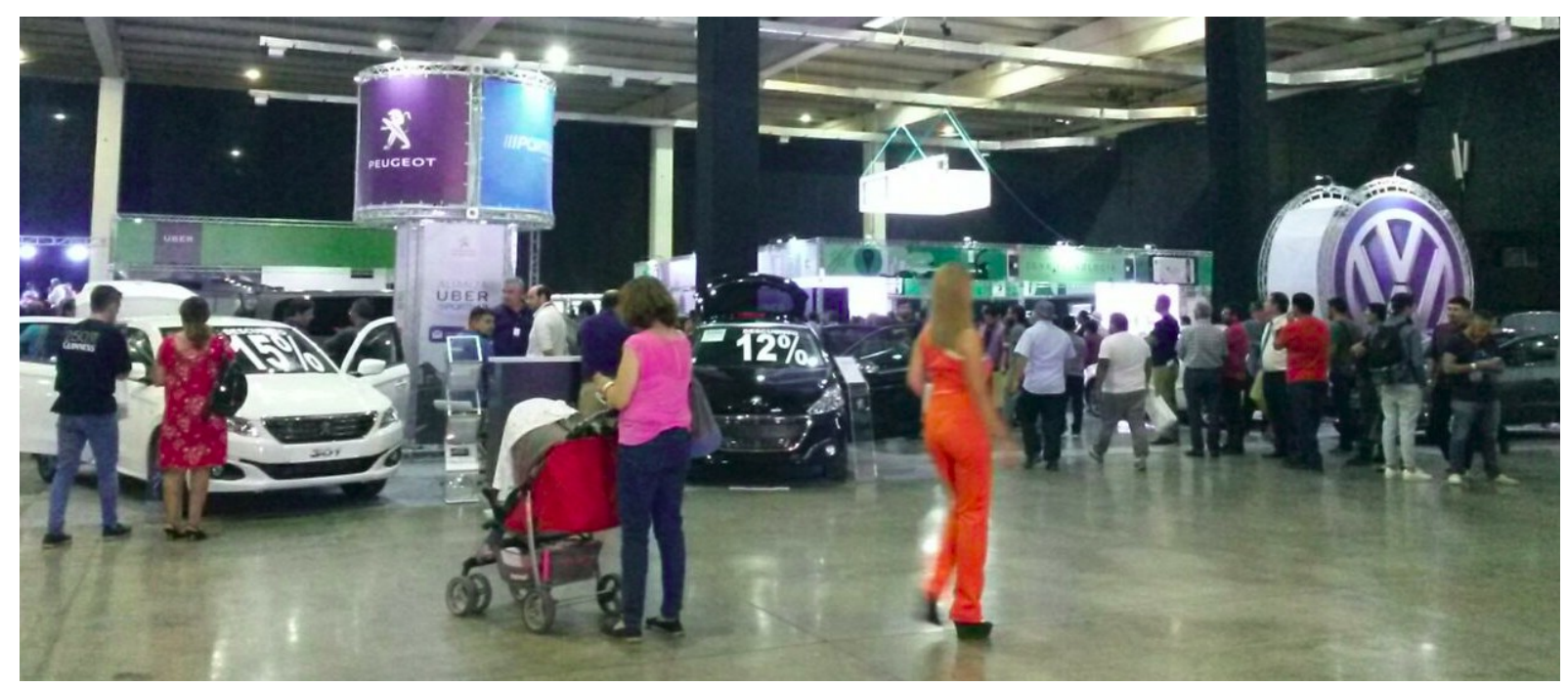

Fonte: autoria própria.

Figura 2.4. Venda de seguro para automóveis em feira promovida pela Uber (2017).

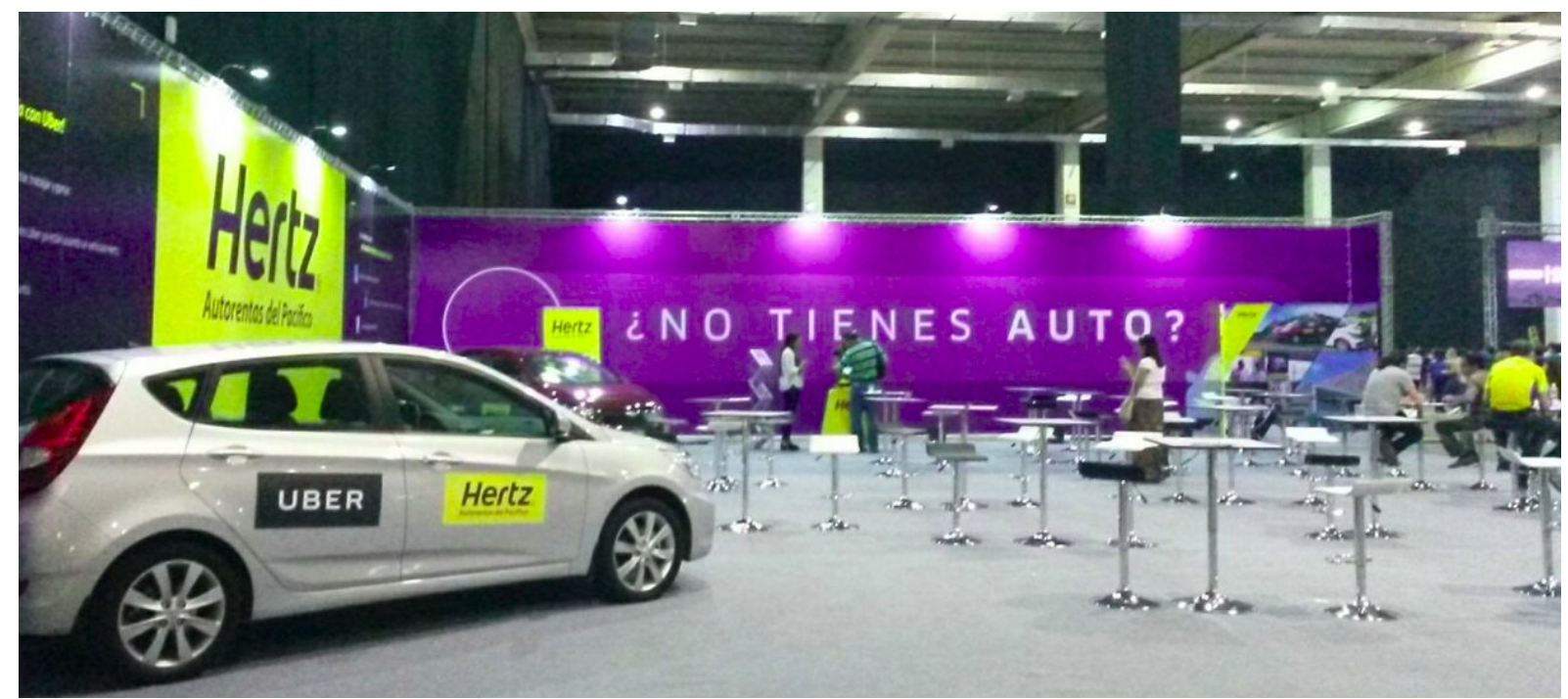

Fonte: autoria própria.

Consideradas uma nova forma de terceirização, as empresas de aplicativos possuem cada vez mais visibilidade, mas pouca materialidade, apresentando-se como mera mediação entre serviços e consumidores. Em 2019, havia quase 14 milhões de pessoas trabalhando na "economia de plataforma" no 
Brasil, e a quantidade de sujeitos cuja renda provém do trabalho mediado por aplicativos vem crescendo (MOREIRA; POMAR, 2019).

De acordo com levantamento de Abílio et al. (2020), em abril de 2020, $70,5 \%$ dos entregadores utilizavam duas ou mais plataformas, e 5,7\% chegavam a estar registrados em quatro ou mais delas (como iFood, Rappi, Uber Eats, Glovo e Loggi - Figura 2.5). Eles relataram jornadas de trabalho de mais de nove horas durante todos os dias da semana, apesar de queda na remuneração durante a pandemia de Covid-19. Seus rendimentos não costumavam superar os $\mathrm{R} \$ 2.080,00$ por mês, e 57,7\% não receberam qualquer apoio das empresas donas dos aplicativos para prevenir riscos de contaminação por coronavírus durante a jornada de trabalho ${ }^{35}$.

Figura 2.5. Entregadores trabalhando para as empresas Rappi, Glovo e Uber Eats.

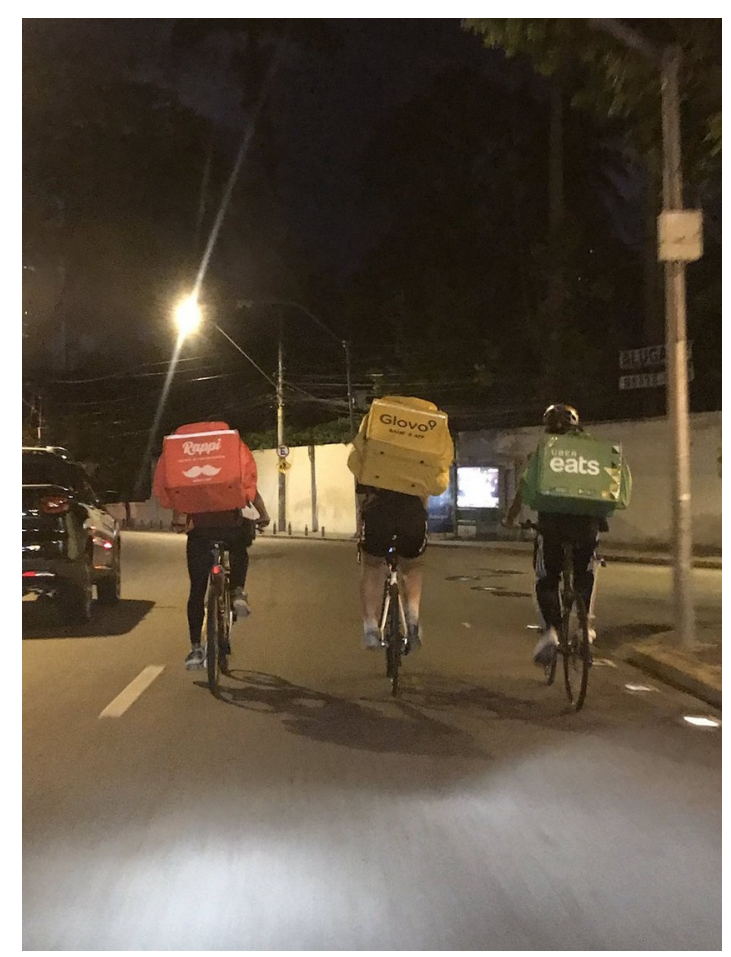

Fonte: autoria desconhecida. Disponível em:

<https://twitter.com/dadopontual/status/1077315134022922243>.

35 Em levantamento de Filgueiras e Antunes (2020, p. 36), um exemplo é um "entregador [que] trabalhou sete dias seguidos, ficou on-line por mais de 61 horas, e recebeu apenas 212 reais. Em São Paulo, trabalhando 9 h24min por dia, os entregadores ganham R\$ 936,00 por mês (...); se fosse uma jornada legal de 44 horas, eles receberiam $\mathrm{R} \$ 762,66$ por mês. Em Salvador, um/a entregador/a recebe em média $\mathrm{R} \$ 1.100,00$ por mês; mas, quando se restringem a uma jornada de 44 horas, conseguem apenas $\mathrm{R} \$ 780,64$ mensais. Em ambos os casos, a renda média da jornada regular é muito inferior ao salário mínimo". 
Filgueiras e Antunes (2020, p. 33) endossam a posição de Abílio (2020) sobre a transferência de riscos e o aumento do controle sobre os trabalhadores, travestidos de uma psicosfera de liberdade e flexibilidade ("trabalhar quando e onde quiser"), largamente difundida em peças de propaganda das plataformas digitais. Em um cenário como o da pandemia de 2020, com crescente insegurança financeira e maior utilização de tecnologias na mediação de atividades cotidianas, aprofundaram-se para os entregadores condições como a falta de garantias de vínculos formais e salários e a imposição de ritmos e metas de produtividade dificilmente alcançáveis sem esgotamento físico e mental.

Ademais, fetichiza-se a tecnologia como se fora indiscutivelmente autônoma e positiva, quando de fato trata-se de algoritmos desenhados para acentuar tendências. Os "ambientes de trabalho flexíveis" proporcionados pelas plataformas seriam ideais, especialmente neste momento histórico, para evitar a "rigidez" dos empregos tradicionais e proporcionar renda extra no tempo livre (FILGUEIRAS; ANTUNES, 2020, p. 31). Note-se que essa é uma tendência metropolitana, onde os custos de vida são mais altos, bem como o são as altas demandas por serviços como os de entregas ou mediados pelas plataformas, em geral.

Conforme pontua Abílio (2020, p. 19), para o chamado "trabalhador justin-time" não existem previsões ou garantias quanto a remuneração, carga ou tempo de trabalho, mas ele deve sempre estar disponível. "Nessa consolidação há um embaçamento entre o que é e o que não é tempo de trabalho, o que também pode significar que todo tempo é potencialmente tempo de trabalho". A extrema flexibilidade acompanha um ideário de inevitabilidade da tecnologia, que "constitui, na verdade, a transferência deliberada de riscos para aumentar o controle sobre os/as trabalhadores/as, pois essa liberdade significa ausência de salário garantido e incremento de custos fixos que se convertem em responsabilidade dos mesmos" - disfarçados da possibilidade de obter renda extra, quando e onde se desejar (FILGUEIRAS; ANTUNES, 2020, p. 31-33).

Existe uma perversa contradição entre o fato de que todo o trabalho dos entregadores é monitorado - suas localizações, seus comportamentos - e os 
usuários são encorajados a distribuir avaliações e notas (em "estrelas"). Por outro lado, as plataformas territoriais, cuja atuação é estritamente vinculada à materialidade do espaço geográfico (TOZI, 2019, p. 8-9), pouco revelam sobre onde atuam, com quantos veículos ou a quantidade de viagens realizadas. Ainda que os dados providos pelos "colaboradores" sejam combustíveis para a economia cognitiva, são as grandes empresas que assumem o protagonismo da organização e da fragmentação do território com base nos algoritmos (TOZI, 2020) e no "conhecimento apurado e sistemático do território e dos seus usos, permitindo a atualização instantânea da ação" (TOZI, 2017, p. 191). Portanto, a descentralização da coleta de informações é indissociável da centralização do acúmulo de capital e da produção de normas no ramo dos aplicativos (idem, p. 193), num jogo de forças centrífugas e centrípetas que se retroalimentam.

O mercado de software se divide em ao menos quatro grandes categorias, nas quais esses trabalhadores irão se inserir ${ }^{36}$ : empresas públicas; empresas privadas voltadas a sistemas do tipo "back office", ou seja, que dão suporte a outros ramos econômicos; startups de tecnologia ou empresas com produtos e departamentos de inovação; e empresas voltadas à terceirização do trabalho. Essa classificação tem relação direta com a distinção que propomos entre consumo produtivo e consumptivo do software como serviço, já que o produto oferecido reflete e influencia a tipologia da empresa.

No caso das "empresas de produtos", o software define o negócio. Muitas empresas produtoras de aplicativos se encaixam neste grupo. Por exemplo, firmas como Ifood deixariam de existir caso o aplicativo desaparecesse. Já a terceirização se subdivide em: pequenas agências que oferecem pequenos produtos semicustomizáveis (como websites para comércio eletrônico), pequenas e com pouca estrutura, capital e organização; os sistemas para busca de freelancers (ou "body shops"), que mantém bancos de currículos e contratam programadores por projeto; e as consultorias e fábricas de software, que oferecem serviços como

36 Ressalte-se que os programadores não podem ser enquadrados na categoria de microempreendedor individual (MEI), pois se trata de uma atividade já regulamentada, de cunho intelectual e científico e não classificada como informal. Outros profissionais, como os que realizam conserto de computadores, poderiam ser registrados como MEI. Algumas alternativas aos desenvolvedores de softwares são a microempresa e a empresa de pequeno porte, com as naturezas jurídicas Empresa Individual (EI), Sociedade de Responsabilidade Limitada (LTDA) ou Empresa Individual de Responsabilidade Limitada (EIRELI). 
suporte técnico e treinamentos.

Carr (2004, p. 42) afirmava que criar um programa de computador era um processo caro, que requeria trabalho meticuloso e altamente especializado, garantia de qualidade rigorosa, extraordinária coordenação e testes intermináveis. Mas como, uma vez escrito o algoritmo, havia poucas restrições físicas à produção de um software, pois sua reprodução e sua distribuição são extremamente baratas. Ressalte-se, no entanto, que é uma indústria que muda muito rapidamente. Por exemplo, a classificação entre software de baixo e alto valor agregado proposta por Roselino (2006), na qual o software sob encomenda era considerado de alto valor agregado, já não parece representar com tanta precisão a realidade do setor. Com o avanço das linguagens de programação e da formação de mão de obra especializada, já não se exige formação de tão alto nível para conceber um aplicativo, do começo ao fim.

Como lembra Arroyo (2006, p. 183), “a divisão internacional do trabalho é uma construção histórico-geográfica que mostra o caráter desigual do processo de desenvolvimento capitalista, isto é, de relações de subordinação entre países" que se alteram conforme o período histórico. A cada período, por sua vez, correspondem um sistema técnico e um sistema regulatório predominantes. Freeman e Perez (1988, p. 47) preferiram propor o conceito de paradigma tecnoeconômico, a fim de ampliar a abrangência da ideia de paradigma tecnológico para além do progresso técnico, incluindo os custos associados à produção e à distribuição.

O paradigma tecnoeconômico é definido como "uma combinação de inovações de produto, de processo, técnicas, organizacionais e administrativas", sendo resultado da seleção de "uma série de combinações viáveis de inovações técnicas, organizacionais e institucionais, provocando transformações que permeiam toda a economia" (LA ROVERE, 2006, p. 291). Tal enfoque é mais holístico e abarca, por exemplo, as importantes modificações que as novas TICs engendraram em diversos aspectos da economia, da sociedade e dos territórios, conformando o meio técnico-científico-informacional.

Em função dessa mudança de paradigma, surgem novas formas de 
organização da produção que permitem aos fluxos de capital e de informação deslocarem-se com mais rapidez (LA ROVERE, 2006, p. 293). O quadro proposto por Tigre (1998) mostra alguns fatores de distinção entre o que denomina paradigmas fordista e das TICs (Quadro 2.3).

Quadro 2.3. Características dos paradigmas tecnoeconômicos fordista e das tecnologias de informação e comunicação (TICs).

\begin{tabular}{ll}
\hline Paradigma fordista & Paradigma das TICs \\
\hline Intensivo em energia & Intensivo em informação \\
Padronização de produtos & Produção sob medida \\
Mix de produtos estável & $\begin{array}{l}\text { Rápidas mudanças no mix de produtos } \\
\text { Firmas isoladas }\end{array}$ \\
Redes de firmas \\
firmanização hierárquica da & Organização simplificada da firma \\
Produção em departamentos & Produção integrada \\
Produtos com serviços & Serviços com produtos \\
Centralização das informações & Distribuição de inteligência \\
Especialização da mão de obra & Polivalência da mão de obra \\
Planejamento estratégico & Visão estratégica \\
Controle governamental & Governo como coordenador e regulador \\
\hline
\end{tabular}

Fonte: Tigre (1998).

Note-se que o Estado aparece, no quadro acima, como um regulador e coordenador, pois vai perdendo poder para as corporações, sobretudo as do ramo de TIC. Uma outra especificidade que vem crescendo entre as firmas produtoras de software e que difere do período fordista é uma tentativa de prover conhecimento aos trabalhadores sobre etapas da produção diferentes daquelas em que atuam. Esse processo, conhecido como "cultura DevOps" (derivado do inglês, "development" and "operations"), adota as chamadas metodologias de trabalho ágeis e se define como

Uma forma de reunir e integrar os desenvolvedores de sistemas com outros profissionais da área de tecnologia, proporcionando agilidade na obtenção de soluções para os negócios das empresas. Com esse método, os profissionais colaboram entre si e conseguem entregar, mais rapidamente e com maior qualidade, sistemas que demorariam mais tempo para serem desenvolvidos (CABRAL et al., 2017, p. 93). 
A penetração das TI é mais evidente no setor de serviços, o que "repercute diretamente na produção e formação da classe trabalhadora" e torna mais difusas as barreiras entre o setor industrial e o de serviços (WOLFF, 2005, p. 128-129). Woodall (1996 apud WOLFF, 2005, p. 129) exemplifica a confusão: “o software para automóveis que é produzido pela própria montadora é considerado parte do setor industrial, mas se for comprado de um fornecedor externo será computado como serviço". Duas décadas e meia mais tarde, assentou-se a tendência de terceirizar a produção dos softwares para firmas especializadas, em vez de realizar-se majoritariamente a produção vertical desse tipo de produto (na mesma firma que produz o bem tangível). Esse trabalhador flexível é funcional às necessidades do capitalismo pós-fordista:

Urge a necessidade de disseminação de um novo modelo de trabalhador, flexível e polivalente tal qual a nova maquinaria que, dada sua complexidade, demanda a utilização de toda a capacidade criativa em seu manejo. Tal capacidade é requerida também na produção de ideias que contribuam para o desenvolvimento e aperfeiçoamento de programas (softwares) capazes de aumentar a produtividade e o desempenho das máquinas de modo a prevenir a ocorrência de falhas, desvios e desperdícios no processo produtivo (WOLFF, 2005, p. 140-141).

Os desenhos das firmas do ramo de TI mudaram drasticamente ao longo das últimas décadas: atualmente, não é raro encontrar mesas e cabines vazias, uma vez que o trabalho remoto em modelo home office é uma tendência crescente. Também se difundem os ambientes de trabalho mais informais, com oferta de "amenidades" como espaços esportivos, grandes cozinhas e lounges de entretenimento, com jogos e televisões. São calculadas expressões da psicosfera moderna e arrojada que procuram disseminar.

Quanto ao modo como se organiza a produção nesse tipo de empresa, existe hoje um forte estímulo pelo compartilhamento entre elas de projetos e até mesmo de funcionários com certas habilidades técnicas, com o objetivo de chegar a avanços tecnológicos mais significativos. Essa mudança cultural em relação a décadas anteriores, que abarca forte incentivo ao uso de softwares livres, torna-se cada vez mais trivial entre empresas de vários tamanhos - contrariando o paradigma anterior, quando prevaleciam o software proprietário e sérias 
preocupações com a propriedade intelectual dos códigos.

Outros modelos de produção de software que vêm se ampliando são o outsourcing (com subcontratação de uma entidade externa para desenvolver uma parte específica de um produto ou serviço fornecido por uma empresa), o offshoring (quando há subcontratação de empresas ou pessoas em outros países para desenvolver, produzir ou testar programas) e as startups. Quanto a estas últimas, a trajetória usual é de que requeiram investimentos de capital de risco para lançar um protótipo, prosperem e, conforme atinjam mais sucesso, sejam adquiridas por grandes firmas transnacionais. É importante ressaltar que as relações entre esses tipos de empresas não são necessariamente harmoniosas. Uma prática conhecida das gigantes no ramo de TI é a intimidação - por meios técnicos, políticos e econômicos - das empresas menores que começam a se mostrar competitivas, conforme exposto em diversos relatos de donos de startups falidas (OPPONG, 2015).

Startups são empresas geralmente de base tecnológica - ou seja, cujo modelo de negócio se fundamenta em tecnologia - que pretendem apresentar inovações em seus produtos. Trata-se de um tipo de negócio de alto risco, o que não é necessariamente atraente em países com economia desestabilizada, como o Brasil. Mesmo grandes firmas, como SpaceX e Tik Tok, ainda são consideradas startups por conta de terem seus produtos ainda em fase de experimentação.

Em relatório da organização Startup Genome sobre o atual "ecossistema das startups" (2019, p. 130), o único caso brasileiro citado é o de São Paulo (SP). Algumas características nele identificadas foram que as ofertas de salário para engenheiros de software e os investimentos em fases iniciais de startups são menores que a média global, e que existe uma ênfase nos setores de fintechs ${ }^{37} \mathrm{e}$ ciências da vida. Como fatores atrativos para que se localizem na capital paulista, são listadas as universidades e a carga tributária reduzida para importações e exportações.

37 Em definição de Schiaffino e Parserisas (2019, p. 13), as fintechs são firmas que oferecem serviços financeiros por meio de plataformas digitais. Os principais ramos em que atuam incluem transações e pagamentos, online banking, negociação de mercados, gestão de matérias-primas, financiamento, empréstimos e assessoria online. Esses serviços são executados em páginas web, aplicativos em celulares ou em meios mais tradicionais, porém com mediação tecnológica. 
As startups que atingem mais de 1 bilhão de dólares em valor de mercado são chamadas de "unicórnios", por serem consideradas raras e especiais. Aquelas que valem mais de US\$10 bilhões podem ser chamadas de "decacórnios", e as que atingem o valor de US\$100 bilhões são os "hectocórnios". De acordo com a consultoria CBInsights (2021), dentre os 596 mais valiosos unicórnios no mundo em 2021, 11 eram brasileiras (Quadro 2.4). A título de comparação, 218 eram chinesas, 193 estadunidenses, 39 indianas, 29 britânicas, 16 alemãs e 11 francesas. Da América Latina, existem na lista as colombianas Rappi e LifeMiles, a mexicana Kavak e a uruguaia dLocal, totalizando 15 empresas do continente (Mapa 2.17). 
Quadro 2.4. Características de startups “unicórnio” brasileiras (2021).

\begin{tabular}{|c|c|c|c|c|}
\hline Startup & $\begin{array}{l}\text { Valor de } \\
\text { mercado } \\
\text { (US\$ } \\
\text { bilhões) } \\
\end{array}$ & Ramo de atuação & Investidores & $\begin{array}{l}\text { Ano em que } \\
\text { se tornou } \\
\text { "unicórnio" }\end{array}$ \\
\hline Nubank & 25,0 & Finanças & $\begin{array}{l}\text { Sequoia Capital, Redpoint } \\
\text { e.ventures, Kaszek } \\
\text { Ventures }\end{array}$ & 2018 \\
\hline Wildlife Studios & 3,0 & Videogames & $\begin{array}{l}\text { Benchmark, Bessemer } \\
\text { Venture Partners }\end{array}$ & 2019 \\
\hline Creditas & 1,75 & Finanças & $\begin{array}{l}\text { Kaszek Ventures, } \\
\text { Amadeus Capital Partners, } \\
\text { Quona Capital }\end{array}$ & 2020 \\
\hline VTEX & 1,7 & Comércio eletrônico & $\begin{array}{l}\text { Riverwood Capital, Gavea } \\
\text { Investimentos, Endeavor }\end{array}$ & 2020 \\
\hline Movile & 1,0 & Telecomunicações & $\begin{array}{l}\text { Innova Capital - FIP, 3G } \\
\text { Capital Management, } \\
\text { Prosus Ventures }\end{array}$ & 2018 \\
\hline iFood & 1,0 & Logística e entregas & $\begin{array}{l}\text { Movile, Just Eat, Naspers } \\
\text { Qualcomm Ventures, }\end{array}$ & 2018 \\
\hline Loggi & 1,0 & Logística e entregas & $\begin{array}{l}\text { SoftBank Group. } \\
\text { Monashees+ }\end{array}$ & 2019 \\
\hline QuintoAndar & 1,0 & Habitação & $\begin{array}{l}\text { Kaszek Ventures, General } \\
\text { Atlantic, SoftBank Group }\end{array}$ & 2019 \\
\hline EBANX & 1,0 & Finanças & $\begin{array}{l}\text { FTV Capital, Endeavor } \\
\text { Monashees }+ \text { Andreessen }\end{array}$ & 2019 \\
\hline Loft & 1,0 & Habitação & $\begin{array}{l}\text { Monashees+, Andreessen } \\
\text { Horowitz, QED Investors }\end{array}$ & 2020 \\
\hline MadeiraMadeira & 1,0 & Móveis & $\begin{array}{l}\text { Flybridge Capital } \\
\text { Partners, SoftBank Group, } \\
\text { Monashees+ }\end{array}$ & 2021 \\
\hline
\end{tabular}


Das empresas listadas no Quadro 2.4, diversas possuem aplicativos como um de seus principais meios de uso, como é o caso de Nubank, iFood e Loggi. Outras funcionam como websites para compras ou aluguel de imóveis preferencialmente no navegador da Internet, como QuintoAndar, Loft e MadeiraMadeira. Já firmas como VTEX, Movile e EBANX dão suporte a operações de compras pela internet, por meio do processamento de pagamentos e do envio de mensagens aos usuários que efetuam uma operação de compra. Note-se ainda que atingiram o status de "unicórnio" somente a partir de 2018; porém, na lista da CBInsights, existem empresas localizadas nos países centrais que chegaram a esse patamar em 2010.

Mapa 2.17. Startups "unicórnio" por país (2021).

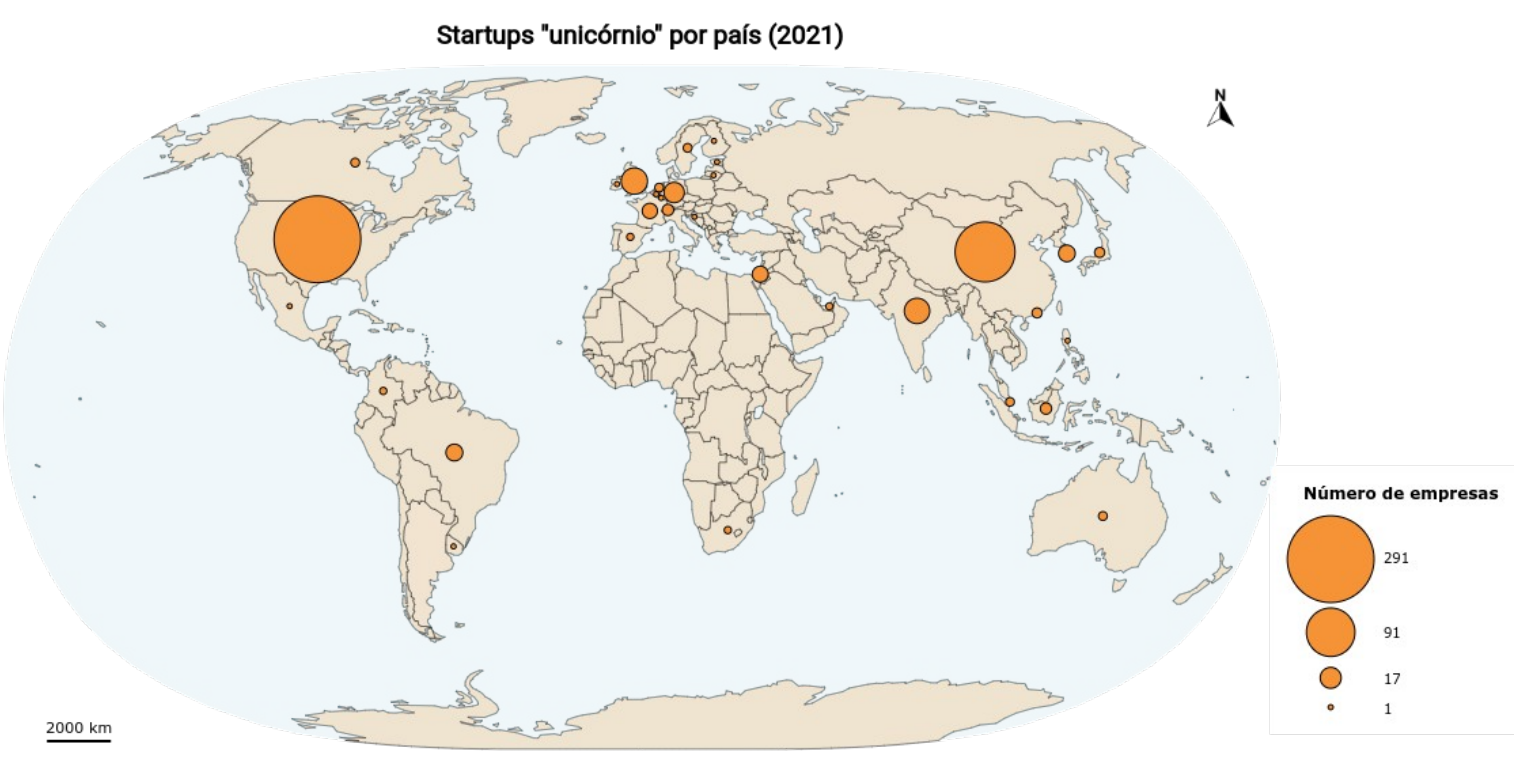

Fonte: elaboração própria, a partir de CBInsights (2021).

Quanto aos ramos de atuação, 93 das empresas "unicórnio" são fintechs e 92 são do ramo de software e serviços de internet. 32 são trabalham com logística e entregas, 71 com comércio eletrônico, 24 com análise e gerenciamento de dados e 49 em inteligência artificial. 23 são do ramo de cibersegurança e 18 são as chamadas "edtech", que ofertam tecnologias para educação. 66 são financiadas pela investidora Sequoia Capital e é comum que grupos de venture capital aportem 
grandes somas de dinheiro em startups.

Ainda que seja um tipo de empresa com grande apelo midiático, é muito difícil atingir alto valor de mercado, especialmente para as firmas que se localizam nos países periféricos, com menos acesso a crédito e incentivos econômicos em geral. De todo modo, é evidente que as finanças constituem uma divisão do trabalho que coexiste com outras formas de se trabalhar nas cidades e no território (SCHIAFFINO; PARSERISAS, 2019, p. 3). Nesse contexto, quando da união da ciência e da técnica, nasce o mercado global - no qual se situam as referidas empresas (SANTOS, 2009, p. 238).

Entre as corporações produtoras de aplicativos, destacam-se dois grupos conhecidos como GAFAM (Google, Amazon, Facebook, Apple e Microsoft) e NATU (Netflix, Airbnb, Tesla e Uber). Apesar de raramente divulgarem números a respeito dos mercados em que atuam, Tozi (2020) mostra que, em 2016 e 2017, o Brasil era o segundo mercado mais rentável no mundo para a Uber, especialmente as cidades de São Paulo e Rio de Janeiro, o que coincidiu com um aumento nos gastos com transporte nos orçamentos familiares e nos índices de desemprego.

Tais firmas buscam variar suas estratégias territoriais e diversificar seus produtos por meio da "colonização" de outros mercados - por exemplo, com o lançamento pela Uber de recursos como o Uber Eats. Elas também executam planos ferozes de internacionalização, beneficiando-se de lacunas regulatórias em diversos países e de vulnerabilidades em momentos como o de crise sanitária, como se fossem a perfeita solução para os problemas do mundo moderno. Tais fatores acendem alertas de que os produtos do ramo de TI não são neutros, uma dádiva ou mero resultado natural da inovação tecnológica: algoritmos são desenhados por pessoas dentro de contextos e com intencionalidades, eles mesmos conformando um conjunto de objetos e ações. 


\subsection{Transformações na indústria de software no contexto da globalização}

O vigor da expansão do "fenômeno dos aplicativos" influencia e é influenciado pela fluidez e pela porosidade das formações socioespaciais às demandas e imposições das empresas transnacionais do ramo de TI. A velocidade com que desenvolvem e difundem novos produtos é avassaladora e constitui um modo de violência da informação (SANTOS, 2000). Consequentemente, os territórios buscam adequar-se às novas exigências técnicas (por exemplo, padrões de conectividade mais elevados, tais como redes móveis $4 \mathrm{G}$ e $5 \mathrm{G}$ ). A difusão dos aplicativos alimenta e é alimentada por esses fatores, pois depende de modernizações nos macrossistemas técnicos de telecomunicações - que, no âmbito da regulação híbrida do território e por conta de sua dimensão, são promovidas por nexos entre Estado e mercado.

Especificamente no campo da produção de bens intangíveis, como os aplicativos, vem crescendo a importância das corporações transnacionais tomadas aqui, conforme proposto por Dicken (2011, p. 60-61), como firmas com capacidade de coordenar e controlar operações em mais de um país, via processos e transações em redes de globais de produção (Global Production Networks - GPN). Esse tipo de empresa atua de forma flexível e fluída através das fronteiras nacionais (transferindo recursos e operações em escala global) e aproveita as diferenças geográficas na distribuição dos meios de produção (como recursos naturais e força de trabalho) e as políticas estatais (como subsídios ou barreiras comerciais) (COE; DICKEN; HESS, 2008).

A respeito das empresas globais, Silveira (2000, p. 121-122) aponta que elas são notáveis criadoras de normas que garantem a eficácia de seu trabalho, o que também é inerente à tecnologia de ponta, até mesmo para o usuário. As normas são, portanto, essenciais para garantir competitividade e participação no mercado globalizado: "quando uma empresa ou um país pretendem participar no chamado mercado global, devem, impreterivelmente, cumprir as regras da eficiência, da competitividade e da fluidez consagradas". 
Há ainda a questão da interoperabilidade entre plataformas, para que se possa utilizar os mais modernos objetos técnicos. Nesse tipo de situação, as firmas globais acabam ditando padrões técnicos e regulatórios que devem ser atendidos por outras empresas e pelos programadores - como aconteceu no processo de ascensão da computação em nuvem -, consolidando mais poder político e econômico. Em 2019, cinco conglomerados que trabalham com essa tecnologia lideraram o mercado de software como serviço: Microsoft, Salesforce, Adobe, SAP e Oracle. Mas mesmo elas devem manter-se atentas e adaptar seus produtos às demandas dos consumidores, que mudam muito rapidamente (HOLST, 2020).

Mesmo durante a pandemia, quatro das cinco maiores empresas do ramo de tecnologia tiveram ganhos e lucros significativos e devem continuar crescendo (Tabela 2.9). Combinadas, elas atingem $17,4 \%$ do valor de mercado das empresas listadas no índice Standard and Poor's 500 (S\&P 500). Apesar do saldo negativo, a Google tem previsão de rendimentos de 30,8\% em 2021 e 20,9\% em 2022, numa espécie de efeito-rebote após a queda. Por sua vez, a Apple vendeu um "mero" bilhão de iPhones nos últimos dez anos, mas é esperado que retome o crescimento, vendendo mais de 27 bilhões de dispositivos em três anos e somando um mercado de 1,7 trilhão de dólares (MIAN, 2020). Tais corporações atingiram um nível tão grande de domínio em um mercado extremamente estratégico que seus ganhos são perenes mesmo em tempos de crise econômica para outros vários ramos.

Tabela 2.9. Rendimentos e receita das empresas "Big Tech", em relação ao ano anterior (outubro de 2020).

\begin{tabular}{lll}
\hline Empresa & Rendimentos (\%) & Receita (\%) \\
\hline Apple & 1,7 & 4,9 \\
Amazon & 36,8 & 32,0 \\
Google & $-15,2$ & $-11,9$ \\
Microsoft & 20,2 & 13,6 \\
Facebook & 25,2 & 14,1 \\
\hline
\end{tabular}

Fonte: elaboração própria, a partir de Mian (2020). 
A dinâmica entre as corporações nem sempre ocorre com cooperação. Aplicativos como os da Epic Games (empresa estadunidense que produz jogos virtuais, entre eles o Fortnite) possuem sistemas de pagamento para venda de itens extras dentro do próprio programa, de modo a evitar as lojas online de aplicativos da Apple e da Google. A Apple, por sua vez, respondeu removendo o Fortnite de sua plataforma, o que gerou uma batalha judicial, ainda em andamento, sobre o tipo de mercado dominado pela Apple (se de aplicativos ou de jogos). A App Store (para iPhones) representa por volta de 30\% da receita anual da companhia. A Epic Games alega que a Apple possui monopólio sobre os aplicativos para iPhone e limita os usuários a utilizarem apenas o que estiver dentro de seu próprio ecossistema, enquanto a Apple afirma que o faz por razões de segurança. Já a Play Store da Google permite o download de aplicativos por outros meios.

Também complexo é o tema da localização dos servidores das corporações citadas. Ao tratarem o território como recurso e a informação de modo estratégico (SILVA, 2001), elas planejam com esmero onde alocar esses computadores, ao ponto de não divulgarem seus endereços exatos. O sigilo é propagandeado como fator de segurança para os usuários que a elas confiam a guarda e o processamento de seus dados, mas não deixa de possuir conotação política, tendo em vista que o acesso à informação e o domínio das técnicas da informática são meios para obtenção de poder (RAFFESTIN, 1993).

A instalação e a modernização das redes técnicas que sustentam a economia baseada em TI consistem em um processo de valorização de porções do espaço, pois elas apoiam a circulação de bens tangíveis e intangíveis. Essa dinâmica simultaneamente alimenta e é condicionada por mudanças nas divisões espaciais do trabalho e pela criação de especializações produtivas (SANTOS, 2005; ARROYO, 2015, p. 41). No que diz respeito ao território brasileiro, criam-se as condições para a predominância de capital estrangeiro na indústria de software e a consequente transferência de capital doméstico para o exterior.

A ABES (2018, p. 17) aponta que $74,5 \%$ dos softwares comercializados no Brasil são desenvolvidos no exterior e apenas $2,0 \%$ da produção nacional é destinada à exportação. Os Estados Unidos da América (EUA) são o maior parceiro 
do Brasil no comércio de serviços de informática e informação (OECD, 2018; BRASIL, 2017). Tais dados enfatizam uma desigualdade notável em um setor econômico intensivo em tecnologia, como é o de produção de software - o que traz consequências para ambos os países em termos de desenvolvimento econômico.

Na definição de Softex (2002), tradicionalmente se divide a produção de programas de computador em software de pacote (para uso cotidiano, como um processador de texto), serviços de software (programas customizados, apoio a clientes, treinamento e manutenção) e software embarcado (que funciona de modo mais simbiótico com o hardware). No entanto, as empresas costumam variar sua atuação para além de apenas uma dessas categorias, desenvolvendo-as simultaneamente.

Atividades como manutenção de programas exigem tarefas mais simples, bem especificadas pelos clientes e com menor remuneração, o que gera competição por preços entre as empresas. Esse mercado era usualmente dominado por empresas locais, mas com a difusão da comunicação via Internet, passou a ter maior participação de firmas offshore, especialmente na Índia. Isso também possibilita aos clientes escolher contratar serviços na localidade que ofereça preços mais atrativos.

As multinacionais especializadas em consultoria são alguns dos maiores agentes nesse ramo, por terem construído uma reputação associada sobretudo a serviços de valor mais elevado (como pesquisa e desenvolvimento), que envolvem maior incerteza quanto ao resultado. Também no segmento de produto/pacote em software há participação significativa das multinacionais, pois se requer investimentos elevados com temas como pesquisa de mercado, marketing e inovação tecnológica, antes de realizar vendas - o que aumenta os riscos de falhas e a necessidade de investimentos. Os programas resultantes podem ser mais genéricos, como as suítes para escritório (como Microsoft office), ou específicos ${ }^{38}$ para setores como aviônica e engenharia (SOFTEX, 2002, p. 27).

38 "O produto customizável, como o ERP, ou as soluções específicas para segmentos verticais como o financeiro ou as telecomunicações (...) envolve normalmente uma solução nuclear (kernel) que se mantém em todas as vendas, mas requer igualmente adaptação e desenvolvimento específico substancial para cada cliente. A adaptação pode ser feita por terceiros relativos ao fornecedor do software ou pela própria empresa" (SOFTEX, 2002, p. 27) 
A produção de software como serviço é uma atividade econômica desempenhada por um conjunto de firmas muito especializadas. Esse produto, por sua vez, é crescentemente absorvido por empresas de outros ramos e por usuários comuns. As empresas que o produzem são crescentemente contratadas por agentes do Estado e por outras firmas. Porém, esse processo não se dá meramente pela compra de software, que poderia ser importado - como ocorre com os produtos Microsoft, por exemplo. Esses agentes são, mais do que isso, grandes produtores do ramo da informação, de modo mais geral. Atuam em ramos afins, como a publicidade e a produção de hardware, e é um desafio definir o alcance de suas atividades.

No âmbito histórico, Mahmoudi (2017, p. 108) pontua que, nos anos 1990, as firmas globais utilizavam-se da centralização do capital e das operações como uma estratégia para gerenciar os custos do trabalho e extrair valor. A imprevisibilidade dos ciclos de produto as levava a recorrer a contratos de trabalho temporários para as tarefas mais rotineiras de programação, incluindo escrita e testagem de algoritmos. Elas também procuravam gerir as despesas de trabalho terceirizando certas tarefas ou contratando empresas offshore, em países com mão de obra mais barata e menor tributação. No período atual, ainda é comum firmar contratos flexíveis para produção em locais periféricos; porém, já não há tanta dependência da venda do produto em larga escala para gerar a mesma riqueza que se conseguia antes com os softwares de prateleira, não customizáveis (MAHMOUDI, 2017, p. 109).

Entre 1976 e 1982, a IBM controlava mais de 60\% do mercado brasileiro de computadores mainframe, seguida da Burroughs - ambas tradicionais firmas estadunidenses -, com mais de $14 \%$. No mesmo período, a Cobra (Computadores Brasileiros S.A., derivada do projeto "Patinho Feio", para produção do primeiro computador nacional) liderava o mercado local de minicomputadores. No início dos anos 1980 , em torno de $70 \%$ dos computadores brasileiros eram utilizados no setor privado (PIRAGIBE, 1985, p. 161; 167-168; 181). As tabelas 2.10 e 2.11 mostram, respectivamente, o desenvolvimento da computação eletrônica em vários países, e o estado do mercado mundial de software e serviços em TI em 2018. 
Boa parte dos países se repetem, tendo mantido uma posição de liderança mesmo diante de muitos avanços nas TI nas últimas décadas - provavelmente, pois tratase de um ramo que gera muito valor agregado e retorno de investimentos em pesquisa e desenvolvimento.

Tabela 2.10. Resumo do desenvolvimento da tecnologia de computação eletrônica em países selecionados.

\begin{tabular}{|c|c|c|c|}
\hline \multirow[b]{2}{*}{ País } & \multirow[b]{2}{*}{$\begin{array}{l}\text { Primeiro computador } \\
\text { colocado no mercado }\end{array}$} & \multicolumn{2}{|c|}{ Início dos trabalhos } \\
\hline & & $\begin{array}{l}\text { de pesquisa e } \\
\text { desenvolvimento }\end{array}$ & $\begin{array}{l}\text { Tempo transcorrido } \\
\text { (anos) }\end{array}$ \\
\hline Estados Unidos & 1952 & 1937 & 15 \\
\hline Inglaterra & 1953 & 1947 & 6 \\
\hline Alemanha & 1954 & 1936 & 18 \\
\hline França & 1957 & 1946 & 11 \\
\hline Rússia & 1958 & 1948 & 10 \\
\hline Japão & 1959 & 1952 & 7 \\
\hline Holanda & 1959 & 1951 & 8 \\
\hline Itália & 1960 & 1954 & 6 \\
\hline Suécia & 1962 & 1947 & 15 \\
\hline Dinamarca & 1962 & 1954 & 8 \\
\hline Bélgica & 1964 & 1957 & 7 \\
\hline Alemanha Oriental & 1964 & 1949 & 15 \\
\hline Canadá & 1964 & 1949 & 15 \\
\hline Polônia & 1965 & 1954 & 10 \\
\hline China & 1966 & 1954 & 12 \\
\hline Israel & 1968 & 1954 & 14 \\
\hline Brasil & $1979^{39}$ & 1971 & 8 \\
\hline
\end{tabular}

Fonte: elaboração própria, adaptado de Piragibe (1985, p. 144).

Tabela 2.11. Mercado global de software e serviços em TI (2018).

\begin{tabular}{llll}
\hline Posição & País & Mercado (US\$ bilhões) & \% do total \\
\hline 1 & Estados Unidos & 563 & 46,1 \\
2 & Japão & 79 & 6,5 \\
3 & Reino Unido & 75 & 6,2 \\
4 & Alemanha & 65 & 5,4 \\
5 & França & 47 & 3,9 \\
6 & China & 41 & 3,4 \\
7 & Canadá & 31 & 2,5 \\
8 & Austrália & 24 & 2,0 \\
9 & Brasil & 23 & 1,9 \\
\hline
\end{tabular}

Fonte: elaboração própria, a partir de ABES (2019).

39 Antes de computadores brasileiros serem colocados no mercado, bancos como Bradesco, Itaú, Bamerindus e Banco Nacional já haviam adquirido máquinas mainframe importadas, na década de 1960.0 Bradesco instalou seu primeiro computador em 1962 (DINIZ, 2004, p. 56). 
A Tabela 2.11 mostra ainda uma predominância de países do chamado "Norte Global", com destaque para os Estados Unidos, que representam quase metade do total. Isso ocorre pois a maior parte das principais empresas do ramo são estadunidenses e, mesmo considerando a produção offshore, o lucro ainda retorna e é retido nos EUA. Este país também é mais atrativo pelo fato de possuir mais mão de obra disponível, com fortes laços entre a academia e o mercado resultando num grande número de especialistas empregados nessas firmas.

O Brasil é o principal importador e o segundo maior exportador latinoamericano de produtos de TI para os Estados Unidos, atrás apenas do México. A Tabela 2.12 contém os dados do mercado brasileiro de TICs por segmento. Em 2016, o Brasil exportou 485 milhões de dólares, sendo 61\% em serviços de computação, especialmente nos ramos de business intelligence, digitalização e marketing digital e serviços em nuvem. De acordo com Amorim et al. (2018), as empresas exportadoras do Brasil optam por adaptar ou mesmo substituir sua produção conforme a demanda estadunidense, aprofundando-se a grande dependência desse mercado consumidor. Ademais, as empresas participantes do projeto Brasil IT+ (programa para internacionalização desenvolvido pela Softex e pela Agência Brasileira de Promoção de Exportações e Investimentos, a Apex-Brasil) reportaram ser ainda mais focadas nos serviços em nuvem.

Tabela 2.12. Produção total de TICs no Brasil (2018).

\begin{tabular}{llll}
\hline $\begin{array}{l}\text { Segmento do } \\
\text { mercado }\end{array}$ & $\begin{array}{l}\text { Mercado } \\
\text { doméstico (US\$ } \\
\text { milhões) }\end{array}$ & $\begin{array}{l}\text { Mercado para } \\
\text { exportação (US\$ } \\
\text { milhões) }\end{array}$ & $\begin{array}{l}\text { Mercado total (US\$ } \\
\text { milhões) }\end{array}$ \\
\hline Software & 10.479 & 200 & 10.679 \\
Serviços & 12.262 & 566 & 12.828 \\
Hardware & 23.896 & 344 & 47.747 \\
Subtotal de TI & 50.433 & 1.110 & 50.433 \\
Telecomunicações & 97.070 & - & 98.180 \\
\hline
\end{tabular}

Fonte: elaboração própria, a partir de ABES (2019).

Gradualmente, autoridades locais vão definindo as plataformas não simplesmente como empresas de intermediação, mas sim atuantes em nichos 
específicos (como transporte ou hotelaria). Elas princípios de regulação e dos sistemas fiscais internacionais datados da primeira metade do século XIX, quando os territórios ainda não haviam se informatizado. Contudo, no atual período histórico e diante do enorme poder econômico das corporações de TI, é difícil aos governos acompanhar os movimentos delas com regulação fiscal apropriada (ERWIN; KARAMAN, 2017, p. 25). Para tornar a situação ainda mais complicada, raramente há firmas equivalentes estatais ou privadas locais, regionais ou nacionais capazes de concorrer com as gigantes. No Brasil, as corporações com receita superior a $\mathrm{R} \$ 100$ milhões dos ramos de tecnologia e serviços de informação (as "big techs") chegam a pagar 76\% menos em impostos do que firmas de outros setores (MOREIRA, 2021).

Esse contexto leva as grandes empresas transnacionais a se aproveitarem das especificidades de cada formação socioespacial para distribuir suas atividades pelo planeta. Um dos maiores exemplos é a Uber, que possui escritórios em diversos países, cada um com uma finalidade relacionada àquele local - conforme esquema expresso na Figura 2.6. Tal fragmentação amplia a capacidade de lucro em cada etapa produtiva, mas a maioria dos ganhos retorna aos Estados Unidos (matriz da empresa), após passar por lugares com condições fiscais mais favoráveis a seu negócio, como a Holanda. 
Figura 2.6. Esquema representativo da estrutura produtiva transnacional da Uber.

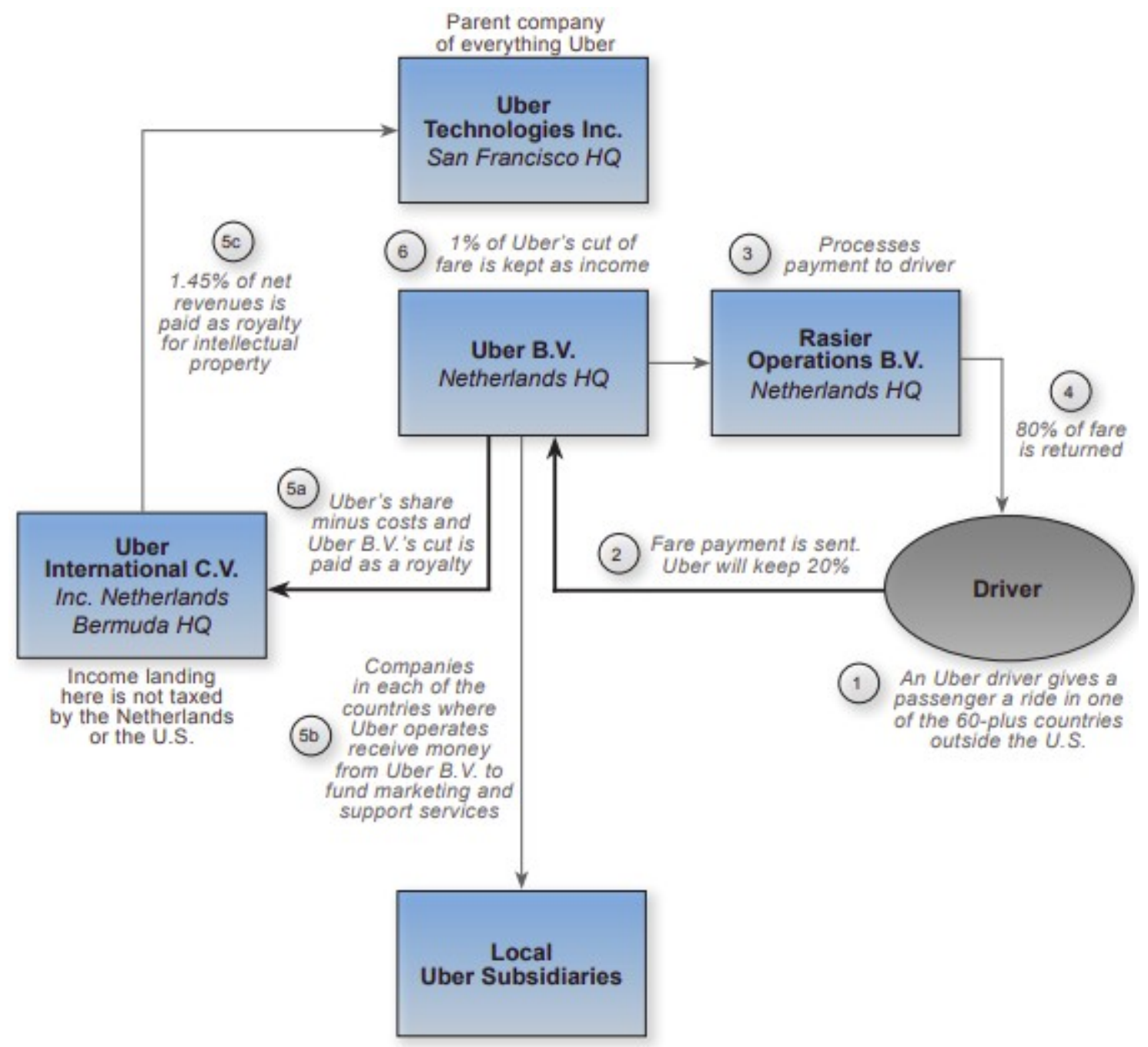

Fonte: Erwin e Karaman (2017, p. 26).

Instaura-se, portanto, um debate normativo a respeito da topologia das corporações que controlam as plataformas. O dinheiro que é extraído nos lugares não retorna a eles e não há compromisso com a sociedade que ali vive (sobretudo com os motoristas, que são taxados em ao menos $20 \%$ ), denotando um uso estritamente corporativo do território. A informação e as finanças provam estar enredadas no centro da geopolítica da TI no mundo, ao passo que os territórios cada vez mais se alienam e se tornam submissos ao mercado global, preparando-se com normas e sistemas de engenharia para atrair investimentos estrangeiros (CATAIA, 2001, p. 221). Como alertava Isnard (1982, p. 55), a própria sobrevivência dos espaços alienados fica atrelada a sua integração ao mercado mundial, 
incluindo-se o poder público, que acaba por tomar ações gradativamente mais neoliberalizantes.

Mascaro (2013, p. 114-115) destaca que, por um lado, o mercado não deve ser entendido como "instância natural, equilibrada ou suficiente, tal qual o fazem os economistas neoliberais"; por outro, tampouco o Estado deve ter a função de "ordenar o mercado para a plena estabilidade ou o bem comum". Tal concepção simplesmente não abarca a natureza conflituosa da economia capitalista, "lastreada na apropriação de capitais e no trabalho explorado, [em que] o Estado se apresenta em relação direta com a multiplicidade das contradições econômicas e sociais". 0 autor continua: "o papel do Estado na regulação se revela a partir da sua manifestação estrutural e funcional, como forma necessária da reprodução do capital" (MASCARO, 2013, p. 115).

Ainda sobre o neoliberalismo como fator que perpassa diversos ramos da produção capitalista, Martins (2011, p. 316-317) aponta que sua afirmação na América Latina tem como determinante "a derrota da ofensiva dos movimentos populares que se desenvolve nos anos 1960 e 1970, com a imposição de regimes ditatoriais fascistizantes e processos de redemocratização articulados à hegemonia estadunidense na região". Como reação a instabilidades econômicas deste país até a década de 1970, o neoliberalismo passa a ser um instrumento de ofensiva ideológica que afeta profundamente os padrões de desenvolvimento no continente latino-americano, e que se intensifica especialmente com as políticas de substituição de importações nas décadas de 1980 e 1990:

Através dessa ofensiva, os Estados Unidos buscavam: reduzir seus déficits comerciais com o mundo por meio da conquista de saldos comerciais com a América Latina; criar as condições para que seus investidores venham a auferir rendas e incorporar ativos através da especulação e da barganha; e baixar ao mínimo as restrições à circulação de mercadorias e capitais, viabilizando uma reorganização do trabalho regional que reduza os custos de produção e aumente a competitividade de suas empresas (...). A drenagem de recursos que se impõe à América Latina nos anos 1980 exigiu a obtenção de fortes saldos comerciais para financiá-los, o que vinculou os experimentos neoliberais a regimes autoritários. Estes impulsionavam amplamente a superexploração do trabalho, compensando os efeitos negativos da abertura comercial (MARTINS, 2011, p. 317). 
Quando se trata de sistemas técnicos mais complexos, de largo alcance territorial (tais como os de telecomunicações, no caso de um país), poucos agentes têm capital e nível de organização suficientes para sustentar-se no ramo. São, portanto, parte do circuito superior da economia urbana (SANTOS, 2004), e sustentam uma concentração de mercado que acaba reforçada Assim se reproduz no território brasileiro uma lógica recorrente em vários outros setores: a de predominância do capital estrangeiro, e de consequente transferência do capital nacional para o exterior.

Lopes (1998, p. 113) aponta ainda que os satélites foram um objeto utilizado para a prospecção de minerais preciosos na América Latina, na África Equatorial e no Sudeste da Ásia, no escopo de programas de pesquisa espacial de países hegemônicos na economia global. No século XXI, os satélites para comunicação são um instrumento de coleta de dados de geolocalização do mundo todo, aumentando o conhecimento daqueles mesmos países sobre territórios alheios e sobre potenciais mercados consumidores de produtos informacionais.

Em países com industrialização tardia, como é o caso do Brasil, muitas empresas locais começam a se estruturar na retaguarda dos impulsos modernizadores externos, mas possuem um papel específico na divisão territorial do trabalho. A princípio se poderia deduzir que firmas nacionais detêm melhor o conhecimento sobre mercados locais por conta da proximidade física, mas as corporações transnacionais são capazes de desenvolver e acessar ferramentas que lhes permitem ter cognoscibilidade do planeta, ou seja, conhecer o que há em todo ele de modo extenso, concreto e aprofundado, mesmo à distância. $\mathrm{O}$ próprio trabalho mediado pelas plataformas é controlado por aplicativos baseados em geolocalização, como ocorre com os entregadores e motoristas.

No campo dos usuários, ainda que o programa seja passível de download gratuito, existe a concordância com os termos de uso, resultando numa espécie de contratação dos serviços às escuras. A renda das plataformas, portanto, não vem necessariamente da compra, mas sim de propaganda (cada vez mais direcionada), da venda de dados pessoais coletados, de sua conversão em estratégias de lucro, de serviços de suporte ou treinamento para uso do software, ou mesmo itens extras 
que possam ser comprados dentro dos aplicativos. No caso das organizações, práticas comuns são a venda de suítes de softwares para empresas ou para uso acadêmico, que costuma garantir maior número de funcionalidades gratuitas. Ainda que esteja prosperando a cultura de software livre, em contrapartida à antiga proeminência do software proprietário, usualmente existe maior foco em nichos e em personalização dos produtos - similar à passagem da predominância do Fordismo para o Toyotismo na indústria automobilística.

Disso emergem debates em torno da propriedade intelectual de softwares, que geram tensões regulatórias nas escalas local e global. De acordo com Softex (2002, p. 44), os tipos de propriedade intelectual para programas de computador envolvem pedidos de registro de software, software registrado, pedidos de patente, patentes aprovadas, licenciamentos de tecnologia e trade secrets (segredos comerciais) depositados. No início dos anos 2000, as empresas médias depositavam a grande maioria das patentes e faziam o maior número de pedidos de registro de software.

No entanto, o chamado "direito à propriedade do trabalho intelectual" já nasceu polêmico, por conta de seus significados contraditórios e por conta do prazo limitado de validade das patentes. Tais debates estão diretamente relacionados ao desenvolvimento dos monopólios nos ramos de TI e entretenimento e à globalização, com histórico de lobby de firmas como Disney, Time Warner e Viacom pela ampliação dos prazos. Houve ainda mudanças no direito à propriedade ao longo do tempo, de modo que atualmente se confundem o copyright (direito de propriedade para o trabalho intelectual) e as marcas e patentes, também fruto de trabalho intelectual, mas voltado para o mercado e protegidas pelo direito de propriedade industrial. "A organização internacional do comércio apagou a distinção entre propriedade intelectual e industrial: inventou as TRIPS, Trade Related Intellectual Properties, propriedades intelectuais relacionadas ao comércio" (REPORTAGEM, 2003b, p. 53).

Ao final dos anos 1990, as empresas da indústria de entretenimento impediam cópias piratas e a reprodução de cópias legais de seus conteúdos em equipamentos não autorizados, como aparelhos de DVD. Essas disputas geraram 
processos judiciais em diversos países contra hackers e empresas de software, para conter a reprodução online de arquivos de músicas e filmes. Por outro lado, também se intensificaram os esforços por disseminação de software livre e para que conhecimentos em informática fossem acessíveis para um maior número de usuários. Nessa época começavam a se popularizar a Internet e os softwares, que foram fruto de investimentos

Em institutos de pesquisa públicos e privados, em sua maior parte dependentes de fundos do Departamento de Defesa norteamericano, enquanto a tecnologia dos computadores pessoais foi fortemente determinada pelos interesses corporativos de manipulação e transmissão de informação, de um lado, e de ampliação e interconexão de mercados, de outro (REPORTAGEM, 2003a, p. 9).

Em estudo, a Softex (2002, p. 45) observa que as microempresas brasileiras produtoras de software geravam mais propriedade intelectual, usualmente relacionado ao foco em produto (como por exemplo, software customizável) e em pesquisa e desenvolvimento. Nos anos 2020, a indústria evoluiu para o conceito de serviços, distanciando-se do software de prateleira. Os aplicativos se inserem num conjunto de serviços que já funciona na lógica corporativa contemporânea, com enorme foco em publicidade - um exemplo sendo as redes sociais. Para além de conectar as pessoas por postagens e mensageria, elas proporcionam às empresas anunciantes um refino do que pode ser ofertado para potenciais clientes.

As críticas quanto à privacidade dos usuários e a exibição de produtos cada vez mais direcionados são consideradas pelas corporações "barreiras à competitividade" do software brasileiro, entre muitas outras (Tabela 2.13). Conforme já assinalava Softex (2002, p. 50), "as grandes empresas citam como principal barreira a questão da imagem do software brasileiro; já as micro e pequenas têm o acesso ao capital como principal barreira, e as médias destacam além desta a falta de incentivos para exportação". A carga tributária incidente sobre salário era motivo de queixa entre fábricas de software, mas o cenário se alterou muito com a reforma trabalhista aprovada em 2017 no Brasil. 
Tabela 2.13. Subdivisões da indústria de software e barreiras a seu desenvolvimento, segundo empresários do ramo.

\begin{tabular}{|c|c|}
\hline Mercado & Barreiras reportadas \\
\hline \multirow{7}{*}{ Gestão integrada (como os ERPs) } & Acesso ao capital; \\
\hline & Dificuldade em encontrar e pagar mão de obra \\
\hline & qualificada para gestão; \\
\hline & Falta de mecanismos de incentivo à exportação \\
\hline & (incentivos fiscais e facilitação); \\
\hline & Fraca cultura exportadora; \\
\hline & Compras governamentais. \\
\hline \multirow{8}{*}{ Financeiro/bancário } & Deficiência em marketing; \\
\hline & Ausência de uma política industrial; \\
\hline & Modelo brasileiro de multiplicidade de \\
\hline & conhecimento (não especializada); \\
\hline & Preferência por tecnologia importada (no mercado \\
\hline & interno) e desconhecimento do software brasileiro \\
\hline & (no mercado externo); \\
\hline & Carga tributária incidente sobre salários. \\
\hline \multirow{4}{*}{ Open software } & Preferência por tecnologia importada (no mercado \\
\hline & interno) e desconhecimento do software brasileiro \\
\hline & (no mercado externo); \\
\hline & Compras governamentais. \\
\hline \multirow{2}{*}{ Educação } & Falta de mecanismos de incentivo à exportação \\
\hline & (incentivos fiscais e exportação). \\
\hline \multirow{8}{*}{ Telecomunicações } & Falta de mecanismos de incentivo à exportação \\
\hline & (incentivos fiscais e exportação); \\
\hline & Ausência de uma política industrial; \\
\hline & Preferência por tecnologia importada (no mercado \\
\hline & interno) e desconhecimento do software brasileiro \\
\hline & (no mercado externo); \\
\hline & Burocracia (barreiras regulatórias, demora e \\
\hline & ineficiência). \\
\hline \multirow{4}{*}{ Automação industrial } & Preferência por tecnologia importada (no mercado \\
\hline & interno) e desconhecimento do software brasileiro \\
\hline & (no mercado externo); \\
\hline & Burocracia. \\
\hline \multirow[t]{2}{*}{$\overline{\text { Fábricas de software }}$} & Carga tributária incidente sobre salários; \\
\hline & Preferência por tecnologia importada (no mercado \\
\hline
\end{tabular}




\begin{tabular}{ll}
\hline & $\begin{array}{l}\text { interno) e desconhecimento do software brasileiro } \\
\text { (no mercado externo); } \\
\text { Ausência de uma política industrial. }\end{array}$ \\
\hline Compras governamentais; \\
Futomação comercial & $\begin{array}{l}\text { (incentivos fiscais e exportação); } \\
\text { Conhecimento limitado da demanda externa. }\end{array}$ \\
\hline E-business/content document & Acesso ao capital; \\
management & Falta de cultura de cooperação/associação; \\
\hline Outros & Ausência de uma política industrial. \\
\hline Fonte: elaboração própria adaptado de Softex (2002, p. 52).
\end{tabular}

Fonte: elaboração própria, adaptado de Softex (2002, p. 52).

Outros problemas relatados foram que a maioria das empresas baseia seu modelo de negócio em produtos e não em serviços, que garantem a maior fatia da comercialização, e se aproveita pouco do que é produzido nas universidades. Ademais, a pesquisa científica e tecnológica no Brasil é muitas vezes subordinada a investimentos de capital externo - com laboratórios patrocinados por corporações dentro dos campi, por exemplo -, o que afeta a produção de software, especialmente em polos de tecnologia. Muitas empresas brasileiras justamente passaram do financiamento com capital próprio para o capital externo de risco, culminando na multiplicação do modelo de negócio das startups.

A produção de empresas brasileiras no ramo de informática cresceu 20 vezes em onze anos (entre 1979 e 1990), passando de 200 milhões a 4 bilhões de dólares. Desde então, a participação das TI no Produto Interno Bruto (PIB) nacional também cresceu, triplicando entre 1991 e 2001. Em contrapartida, a política de reserva de mercado adotada nos anos 1980 (sobretudo por meio da Política Nacional de Informática - PNI, Lei n. 7.232, de 1984) definhou, dando lugar à liberação de importações e a maior abertura para integração à economia internacional, em grande parte por pressão dos EUA e ameaça de sanções comerciais: "adotou-se então uma linha de produtos sofisticados (não necessariamente os mais adequados ao desenvolvimento nacional) com os quais a tecnologia nacional não podia competir" (DIEGUEZ, 2003, p. 61). 
A respeito da reserva de mercado em tecnologia de modo geral, Furtado (2014, p. 36) destaca que foi necessário estabelecer um marco institucional nacional frente ao possível domínio do mercado por empresas estadunidenses. A ideia seria prevenir que a tecnologia acarretasse em ainda mais concentração de renda, assim como promover maior integração econômica, orientar o progresso tecnológico e alterar a organização agrária e empresarial que havia na época. Sobre a intrusão disruptiva das corporações nos espaços, o autor afirma (2014, p. 40-41), metaforicamente:

Com sua avançada tecnologia e elevada capitalização, as grandes empresas - ao penetrarem numa economia subdesenvolvida, particularmente quando apoiadas por muitos privilégios provocam efeitos semelhantes aos de certas grandes árvores exóticas introduzidas em determinadas áreas: drenam toda a água e ressecam o terreno, provocando um desequilíbrio na flora e na fauna, com o surgimento de pragas e congêneres. Com efeito, a penetração indiscriminada em uma estrutura econômica frágil de grandes consórcios, caracterizados por elevada inflexibilidade administrativa e grande poder financeiro, tende a provocar desequilíbrios estruturais de difícil correção, tais como maiores disparidades de níveis de vida entre grupos de população e rápida acumulação de desemprego aberto e disfarçado. Por causa da reduzida capacidade de controle dos governos nacionais, as grandes empresas estrangeiras já atuam com mais liberdade do que seria de esperar.

O autor sugere que, nessas condições, o desenvolvimento econômico fica comprometido pela restrita participação política, dominada pelas grandes empresas. Essa situação agrava tensões sociais e disparidades de níveis de vida entre grupos sociais e porções do território (FURTADO, 2014, p. 41) - e é exatamente o que se vê em diversos lugares com a chegada de grandes empresas da chamada "economia do compartilhamento", trazendo vetores de desordem. Também se difundem discursos sobre o suposto "gap tecnológico" entre países desenvolvidos e subdesenvolvidos, cuja ideologia recomenda que seja ultrapassado:

Identificando desenvolvimento com inovação ou progresso técnico, atribui-se a este o papel de fator determinante daquele (...). 0 paradigma da dimensão tecnológica da sociedade insere um determinismo técnico implícito, reduzindo o desenvolvimento ao progresso técnico e/ou à estratégia de negócios, negando 
automaticamente a validade de políticas e diretrizes que não estejam orientadas para fechar o gap e alcançar as sociedades de consumo afluente (RATTNER, 1984, p. 26).

Conforme explica Silveira (2009, p. 28), as tecnologias novas ou refuncionalizadas moveram a concorrência entre os lugares da escala regional para a global, aprofundando as especializações dos territórios e a divisão territorial do trabalho. Tal reestruturação escalar teve como alguns de seus impulsos "o deslocamento de parte da produção de serviços diversos e confecção de softwares para a Índia” e “a especialização dos territórios asiáticos em alta tecnologia" (idem). Em 2021, já se vê um espalhamento maior pelo mundo entre as firmas e bolsões de trabalhadores especializados nesses ramos produtivos. Associadamente, as corporações adotam um discurso determinista relacionado à suposta dissolução das fronteiras pelas TI. No entanto, como nota Arroyo (2000, p. 118),

\begin{abstract}
Embora operem na escala global, continuam sendo "nacionais", isto é, possuem uma identificação específica com o país onde têm origem. A maioria das grandes corporações japonesas, alemãs ou americanas concentra sua atuação principal nos respectivos países, nos quais funções centrais, como pesquisa e desenvolvimento, e aquelas atividades geradoras de maior valor tendem a se realizar. Por outro lado, as filiais dessas corporações mantêm o principal dos seus fluxos de importação, de tecnologia e de financiamento com as respectivas economias de origem.
\end{abstract}

Tais grupos econômicos acabam erodindo o monopólio dos Estados nacionais sobre as normas, criando uma relação de simbiose entre esses agentes e impondo suas vontades econômicas e políticas. Belluzzo (1997, p. 192) aponta que as corporações necessitam do apoio e da influência do Estado, por meio de fatores como os sistemas nacionais de ciência e tecnologia, justamente por conta dos riscos e incertezas do mercado.

Não é raro que debates sobre as TI tragam à tona expressões como o "fim da geografia" (O’BRIEN, 1992), a emergência de um "mundo sem fronteiras" (OHMAE, 1999), a "morte da distância" (CAIRNCROSS, 2001) ou a compressão do tempo-espaço (HARVEY, 2010), o que poderia transformar o mundo em uma "aldeia global" (MCLUHAN, 1962) habitada por uma "sociedade em rede" 
(CASTELLS, 1996). Por sua natureza fluida e ubíqua, de trânsito facilitado pelas infovias e dificuldade de apreensão imediata pela observação da paisagem, os bens intangíveis embaralham noções sobre a importância das distâncias, da contiguidade e da co-presença (BATHELT et al., 2004; BOSCHMA, 2005). Todos esses âmbitos, mesmo sendo parte de condições geográficas essenciais à produção, geram questionamentos tecnoutópicos e de supressão da relevância do território. Além disso, as variáveis espaciais e as distâncias (em suas várias acepções) se alteram ao longo do tempo histórico, em função de mudanças nas materialidades e nas normas (em outras palavras, nas bases técnicas e normativo-institucionais), e nos auxiliam a desvendar as características do meio geográfico correspondente.

É inequívoco, no entanto, que as TI podem ser ferramentas de subordinação à lógica global: conforme aponta Santos (2009, p. 240), “torna-se mais nítida a associação entre objetos modernos e atores hegemônicos". Associadamente, o monopólio (de conhecimentos, reputação, capacidades etc.) é importante para manter o poder das grandes firmas, pois é sua principal fonte de ganhos, mesmo que efêmero e pontual (POSSAS, 2006, p. 38). Um grande exemplo é a difusão da Internet das Coisas, com uso intenso de aplicativos para desempenhar funções cada vez mais hipertélicas, ou seja, extremamente especializadas (SIMONDON, 1989; SANTOS, 2009, p. 39). Há pelo menos uma década vem sendo trabalhada, a partir das grandes empresas de tecnologia, uma narrativa voltada à divulgação da Internet das Coisas como sinônimo de progresso, conformando uma psicosfera que prepara a implantação de uma tecnosfera que, ainda hoje, chega a poucos - já que o uso desses objetos conectados ainda é muito restrito aos agentes hegemônicos, sendo mais comum entre corporações, nos processos produtivos.

Por sua vez, os aplicativos vão se tornando mais capilarizados ao passo em que diminuem os preços de dispositivos imbuídos de TI, de maior ou menor grau de dificuldade de utilização, por diversos agentes. Nesse contexto, instala-se uma psicosfera de onipresença, instantaneidade e progresso que, acompanhada da tecnosfera, conforma "os dois pilares com os quais o meio técnico-científicoinformacional introduz a racionalidade, a irracionalidade e a contra-racionalidade no próprio conteúdo do território" (SANTOS, 2009, p. 256). Essa psicosfera é 
difundida pelas próprias corporações do setor, precedendo a tecnosfera compreendida pelos objetos informacionais portadores dos aplicativos, conforme discutiremos na próxima parte deste trabalho. 


\section{Capítulo 3. Do data center à palma da mão: usos dos aplicativos, usos do território}

O crescimento da indústria de software como serviço é intrinsicamente ligado a seu consumo, como ocorre com bens tangíveis e intangíveis em geral. Tecnologias para armazenamento e conexão entre computadores, como a computação em nuvem e a Internet das Coisas, têm significativas implicações para o consumo consumptivo e também acarretam novos modelos de consumo produtivo. É possível observar tanto novos usos do território quanto a imposição de consensos e "novidades regulatórias" por grandes empresas do ramo, no contexto do novo neoliberalismo.

Entretanto, não se pode esquecer o fato de que as grandes firmas teleoperadoras são, há décadas (especialmente após as privatizações no ramo, nos anos 1990) e mesmo antes da popularização da Internet, agentes de grande influência que usam o território como recurso. Por outro lado, também existem cada vez mais usos alternativos aos hegemônicos, pela possibilidade de maior comunicação entre os agentes, potencialmente contribuindo para a criação e o reforço de articulações políticas e sociais.

Os usos dos aplicativos se desenham conforme a localização dos agentes (por exemplo, em áreas urbanas ou rurais, com maior ou menor acesso a conectividade), quanto às formas de organização social que adotam - como é o caso de comunidades que se organizam para criar aplicativos, ou de trabalhadores do ramo que decidem reivindicar mais direitos -, ou ainda conforme suas necessidades: por exemplo, grandes firmas produtoras de aplicativos podem se associar para resolver problemas comuns ou realizar lobbies quando se envolvem em impasses regulatórios.

Algumas pautas de debates contemporâneos que emergem dos usos possíveis das TI e da telemática compreendem, por exemplo, a questão da privacidade e da proteção de dados pessoais (cada vez mais coletados e comercializados pelas grandes firmas, com potencial para uso comercial e de 
vigilância em massa), a Internet das Coisas e a apropriação do termo "economia do compartilhamento" pelas empresas produtoras de software como serviço (ZANATTA, 2017). Por isso, conforme ressalta Blanco (2015, p. 18), é fundamental não dissociar o estudo da informação e das redes técnicas dos complexos processos sociais que as originam, constroem, operam, transformam, definem sua obsolescência e suas condições de uso. Trata-se de não entender essas tecnologias apenas do ponto de vista dos objetos e sistemas de engenharia, mas também como portadoras de projetos resultantes da ação social (RIBEIRO, 2000; 2014).

A associação entre a Internet e dispositivos como os celulares e computadores gerou ainda um importante mercado de consumo de produtos financeiros, conforme apontam Schiaffino e Parserisas (2019, p. 18). Tais produtos são oferecidos pelos circuitos superior e superior marginal da economia urbana, nas plataformas e nas propagandas em redes digitais. Isso é possível pelo tamanho grau de importância das finanças na organização das empresas e na vida cotidiana, intermediando diversas atividades. Observa-se um movimento das partes para o todo, descrito por Santos (1984, p. 17):

Atualmente, com a internacionalização das técnicas, da produção e do produto, do capital e do trabalho, dos gostos e do consumo, a mundialização das relações sociais de todos os tipos (econômica, financeira, política...) é a garantia de universalidade que permite compreender cada fração do espaço mundial em função do espaço global.

O consumo é parte fundamental dessa dinâmica pois as mercadorias necessitam chegar ao mercado através das companhias e daí atingir potenciais consumidores. Nesse âmbito, as relações entre as pessoas não são diretas e imediatas, mas sim mediadas por mercadorias (BRUSCHI et al., 2016, p. 70), o que fica bastante evidente com o uso das TI para mediar relações sociais.

Para que ampliem sua base de usuários-consumidores, diversos agentes promovem, associadamente, a capilarização de redes de comunicação no território, sobretudo as de Internet de alta velocidade (banda larga), por meio de políticas públicas e ações privadas. Ao mesmo tempo, os agentes hegemônicos pressionam pela adequação de normas a seus planos e interesses, inclusive reunindo equipes 
jurídicas especializadas.

No período da globalização, se instaura um "sistema ideológico tecido ao redor do consumo e da informação ideologizados", que se baseia em modernos objetos e encadeia ações relacionadas (SANTOS, 2000, p. 49). Com os avanços na informatização do território, a infraestrutura de conectividade já não é mais tão visível na paisagem, mas é essencial pois corresponde a

Tudo aquilo que dá sustentação para que programas, sistemas, conexões e acessos funcionem corretamente, e que muitas vezes nem é percebido pelos usuários finais. Nesse sentido, estamos nos referindo a redes de cabos, fibras ópticas, roteadores, switches, conectores, servidores etc. que possibilitam a operação de computadores pessoais e profissionais, celulares, smartphones, entre outros (CABRAL et al., 2017, p. 144).

As máquinas remotas existem pelo menos desde os anos 1970, mas o armazenamento em nuvem permite ter os dados organizados e acessíveis, o que torna o serviço ainda mais caro e complexo. São justamente a especificidade e a complexidade desses serviços que conferem ao fornecedor maior controle sobre a infraestrutura e sobre os próprios dados coletados, tornando essas técnicas menos doces ao usuário. No período técnico-científico, já eram utilizados sensores e mecanismos de automação em objetos (por exemplo, com portas que se abrem automaticamente ao detectarem uma pessoa), mas a Internet das Coisas viabilizou a comunicação entre os dispositivos, sem necessidade de comando humano - como quando máquinas agrícolas se comunicam e se movimentam autonomamente.

Isso traz a necessidade de maior conectividade no meio rural, para que os dados produzidos pela atividade das máquinas possam ser coletados, enviados e armazenados, geralmente em servidores na nuvem. Quando esse processo é feito por meio de aplicativos, o que é bastante comum, se configura seu consumo produtivo. Este foi assim descrito por Santos (1993) "porque gera novas demandas produtivas no campo e intensifica as trocas entre os lugares de produção agrícola e as cidades". Por outro lado, o consumo consumptivo "se torna mais expressivo na medida em que ocorre o aumento dos rendimentos e salários da população" (ALVES, 2015, p. 229). 
No processo de consolidação de uma psicosfera que promove o consumo por meio das redes digitais, tem-se por um lado o crescimento do uso de celulares no Brasil e no mundo e, por outro, o surgimento de agentes como os "influenciadores digitais", que ajudam a moldar novas necessidades de consumo. Também extremamente relevante é o grupo de empresas que operam tanto a tecnosfera quanto a psicosfera, como expresso na discussão sobre os projetos da Google para implantação de cabos submarinos no continente americano.

A chamada "economia dos aplicativos" traz consigo uma miríade de novas definições e denominações, tais como "economia de plataforma", "capitalismo de dados", "capitalismo cognitivo" e "economia do compartilhamento". Em geral, todos os termos se referem à intermediação da prestação de serviços praticada por empresas de TI. Ainda que haja micro, pequenas e médias empresas produzindo aplicativos para essa finalidade, o mercado brasileiro é dominado pelas corporações, sobretudo as estadunidenses.

O funcionamento dessas plataformas consiste essencialmente em sistemas baseados em mecanismos de reputação, em publicidade direcionada e na coleta massiva de dados pessoais na Internet. Sua arquitetura técnica, em vez de descentralizar o conteúdo - como se poderia esperar numa rede de tipo "todos para todos", como é a Internet, e com a comunicação facilitada por características das redes digitais - acabou por centralizá-lo em torno de poucos websites e programas (como Facebook, Instagram e Twitter). Táticas da extrema direita têm se beneficiado desse modelo para disseminar discursos de ódio e informações falsas, com sérias consequências para a democracia em uma série de países. Como sugere Silva (2014, p. 28-29), no período da globalização, cresceu o número de pessoas com maior escolaridade, mas isso não é sinônimo de ampliação de sua consciência de mundo:

Trata-se de um contexto recente - décadas de 2000 e 2010, atravessado pela intensificação da racionalidade tecnocrática e desenvolvimentista que se une à produção da sociedade de consumo e à intensificação e aceleração das ações rotineiras das grandes empresas que reduzem em muito nossa compreensão do nosso estar no mundo. 
O cotidiano acelerado chega à palma da mão: a Figura 3.1 mostra que os aplicativos Facebook, Instagram e WhatsApp estavam presentes em $30 \%$ ou mais das telas iniciais dos smartphones das pessoas entrevistadas, em pesquisa de 2020. A Tabela 3.1 os agrupa em categorias, a partir da finalidade de uso. Note-se que, dos 59 aplicativos listados, quatro pertencem ao Facebook (Facebook, Messenger, Instagram e WhatsApp, no topo dos mais acessados) e cinco à Alphabet Inc. (Youtube, Google, Gmail, Chrome e Google Maps).

Figura 3.1. Principais aplicativos presentes nas telas iniciais de celulares de brasileiros.

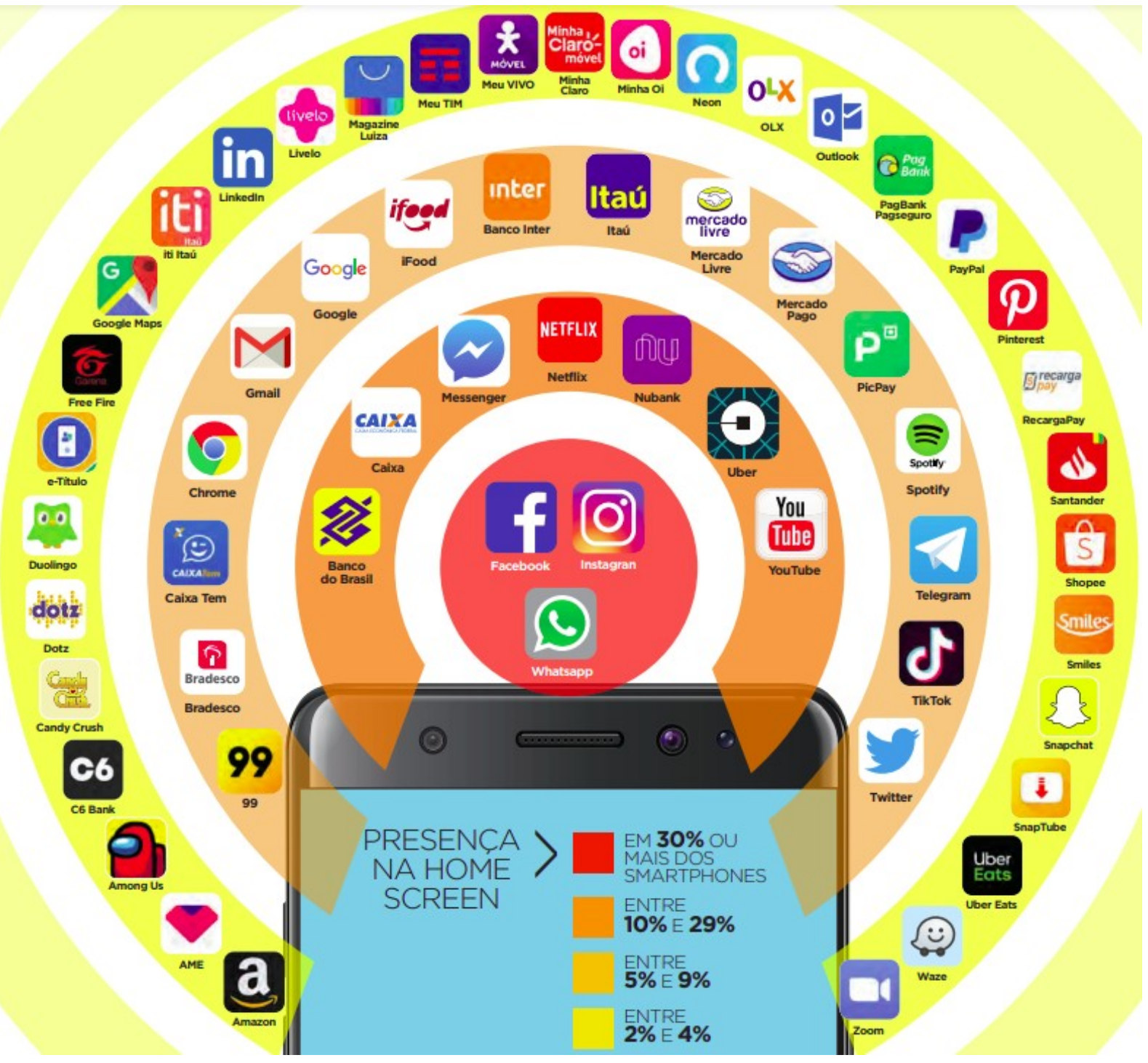

Fonte: Panorama Mobile Time/Opinion Box - Uso de Apps no Brasil - dezembro de 2020. 
Tabela 3.1. Categorias dos aplicativos mais presentes nas telas iniciais de celulares dos brasileiros.

\begin{tabular}{ll}
\hline Categoria & Aplicativos \\
\hline Comunicação e redes digitais & $\begin{array}{l}\text { Facebook, Instagram, WhatsApp, Messenger, Telegram, } \\
\text { Twitter, TikTok, Snapchat, Outlook, Gmail, Zoom, LinkedIn }\end{array}$ \\
\hline Entretenimento & $\begin{array}{l}\text { Netflix, Youtube, Spotify, Among Us, Free Fire, Candy } \\
\text { Crush, Pinterest }\end{array}$ \\
\hline Finanças & $\begin{array}{l}\text { Banco do Brasil, Caixa, Caixa Tem, Nubank, Banco Inter, } \\
\text { Itaú, iti Itaú, Bradesco, Santander, C6Bank, Neon, PayPal, } \\
\text { PicPay, PagBank Pagseguro }\end{array}$ \\
\hline $\begin{array}{l}\text { Comércio eletrônico e } \\
\text { programas de pontos }\end{array}$ & $\begin{array}{l}\text { Mercado Livre, Mercado Pago, OLX, Magazine Luiza, } \\
\text { Shopee, Smiles, Amazon, iFood, Uber Eats, Dotz, AME, } \\
\text { Recarga ou gerenciamento de } \\
\text { planos de conexão móvel }\end{array}$ \\
$\begin{array}{ll}\text { Transporte } \\
\text { Ferramentas de busca e } \\
\text { download }\end{array}$ & Google Maps, Waze, Uber, 99 \\
\hline Serviços públicos & Chrome, Google, Snaptube \\
\hline Educação & Duolingo \\
\hline Fontulo
\end{tabular}

Fonte: elaboração própria, a partir de Panorama Mobile Time/Opinion Box - Uso de Apps no Brasil - dezembro de 2020.

Silveira (2015, p. 15) observa que boa parte do lucro das corporações de tecnologia vem do que chama de uma "microeconomia da interceptação de dados" coletados nas plataformas e nos serviços web:

O grande valor do Google não está em seus milhares de servidores, prédios, veículos ou terrenos, mas na sua capacidade de obter dados de milhões de pessoas no planeta e cruzá-los a fim de formar perfis de consumidores potenciais, organizar as características finas dos comportamentos e agrupar os diversos tipos de preferências culturais, econômicas e até mesmo ideológicas. $\mathrm{O}$ grande negócio do capitalismo cognitivo é a modulação dos comportamentos. Para isso, é indispensável obter informações constantes, se possível em tempo real, dos potenciais consumidores de algo que essas corporações podem oferecer enquanto se deslocam pelo espaço, conectados por redes digitais (SILVEIRA, 2015, p. 15).

Ainda assim, uma empresa como a Google percebe a importância estratégica de ir além da receita advinda dos dados. Os investimentos em seus 
próprios celular (o Google Pixel, de 2016) e sistema operacional (o Android, lançado em 2008) garantiram a participação de $80 \%$ no mercado de smartphones e o registro de mais de um bilhão de dispositivos utilizando Android, com mais de um milhão de aparelhos novos por dia (ASSANGE, 2015, p. 53). Esses dados são avassaladores, mas dos diversos contrastes e contradições da sociedade, em relação com os objetos técnicos informacionais, emergem novas conexões entre grupos da sociedade civil organizada, pela defesa de liberdades e direitos dentro e fora das redes. Antes de tudo, elas são meios de comunicação, que também servem para emancipação.

\subsection{Conectividade e novos padrões de consumo de software na cidade e no campo}

Com a informatização do território, abriu-se uma gama de novas possibilidades para os agentes corporativos ofertarem seus produtos e serviços, por conseguirem chegar aos clientes de diversas maneiras. Conforme nota Silveira (2000, p. 124), o mercado produz heterogeneidade e "segmenta a sociedade em função do acesso possível a produtos e serviços, segundo níveis de renda". Com as TI e o big data, tal segmentação passa a ser ainda mais refinada, com categorias para além da renda, que incorporam as atividades virtuais e os gostos dos consumidores, captados pelo rastreamento de suas atividades em websites e aplicativos. São feitas sucessivas triagens nos dados, personalizando as ofertas aos usuários, num processo conhecido no ramo de entretenimento como "narrowcasting" - já utilizado no século XX com a seleção de conteúdos em fitas cassete, revistas especializadas e televisão a cabo (NEGROPONTE, 1995, p. 157).

Num cenário de crescente digitalização e acesso ao crédito em países periféricos, afloram ainda questões delicadas como a discriminação econômica baseada no traçado de perfis de indivíduos (o credit scoring) e a criação de "bolhas" de discursos e pensamentos únicos. Outra questão que se coloca é a inclusão digital, uma primeira demanda em direção à democratização das 
comunicações. Ainda assim, mesmo a parcela "ciberexcluída" da população, que não tem acesso à Internet, está sujeita à cibervigilância - seja em espaços públicos (através de aparelhos de segurança conectados via Internet das Coisas, reconhecimento facial, biometria, câmeras, drones etc.) ou quando têm seus dados pessoais coletados eletronicamente (via cartões de crédito, de transporte ou outros, quando se pedem números de documentos ao realizar-se uma compra etc.). Nesses casos, mesmo que o indivíduo não haja consentido em estar online, suas interações com o meio são compiladas e manipuladas eletronicamente, fazendo interagir as dimensões online e offline do uso de softwares.

Além disso, na América Latina a taxa de acesso à Internet é baixa, de 45 a 55\% da população (CEPAL, 2016). Isso dificulta ainda mais uma aproximação com mecanismos de proteção aos dados pessoais na rede, sobretudo diante do oligopólio das grandes produtoras de hardware e de software proprietário (nãolivre). Os Estados, de certa forma, tentam responder ao atual cenário por meio de atualizações de planos de defesa ou inteligência, apresentando "estratégias de cibersegurança" ou atuando na chamada governança da Internet. Essa prática, em escala global ou nacional, é em grande medida principiológica, ou seja, sugere diretrizes para o uso da rede, mas não regras estritas e punitivas. No entanto, normas como a recente Global Data Protection Regulation (GDPR), em vigor desde maio de 2018 na Europa, ou a regulamentação do marco civil da Internet brasileiro, de maio de 2016, podem propor condições mais efetivas a respeito da privacidade e de vários outros assuntos correlatos.

Para além das normas voltadas à Internet, existem ainda aquelas provenientes de outras áreas do Direito que são empregadas para temas digitais, principalmente em países onde não há normas específicas sobre privacidade na rede. Utilizam-se o direito do consumidor, os direitos humanos, os códigos civis e penais (sobretudo no caso de crimes virtuais), o direito empresarial (para questões entre firmas, ou mesmo sobre direitos autorais), entre outros. Todos eles estão submetidos, por sua vez, a condicionantes sociais, econômicos, históricos e culturais próprios de cada formação socioespacial.

Diante desse cenário, observamos a crescente judicialização de conflitos 
no âmbito virtual, partindo-se de um pressuposto de que qualquer problema ou reivindicação setorial na Internet, ou na indústria das TICs, seria solucionável através de leis ou da governança multissetorial, e que estas seriam neutras. É relativamente comum deparar-nos ainda com discursos de que "já não existe privacidade", o que anularia qualquer possibilidade de resistência contra a cibervigilância. Ou seja, a única saída seria aceitar que sejamos todos vigiados, a fim de garantir a segurança diante dos chamados "cavaleiros do apocalipse da informação" - o terrorismo, a lavagem de dinheiro, a pornografia infantil e a guerra contra algumas drogas (ASSANGE et al., 2013) -, ameaças que, em realidade, reproduzem o que há no mundo "não virtual" e apenas fetichizam negativamente o uso da Internet. O ciberespaço não se trata de uma dimensão paralela da realidade, mas sim intrinsecamente conectada com a concretude do espaço geográfico.

Tal narrativa passa pelo desconhecimento do usuário comum sobre o funcionamento das tecnologias. Não há meio e nem necessidade de dominar profundamente o funcionamento dos diversos aparatos técnicos que utilizamos no cotidiano; o problema é a perversa operacionalização desse desconhecimento por certos agentes, para finalidades obscuras e privatistas. Práticas como essa e a de descredenciamento da privacidade são similares ao que experienciamos nas últimas décadas, tais como as ideias de "fim do território" e "fim das fronteiras". Sua serventia vai no sentido de justificar atitudes políticas e econômicas orientadas para uma suposta inevitabilidade, de modo que se aceite o pensamento único (SANTOS, 2000) imposto pelos agentes hegemônicos.

Ainda que a Internet seja uma rede globalizada, não existe uma lei de privacidade que valha para todo o planeta, e mesmo as normas da governança da Internet encontram "fricções espaciais". A cibervigilância, por sua vez, também responde a dinâmicas geopolíticas que já operavam antes da massificação do uso da Internet: práticas de criptografia, espionagem e inteligência estatal ou empresarial são muito antigas e já possibilitavam a vigilância sobre usuários de redes de comunicação e circulação. Atualmente, um discurso baseado nisso reforça perspectivas tecnofóbicas, por um lado, e tecnossolucionistas, por outro. Isso é 
potencializado pela modernização de sistemas técnicos fora do âmbito estrito das redes de telecomunicações, como se vê no espaço urbano, em sistemas de iluminação ou controle de tráfego, conformando as "smart cities", ou mesmo no campo, quando analisamos processos produtivos com uso de agricultura digital.

A abordagem de Mazzucato (2014, p. 38-39) sobre a atuação do Estado nas atividades ligadas a investimentos de risco e à evolução tecnológica radical é interessante pois desvela os modos como esse agente é recorrentemente um protagonista na dita "economia do conhecimento", e mesmo a principal fonte de dinamismo das economias centrais no sistema mundial. Ainda que também o setor privado contribua significativamente para a criação e a difusão de inovações, foi o Estado que historicamente assumiu grandes incertezas em indústrias como as de aviação, biotecnologia, agricultura moderna, energia nuclear e, claro, computação e Internet. Ademais, é também este agente que usualmente protagoniza a garantia de infraestrutura e ordenamento jurídico que dão suporte às inovações tecnológicas. Assim se caracterizam as chamadas "incertezas knightianas" (nome originado dos estudos do economista Frank Knight), um tipo de risco tão incerto que não se pode medir e que não é atrativo para as corporações (MAZZUCATO, 2014, p. 25-26).

Um caso emblemático é o iPhone (telefone celular desenvolvido pela empresa estadunidense Apple), dispositivo que atrai grande parte do mercado de aplicativos. A Apple chegou a seu atual lugar de destaque em informática e telecomunicações por reconhecer o potencial de tecnologias emergentes, por aplicar engenharia sofisticada em tais tecnologias e por sua estratégia focada no design de produtos (MAZZUCATO, 2014, p. 134). No entanto, também recebeu investimentos massivos do Estado, direta ou indiretamente, sobretudo em três áreas:

- Investimento direto de capital nos estágios iniciais de criação e crescimento;

- Acesso a tecnologias resultantes de programas de pesquisa governamentais, iniciativas militares e contratos públicos, ou desenvolvidas por instituições de pesquisa públicas, todas financiadas com recursos federais ou estaduais; 
- Criação de políticas fiscais, comerciais ou de tecnologia que apoiavam empresas americanas como a Apple, permitindo que elas mantivessem seus esforços voltados para a inovação em períodos nos quais os desafios nacionais e/ou mundiais impediam que as empresas norte-americanas continuassem à frente, ou faziam com que ficassem atrás na corrida pelos mercados mundiais (MAZZUCATO, 2014, p. 134).

Dados do Cetic.br (2020, p. 37) mostram que existe influência das corporações do ramo de aplicativos inclusive sobre a camada de infraestrutura da Internet no Brasil. Após o início da pandemia do novo coronavírus, quando uma série de atividades (profissionais ou não) passou a ser desempenhada à distância e via Internet, registraram-se picos no tráfego web relacionados ao uso de streaming. As velocidades de download registraram aumento concomitantemente à diminuição preventiva da qualidade dos serviços de streaming de vídeos pela Netflix e pelo Facebook, que costumam operar com mecanismos que "sequestram" banda para seus aplicativos.

A tendência de crescimento nos lucros dessas e de outras empresas se estendeu por 2021, como mostram os dados reunidos por Huddleston Jr. (2021). No primeiro trimestre do ano, a Amazon teve uma receita de US\$ 837.330,25 por minuto; a Apple, US\$ 691,234.57; Alphabet, US\$ 426.805,56; Microsoft, US\$ 321.805,56; Facebook, US\$201.936,73; e a Netflix, US\$55.270,06.

Como afirma Silveira (2000, p. 125), "as grandes empresas, globais e nacionais, usam o território nacional segundo seu poder e as aptidões dos lugares", e isso não é diferente com as economias pobres. O consumo de informação "participa do alastramento de uma psicosfera modernizadora, impondo racionalidades mas também despertando ou fabricando um imaginário". Tecnosfera e psicosfera são, então, "formas de existência do meio técnicocientífico-informacional, condicionam os comportamentos e entretecem racionalidades e emoções convergentes e conflitantes" (SANTOS; SILVEIRA, 2011, p. 242-243).

$\mathrm{O}$ acesso à Internet tornou-se mercadoria no circuito inferior da economia urbana dos países subdesenvolvidos, como exemplificado na Figura 3.2. Já o aumento das conexões móveis trouxe consigo a criação de planos de consumo 
de dados mais baratos, em diferentes modalidades ofertadas pelas teleoperadoras. Na figura 3.3 podem-se ver os logotipos da estatal boliviana Entel, da Viva também boliviana, porém privada - e da Tigo, operadora colombiana. 0 crescimento desses acessos também permite ampliar o mercado socialmente necessário, com informação e pequenas quantidades de dinheiro circulando localmente a partir de tecnologias globais.

Figura 3.2. Café com oferta de acesso à Internet em Copacabana (Bolívia), 2017.

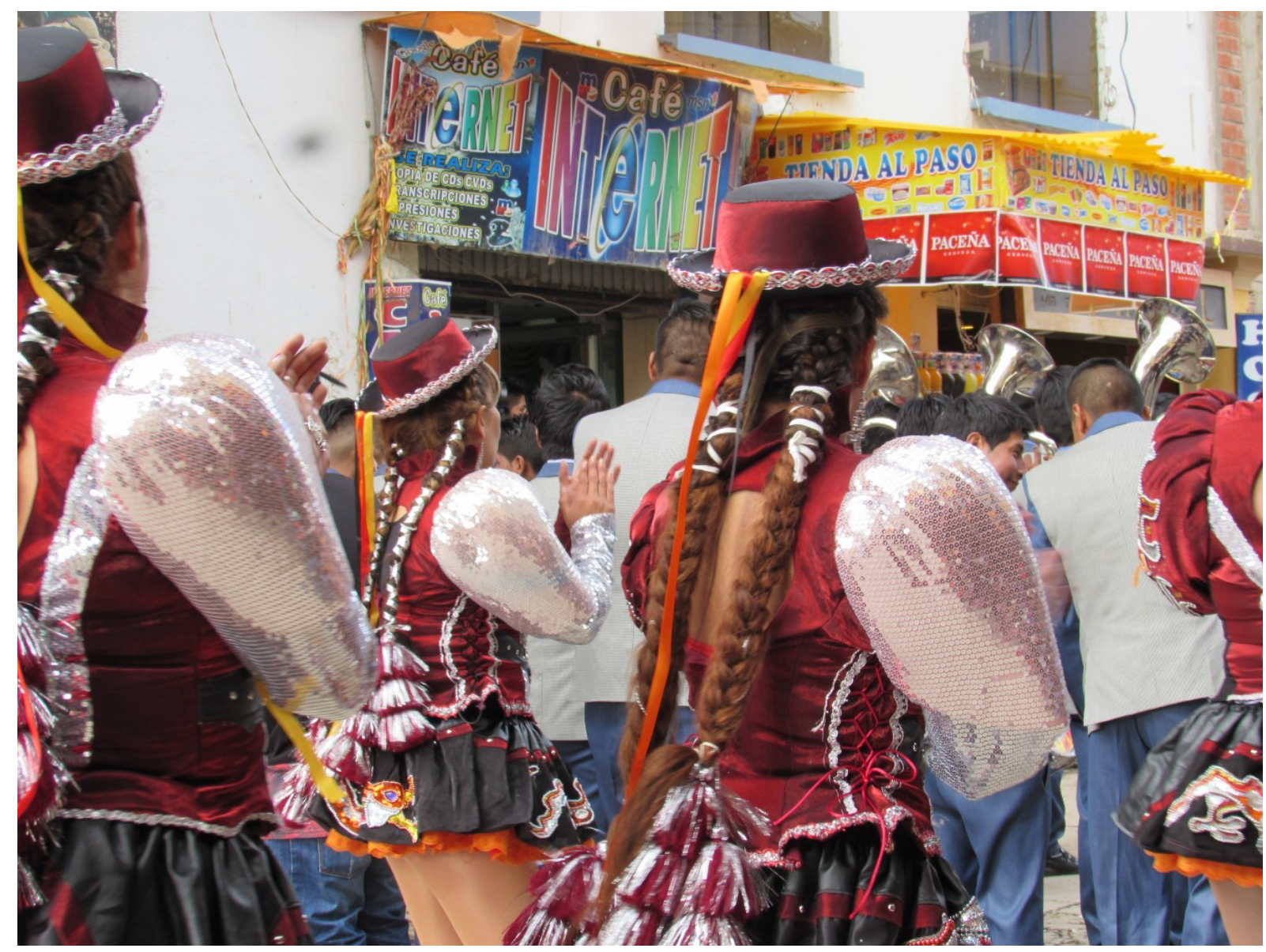

Fonte: autoria própria. 
Figura 3.3. Lojas de variedades exibindo os logotipos das operadoras de telefonia móvel Entel, Tigo e Viva em San Pedro de Tiquina (Bolívia), 2017.

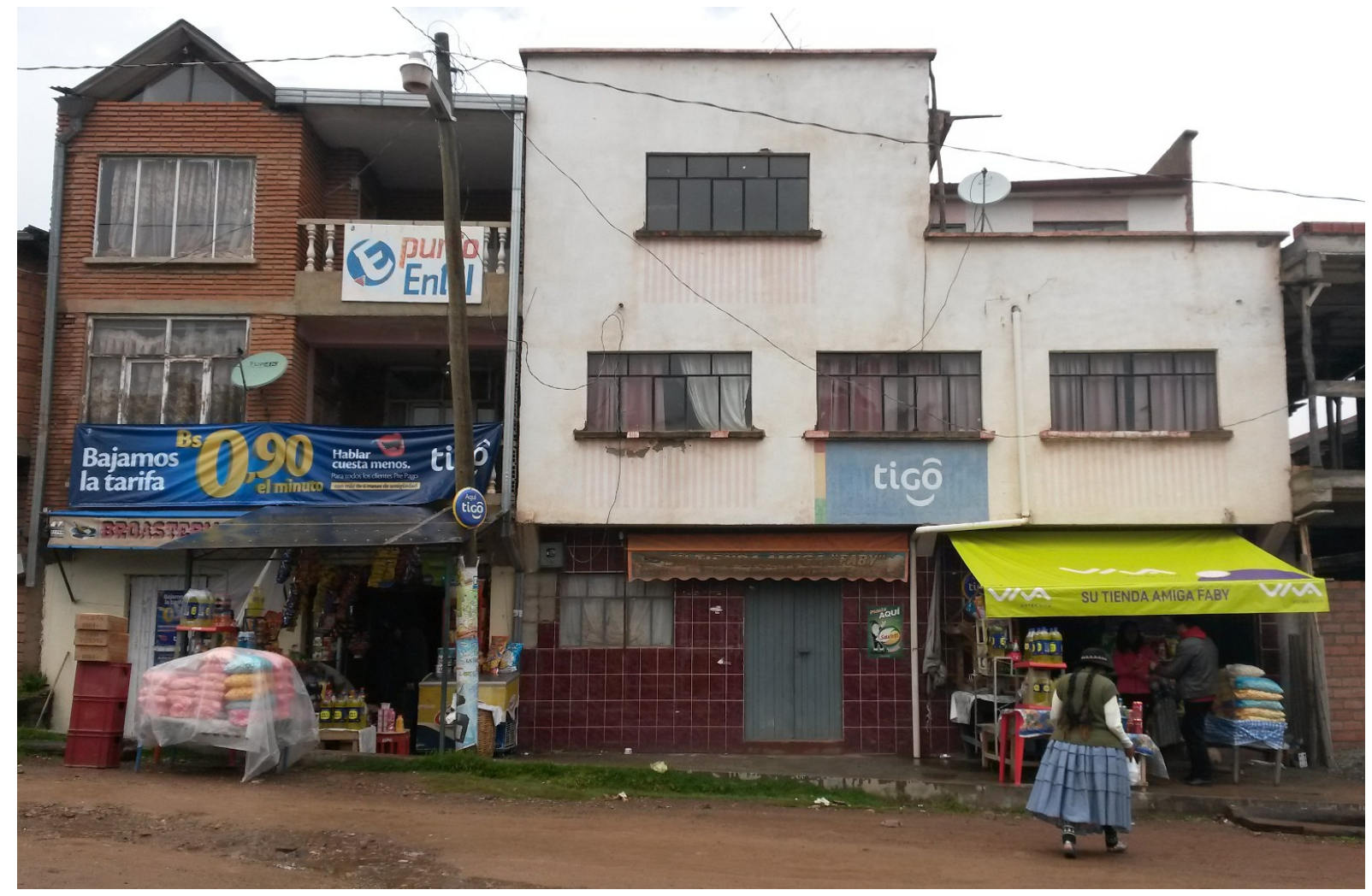

Fonte: autoria própria.

Os aplicativos voltados ao consumo produtivo dão suporte ao funcionamento de outros sistemas, automatizando-os ou tornando-os mais eficientes, especialmente no circuito superior da economia. Em análise de Schiaffino e Parserisas (2019, p. 11) sobre o banco argentino Macro, vê-se como foi desenvolvida uma tecnologia para associar o aplicativo do próprio banco ao teclado dos celulares dos clientes, como se fosse um novo canal de serviço. Este tornou possível movimentar dinheiro por aplicativos como WhatsApp, Messenger, Skype e Telegram. É justamente o fato de que os telefones móveis contém em si ferramentas para envio de mensagens de voz, imagens, músicas, correios eletrônicos, compra e venda, pagamentos, localização e integração com outros dispositivos que os torna protagonistas na economia das cidades, sendo fundamental incentivar a ampliação de sua oferta e demanda. Tais objetos 
ampliam os contextos dos agentes e transformam a vida de relações nas cidades, gerando novos nexos no território (SCHIAFFINO; PARSERISAS, 2019, p. 11). No Quadro 3.1, apresentamos um panorama das principais finalidades para as quais existem serviços online oferecidos por meio de aplicativos.

Quadro 3.1. Serviços online oferecidos por meio de aplicativos executados em dispositivos móveis.

\begin{tabular}{ll}
\hline Tipos de serviços & Exemplos de empresas que os oferecem \\
\hline E-varejo (comércio eletrônico varejista) & Alibaba, Amazon, Groupon \\
$\begin{array}{l}\text { E-viagem (inclui compra de passagens, } \\
\text { hospedagem e transporte) }\end{array}$ & Airbnb, Expedia, Uber \\
Vídeo & Netflix, Youtube \\
Música & Spotify, Pandora \\
Publicações (livros digitais) & Amazon, Kindle, Kobo \\
Jogos e apostas & Tencent, Betfair \\
Redes digitais & Facebook, LinkedIn, Twitter \\
Comunicação & WhatsApp, Skype, Snapchat \\
Busca e indexação & Google, Baidu \\
Informação e referência (enciclopédias, & Google Maps, Wikipedia \\
mapas) & \\
Serviços na nuvem & Amazon Web Services, Microsoft Azure \\
$\begin{array}{l}\text { Outros serviços (exemplos: reparos } \\
\text { domésticos, aprendizagem de idiomas) }\end{array}$ & TaskRabbit, Duolingo \\
\hline
\end{tabular}

Fonte: elaboração própria, adaptado de GSMA (2016, p. 13).

Danielle Levitas, vice-presidente executiva da empresa App Annie (que realiza análise de dados do mercado de aplicativos mundial), relata que os consumidores gastaram um total de 101 bilhões de dólares em aplicativos em 2018, em escala global. Os gastos correspondem a duas vezes o mercado global de tênis e três vezes o de produtos de higiene dental (JONES, 2020). Conforme dados de 2019 
analisados pela firma Sensor Tower (2020, p. 40-42), os maiores consumidores mundiais de aplicativos são Índia, Estados Unidos e Brasil, seguidos de Rússia e Indonésia. O Brasil só chega à terceira posição por ter o segundo maior número de usuários da Google Play Store, mas não compõe o topo do ranking para usuários de iPhone - dispositivos que são encontrados no Brasil por preços muito mais elevados do que celulares de outras marcas.

As maiores empresas donas dos aplicativos mais consumidos são as estadunidenses Facebook e Google, as chinesas ByteDance (desenvolvedora do Tik Tok) e Tencent (dona do WeChat) e a francesa Voodoo, produtora de jogos para celular (SENSOR TOWER, 2020, p. 47). O topo da lista dos aplicativos com mais downloads se manteve com WhatsApp, Facebook e Instagram em 2016 e 2017, até o lançamento do Tik Tok, que chegou ao quarto lugar em 2018 e ao segundo, em 2019 (idem, p. 57).

No Brasil, o Tik Tok liderou o ranking de downloads na plataforma Google Play em abril de 2021, seguido do Kwai (que funciona de forma semelhante, para gravação e compartilhamento de vídeos curtos) e de diversos jogos (nas versões gratuitas, Hair Challenge e Bridge Race, e nas pagas, Minecraft e Grand Theft Auto: San Andreas). O WhatsApp aparecia apenas na décima segunda posição, e o Instagram na décima oitava. Aplicativos financeiros (Nubank, Caixa Tem, PicPay e Banco PAN) foram mais baixados que as redes digitais - que provavelmente já estavam presentes nos celulares -, assim como aplicativos para serviços públicos, como Carteira de Trabalho Digital e Carteira Digital de Trânsito. Google Meet, Google Classroom e Zoom se mantiveram entre os trinta aplicativos mais baixados, por conta das necessidades de comunicação online para estudo e trabalho. Observamos, ainda, que para usuários brasileiros de iPhone, o ranking se parecia muito mais ao mundial, que discutimos anteriormente, do que com o dos usuários de Android, conforme mostram as figuras 3.4 e 3.5 (APP ANNIE, 2021). 
Figura 3.4. Aplicativos mais baixados por brasileiros na Google Play Store (30/04/2021).

\begin{tabular}{|c|c|c|c|c|}
\hline 1 & $\begin{array}{l}\text { TikTok Lite } \\
\text { TikTok Pte Ltd }\end{array}$ & 15 & & $\begin{array}{l}\text { Banco PAN - cartāo de crédito .... } \\
\text { (e) Banco PAN }\end{array}$ \\
\hline 2 & $\begin{array}{l}\text { Oo Kwai - Watch cool and funny vi... } \\
\text { of, } 0 \text { OneSmile }\end{array}$ & 16 & & $\begin{array}{l}\text { Helo - Funny Video, WhatsApp... } \\
\text { POLIGON }\end{array}$ \\
\hline 3 & $\begin{array}{l}\text { TikTok } \\
\text { TikTok Pte Ltd }\end{array}$ & 17 & & $\begin{array}{l}\text { Carteira de Trabalho Digital } \\
\text { Federal Government of Brazil }\end{array}$ \\
\hline 4 & $\begin{array}{l}\text { Shopee: Compre e Venda Onli... } \\
\text { - SHOPEE }\end{array}$ & 18 & & $\begin{array}{l}\text { Instagram } \\
\text { 트 Instagram }\end{array}$ \\
\hline 5 & $\begin{array}{l}\text { Hair Challenge } \\
\text { to Rollic }\end{array}$ & 19 & & $\begin{array}{l}\text { Mercado Libre: compra fácil y r... } \\
\text { = Mercadolibre }\end{array}$ \\
\hline 6 & $\begin{array}{l}\text { Bridge Race } \\
\text { - Supersonic }\end{array}$ & 20 & & $\begin{array}{l}\text { Brainly - Home Learning \& Ho... } \\
\text { Brainly }\end{array}$ \\
\hline 7 & $\begin{array}{l}\text { Google Meet - Secure Video M... } \\
\text { Eoogle }\end{array}$ & 21 & & $\begin{array}{l}\text { Banco PagBank PagSeguro co... } \\
\text { ש PagSeguro }\end{array}$ \\
\hline 8 & $\begin{array}{l}\text { Resso } \\
\text { 트 Moon Video }\end{array}$ & 22 & & $\begin{array}{l}\text { CAIXA } \\
\text { (a) Caixa Economica Federal }\end{array}$ \\
\hline 9 & $\begin{array}{l}\text { Nubank: Conta, Cartão de créd... } \\
\text { Nubank }\end{array}$ & 23 & & $\begin{array}{l}\text { Carteira Digital de Trânsito } \\
\text { (ש) Federal Government of Brazil }\end{array}$ \\
\hline 10 & Vai Juliettel & 24 & & $\begin{array}{l}\text { CapCut - Video Editor } \\
\text { ByteDance }\end{array}$ \\
\hline 11 & $\begin{array}{l}\text { CAIXA Tem } \\
\text { C Caixa Economica Federal }\end{array}$ & 25 & & $\begin{array}{l}\text { Americanas: as melhores com... } \\
\text { B2W Digital }\end{array}$ \\
\hline 12 & $\begin{array}{l}\text { WhatsApp Messenger } \\
\text { 트 WhatsApp }\end{array}$ & 26 & 㖦回 & $\begin{array}{l}\text { QR \& Barcode Reader } \\
\text { TeaCapps }\end{array}$ \\
\hline 13 & $\begin{array}{l}\text { PicPay: Pagamentos, Transferê... } \\
\text { (ש) PicPay }\end{array}$ & 27 & & $\begin{array}{l}\text { Garena Free Fire- World Series } \\
\text { Garena Online }\end{array}$ \\
\hline 14 & $\begin{array}{l}\text { SHEIN-Fashion Shopping Online } \\
\text { Shein }\end{array}$ & 28 & 2 & $\begin{array}{l}\text { Mercado Pago } \\
\text { - Mercadolibre }\end{array}$ \\
\hline
\end{tabular}

Fonte: App Annie (2021). 
Figura 3.5. Aplicativos mais baixados por brasileiros na AppStore (30/04/2021).

\begin{tabular}{|c|c|c|c|c|}
\hline 1 & $\frac{O D}{O A}$ & $\begin{array}{l}\text { Kwai - Red Social de Videos } \\
\text { Joyo Technology }\end{array}$ & 15 & Q Google Maps \\
\hline 2 & & $\begin{array}{l}\text { TikTok } \\
\text { TikTok Pte Ltd }\end{array}$ & 16 & $\begin{array}{l}\text { PicPay } \\
\text { (A) PicPay }\end{array}$ \\
\hline 3 & & $\begin{array}{l}\text { Shopee: Compre e Venda Online } \\
\text { SHOPEE }\end{array}$ & 17 & $\begin{array}{l}\text { Spotify: Discover new music } \\
\text { :E Spotify }\end{array}$ \\
\hline 4 & & $\begin{array}{l}\text { WhatsApp Messenger } \\
\text { WhatsApp }\end{array}$ & 18 & $\begin{array}{l}\text { iFood: Delivery de comida } \\
\text { iFood }\end{array}$ \\
\hline 5 & & 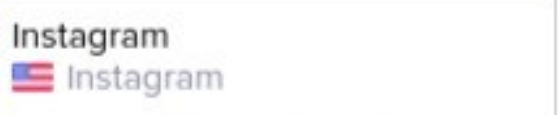 & 19 & $\begin{array}{l}\text { Google Chrome } \\
\text { EEoogle }\end{array}$ \\
\hline 6 & & $\begin{array}{l}\text { YouTube: Watch, Listen, Stream } \\
\text { E Google }\end{array}$ & 20 & $\begin{array}{l}\text { Uber - Request a ride } \\
\text { E Uber Technologies }\end{array}$ \\
\hline 7 & & $\begin{array}{l}\text { Facebook } \\
\text { EE Facebook }\end{array}$ & 21 & (A) Mercado Libre \\
\hline 8 & & $\begin{array}{l}\text { Nubank - Conta e Cartão } \\
\text { ๘ Nubank }\end{array}$ & 22 & $\begin{array}{l}\text { Carteira Digital de Trânsito } \\
\text { ( }) \text { Federal Government of Brazil }\end{array}$ \\
\hline 9 & & $\begin{array}{l}\text { Messenger } \\
\text { 트 Facebook }\end{array}$ & 23 & $\begin{array}{l}\text { AliExpress Shopping App } \\
\text { Alibaba }\end{array}$ \\
\hline 10 & & $\begin{array}{l}\text { Gmail - Email by Google } \\
\text { E Google }\end{array}$ & 24 & $\begin{array}{l}\text { Google Photos } \\
\text { (A Eoogle }\end{array}$ \\
\hline 11 & & $\begin{array}{l}\text { SHEIN-Fashion Shopping Online } \\
\text { Shein }\end{array}$ & 25 & $\begin{array}{l}\text { CAIXA } \\
\text { Calxa Economica Federal }\end{array}$ \\
\hline 12 & & $\begin{array}{l}\text { Google Meet } \\
\text { 트 Google }\end{array}$ & 26 & $\begin{array}{l}\text { Ra Caixa Tem } \\
{[0 \text { Caixa Economica Federal }}\end{array}$ \\
\hline 13 & & $\begin{array}{l}\text { Google } \\
\text { E Google }\end{array}$ & 27 & $\begin{array}{l}\text { Carteira de Trabalho Digital } \\
\text { Federal Government of Brazil }\end{array}$ \\
\hline 14 & & $\begin{array}{l}\text { Telegram Messenger } \\
\text { Telegram }\end{array}$ & 28 & $\begin{array}{l}\text { Netflix } \\
\text { 트 Netflix }\end{array}$ \\
\hline
\end{tabular}

Fonte: App Annie (2021).

De acordo com a $31^{\mathrm{a}}$ Pesquisa Anual do Uso de TI nas Empresas, publicada em 2020 pela Fundação Getúlio Vargas (FGV) com base em dados de mais de 10.000 médias e grandes empresas brasileiras de capital privado, existem 424 
milhões de dispositivos digitais (computador, notebook, tablet e smartphone) em uso no Brasil, ou uma média de dois por habitante. Por conta da pandemia de Covid-19, acelerou-se a digitalização de muitas empresas, mesmo com a retração da economia. Os projetos de modernização conduzidos pelas companhias foram identificados majoritariamente nas áreas de Inteligência Analítica (Analytics), novos Sistemas Integrados de Gestão (ERP), Governança de TI, Inteligência Artificial e Internet das Coisas. As categorias de softwares mais usadas são de correio eletrônico (25\%), navegação na web (21\%), planilha eletrônica (18\%), processamento de texto (9\%), bancos de dados (8\%) e gráficos (5\%) (MEIRELLES, 2020).

Ainda segundo a pesquisa, as firmas aumentaram seus investimentos e gastos com TI para em média $8 \%$ de suas receitas, resultando em um custo anual médio de $\mathrm{R} \$ 52.000,000$ por funcionário - abaixo apenas dos gastos nos segmentos financeiro e de comunicações. Quanto aos programas mais utilizados, no ramo de Inteligência Analítica (Business Intelligence and Analytics) as corporações cujos produtos dominam o mercado são, na ordem, SAP (25\%), Oracle (16\%), Totvs (15\%), Microsoft (14\%), Qlik (13\%) e IBM (8\%), somando 91\% do total. No segmento de ERP, Totvs (33\%), SAP (32\%) e Oracle (12\%) somam $77 \%$ do mercado para empresas, mas a Microsoft chega a $90 \%$ do consumo de usuários finais. Observe-se que essas mesmas empresas controlam a maior parte dos serviços de computação em nuvem, como discutido no Capítulo 1 deste trabalho.

As ferramentas de ERP são recorrentes nas atividades intra-empresa, contendo softwares para monitoramento de pedidos de clientes e relações com fornecedores, coleta de dados sobre fluxos produtivos e identificação de demandas dos clientes. Daí advém uma crescente opção por marketing empresarial na Internet em vez da mídia impressa, pois esse recurso também está disponível nos ERPs, com redução de custos com propaganda e comércio eletrônico (LA ROVERE, 2006, p. 296-297).

A respeito do e-commerce, Venceslau (2019) nota que ele contribui para intensificar a lógica do consumo, mas de modo condicionado às características técnicas e políticas dos lugares, que afetam a circulação das mercadorias. Os fluxos 
são ainda centralizados nas metrópoles, mas os espaços de consumo apresentam maior desconcentração, ainda que de modo heterogêneo. Não se trata, portanto, de uma dicotomia entre o "virtual" e o "material", mas sim de uma relação de complementaridade entre essas instâncias.

Uma das maiores fontes de consumo de entretenimento (sobretudo de música e vídeos) nesta segunda década do século XXI são os aplicativos para streaming, que possibilitam a transmissão e reprodução de mídias ao vivo ou gravadas. $\mathrm{Na}$ indústria musical, os meios digitais estão gradativamente substituindo os físicos, trazendo a reboque quedas na arrecadação dos artistas, em geral pelo download de álbuns e canções ilegalmente. Ainda assim, o modelo de acesso digital é mais prático que o analógico, e o Brasil é o terceiro país que mais usa streaming de música licenciado no mundo (MENEZES, 2017).

Alguns dados do ramo indicam que esse modelo é mais vantajoso para as gravadoras do que para os artistas. 0 streaming possibilita a elas monetizar o catálogo de canções já disponíveis, não focando tanto nos lançamentos. Além disso, as gravadoras recebem verba de acordo com os ouvintes, em plataformas como Youtube (onde $95 \%$ dos brasileiros escutam música), Deezer e Spotify. Mesmo o perfil de consumo dos usuários vem se alterando nesta época do streaming, quando utilizam tais serviços para descobrir novos artistas ou focar mais em playlists ou canções isoladas e menos em álbuns - o que é influenciado pela própria recomendação dos algoritmos das plataformas (MENEZES, 2017).

Entre agosto de 2014 e agosto de 2017, foram contabilizados 134 bilhões de "plays" (quantidade de vezes em que um vídeo é reproduzido) no Youtube em 1.245 cidades brasileiras, correspondentes a $75 \%$ da população (MARIANI; TAKAHASHI, 2017). Mas especialistas do ramo ainda crêem que o sucesso de uma canção no país depende do rádio, que sustenta o domínio das gravadoras. Mesmo que haja maior facilidade em consumir conteúdo sem pagar por ele, tecnologias como a blockchain possibilitam certificar os direitos autorais por uma peça fonográfica. Outra opção é utilizar plataformas diferentes, como as redes sociais digitais, para criar um vínculo mais próximo entre artistas e seus fãs, encorajando estes a apoiar os ídolos com a compra de produtos ou de sua música. 
Em cidades de pequeno porte, com até 50 mil habitantes, as rádios passaram a adotar o modelo de streaming, acompanhando a popularização dos smartphones com acesso à Internet. Um exemplo de aplicativo gratuito com milhões de downloads é o MobiAbert, viabilizado pela empresa curitibana Access, de gestão de emissoras de rádio. Startups também se unem às pequenas rádios, como é o caso da Ciclano, vinculada à aceleradora canadense Launch Academy. A inspiração para esse modelo de negócio também vem do exterior, como do serviço TuneIn (FIGUEIRÓ, 2018), no ar desde 2002.

Outros exemplos de consumo automatizado por meio de aplicativos são o autoatendimento em redes de alimentação rápida (fast-food), do McDonald's ao grupo Carrefour; tradução de manuais de carros (como o Meu Volkswagen); e comandos de voz e vídeo para idosos em serviços de firmas como Gol, para embarque nos voos, Renner, para busca por imagens, e Bradesco, em parceria com o laboratório InovaBra Lab, que congrega startups nacionais (PERRIN, 2018b; RIBEIRO, 2018; SOARES, 2018).

$\mathrm{Na}$ conjuntura da banalização das técnicas, a capilarização dos aplicativos se dá tanto na cidade quanto no campo. Neste último, não se trata apenas do uso para a agricultura científica e globalizada, mas também por pequenos produtores rurais, cooperativas, grupos de indígenas e camponeses. Ao lançar o Plano Safra 2020/2021, o Ministério da Agricultura, Pecuária e Abastecimento (Mapa) incluiu o aplicativo PSR - Programa de Seguro Rural, desenvolvido em parceria com a Embrapa Informática Agropecuária, para que os produtores possam conhecer opções de seguro rural (BRASIL, 2020). Já no âmbito do Programa de Aquisição de Alimentos (PAA), organizações da agricultura familiar podem utilizar o aplicativo PAAnet Proposta, desenvolvido pela Companhia Nacional de Abastecimento (Conab), para envio de suas solicitações às superintendências regionais via Internet (LOPES; FORNAZIER, 2015, p. 41).

A Universidade Federal Rural da Amazônia (UFRA) e a Organização das Cooperativas Brasileiras no Estado do Pará (OCB/PA) criaram o aplicativo Compras Coop-Pa, em 2020, para intermediar o acesso da população a produtos de 62 cooperativas, envolvendo cerca de 3.600 produtores rurais cooperados que tiveram 
suas vendas prejudicadas durante a pandemia de Covid-19 (ICIBE, 2020). Mas o mercado também está interessado em atingir a agricultura familiar, que corresponde a 4 milhões de produtores: o DataLab da Serasa Experian lançou um aplicativo do tipo marketplace, que funciona como um "shopping virtual de crédito voltado para o produtor familiar (...) [para] aproximar o sistema financeiro dos potenciais interessados em tomar esses recursos". A Serasa deve emprestar R\$ 1,25 bilhão na fase inicial de funcionamento da plataforma - desenvolvida após a compra da empresa de big data Brain Ag, voltada para operações financeiras rurais -, e recebe uma comissão pelos negócios bem-sucedidos (DE CHIARA, 2021).

No agronegócio, existe um abrangente círculo de cooperação voltado à ampliação da tecnosfera. De 2012 a 2017, R\$ 20,6 milhões foram investidos em 41 projetos de ciência, tecnologia e inovação pela Financiadora de Estudos e Projetos (FINEP) em subvenção para empresas nas regiões Norte, Nordeste e Centro-Oeste do Brasil. Esses valores não precisam ser reembolsados, assim como os $\mathrm{R} \$ 321,9$ milhões destinados a 84 convênios com universidades e institutos de ciência e tecnologia públicos (por exemplo, para bolsas de pesquisa). Além disso, foram liberados $\mathrm{R} \$ 573,8$ milhões em empréstimos para 13 projetos, com taxas de juros muito inferiores às praticadas pelos bancos. Ainda assim, apenas 35\% dos investimentos em inovação no país são destinados às três regiões mencionadas, onde se localizavam 300 de 2.500 das micro e pequenas empresas beneficiadas (STEPHAN, 2018).

Vários dos investimentos são para projetos envolvendo startups em parques tecnológicos. Outros abarcam montadoras automobilísticas (inclusive com desenvolvimento de veículos elétricos, em Anápolis e Goianésia) e laboratórios farmacêuticos, no estado de Goiás. No Parque Tecnológico de Mato Grosso (em Várzea Grande), foi desenvolvido o aplicativo MaqFacil, com a finalidade de conectar donos de equipamentos agrícolas ociosos a fazendeiros que necessitam das ferramentas, mas não possuem a verba necessária para investir nelas (STEPHAN, 2018).

Especialistas técnicos e gestores públicos identificam gargalos relacionados à falta de acesso digital nessas regiões do Brasil, que impactam 
sobremaneira os pequenos agricultores. A agricultura familiar representa $84 \%$ da produção rural brasileira, de acordo com o extinto Ministério do Desenvolvimento Agrário, mas recebe pouco dos benefícios da inovação tecnológica. A agricultura de precisão e a coleta de dados podem possibilitar, por exemplo, o estabelecimento de planos de avaliação do solo para melhor planejamento da colheita. Mas tudo isso esbarra em dificuldades de conexão à Internet, um problema diretamente relacionado à localização do produtor e ao interesse das teleoperadoras em oferecer seu serviço ali (ROSA, 2018). Como observam Santos e Silveira (2011, p. 11), as "inovações técnicas e organizacionais na agricultura concorrem para criar um novo uso do tempo e um novo uso da terra", e o Estado é um agente ativo na globalização da agricultura no Brasil, por meio de diversas políticas públicas (por exemplo, de crédito rural) ao longo dos anos.

Um exemplo de espaço onde se podem reconhecer os círculos de cooperação que balizam a difusão das TI em diversos ramos econômicos, incluindo a agricultura, são as feiras. A Agrifutura, ocorrida no Instituto Biológico de São Paulo (SP) em 3 e 4 de março de 2018, apresentou aplicações das TI no agronegócio, contendo fórum de palestras, mostras de pesquisas e startups, exposição de tecnologias inovadoras e um hackathon (no qual pessoas interessadas em assuntos como clima, doenças e pragas, comercialização ou extensão rural se debruçam sobre um problema por algumas horas, a fim de sugerir soluções), mostrando interseções entre as "Ciências do Campo" e a Ciência da Computação.

Entre os agentes presentes na feira havia produtores rurais, pesquisadores, investidores, indústrias, comerciantes, startups, desenvolvedores de software e hackers. A realização foi feita pelo Governo do Estado de São Paulo, pela Agência Paulista de Tecnologia dos Agronegócios (APTA) (que compreende o Instituto Biológico e outras instituições de pesquisa), pela Fundação de Desenvolvimento da Pesquisa do Agronegócio (Fundepag) e pela Agência Brasileira de Desenvolvimento Industrial (ABDI). Esta última se define como "um dos agentes estratégicos da indústria 4.0" no Brasil, segundo texto em destaque no folder informativo do evento.

A mostra de startups teve a presença de 24 empresas, com produtos 
como aplicativos para gestão de negócios, equipamentos de controle de produção e pós-colheita (sensores, drones, leitores, medidores etc.), e programas de big data, machine learning e marketplace. Entre empresas expositoras com estandes havia John Deere, Bayer, Embrapa, Banco do Brasil, Sicoob, MundoCoop e CATI. As palestras contemplaram os temas big data e Internet, serviços tecnológicos, agricultura digital, Internet das Coisas e gestão agronômica.

Alguns exemplos de empresas participantes e suas tecnologias continham empresas produtoras de software para gestão agrícola, e para uso de dados via satélite para analisar folhas de vegetais. A Tabela 3.2 traz temas que foram debatidos no evento e as tecnologias desenvolvidas por organizações, que demonstram a capilaridade do meio técnico-científico-informacional no agronegócio. A Figura 3.6 mostra uma nuvem de palavras no folder da feira, contendo "aplicativos" e outras tecnologias como temas de destaque. 
Tabela 3.2. Temas relacionados às TI tratados em palestras na feira Agrifutura (2018).

\begin{tabular}{|c|c|c|}
\hline Tema geral & Tema da palestra & $\begin{array}{l}\text { Empresa ou instituição } \\
\text { expositora }\end{array}$ \\
\hline Pós-colheita & $\begin{array}{l}\text { Avaliação por } \\
\text { imagem/seleção robótica }\end{array}$ & $\begin{array}{l}\text { Instituto Agronômico de } \\
\text { Campinas }\end{array}$ \\
\hline Pulverização controlada & $\begin{array}{l}\text { Aplicativo e papel } \\
\text { hidrossensível }\end{array}$ & DropScope \\
\hline Big data & Estações para sensoriamento & Scicorp \\
\hline Pós-colheita & $\begin{array}{l}\text { Medição de indicadores em } \\
\text { frutas }\end{array}$ & Fit Instruments \\
\hline Genética & $\begin{array}{l}\text { Melhoramento genético de } \\
\text { frutas }\end{array}$ & $\begin{array}{l}\text { Instituto Agronômico de } \\
\text { Campinas }\end{array}$ \\
\hline Prescrição agronômica & Monitoramento de cultivo & Agrosmart \\
\hline Fazenda inteligente & $\begin{array}{l}\text { Expansão do digital para } \\
\text { pequenas propriedades }\end{array}$ & SPVentures \\
\hline Inteligência Artificial & Sistema Watson & IBM \\
\hline Tecnologias da Informação & Monitoramento de rebanho & CowMed \\
\hline Indústria 4.0 & Integração de cadeias & ABDI \\
\hline Market place & $\begin{array}{l}\text { Como usar a Internet para } \\
\text { venda direta }\end{array}$ & The Best Coffee in Brazil \\
\hline Crédito agrícola & $\begin{array}{l}\text { Operações de troca de } \\
\text { commodities }\end{array}$ & Bart Digital \\
\hline Logística & Inteligência artificial & TEVEC \\
\hline Zootecnia & $\begin{array}{l}\text { Automação da piscicultura: } \\
\text { Classifish (classificação } \\
\text { automatizada de peixes por } \\
\text { peso) }\end{array}$ & Escama Forte \\
\hline Monitoramento e prevenção & $\begin{array}{l}\text { Detecção de incêndios com } \\
\text { câmeras e softwares }\end{array}$ & $\begin{array}{l}\text { Sintecsys (atualmente } \\
\text { umgrauemeio) }\end{array}$ \\
\hline Agricultura de precisão & Informação aérea & G-Drones \\
\hline Leitura de indicadores & $\begin{array}{l}\text { Análise do solo com } \\
\text { aplicativo Specsolo }\end{array}$ & Speclab \\
\hline Agricultura de precisão & Sistema de informações & John Deere \\
\hline Conectividade & $\begin{array}{l}\text { Conexões alternativas à } \\
\text { telefonia }\end{array}$ & $\mathrm{CPqD}$ \\
\hline Conectividade (produtor) & $\begin{array}{l}\text { Experiências de conexão } \\
\text { alternativa }\end{array}$ & Usina São Martinho \\
\hline Manejo de gado & $\begin{array}{l}\text { Monitoramento de animais } \\
\text { com aplicativo Beef Trader }\end{array}$ & Arrobatech \\
\hline Internet - Android & Comercialização de gado & Boi na Linha \\
\hline Agricultura digital & $\begin{array}{l}\text { Gestão agrícola e financeira } \\
\text { com software }\end{array}$ & Aegro \\
\hline
\end{tabular}




\begin{tabular}{lll}
\hline $\begin{array}{l}\text { Telemetria e gerenciamento } \\
\text { de dados meteorológicos }\end{array}$ & Decisões estratégicas & ATIVA Soluções \\
\hline Agricultura digital & Plataforma Biofuturo & EPE \\
\hline Sistemas de compras & Sistema Rama & Abras \\
\hline Rastreabilidade & $\begin{array}{l}\text { Novas relações } \\
\text { produtor/atacado/varejo }\end{array}$ & Pari Passu \\
\hline
\end{tabular}

Fonte: elaboração própria, a partir de folder da feira Agrifutura (2018).

Como mais exemplos de resultados dos círculos de cooperação, note-se que o aplicativo Beef Trader foi desenvolvido com financiamento da FAPESP e empregou pessoas nas ocupações de programadores e desenvolvedores web. Já no âmbito das estratégias para atração de mais usuários, a plataforma Boi na Linha é um marketplace com acesso gratuito, cujo lucro provavelmente resulta de comissões sobre os negócios fechados entre quem a utiliza.

Figura 3.6. Detalhe de folder do evento Agrifutura, ocorrido em São Paulo (SP), em 2018.

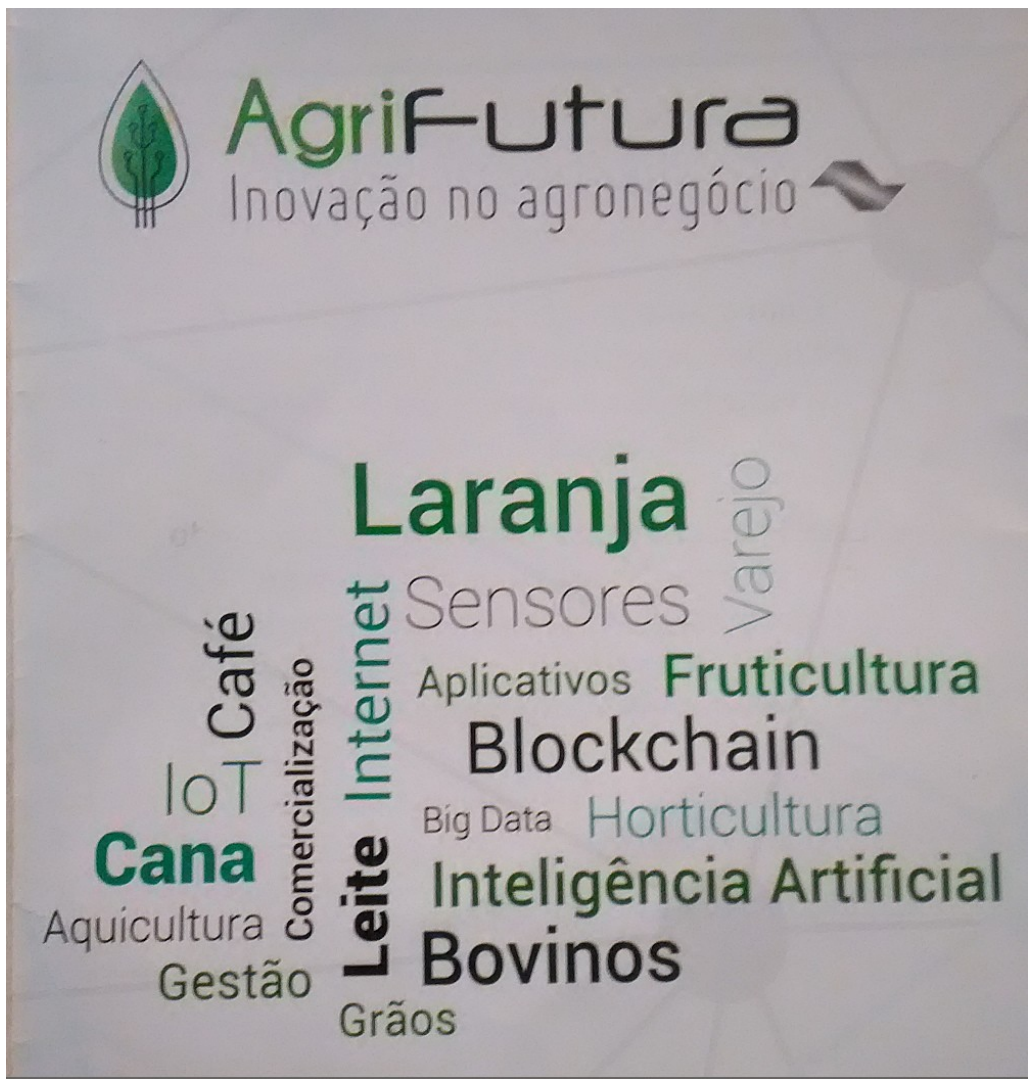

Fonte: autoria própria. 
Alves (2015, p. 250-251) aponta que, para atender às demandas da agropecuária moderna, em lugares como o município de Luís Eduardo Magalhães (BA), é necessário haver condições materiais específicas, com conteúdo informacional e científico que permita oferecer respostas econômicas imediatas às firmas que ali se instalam. Kahil (s.d.) identifica que "o espaço objetiva e é objeto de normatização da racionalidade hegemônica refletida em sua morfologia, que por sua vez (...) também induz os sistemas sócio-culturais a se adaptarem àquela ordem instituída", mesmo que não se trate de uma grande aglomeração urbana.

Dentre as modernizações necessárias à adequação do território aos vetores da globalização, são muito importantes aquelas relacionadas às finanças. 0 Brasil favorece o crescimento de fintechs, por conta da regulação que se adiantou a mudanças tecnológicas que surgiam no ramo. Elas foram regulamentadas em 2018 pelo Conselho Monetário Nacional, em dois modelos: Sociedade de Crédito Direto (SCD), em que empresas emprestam recursos próprios por meio de plataformas eletrônicas; e Sociedade de Empréstimo entre Pessoas (SEP), quando as firmas intermediam empréstimos entre empresas e pessoas ou entre pessoas (o chamado peer-to-peer lending). Ambas as modalidades também são autorizadas a realizar análise de crédito, cobranças, emitir moeda eletrônica e atuar como representantes de seguros. O capital mínimo necessário é R $\$ 1$ milhão, e fundos de investimento podem estar no controle das fintechs, desde que junto a outros investidores (PERRIN, 2018a).

Em 2016, foram investidos US\$ 161 milhões em fintechs brasileiras. Elas eram um total de 309 firmas em 2018, divididas nos seguintes segmentos: 41\% em ações variadas, de seguros a criptomoedas; $28 \%$ em pagamentos e transferências (exemplos: Moip, iZettle, PicPay, Koin, PayPal e PagSeguro); 19\% em gestão financeira empresarial (exemplos: Contabilizei, contaMobi, Conta Azul, FitBank, Conciliadora e SmartMei); e 12\% em crédito (exemplos: Creditas, Just, Avante, Biva, Geru e Easy Crédito) (PERRIN, 2018a).

O Banco Central do Brasil (Bacen) chegou a criar um laboratório de inovações financeiras, o Lift, para auxiliar empreendedores do ramo financeiro a 
desenvolver protótipos, e prestadoras de serviços de pagamento já eram autorizadas a operar desde 2013, com um grupo de estudos constituído desde 2016 no BC. Os grandes bancos tampouco se colocaram como barreiras ao incentivo às fintechs no país, e o marco regulatório nacional é considerado mais flexível que o de países como Estados Unidos e México, que também já têm diretrizes para as fintechs (PERRIN, 2018a). Percebe-se que se trata de um movimento mundial e coordenado de adaptação nas relações entre informações e finanças, em que padrões e recomendações - via tecnosfera e psicosfera, conjugadas - se espalham para alargar os espaços de atuação das grandes firmas.

\subsection{Economias do compartilhamento e o estímulo ao consumo de aplicativos: criação e difusão de novos consensos no espaço geográfico}

O uso de aplicativos para comunicação via telefone celular se popularizou imensamente, seja por mensagens escritas, figuras, sons ou vídeos. Porém, ao passo que trafega praticamente em tempo real, a informação chega acompanhada de perigosos vieses e pontos de vista restritos. Os filtros invisíveis da rede criam bolhas de conteúdo personalizado para os usuários, e seus dados são utilizados para gerar publicidade direcionada nos websites e aplicativos (PARISER, 2012). Conforme observado por Chaui $(2019$, p. 28), “a multimídia potencializa o fenômeno da indistinção entre as mensagens e os conteúdos", sejam notícias ou opiniões vindas das mais variadas fontes, nacionalidades, centros de pesquisa ou até dos influenciadores digitais.

Conforme aponta Ramonet (2019, p. 122), as plataformas online de entretenimento (Netflix, Amazon Prime, Hulu) vêm substituindo a televisão, e mesmo os aparelhos televisores são gradualmente mais utilizados para assistir a vídeos disponibilizados nessas plataformas ou no Youtube. Esses conteúdos são personalizados, consumidos individualmente ao invés de em uma cadeia de transmissão simultânea, como era o caráter de ferramenta de massas que tinha a 
televisão tradicional. Durante a pandemia do novo coronavírus, o entretenimento foi justamente uma das categorias de buscas e aplicativos mais acessadas pela população brasileira (CETIC.BR, 2020; CARVALHO; BONZO; ZENAIDE, 2020).

Os recursos mais utilizados pelos usuários no Brasil são o envio de mensagens pelos aplicativos WhatsApp, Facebook e Skype (92\%), redes sociais digitais, como Snapchat e Facebook (76\%), chamadas de vídeo por Skype ou WhatsApp (73\%), serviços de governo eletrônico (68\%), envio de e-mails (58\%), comércio eletrônico (39\%) e participação em fóruns e listas de e-mails (11\%). Notese que WhatsApp, Facebook e Skype se repetem, dado que oferecem diversos serviços de comunicação e representam um oligopólio no ramo (CETIC.BR, 2020).

Entre um dos mais populares serviços na web estão as ferramentas de indexação - cuja maior representante é a Google -, que contribuem para a concentração do conteúdo na rede, sendo denominadas "hubs" (ZOOK, 2005). Nessas plataformas, se podem realizar buscas gratuitamente, em vez de acessar diretamente os websites, atuando como um filtro à navegação na rede, reunindo o conteúdo nela disponível com o auxílio de algoritmos. Seu lucro provém da publicidade e da coleta de dados baseados nas buscas que realizam os usuários, ao mesmo tempo em que replicam uma configuração antiga do sistema capitalista, com predomínio dos países mais influentes economicamente, mesmo diante de novidades na divisão internacional do trabalho, decorrentes das inovações nas técnicas e da mundialização financeira. Para sustentar uma produção tão massiva e em escala global, as corporações realizam terceirizações em diversos países, com exploração da mão de obra em várias etapas do processo produtivo (FUCHS, 2014).

Novas formas de operar objetos técnicos incorporam-se na produção e na vida cotidiana, com a produção de um consenso que legitima as transformações trazidas com a informatização do território. Como observado por Baym (2010), Bucher e Helmond (2017) os aplicativos chegam mesmo a alterar o modo como as pessoas se relacionam. Com a criação de novas exigências, intencionalidades e necessidades através das TICs, modificam-se também as relações entre outros agentes, mediante o consumo produtivo e consumptivo, e muda a própria dinâmica do espaço geográfico, ao consolidar-se o meio técnico-científico- 
informacional nos lugares, de diversas formas.

Tornam-se mais visíveis a ubiquidade do software e da banalização do uso das TI: eles estão presentes hoje nas mais diversas atividades cotidianas, mediando desde transações bancárias até o funcionamento de grandes redes de comunicação mundial, como a Internet. As tecnologias da informação vêm passando por um processo de "docilização" (GAUDIN, 1978; TOZI, 2012), à medida que seu uso é cada vez mais difundido e imbricado aos processos técnicos; nesse contexto, o preço de dispositivos imbuídos de TI tende a diminuir e vão se configurando, então, tipos diferentes de técnicas, de maior ou menor grau de dificuldade de utilização, por diversos agentes.

Indissociavelmente da difusão da tecnosfera, ocorre a disseminação de uma psicosfera - que, como observa Kahil (s.d.), é parte do sistema sócio-cultural, tendo em vista que o território inclui elementos do "mundo dos símbolos", não apenas os objetos. A sofisticada tecnosfera que apoia a produção e o uso dos aplicativos se vale de uma psicosfera composta por termos, valores e discursos, que resultam num vocabulário próprio (ARROYO, 2006, p. 182). A psicosfera então se conforma

Como lugar de interação da sociedade que age segundo padrões morais e culturais, como sistema autônomo de produção de valores que se abre como espaço de possibilidades de emancipação do ser social. É na aprendizagem e criação das normas e dos valores sociais que se fundamenta a identidade dos homens enquanto membros de um sistema sócio-cultural (KAHIL, s.d.).

O sistema mundial moderno se constituiu a partir das navegações oceânicas, no século XVI: "apoiadas financeiramente pelos genoveses, mas organizadas por Portugal e pela Espanha, essas navegações incorporaram as Américas ao circuito comercial mundial". No seguinte século, Holanda e Inglaterra constituíram hegemonias relacionadas ao fortalecimento do modo de produção capitalista, e a Revolução Industrial transformou a base material que sustentou o processo. Aí estariam as raízes da ideia de globalização, especialmente quando se considera a revolução técnico-científica que gerou mudanças qualitativas na economia e nas sociedades (SANTOS, 2011, p. 7-8). Hoje se observa, de outro modo, 
o funcionamento desse sistema econômico e de poderes também na indústria dos aplicativos e na chamada "economia do compartilhamento".

O dito compartilhamento, no entanto, não envolve apenas postagens ou mensagens, ou a intermediação de serviços, mas também dinheiro, dados pessoais e costumes, alimentando a psicosfera que cria cada vez mais entusiasmo sobre o uso dos aplicativos. Ela fomenta mecanismos de manipulação de dados e a difusão de discursos nas redes digitais, com sérias e duradouras implicações para a sociedade, a economia, a política e os territórios.

Na chamada "economia dos aplicativos" a intermediação da prestação de serviços é apropriada por grandes empresas, que promovem a criação de sistemas baseados em mecanismos de reputação, em publicidade direcionada e na coleta massiva de dados pessoais na Internet. Isso só é possível na escala atual no contexto do big data, da mídia programática (propagandas em websites compradas automaticamente, com softwares específicos) e da computação ubíqua. Tais fatores impulsionam a geração de novas necessidades de consumo na Internet, ao passo que se retroalimenta esse tipo de economia com cada vez mais dados, para fins cada vez mais complexos e refinados.

No entanto, não se está necessariamente produzindo algo novo, mas sim se aprimorando características da economia capitalista. o compartilhamento é necessário para a circulação de bens e capital e influencia as ações no conjunto da divisão social e territorial do trabalho, mas é justamente a psicosfera que sustenta sua remodelação pelos agentes hegemônicos. Os círculos de cooperação no território, por exemplo, e as solidariedades que nele se desenvolvem, são formas de compartilhar interesses e ações deles resultantes.

Num contexto de pobreza urbana e rural, encontrado frequentemente no Brasil, a partilha é atividade antiga e cotidiana, e até forma de sobrevivência. Os agentes contra-hegemônicos podem associar-se de diversos modos, criando vínculos para resistir à enorme exploração de seu trabalho e dos lugares onde vivem. Daí emergem, inclusive, formas de comunicação, que no século XXI são mediadas pelas plataformas e difundidas mesmo entre os estratos mais pobres da sociedade, em decorrência da capilarização dos smartphones e da conectividade 
móvel. Como aponta Fernandes (2009),

As disputas territoriais não se limitam à dimensão econômica. Pelo fato do território ser uma totalidade, e multidimensional, as disputas territoriais se desdobram em todas as dimensões, portanto, as disputas ocorrem também no âmbito político, teórico e ideológico.

Os avanços tecnológicos e especialmente a automação do trabalho não necessariamente resultaram em melhores salários e oportunidades de emprego para a população em geral. A ideologia da eficiência, muito vinculada à inovação tecnológica e ao universo das TI, fomentou a criação de novos métodos na produção de bens e serviços, mas que não se traduziram em melhoria de condições de trabalho. Na realidade, quando se generaliza o desenvolvimento das forças de produção mais eficientes, decrescem tanto o valor das mercadorias quanto o da força de trabalho (BRUSCHI et al., 2016, p. 118).

Nas economias pobres, os cidadãos fazem uso das novas tecnologias introduzidas em seus cotidianos a fim de criarem novas formas de obter renda, a exemplo da Figura 3.7 - o que também apresenta fricções com as porções do território menos informatizadas e com as pessoas com menor acesso a letramento digital. Mesmo assim, os aplicativos de mensageria, de transporte e de venda de alimentos e produtos estão entre os mais utilizados por agentes do circuito inferior da economia urbana como um canal adicional de interação com seus clientes, gerando usos alternativos das plataformas.

Figura 3.7. Anúncio em Teresina (PI) oferece a chamada de carros por aplicativos mediante pagamento.

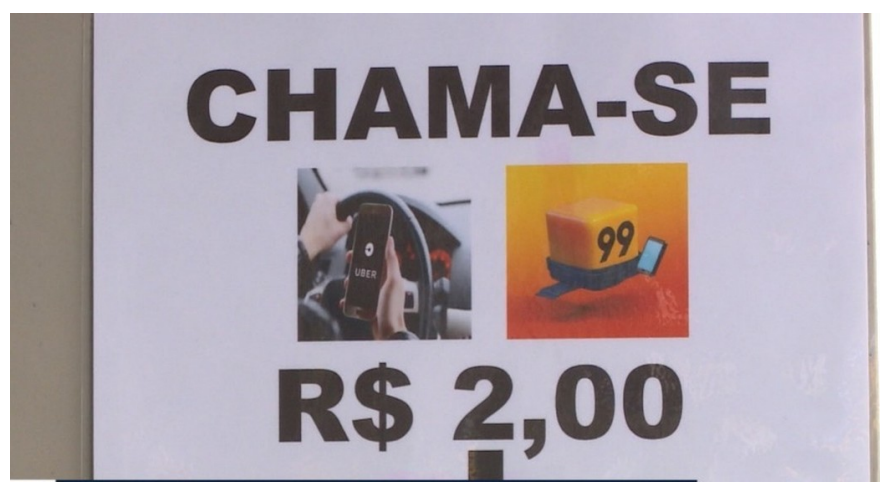

Fonte: Bom Dia Piauí (2020). 
Scholz (2016, p. 27) critica a economia do compartilhamento baseada numa "força global e massiva em favor de "construtores de pontes digitais"' que mediam pessoas oferecendo e buscando serviços, gerando processos extrativos em interações sociais. $\mathrm{O}$ autor destaca que não se trata de um fenômeno de nicho (somente nas TI, por exemplo) e mostra que plataformas de trabalho freelance em geral, como Upwork e Crowd Work, chegam a ter milhões de trabalhadores cadastrados.

Um conhecido caso pioneiro no ramo é o da plataforma Mechanical Turk, operada pela Amazon desde 2005, com o slogan "Tenha acesso a uma força de trabalho global, sob demanda, 24x7" (24 horas, sete dias por semana). Ela permite que um projeto seja quebrado em várias pequenas tarefas, escolhidas por trabalhadores (geralmente bem qualificados) cadastrados no site. Como aponta Scholz (2016, p. 42-43), nesse modelo predomina a sombra da conveniência, escondendo altíssimos custos sociais e gerando o que Huws (2014) chama de uma "absoluta densificação do trabalho".

O Ministério Público do Trabalho (MPT) apresentou um relatório em 2016 no qual descreve como característica comum em aplicativos da "economia de bicos" ("gig economy", em inglês) "o controle exercido pelas empresas sobre os trabalhadores, processos de avaliação pouco transparentes e a possibilidade de a empresa desligar o trabalhador de forma unilateral", o que não parece configurar uma simples mediação entre agentes. A empresa define, de modo sectário, diversos critérios de avaliação e o quanto o trabalhador (dito "parceiro") irá receber pelos serviços prestados, além de monitorar seu comportamento e possivelmente influenciar sua conduta. Especialistas chegam a chamar essa relação de "aliança neofeudal", como aquela entre nobres e vassalos (PRIMI, 2017, p. 30-31).

Como em outros períodos do modo de produção capitalista, os trabalhadores gastam o ganho de seu serviço para sua própria reprodução e nada para vender têm ao fim de cada ciclo produtivo, a não ser o próprio trabalho. Teoricamente, eles são livres para romper seus contratos de trabalho, caso não os favoreçam (o que costuma ser a regra); no entanto, aí mesmo reside sua dependência do processo de exploração de suas atividades (BRUSCHI et al., 2016, p. 
132; 141). No contexto da economia de plataforma, os contratos são muito mais nebulosos, tanto para os usuários quanto para quem deseja vender bens ou serviços, gerando ainda mais confusão e desigualdades entre empregados (mesmo que sejam chamados apenas de "parceiros") e empregadores.

A colaboração entre trabalhadores, tentativamente apropriada pelas corporações donas dos aplicativos mais famosos no mundo, não é um fenômeno recente e ocasiona atritos no momento em que elas tentam aportar nos lugares. Ao iniciar suas atividades em São Paulo e no Rio de Janeiro, a Uber encontrou resistência das respectivas Secretarias Municipais de Transporte e dos taxistas locais, totalizando mais de 60 mil trabalhadores. "As cooperativas [de taxistas] argumentam que pagam impostos, recolhem INSS do motorista, devem obrigações à prefeitura, enquanto os aplicativos trabalhariam totalmente informais" (ROCKMANN, 2015, p. 19-20).

Também já existiam desde o final dos anos 2000 os websites para compra coletiva, usualmente de serviços, como restaurantes ou cinema. Nesse momento já havia um debate regulatório sobre a responsabilidade das páginas web que intermediavam os serviços, quando os consumidores encontravam problemas. Passou então a haver um entendimento de que, ainda que fossem mediadoras das compras, as páginas possuíam responsabilidade, o que fez com que o segmento minguasse (ROCKMANN, 2015, p. 20). Conforme observa Kahil (s.d.): “a racionalidade que permeia a psicosfera (cujo pano de fundo é o mundo vivido) é então a mesma que normatiza a ação instrumental (que tem o sistema econômico e político como pano de fundo)".

Até 2005, 70\% do tráfego na Internet era do tipo peer-to-peer (P2P), uma arquitetura na qual os participantes da infraestrutura (ou nós da rede) têm iguais privilégios. Esse modelo se mantém, de certa forma, em projetos como os coordenados pela Wikimedia Foundation. No entanto, em meados dos anos 2000, avanços tecnológicos (incluindo as modernizações no armazenamento, que resultaram na computação em nuvem) possibilitaram o surgimento do streaming, em vez do compartilhamento de arquivos simplesmente de uma máquina à outra. Nesse período foi lançado o Youtube, uma das plataformas mais hegemônicas na 
produção e no uso político das redes, no modelo "um para todos" - como a televisão, mas com conteúdo direcionado para os usuários e possibilitando o compartilhamento instantâneo de conteúdos nas redes digitais.

Cresceu também o compartilhamento "um para um", por aplicativos que também se tornaram instrumentos políticos hegemônicos, como o WhatsApp, por conta do imenso alcance entre a população e de suas possibilidades técnicas. 0 Brasil foi o terceiro país que mais realizou downloads de aplicativos em 2019, atrás de Índia e Estados Unidos, como mencionamos anteriormente: foram 2 bilhões somente na Google Play Store (SILVA, 2019).

Os downloads não significam apenas o consumo passivo das plataformas, como também o uso por necessidade, para geração de renda: por exemplo, muitos micro e pequenos empresários de diversos ramos optam por colocar seus produtos e serviços à venda nas plataformas, que por sua vez disseminam um ideário de empreendedorismo moderno e até mesmo mais engajado socialmente. Na cidade de São Paulo (SP), a rede social Instagram promoveu a feira \#InstamarketBR, para que alguns negócios selecionados que utilizam a plataforma expusessem seus trabalhos. Nota-se, na programação das palestras (Figuras 3.8 e 3.9), uma retórica em torno da diversidade cultural e focada na identidade pessoal dos vendedores. Ademais, é interessante notar que, ainda que o consumo ocorra no meio digital, não se substituem as interações em pessoa. Também houve a presença do Serviço Brasileiro de Apoio às Micro e Pequenas Empresas (Sebrae), agente historicamente importante na assistência às firmas de menor porte. 
Figuras 3.8 e 3.9. Detalhes em banners na feira \#InstamarketBR (2019).

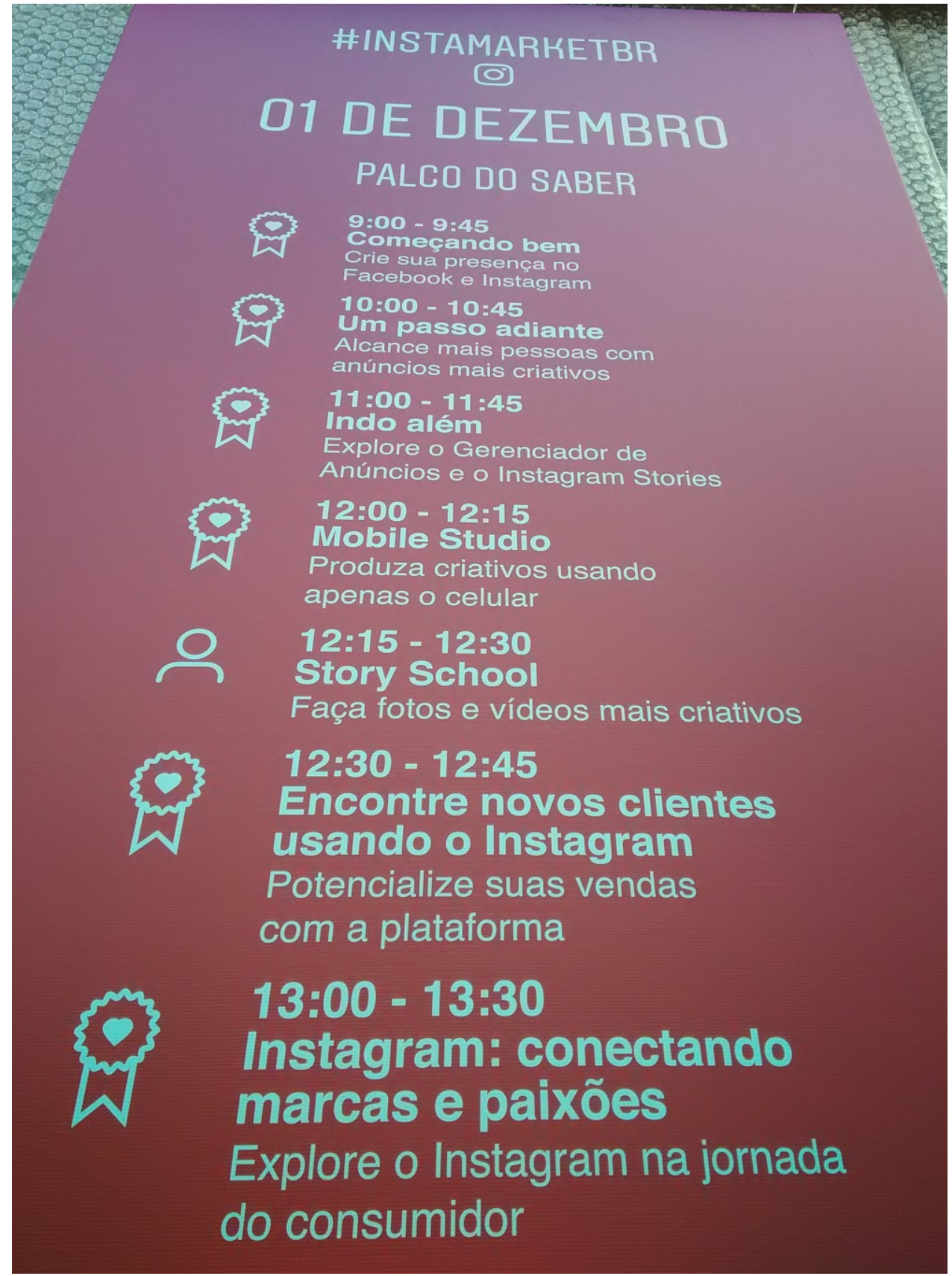




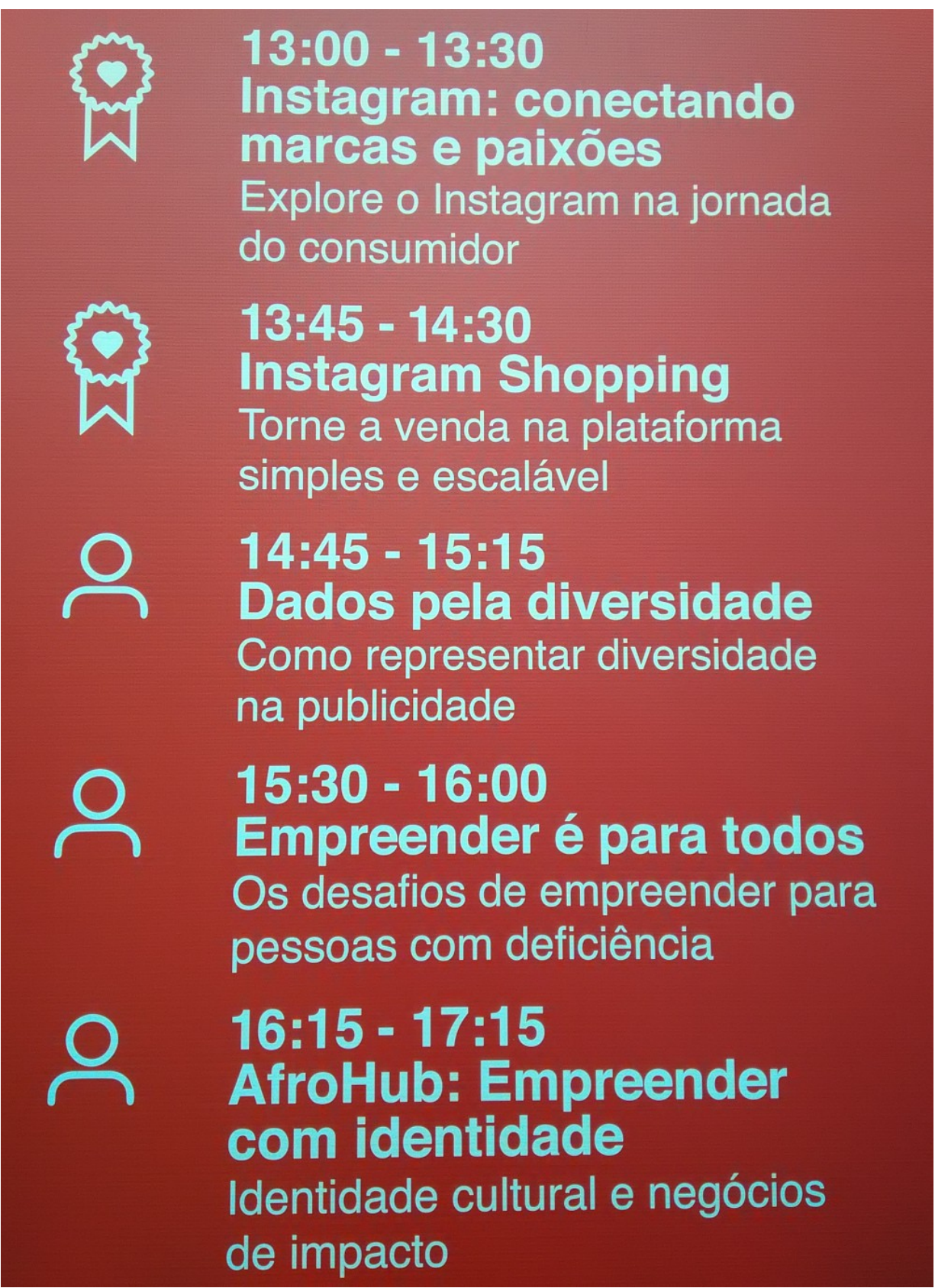

Fonte: autoria própria.

Os serviços oferecidos com intermediação de aplicativos como o Instagram acabam sendo, em muitos casos, uma extensão dos setores produtivos correspondentes. Daí emergem mudanças na organização das firmas e em suas relações internas e externas, com clientes, empregados e terceirizados. $\mathrm{O}$ antigo trabalho por peça aos poucos vem dando lugar ao trabalho por empreitada, que se intensifica com a uberização e com a contratação de trabalhadores em regime freelancer. Algumas características deste tipo de regime são, com base em Bruschi 
et al. (2016, p. 130):

- O salário por empreitada é uma medida da intensidade do trabalho;

- É mais fácil ao empregador elevar a intensidade do trabalho;

- É também facilitada a intermediação entre empregador e trabalhador;

- Estimulam-se a individualidade e a concorrência entre trabalhadores.

Ademais, como aponta Fontes (2019, p. 265), a figura dos gestores gradualmente substitui as tradicionais corporações com famílias proprietárias e contratos de longa duração, com uma expansão internacional que modifica o panorama das relações de trabalho, mas mantém a expropriação de terras e direitos.

As características fabris convivem com outras modalidades de extração de mais-valor nas quais o controle direto sobre os trabalhadores, com contratos flexibilizados ou totalmente desprovidos de direitos, permite transformar valores de uso em meios de produção, quando reunidos pela megapropriedade do capital. Esse é o caso do Uber, em que automóveis de uso corriqueiro se convertem em meios de produção apenas quando seus motoristas (proprietários ou não dos veículos) são acionados por meio de aplicativo que não apenas os conecta com passageiros, mas também controla todos os momentos da atividade do trabalhador, assim como calcula e recolhe instantaneamente o mais-valor produzido (FONTES, 2019, p. 265).

A fim de avolumar ainda mais seus ganhos, a Uber diversifica seus mercados de atuação e amplia os agentes que participam de seu círculo de cooperação. Em eventos promovidos pela empresa, são mostradas novas tecnologias em desenvolvimento, que vão desde serviços de fretamento até o transporte com carros autônomos, barcos e sistemas aéreos desenvolvidos em parceria com a Embraer e a Administração Nacional da Aeronáutica e Espaço (NASA) dos Estados Unidos. $O$ foco de sua atuação parece ser muito mais no ramo de transportes do que apenas em aplicativos.

Como observa Tozi (2020), o Brasil - especialmente as áreas metropolitanas paulista e fluminense - é o segundo território mais rentável para a Uber, depois dos EUA, sendo que São Paulo (SP) foi para a empresa a cidade mais 
rentável do mundo em 2017. Ao aportar de forma brutal nos lugares, as ações da Uber geram implicações como o aumento no costume da população de utilizar aplicativos em vez de transporte público para seu deslocamento, pressionando os orçamentos familiares a ponto de os gastos com transporte ultrapassarem os com alimentação. $O$ autor ainda afirma:

O fato de não possuírem grandes autonomias não impede que [os trabalhadores] sejam chamados de "autônomos", "empreendedores" ou "parceiros", como os motoristas e entregadores. Contudo, outras dimensões da vida social são igualmente afetadas, incluindo o território (...). Como para a empresa o território é sinônimo de mercado, e não da necessidade de deslocar-se, a Uber acabou por oferecer mais uma opção de deslocamento às áreas que proporcionalmente já possuíam as maiores densidades de sistemas públicos e privados de transporte. Resumindo: reforçou a oferta onde ela já era favorável. Sua concorrente direta, a 99 (chinesa), possui estratégia similar, enquanto a Cabify (espanhola), a InDriver (russa) e a Sity (brasileira), concentram-se em nichos de mercados territorialmente selecionados (TOZI, 2020).

A Cabify encerrou as atividades no Brasil no ano de 2021, mas ainda existem diversas plataformas de transporte e entregas operantes, especialmente nas grandes cidades, Isso pois elas preferem atuar em áreas que concentram serviços, comércio, instituições e outras modalidades de transporte, gerando pressão por reorganizações no território, dado que afetam sobremaneira a dinâmica do trânsito local. Para tornar a situação ainda mais problemática, é muito raro que as empresas do ramo publiquem relatórios sobre as viagens, veículos e sua distribuição nas cidades, mantendo privadas as abundantes informações que coletam sobre motoristas, passageiros e territórios. Nesse caso, o "compartilhamento" parece ser restrito a suas atividades internas.

É importante ressaltar, no entanto, que boa parte da população é excluída dos espaços interessantes às corporações da economia de plataforma. Os custos de conexão ainda são altos para as camadas mais pobres da sociedade brasileira, e diversos lugares - inclusive dentro de áreas metropolitanas - não possuem cabeamento de fibra óptica ou estações rádio-base próximas. Essas zonas opacas do território, que usualmente correspondem às periferias, experienciam a escassez de diversos serviços, e não é diferente com o transporte ou as entregas 
por aplicativos.

Isso não faz, no entanto, que a parcela da população que ali vive esteja distante das implicações da informatização do território. Seus dados ainda são coletados nas compras e transações bancárias cotidianas, sobretudo com a capilarização das finanças e dos dispositivos informacionais relacionados: até as chamadas "maquininhas" para cobranças com cartões de crédito ou débito foram incorporadas aos smartphones. Os hábitos e preferências dos cidadãos convertemse em valor-informação de modo instantâneo e arbitrário, sem sequer haverem concordado com dividir seus dados com terceiros. As pessoas são parte fundamental da economia política das cidades, que, como lembra Tozi (2019, p. 3), possui papel ativo na localização e na lucratividade das firmas - que, mesmo se auto-definindo como empresas de tecnologia, são completamente dependentes da materialidade do território. Como observa o autor,

A chegada da Uber ao território nacional representa a constituição de novos setores econômicos oligopólicos ou monopólicos nos quais a descentralização dos coletores de informações e de dinheiro é acompanhada da re-centralização da produção de normas e da acumulação de capital. Nessa situação, ao contrário de um mercado socialmente e localmente necessário, ocorre o fenômeno da 'vampirização' do circuito inferior pelo circuito superior, transferindo a renda que antes circulava no primeiro para o segundo (TOZI, 2017, p. 193).

As empresas participantes do circuito superior da economia apropriamse inclusive do imaginário sobre modernidade e inovação, ao qual usualmente se atribui conotação positiva e atributos de sofisticação e complexidade, ao contrário de tecnologias convencionais (RATTNER, 1984, p. 26) ou daquelas utilizadas pelo circuito inferior. Os trabalhadores informais são frequentemente classificados como ilícitos quando transgridem normas, enquanto as corporações, se fazem algo similar, são “arrojadas" e "ousadas”. Esse ideário é muito comum no ramo de TI:

A ordem mundial vai no encalço da ordem local, a partir da instauração de novas "legalidades" e "ilegalidades" no território. É o exemplo da informática, com recentes normas e fiscalizações que se alastram pelos países. Hoje, as normas globais (...) como a Business Software Alliance (BSA) pretendem acabar com as cópias ilegais de software que, nos seus cálculos, alcançam $68 \%$ dos casos na América Latina. 0 risco da heresia adota formas científicas como 
(...) a perda do direito de atualização dos programas. Fatalidade da história, esses fatos são assinalados sem relação com seus responsáveis, as corporações mundiais da informática (SILVEIRA, 2000, p. 125).

Para se adequar ao paradigma administrativo moderno, os agentes devem agir de acordo com valores e práticas sistematizados para a eficácia, o bom desempenho e o sucesso, essencialmente calcados no individualismo e no empreendedorismo (SILVA, 2015, p. 57-58). Embora trate-se de um direito, a educação é um ramo no qual esses princípios têm se proliferado, pelo uso de aplicativos desenvolvidos pelas corporações de TI. Diversos colégios de elite em São Paulo (SP) chegam a possuir um espaço físico chamado Google Learning Space (BALMANT, 2018), mas os produtos virtuais são ainda mais comuns, como o Google Sala de Aula. Em geral, esses sistemas servem para automatizar planos de estudo, evidentemente com base na coleta dos dados de comportamento dos alunos. Mesmo o poder público vem utilizando-nos com mais frequência: o Ministério da Educação escolheu um software da empresa Geekie como "plataforma de estudos oficial do Enem" (Exame Nacional do Ensino Médio).

É crítico o fato de que os tentáculos das plataformas estejam tão presentes em diversos ambientes. Elas promovem o monitoramento dos padrões de relacionamentos sociais, das páginas visitadas e palavras buscadas na web, a fim de apurar a eficácia da publicidade dirigida. Há numerosos relatos sobre situações em que os bancos de dados resultantes foram compartilhados com órgãos de inteligência de governos, por vezes com autorização dos poderes legislativo e judiciário (ASSANGE et al., 2013). Tecnologias como o aprendizado de máquina têm o potencial de serem convertidas em uma complexa forma de controle social e de difusão dos limiares entre o que é público e privado entre os usuários das TI: de acordo com pesquisa da empresa de consultoria Deloitte, em 2017, 29\% das firmas usaram jogos ou simulações virtuais para encontrar candidatos a vagas de emprego, e 28\% utilizaram redes sociais no recrutamento (CINTRA, 2018).

Um exemplo é a empresa Thinkseg, uma das chamadas "insurtechs" (do inglês, "insurance techs"), que intermedia corretores e clientes de seguradoras como Bradesco Seguros, SulAmérica e Odontoprev. O ramo de seguros tem 
utilizado extensivamente aplicativos e inteligência artificial para desenhar perfis de usuários, sendo o que mais investe em tecnologia, com uma média de US\$ 124 milhões em 2015. Os comportamentos dos usuários são registrados e previstos, a fim de ofertar novos produtos e automatizar a comunicação com clientes pelos canais virtuais, como websites (CALLEGARI, 2018). Já a Porto Seguro criou sua própria aceleradora de startups para desenvolver produtos de TI.

As startups funcionam como uma importante expressão dos nexos entre informação e finanças na economia das plataformas. Arroyo (2006, p. 179) lista como alguns dos novos principais agentes financeiros privados do período da globalização os investidores institucionais (fundos de pensão, fundos mútuos, seguradoras) e os global hedge funds (investidores que agrupam capital privado). Junto aos fundos e empresas de capital de risco (venture capital), suas atividades ao mesmo tempo potencializam a especulação e criam sinalizações para o mercado financeiro.

Entre as pequenas e inovadoras firmas de TI se mobilizam uma cadeia de fundos de investimentos, investidores independentes, incubadoras e aceleradoras. Em troca de uma participação minoritária nas nascentes empresas, estas últimas prestam assistência técnica e financeira e "adotam" as startups, oferecendo um pequeno aporte de capital, mentoria e noções de apresentação de projetos a possíveis investidores. Foi nesse contexto que nasceram políticas como o programa Startup Brasil, do Governo Federal. Mesmo com uma série de incentivos, donos de aplicativos (como Paulo Veras, do 99taxis) queixam-se de fatores como o tempo de registro da firma, obrigações legais e enquadramentos fiscais (RONCOLATO, 2013, p. 39-41).

$\mathrm{Na}$ atual fase do modo de produção capitalista, Mbembe (2017) nota que há cada vez menos preocupação com a criação de riqueza social, e se aceleram processos de desvalorização e dispensabilidade, de rápida superação e desinvestimentos naquilo que não interessa meramente à geração de mais valor. Sob a égide do neoliberalismo, a mescla das pessoas com os objetos informacionais estende a obsolescência e o descarte para a mercantilização da atenção humana, especialmente valiosa para fins de manipulação política. Torna-se mais acessível 
aos agentes hegemônicos moldar os desejos pessoais e reformular seu mundo simbólico, borrando as distinções entre o que é real e ficção (as chamadas "fake news").

Esse processo se dá com a disseminação de informações incorretas com a intenção de enganar os receptores, carregadas de sensacionalismo e linguagem emocional, e produzidas para chamar a atenção e parecer convincentes. Com a ascensão da economia de plataforma, a atenção dos usuários se tornou uma mercadoria, e para tentar obtê-la, agentes maliciosos promovem um efeito de influência contínua sobre a memória e o raciocínio das pessoas, mesmo após a correção das desinformações (LEWANDOWSKY et al., 2020, p. 5).

Não se deve desprezar, no entanto, o fato de que as TI e suas redes "criam simultaneamente racionalidade e irracionalidade, libertam e subordinam. Estimulam, também, a face ativa da sociedade, uma multiplicação interminável de atividades" (RIBEIRO, 2000, p. 21). A ampliação da conectividade traz consigo a possibilidade de indivíduos e da sociedade civil organizada produzirem novos conteúdos e conexões, dos quais podem emergir usos emancipatórios.

\subsection{Mais conexões, outros usos possíveis: as TI como campo de disputa}

Conforme visto no Capítulo 1 deste trabalho, a esmagadora maioria da população brasileira utiliza celulares para se conectar à Internet, e quase a metade utiliza apenas esse tipo de dispositivo (CETIC.BR, 2020). A introdução dos aplicativos na vida cotidiana acompanhou essa difusão da conectividade móvel, e a disponibilidade de redes técnicas mais capilares e modernas conformou novos usos do território, pelos agentes hegemônicos e contra-hegemônicos. Essa coexistência de ações e intencionalidades diante das novas tecnologias gera tensões, mas como observa Silveira (2016, p. 99), 
Apesar de sua inserção subordinada nos eventos determinantes da globalização, o circuito inferior também ajuda a produção do acontecer solidário. Graças à banalização da informação, os pobres conhecem e passam a utilizar certas técnicas que rearranjam sua divisão do trabalho. Esse fato acaba por reforçar a realização compulsória de tarefas comuns. O consumo, ancorado na publicidade e no crédito, ainda mais quando uma boa parcela dos objetos é semovente, alarga o uso dessa nova base técnica inclusive em áreas pouco modernas. Amparados na convergência técnica e nas necessidades contemporâneas da produção e comunicação de ideias, imagens e dados em geral, telefones celulares, computadores, equipamentos de fotografia e vídeo tornam-se mais acessíveis às diversas camadas sociais.

Pelo menos desde os anos 1980, tem se fortalecido a difusão de uma psicosfera que associa um "futuro ideal" à presença nos lugares de fatores como conexões rápidas via Internet, possibilidade de teletrabalho e de se acessar rapidamente o que há de mais novo no mundo. No Brasil e em outros países subdesenvolvidos, as modernizações do território são um processo incompleto, seja quanto às redes de telecomunicações ou em outras. Portanto, os subespaços recebem esses vetores de modo heterogêneo, e lidam com eles de maneiras particulares.

$\mathrm{Na}$ "economia das plataformas", a eliminação de intermediários nas compras de bens e especialmente nas contratações de serviços pode promover a redução de custos, mas também problemas como evasão fiscal, desregulamentação, aumento da informalidade e diminuição média de salários. Esses fatores são ainda mais delicados nas economias pobres, além de carregarem uma ressignificação não necessariamente positiva da ideia de compartilhamento. O "novo trabalho digital" causa desordem nos mercados locais de grandes cidades, especialmente de transporte e habitação - por exemplo, aprofundando a gentrificação em cidades onde o aluguel via plataformas se populariza (TAVOLARI, 2019).

Com a ascensão desse modelo, assentado numa perversa conexão entre informação, propaganda e geração de cada vez mais dinheiro às corporações do ramo, as "novidades" como inteligência artificial são usadas para a reprodução de padrões produtivos concebidos nos países centrais da economia capitalista. Os algoritmos utilizados nas redes digitais ou nas caixas de email são capazes de direcionar quais conteúdos aparecerão em qual ordem, e quais virão em seguida; 
um website que executa a busca de produtos com desconto pode fazê-lo com muito mais rapidez e exatidão do que um ser humano, com recursos computacionais cada vez mais eficientes. Ainda que essas funções desempenhadas pelas máquinas sejam muito atraentes, o fato de que os computadores podem aprender com os dados, a fim de tomar decisões e realizar previsões, incitam o usuário de serviços a continuar utilizando-nos sem que necessariamente se dê conta disso.

Cada interação com os aplicativos ou websites acrescenta um ensinamento ao computador sobre as opiniões e preferências do usuário, criandose um ciclo de maior sofisticação e precisão do algoritmo. A vantagem de utilizar uma máquina é que sua capacidade de processar as informações é muito maior que a de cérebros humanos, permitindo-a testar vários cenários possíveis, até escolher aquele que melhor se ajuste a um certo objetivo - por exemplo, manter um usuário engajado num site, recomendar conteúdo em serviços de streaming ou compra pela Internet, reconhecimento facial ou prevenção de fraudes bancárias. Esse processo é parte fundamental do escopo da inteligência artificial, e o software é o instrumento de medida e captura dos dados.

Daí se desenvolve uma gestão ultraespecializada do consumo. Como mostram às pessoas resultados que teoricamente são aquilo que elas querem continuar a ver, geram-se bolhas que distorcem a realidade e reforçam a mesma visão de mundo, em vez de apresentar perspectivas mais variadas. Assim podem ser perpetuados comportamentos e opiniões preconceituosos, ou ainda afetar situações como resultados de eleições, muitas vezes sem que os usuários se deem conta disso.

Esse viés também afeta os próprios programas, como ocorre com os seres humanos. Quando, por exemplo, um algoritmo para classificação de imagens é alimentado com fotografias de pessoas de um certo fenótipo (como a pele branca), ficará limitado a esses dados incompletos, tendenciosos ou pouco representativos do todo, e isso influenciará os resultados do problema que irá resolver. Eles irão reproduzir preconceitos identificados há tempos nas sociedades, num claro exemplo de como as técnicas não são neutras, e sim interdependentes das circunstâncias e agentes que as criam e operam. 
Um computador só é capaz de seguir um algoritmo quando é programado para isso, ou seja, quando recebe uma sequência instruções de um usuário ou de outro dispositivo e que consegue decodificar e obedecer, para resolução de um problema e chegada a um resultado concreto. Por isso, a regulação do uso de dados pessoais é um ponto especialmente crítico, que leva até à emergência de novas profissões, como "data protection officer", no limiar entre Computação, Direito e Economia.

Tal como escolhemos as palavras ao escrever um texto, com determinada intencionalidade, por trás de cada código escrito e executado existem pessoas decidindo os problemas a resolver, como resolvê-los, e quais dados serão utilizados nessa empreitada. Existem casos de discriminação contra mulheres em processos de seleção profissional ou em serviços de tradução automática pela Internet; de racismo em tentativas de prevenção a crimes em transporte público (via filmagens de câmeras de segurança); ou na detecção de possível reincidência em delitos entre ex-presidiários. Conforme as empresas produtoras de software se recusam a revelar seus algoritmos, os usuários ou empregados que tentam denunciar os vieses são reprimidos, e falta transparência e responsabilização na busca de resolver e evitar esses graves episódios.

Ao contrário de muitas práticas questionáveis das corporações de TI, no cotidiano das grandes cidades, o trabalho popular é criminalizado - mas encontra caminhos para ocorrer mesmo assim. Com a mediação dos aplicativos, os mecanismos de servidão podem ser potencializados, mas também podem se desenvolver novas propostas de emancipação. Assim como a História é dialética, a Internet possui um caráter dialógico que potencialmente serve a usos revolucionários. Os receptores das mensagens podem ser também produtores e difusores de conteúdo, pela própria arquitetura da rede. Como relata Souza (2015, p. 216),

Os zapatistas tornaram-se conhecidos por seu uso inteligente da Internet desde meados dos anos 1990, e foi isso que alavancou a possibilidade de encetarem uma "política de escalas" que lhes garantiu notoriedade e lhes granjeou simpatias e até uma certa proteção maior, graças à exposição de suas demandas e denúncias perante uma opinião pública internacional. Mais de quinze anos 
depois, foi a vez de a "Primavera Árabe" (e, antes disso, já no Irã) demonstrar a utilidade de um uso maciço das redes sociais para convocar manifestações e protestos em espaços públicos, simbolizados pela Praça Tahrir, no Cairo - o que, de quebra, mostrou que entre as novas tecnologias de comunicação e os protestos presenciais havia e há antes uma relação de mútua complementaridade que de substituição ou exclusão de uma pela outra coisa.

Criam-se usos não necessariamente funcionais ao processo geral de produção, e emergem entre os trabalhadores do ramo de TI organizações de solidariedade e iniciativas contra-hegemônicas. Sua atuação questiona tanto a produção dos algoritmos quanto suas condições de trabalho. Daí nascem termos como "ativismo digital" e "data-ativismo", em meio a um contexto em que mesmo os aplicativos mais difundidos (como WhatsApp e Facebook) também são funcionais a outros projetos, como mediação entre trabalhadores informais e consumidores de pequenos serviços.

Há uma capacidade de amplificação dos discursos que não era possível antes do atual grau de capilaridade das TICs. Expressa-se um potencial uso antimonopólio dessas tecnologias: por exemplo, com a miniaturização e a portabilidade das câmeras digitais, inclusive sendo parte dos smartphones, é possível gravar situações com uma facilidade impensável poucas décadas atrás. Silva (2014, p. 33) lembra que a totalidade é mais ampla que a prática coercitiva do território normado, pois compreende a vida coletiva e os espaços de criatividade dos vários grupos "que demarcam o diálogo entre a universalidade e a diferença".

Tendo em vista que se trata de uma rede híbrida, existem interessantes iniciativas tanto para a dimensão da conectividade quanto a do conteúdo da Internet, no Brasil e na América Latina. No escopo do Plano Nacional de Banda Larga do Governo Federal brasileiro, foi ampliada a conectividade nas escolas e em centros de saúde, em áreas urbanas e rurais. No continente, elas incluem projetos escolares na Colômbia e no Chile, de gestão de governos municipais em Buenos Aires (Argentina), Montevidéu (Uruguai), El Bosque, Puente Alto, Los Andes e Rancagua (Chile). Em tais situações, se emprega uma concepção da Internet como campo simbólico de circulação do capital cultural, e como sistema de distribuição de signos e símbolos (ou de conhecimento) impulsionado pela educação. 
Para este campo, fortemente articulado com os temas de fomento à participação cidadã e inclusão digital, destacam-se projetos como o uso da Internet no sistema escolar em Pinamar (Argentina) e a comunidade virtual MISTICA (Metodología de Impacto Social de las Tecnologías de la Información y de la Comunicación en América), ainda no início dos anos 2000 (BONILLA; CLICHE, 2001, p. 20). Nota-se que a pauta da democratização do acesso às TI e de seus usos não é recente; os exemplos citados mostram o reconhecimento de sua importância há mais de duas décadas.

Na Bahia, desde 2003 funcionam os Centros Digitais de Cidadania (CDCs), no escopo do programa Cidadania Digital, executado pela Secretaria de Ciência, Tecnologia e Inovação (SECTI) - o maior programa de inclusão digital no Brasil ao final dos anos 2000. Cada município do estado possui pelo menos uma unidade, e as rurais têm projetos financiados pela FINEP. A gestão dos centros e os sistemas operacionais são feitas com softwares livres, assim como a operação dos computadores e servidores disponíveis; um dos sistemas desenvolvidos para os CDCs é o Berimbau Linux (conhecido como Berimbau Livre). Os usuários vão de crianças a idosos, sendo que $93 \%$ eram estudantes em escolas públicas, segundo pesquisa de 2006. Outras atividades nos CDCs incluem manutenção de computadores, oficinas de cultura digital e sustentabilidade, e turmas especiais para idosos ou trabalhadores em fábricas locais (LOPES, 2010, p. 26-28).

Também no escopo da inclusão digital, os telecentros são uma iniciativa de conectividade para incentivar usos comunitários das TICs. Em Belterra (PA), a associação entre telefones celulares e redes $3 G$ de Internet é utilizada para criação de conteúdos online pelos moradores de aldeias e vilarejos nas margens dos rios Amazonas, Arapiuns e Tapajós. Algumas comunidades também têm acesso a aplicativos educativos, Internet de banda larga e câmeras de alta resolução, que dão suporte ao trabalho de grupos como o dos repórteres da Rede Mocoronga de Comunicação (FRANCO, 2010, p. 30).

$\mathrm{O}$ CPqD ofereceu ao projeto um sistema na linguagem de programação Java para gravar e transmitir vídeos pelo navegador no celular, com acesso a conteúdos educativos da TV Cultura. No entanto, não há somente participação do 
Estado: organizações não-governamentais, como o Projeto Saúde \& Alegria, cooperam com o setor privado estrangeiro na região. A firma israelense La Mark, fornecedora da Vivo, doou licenças de um curso de inglês por celular, e a sueca Ericsson instalou antenas, sistemas de rádio comunicação e doou celulares e uma ferramenta de comunicação on e offline para monitoramento ambiental e diagnósticos em saúde (FRANCO, 2010, p. 32-33).

Nota-se que as corporações de TICs concorrem mais no território do que no âmbito econômico, no qual partilham interesses e cooperações. Seu comportamento é oligopolizado, mas elas acabam sofrendo constrangimentos diante dos usos do território, tendo em vista que as escalas da ação e do comando são distintas. O controle distante proveniente dos países centrais nem sempre é capaz de sobrepor as dinâmicas do lugar.

Mesmo diante de perspectivas promissoras para inclusão digital, extensas porções do território continuam sem acesso às TI. Municípios pequenos e distantes de grandes centros urbanos não são atrativos ao setor privado em telecomunicações - ainda que, uma vez instalada a rede de Internet, o tráfego e o retorno dos investimentos cresçam rapidamente. Por isso, por exemplo, a concessão de operadoras para explorar a Região Metropolitana de São Paulo trouxe a obrigação de atender cidades no Amazonas, Amapá, Maranhão, Pará e Roraima. Em lugares como o oeste do Pará, a própria falta de cobertura com malhas viárias dificulta o acesso dos cidadãos a serviços, e entende-se que a conectividade supre pelo menos parte desses deficits (FRANCO, 2010, p. 33).

Para que seja uma das ferramentas para realização de políticas públicas sensíveis às necessidades de comunidades e para a participação cidadã em diversas instâncias, a Internet (e as diversas tecnologias a ela associadas) devem quebrar o padrão de concentração em certas porções do território e entre determinados grupos sociais, que tende a aprofundar desigualdades. Tais questões são especialmente problemáticas na América Latina, onde se encontram altos índices de pobreza e vulnerabilidade, crescente desigualdade no acesso a bens e serviços, além da quase nula representação de importantes grupos sociais para manifestar suas necessidades. A promoção de processos decisórios com maior participação 
social traria potenciais benefícios não apenas no campo das telecomunicações, como também em diversos outros aspectos (MARTíNEZ et al., 2001, p. 513).

Em contrapartida aos problemas citados, Bonilla e Cliche (2001, p. 31) sugerem que a Internet deve ser compreendida como linguagem e ferramenta para permitir a distribuição equitativa do conhecimento e o exercício da cidadania. Em vez da tradicional visão instrumental da tecnologia e do uso das TICs, que acaba por perpetuar a distância entre países pobres e ricos, é mais interessante uma abordagem da rede em diversos contextos sociais e políticos, dentro de campos de força nos quais diversos agentes sociais (estatais, privados e da sociedade civil) intervém. Uma proposta cultural e política inclusiva para a Internet compreende utilizá-la desde o desenvolvimento e a defesa de políticas sociais (de educação, saúde, habitação etc.) até o que se chama de "Direito à Internet", ou seja, princípios para o acesso igualitário a ela.

São cada vez mais levantados questionamentos sobre violações ao princípio de neutralidade da rede por grandes empresas teleoperadoras ou produtoras de conteúdo para a Internet. De acordo com esse princípio, o conteúdo acessado não pode ter sua qualidade determinada pelo agente que provê o acesso à rede. Ou seja, não pode haver discriminação entre pacotes de dados sendo enviados por ela (ZANATTA, 2016, p. 4). Mas isso acaba acontecendo, por exemplo, quando uma operadora de conexão móvel oferece acesso gratuito a aplicativos de mensagens mesmo quando após o esgotamento da franquia de dados contratada pelo usuário.

Essa questão vem do embate entre empresas "pontocom" e teleoperadoras nos Estados Unidos, nos anos 2000. Na ocasião, tornou-se comum entre as "teles" realizar acordos comerciais para facilitar o acesso a aplicações, o que consequentemente discriminava o tráfego:

Estava em discussão, por exemplo, a capacidade de uma grande empresa como NET (ou AT\&T, nos EUA) de tornar o acesso ao Skype mais lento (discriminando os pacotes de dados trocados com os servidores do Skype para "voz sobre IP") ou tornar o conteúdo do Youtube mais rápido - a partir de um acordo comercial feito com a empresa Google (ZANATTA, 2016, p. 10). 
Tais acordos seriam supostamente necessários para aumentar o investimento em infraestrutura e gerar receita às teles; por isso, as firmas produtoras de conteúdo passaram a propor a neutralidade da rede, garantir inovação e manter a Internet "livre" (idem). A Figura 3.10 mostra como a teleoperadora Vivo oferece seus serviços em um pacote de serviços que inclui o acesso a redes sociais de forma gratuita, o que caracteriza o chamado "zero rating". Esta prática gera grande concentração econômica e extração de recursos pelas empresas, configurando estruturas de monopólio.

Figura 3.10. Folder da empresa Vivo sobre pacote de serviços com acesso gratuito a redes sociais.

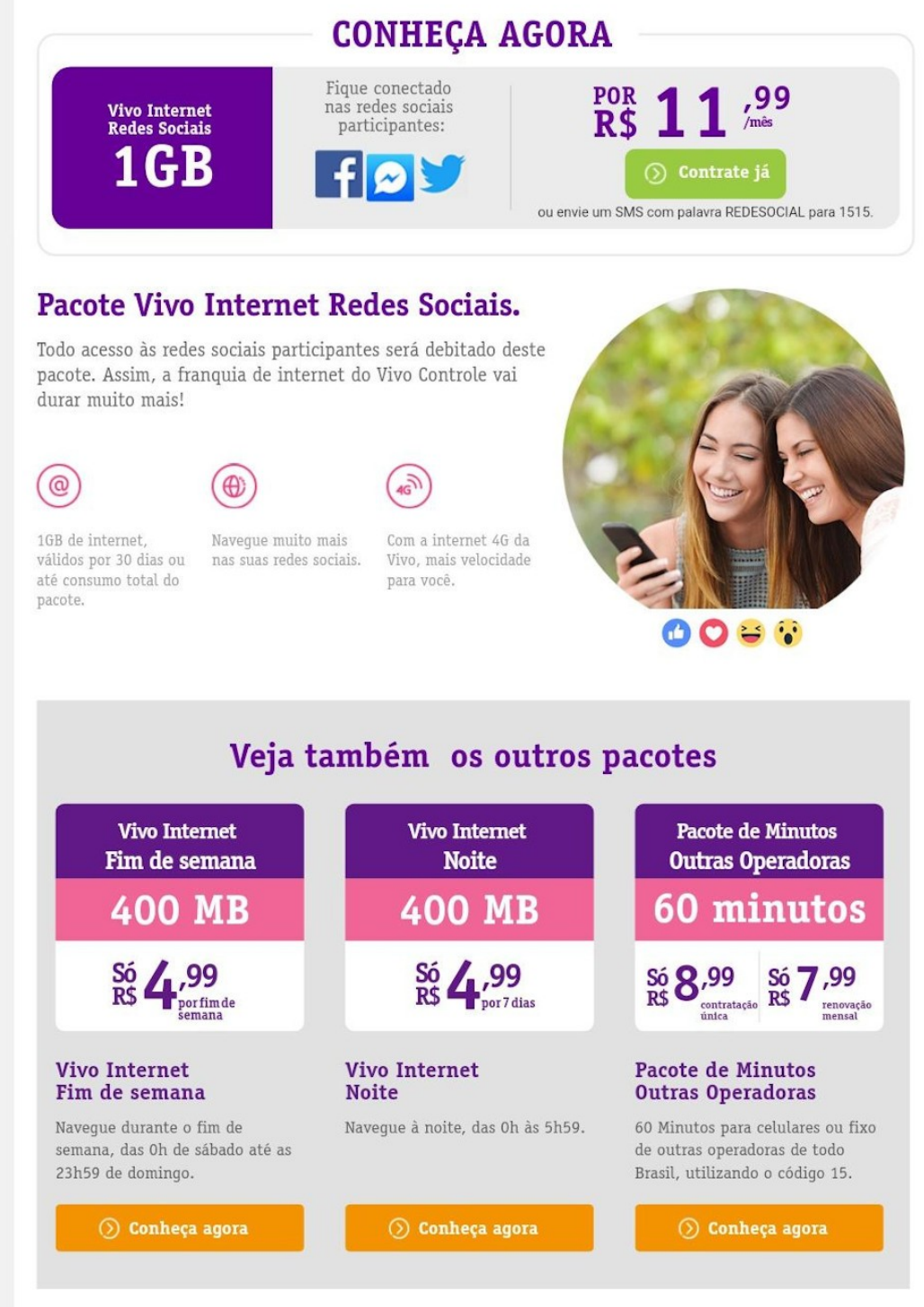

Fonte: e-mail enviado pela empresa a clientes. 
Outro caso de tensão em torno do uso corporativo da Internet é o embate entre a Amazon e a campanha "Nossa Amazônia" a respeito do domínio de internet .amazon. A multinacional pediu à ICANN (Internet Corporation for Assigned Names and Numbers, ou Corporação da Internet para Atribuição de Nomes e Números) o registro exclusivo do domínio em diversos idiomas, por interesse comercial. Os países representantes da Organização do Tratado de Cooperação Amazônica (OTCA) - Brasil, Peru, Bolívia, Colômbia, Venezuela, Equador, Guianas e Suriname - reagiram protocolando um pedido de retirada da solicitação da Amazon, com o apoio de diversas instituições da governança da Internet. Após sete anos, em 2019, a empresa acabou vencendo a disputa, restringindo o uso de uma palavra que possui significados muito além do nome da corporação.

Mesmo que à Internet esteja associada uma psicosfera de amplas possibilidades de conexão e partilha de informações, ela é também campo de disputas, em relação direta com outros âmbitos além do virtual. Especificamente quanto aos aplicativos, as economias do compartilhamento, no plural, ou "sistemas econômicos mediados por tecnologias da informação direcionados ao compartilhamento de recursos para fins de consumo ou de produção", se originam de práticas de reciprocidade em famílias e comunidades. Mas o conceito foi redefinido entre 2009 e 2012, nos Estados Unidos, de modo capitaneado pela mídia especializada (com artigos de "gurus tecnológicos"), por investidores e fundos de capital financeiro. Gradativamente, foi também apropriado pelas grandes empresas do ramo de aplicativos, a fim de promover o agenciamento da prestação de serviços como uma atividade colaborativa, e não exploratória.

Nos anos 2010, um movimento de retomada da economia de compartilhamento com fins de cooperativismo tem se proliferado, criando novas perspectivas e caminhos possíveis. Scholz (2016, p. 58) observa que "cooperativas estão expostas à competição sem dó do mercado, mas, à luz do lucro de $20 \%$ a $30 \%$ que empresas como Uber estão ganhando", podem optar por oferecerem seus serviços por preços mais baixos, a fim de serem mais atrativos aos clientes. A ideia de cooperativismo de plataforma se baseia em três pilares (SCHOLZ, 2016, p. 60-62): 
1) a clonagem das tecnologias utilizadas por plataformas como UpWork, TaskRabbit, Uber e Airbnb, porém valendo-se de um modelo distinto de propriedade do trabalho e de valores democráticos. Promove, assim, uma mudança estrutural na economia sob demanda que beneficia a poucos.

2) as plataformas podem ser de propriedade e operadas por sindicatos ou até mesmo por agentes como cidades, conformando uma solidariedade (que podemos considerar orgânica) em muito dificultada pelo trabalho uberizado, distribuído e usualmente autônomo.

3) o cooperativismo de plataforma ressignifica conceitos como inovação e eficiência com vistas ao benefício coletivo, em vez do lucro de poucos. Promove mudanças tecnológicas, culturais, políticas e sociais.

A ideia de descentralização é interessante inclusive a quem produz aplicativos: a tecnologia blockchain ${ }^{40}$ Ethereum permite aos desenvolvedores de software construí-los colaborativamente, sem uma autoridade central no processo produtivo e na hospedagem em servidores. No atual modelo predominante, um usuário da Internet pode criar conteúdo digital e fazer o upload para o Youtube, mas ele ficará armazenado nos servidores da Google, que pode removê-lo. Do contrário, uma tecnologia descentralizada permite hospedar o material em diversas máquinas, em várias localidades. Também vem crescendo o número de aplicativos voltados para "finanças descentralizadas" (DeFi, ou decentralized finance, em inglês), desenhados para facilitar transações bancárias e empréstimos, substituindo operações tradicionalmente realizadas pelos bancos.

Outro exemplo são as ferramentas da mídia programática, utilizadas na publicidade direcionada, que incluem as chamadas Demand-Side Platforms (DSP). Estas são empregadas para automatização de compras de espaços de propaganda nos websites e nas redes digitais, procurando tornar os preços e as campanhas de marketing o mais atrativos possível para os clientes. Os dados pessoais coletados são analisados e as transações são feitas num modelo de oferta em tempo real, que

40 Blockchain é um sistema de registro de informações distribuído por uma rede de computadores, de modo a dificultar ou impossibilitar alterações. O banco de dados descentralizado resultante desses registros é gerenciado por vários participantes do sistema e conhecido como Distributed Ledger Technology (DLT). A blockchain é um tipo de DLT em que as transações são registradas com uma assinatura criptográfica imutável chamada hash (EUROMONEY, 2021). 
substitui práticas como a realização de ligações e o envio de emails (LI, 2018). Isso somente é interessante ao mercado pelo fato de que milhões de pessoas hoje têm acesso à Internet, como se estivessem disponíveis como nunca para serem alvo das propagandas. Aumentar essa base de usuários é um bom negócio para todos aqueles que se beneficiam da publicidade direcionada, sejam as plataformas ou quem anuncia nelas.

A coleta e os usos de tamanha quantidade de dados pessoais vêm sendo objeto de intensa discussão no âmbito normativo. A Lei Geral de Proteção de Dados (LGPD), em vigor no Brasil desde 16 de agosto de 2020, entende como dados pessoais as informações que identifiquem as pessoas ou as tornem identificáveis, como nome, endereço, localização, número IP, dados escolares ou de saúde, entre outros. Ficam definidos também os chamados dados sensíveis, sejam on ou offline, a respeito da personalidade e das escolhas pessoais do indivíduo, como opiniões públicas, origem racial ou étnica, saúde, genética e filiação a organizações. $\mathrm{Na}$ LGPD é aplicável o Princípio da Extraterritorialidade: se o tratamento dos dados pessoais ou sensíveis ocorreu no território brasileiro, ainda que a empresa responsável pelo processo tenha sede no exterior, estará sujeita à lei nacional. No atual período, como assinala Ramonet (2019, p. 115), questões como as implicações das tecnologias sobre a manipulação de dados são globais e já não podem ser enfrentadas por nenhum Estado de forma isolada.

Diante de tantos usos e possibilidades técnicas e políticas, a Internet pode ser compreendida como uma convergência entre distintas linguagens informáticas e práticas intelectuais e cognitivas, econômicas, políticas, sociais, artísticas e de lazer, na qual as informações são distribuídas em máquinas ao redor do mundo. Nesse emaranhado de redes públicas e privadas, comerciais, governamentais, institucionais e associativas, se forma uma "nebulosa informacional amplamente insondável, diversamente organizada, às vezes aberta e disponível, mas frequentemente fechada e secreta" (MATHIAS, 2009, p. 24). Contudo, apesar da imensa disponibilidade de técnicas e conteúdos, a experiência da maioria das pessoas na Internet fica restrita a poucos aplicativos, opacos ao usuário, "que permitem as múltiplas operações desejadas em um número limitado 
de gestos previstos e uniformes em todo o planeta, sem que tenhamos a menor ideia do que são e significam os protocolos informáticos que empregamos" (idem, p. 27).

Chaui $(2019$, p. 32) reafirma a importância da Internet e das redes sociais como meios de ação democratizadora. Mesmo que o usuário não tenha o domínio técnico dessas tecnologias, elas contribuem para a quebra do monopólio da informação pelas empresas de comunicação de massa e para afirmar o direito democrático à participação. Por outro lado, a aceleração contemporânea atingiu também a circulação de informações, de modo que elas se disseminam cada vez mais rapidamente. Quando a difusão ocorre nessa alta velocidade e sem verificação, cria-se uma situação chamada por Ramonet (2019, p. 125) de “insegurança informacional", que modifica "o campo da informação e as batalhas eleitorais, e redesenhando as opiniões públicas. É um problema para a democracia, que se vê debilitada por conta da imensa confusão criada por tais fenômenos" (RAMONET, 2019, p. 130). Conforme se alcança potencialmente maior liberdade de expressão, a transmissão das informações também é facilitada, mesmo que elas não sejam verdadeiras.

Como assinala Santos (2000, p. 165), as famílias de técnicas que combinam informática e eletrônica, emergentes desde o final do século XX, podem propiciar a superação do imperativo das tecnologias hegemônicas. As características intrínsecas ao software como serviço, como sua imensa flexibilidade para ser empregado em uma série de finalidades, justamente permitem seus tantos usos produtivos e consumptivos. Ambos participam da reprodução do capital, seja pela reintrodução no ciclo produtivo seguinte (com o consumo consumptivo) ou pelo uso organizado e guardado como condição de reprodução (caso do consumo produtivo) (MOREIRA, 2017, p. 59-60). Como o consumo dos aplicativos alimenta o lucro das corporações do ramo, o uso exponencial das plataformas é essencial para seu modelo de negócio, e diretamente dependente da inclusão digital.

Se para os cidadãos o uso da Internet e de aplicativos pode significar maior possibilidade de expressão ou de comunicação com seu grupo (e até mesmo de organização social), para os agentes hegemônicos isso significa a intensificação 
da velocidade e o aumento da densidade de seus fluxos no território, para além do próprio incremento em seu grupo de usuários-consumidores. Implica a capacidade de aprofundar seu lucro, participando até o final do processo de acumulação. Assim, à parte de concepções fantasiosas do que significa ter mais mobilidade ou mais acesso às redes e aos objetos informacionais, há que se ponderar também os usos perversos do território possibilitados por isso, considerando-se os agentes que detêm o controle sobre a produção de tais objetos e redes e sobre o conteúdo que carregam.

Não se pode deixar de notar, no entanto, que se desenhou um novo contexto ao final dos anos 2000 e no início dos anos 2010, com a ampliação da conectividade em escala global e a capilarização de objetos técnicos como computador e telefone celular. Isso propiciou, de certa maneira, a ascensão da chamada "economia política da Internet", com a constituição de grupos em torno de temas como software livre, publicações gratuitas colaborativas na rede (como as chamadas "wikis") e atividades hacker. Ao potencialmente conectar agentes distantes, a Internet e as TI aumentam as possibilidades de trocas, que podem fazer frente a discursos e ações homogeneizantes relacionados ao ideário neoliberal de inevitabilidade de um único e determinado tipo de avanço tecnológico, voltado aos interesses corporativos.

O uso dos softwares se popularizou a ponto de ser uma ferramenta para compreender dinâmicas sociais, econômicas e políticas. Autoridades usam Twitter para se comunicar; conteúdos políticos são disseminados persistentemente pelo WhatsApp; os influenciadores digitais fazem do Instagram um meio de propaganda e marketing próximo de seu público como nunca antes visto. Conforme discute Bacelar (2000, p. 83), os investidores privados selecionam lugares para aportar seus investimentos, no contexto da globalização e da reestruturação produtiva. Em um país tão heterogêneo e com dimensões continentais, como é o caso do Brasil, essa prática de seletividade espacial gera maior desintegração no território.

No período da globalização, os vetores externos continuam incidindo intensamente sobre os lugares, buscando impor uma racionalidade dominante para a qual o território é recurso. Mas a força emanada das horizontalidades nos 
lugares, com suas temporalidades e racionalidades diversas, produzem outras solidariedades e outras existências (CATAIA; RIBEIRO, 2015, p. 18), alternativas aos discursos e às ações predominantes. 


\section{Conclusão}

O surgimento e a propagação do uso dos aplicativos passaram a se intensificar após meados dos anos 2000 , coincidindo com a origem da computação em nuvem, que promoveu a adoção de contratos de prestação de serviços em TI mais flexíveis. Teve início, então, uma considerável reorganização na família de técnicas nesse ramo, com consequente rearranjo nos sistemas de objetos e ações envolvidos na produção de software e trazendo modificações profundas nas dinâmicas do espaço geográfico.

Acompanhando esse movimento, os agentes hegemônicos promovem a formação de mão de obra capacitada para lidar com as novas técnicas - e a própria existência dessa força de trabalho é fator central para o desenvolvimento da tecnosfera modernizada. Associadamente, tem-se a difusão de uma psicosfera que estimula os consumos produtivo e consumptivo dos aplicativos. Tais fatores resultam em novos usos do território e geram transformações no espaço geográfico, ao passo que aprofundam tendências próprias ao capitalismo, como certos aspectos da divisão territorial do trabalho, da seletividade espacial e do uso corporativo do território.

Houve ainda a constituição de uma base normativo-institucional favorável à expansão da indústria de software e serviços em TI, num contexto em que se desenvolveram novos meios de contratação e regulação para o ramo, modificando-o radicalmente. Para que se configurem essas condições para a produção de aplicativos, nota-se a atuação tanto do Estado quanto do mercado em diálogo com condições territoriais relacionadas ao desenvolvimento prévio de indústrias como as de hardware e software tradicionais, desde a segunda metade do século XX.

O que pudemos identificar com nossa pesquisa foi, primeiro, ser necessário reconhecer uma tecnosfera que autoriza o surgimento e a popularização do software como serviço, composta principalmente pela conexão à Internet e pelo armazenamento de grandes volumes de dados nos servidores da 
nuvem. A teleação permite seu acesso por via remota, expandindo as possibilidades de controle e personalização dos produtos.

A importância da tecnologia de computação em nuvem é tamanha para o ramo de software na atualidade, que seu desenvolvimento e sua ascensão podem ser entendidos como evento geográfico, em conjunto com a difusão das redes de telefonia e Internet móveis. Tal mudança técnica revolucionou o modelo de prestação de serviços de informática, sobretudo no ramo dos aplicativos. É importante mencionar que esse evento corresponde a um conjunto de ações que operam em sistema, por meio de uma família de técnicas desenvolvidas desde paradigmas tecnológicos de períodos anteriores.

O aporte teórico de Milton Santos nos proporcionou compreender essa situação balizando-nos também nos conceitos de acontecer hierárquico e solidariedade organizacional, mecanismos fundantes da relação entre as corporações que desenvolveram a tecnologia da nuvem e dos agentes que passaram a utilizá-la nos anos seguintes. Essa transformação trouxe, ainda, uma série de implicações para o espaço geográfico: novos usos do território emergem das novas possibilidades de interação entre os agentes, identificáveis ao analisar-se a dinâmica de produção e de uso dos aplicativos, seja pelos usuários, pelo Estado ou pelas empresas. Debates sobre temas como cidades inteligentes, modernização no campo e participação política digital, todos diretamente relacionados ao meio geográfico da globalização, passam pela necessidade do uso de aplicativos e do armazenamento de dados em servidores da nuvem.

A concentração espacial que se esperaria das grandes empresas desse ramo, com maiores condições de decidir onde situarão suas atividades, na verdade parece se reiterar independentemente do porte, pois as firmas de menor tamanho também estão sujeitas às mesmas forças centrípetas. A suposta "aldeia global" anunciada por McLuhan (1962), oriunda da Internet e das TI, em vez de promover inclusão digital e "derrubar fronteiras", segue reproduzindo desigualdades socioespaciais (SANTOS, 2002), problemas históricos que não se resolvem milagrosamente apenas em função de maior densidade técnica.

Associadamente, desenha-se uma psicosfera de entusiasmo ao consumo 
dos aplicativos, com a criação e a propagação de novos consensos no espaço geográfico. Ela fomenta mecanismos de coleta e manipulação de dados e a difusão de discursos nas redes digitais, com sérias e duradouras implicações para a sociedade, a economia, a política e os territórios.

É importante lembrar que esse tema está cada vez mais em debate público, e que no ano de 2020 as empresas que coletam informações dos usuários pela Internet tiveram de se adequar à nova Lei Geral de Proteção de Dados (LGPD, Lei n. 13.709/2018), cujos efeitos são comparáveis em dimensão aos do Marco Civil da Internet (Lei n. 12.965/2014). Neste último caso, no entanto, a participação popular foi muito mais incorporada no processo legislativo do que é atualmente, de modo que o Brasil era considerado um modelo em regulação de Internet. Hoje, a infeliz conjuntura política nos leva a comemorar a cada retrocesso evitado, como sucedeu com a LGPD.

Desde a ascensão da informação como variável fundamental do período da globalização e do advento da computação de uso em mais larga escala, desde os anos 1990, vem crescendo a relevância dos softwares. Tecnologias para armazenamento de dados e conexão entre dispositivos, como a computação em nuvem e a Internet das Coisas, foram revolucionárias, com significativas implicações para a produção, a distribuição e o consumo consumptivo dos programas de computador, e acarretaram novos modelos de consumo produtivo. A cooperação entre as grandes firmas do ramo foi necessária para sua modernização e propiciou a elas gerar novos negócios, com mais eficiência e maiores níveis de competitividade.

É possível observar tanto novos usos do território quanto a imposição de consensos e "novidades regulatórias" por essas grandes firmas, sobretudo no contexto do neoliberalismo e da precarização do trabalho digital. Por outro lado, também existem cada vez mais usos alternativos aos hegemônicos, pela possibilidade de maior comunicação entre os agentes, potencialmente contribuindo para a criação e o reforço de articulações políticas e sociais. Não faltam exemplos de iniciativas de organização popular, ou simplesmente de interação entre os lugares e pessoas, tanto a partir de aplicativos por eles mesmos 
criados, quanto pelo uso dos softwares hegemônicos (como o WhatsApp, aplicativo de comunicação móvel com mais downloads no Brasil).

A padronização técnica, junto com a capilarização, a hipertelia e a miniaturização dos objetos técnicos informacionais, tornam os aplicativos potencialmente mais eficazes e mais baratos. Esses avanços, evidentemente, se assentam sobre inovações tecnológicas prévias, com significativas mudanças nos paradigmas tecnológicos e de circulação. No entanto, os usos de produtos e serviços em TI devem ser criticamente analisados, considerando as implicações da mudança tecnológica em diversas escalas espaço-temporais - na vida cotidiana, no intervalo de uma década ou um século, dos espaços públicos aos privados.

Por ser um produto tão flexível e capilarizado, uma vez que se baseia no simples preceito da automatização e da aceleração de tarefas, é justificada a alta demanda por mão de obra no ramo de software como serviço, que é deficitária em vários países. Contudo, é exatamente por poder ser empregado em uma gama tão grande de outros setores que seu funcionamento deve ser extremamente refinado, com alto rigor nas etapas de redação e testagem do código. Com a crescente dependência dos algoritmos, ganha-se em agilidade em muitos processos cotidianos e produtivos, mas também há grandes riscos envolvidos no caso de falhas - para citar alguns exemplos: previsões e operações errôneas em processos industriais, em carros automáticos sem condutor, na saúde e em sistemas de exploração de recursos naturais. Isso também resulta em complexos debates que geram opiniões das mais utópicas às mais distópicas sobre a tecnologia, sobretudo considerando-se o uso de inteligência artificial, sem a mediação humana, para tomada de decisões.

Essas questões estão sempre no limiar entre o técnico e o político. Há um diálogo entre norma - que dificilmente acompanha a inovação tecnológica -, e institucionalidade, desafiada pelas grandes empresas. É equivocada, portanto, qualquer noção de que a tecnologia seja vazia de conteúdo social, político e econômico. As tecnologias da inteligência (SILVEIRA, 2015, p. 12) são especialmente estratégicas em um momento como o atual, quando a intensificação de atividades digitais faz crescer a quantidade de informações coletadas dos 
usuários da Internet, possibilitando prever e modular comportamentos com mais precisão.

A "economia dos aplicativos" significa uma gama de atividades que inclui, por exemplo, cidades inteligentes, vigilância, agricultura de precisão e logística. No entanto, ainda que se tenha a impressão de que "estamos todos conectados" e de que absolutamente tudo é quantificável e mediado por algoritmos, quase a metade da população do Brasil ainda não possui acesso à Internet, e participará desse contexto de modo diferenciado. Por exemplo, terão seus dados pessoais coletados quando fornecem o número do Cadastro de Pessoas Físicas (CPF) numa compra, sem necessariamente terem decidido compartilhá-los com terceiros ou sem conhecer os pormenores técnicos envolvidos numa transação financeira por via eletrônica. Essas circunstâncias também evidenciam a capilarização dos objetos técnicos informacionais (SANTOS, 2009), que tornam os aplicativos potencialmente mais eficazes e mais baratos. Tais avanços se assentam sobre inovações tecnológicas prévias, acompanhadas de significativas mudanças nos paradigmas tecnológicos e de circulação.

O tráfego nas infovias e o conteúdo produzido pelos diversos agentes que usam a Internet revelam suas geometrias do poder (MASSEY, 2008; ZUSMAN, 2019; ISRAEL, 2019), e a primazia das tecnologias da informação carrega desafios para interpretação e análise, sobretudo porque presenciamos diuturnamente as mudanças que trazem ao espaço geográfico. Estão estabelecidos complexos debates sobre a seletividade na distribuição espacial de bens e serviços em TI, por seu atual papel de destaque na mediação das relações sociais.

Os territórios abrigam distintos conteúdos técnicos - a saber, níveis de conectividade expressos pela disponibilidade de redes telemáticas - que levam a uma fluidez seletiva da informação, ao passo que cresce sua porosidade ao capital financeiro (ARROYO, 2021), tornam os subespaços mais ou menos atrativos à alocação de empresas de software. Dessa maneira se arranja o contexto do surgimento e da subsequente consolidação da tecnologia do software como serviço: com a ascensão da informação como variável fundamental do período; o advento da computação de uso de mais larga escala, de modo crescente desde os anos 1950, 
em vários ramos econômicos; a capilarização da informática e dos computadores e chips também entre a população; o aumento da conectividade em cada vez mais porções do mundo; e a grande novidade da computação em nuvem, que veio alterar modelos de negócios no campo da informática, afetando a produção, a distribuição e o consumo de software.

Ainda que modernizações tecnológicas sejam tradicionalmente associadas ao meio urbano no imaginário coletivo, pudemos identificar diversos usos dos aplicativos para a agricultura, tanto a científica globalizada quanto entre os pequenos produtores rurais. 0 meio técnico-científico-informacional penetrou os espaços de modo heterogêneo, mas bastante abrangente, não tendo sua difusão resumida ao espaço urbano. A cartografia da produção de softwares mostra a nítida relação entre a presença dessas empresas e da agricultura moderna, acompanhadas da existência de instituições de ensino superior com cursos especializados nesse ramo, fornecendo mão de obra qualificada.

Já no âmbito corporativo, Tozi (2017, p. 191) observa que as plataformas territoriais conseguem atualizar suas ações instantaneamente porque obtêm um conhecimento sistemático e apurado do território e de seus usos. Identificamos diversos tipos de empresas que funcionam a partir de aplicativos, seja os construindo ou utilizando-nos, a ponto da necessidade de acessá-los ter adentrado todas as camadas sociais no Brasil, bem como os meios urbano e rural.

Os agentes produtores de aplicativos no Brasil são, em sua imensa maioria, pequenas empresas fabricantes de programas customizáveis. No entanto, softwares de gerenciamento de bases de dados, gestão de processos e ferramentas de escritório (como editores de textos e gráficos) são também muito utilizados no meio corporativo, mas produzidos por corporações estrangeiras (sobretudo estadunidenses). É importante ressaltar, conforme Arroyo (2009, p. 484), que ainda que se multipliquem, "as empresas médias e pequenas (as subcontratadas, terceirizadas ou franqueadas) continuam sob o controle financeiro, comercial e tecnológico das grandes empresas", que até mesmo são responsáveis pela formulação das normas que regulam as relações entre as firmas.

Como se vê insistentemente na cartografia da produção de software e 
aplicativos, esta se apresenta muito mais na região Concentrada, sobrepondo-se mais ou menos "a outras divisões territoriais do trabalho nas metrópoles, capitais estaduais, capitais regionais, regiões agrícolas e industriais modernas", onde infraestruturas modernas servem a interesses de empresas hegemônicas (SANTOS; SILVEIRA, 2011, p. 140). As metrópoles possibilitam a convivência entre tecnologias antigas e modernas, organizações simples e sofisticadas, grandes e minúsculos volumes de capital, conectadas por interdependências tanto contíguas quanto longínquas (SILVEIRA, 2016, p. 101-102). A apropriação das técnicas é um processo complexo e paradoxal:

De um lado, a vocação invasora da técnica (SANTOS, 1996), que despreza solidariedades com objetos mais antigos, desvaloriza o trabalho dos menos "modernos". De outro, certas técnicas atuais possuem uma qualidade de nova natureza: são divisíveis, flexíveis, doces (GAUDIN, 1978; SANTOS, 1996) porque permitem, por exemplo, com alguns instrumentos e num pequeno local, fabricar um produto ou organizar um serviço que pode ser vendido. Pelo fato de serem altamente demandantes de inteligência e informação, essas técnicas possibilitam usos e escalas distintos. Essa é a sua grande diferença com o sistema técnico do período industrial que autoriza, entre outras coisas, a espessura da porção marginal do circuito superior (SILVEIRA, 2016, p. 98).

Em meio a essas circunstâncias, criaram-se usos não necessariamente funcionais ao processo geral de produção, e emergem entre os trabalhadores do ramo de TI organizações de solidariedade e iniciativas contra-hegemônicas. Sua atuação questiona tanto a produção dos algoritmos quanto suas condições de trabalho.

As bases técnicas e normativas necessárias ao atual grau de informatização que o território brasileiro apresenta são frutos de décadas de movimentação de diversos agentes, que levaram à difusão do meio técnicocientífico-informacional por cada vez mais lugares e tornaram porções dos territórios mais competitivas. O estratégico e intrincado domínio da técnica sustenta a nova natureza do poder, como promessa de acesso à modernidade (RIBEIRO, 2000, p. 19).

Em momentos como a crise sanitária iniciada em 2020, é importante garantir que serviços básicos (como redes de água e energia elétrica) e 
infraestruturas críticas (por exemplo, sistemas de segurança cibernética) estejam disponíveis e em pleno funcionamento. Numa conjuntura em que cada vez mais atividades são realizadas remotamente, é crucial o papel das políticas públicas de conectividade, tais como o Plano Nacional de Banda Larga do Governo Federal (PNBL, implementado entre 2011 e 2016). O planejamento de ações com foco em desigualdades espaciais pode não aparentar efeitos imediatos, mas se mostra relevante a longo prazo para garantir dignidade aos cidadãos em períodos de incerteza, e num momento em que tecnologias e redes digitais foram acionadas em substituição a diversas atividades presenciais.

Alguns temas conjunturais desenham uma agenda de pesquisa: desinformação e fake news; justiça social nas plataformas; regulação de guarda e manipulação de dados pessoais, inclusive transcendendo a escala nacional; participação democrática por via digital; o uso de tecnologia para tarefas emancipatórias e de mobilização política; e o contexto de isolamento social por conta da pandemia do novo coronavírus, com a intensificação do uso dos aplicativos para finalidades como comunicação e entregas.

Por fim, destacamos o alerta de Ramonet (2019, p. 130) sobre como as tendências de pós-verdade e de criação de "fatos alternativos" à realidade têm alterado o campo da informação a ponto de influenciar a opinião pública e criar um estado de confusão que debilita profundamente a democracia. Ambas as facetas de infraestrutura e de conteúdo da Internet, assim como os dispositivos, produtos e serviços que dependem dela para funcionar - como smartphones e aplicativos estão sujeitos a intencionalidades e devem ser objeto de discussão crítica e participativa, a fim de que projetos populares, democratizantes e emancipatórios de usos do território possam aproveitar as possibilidades trazidas pelas novas tecnologias da informação. 


\section{Referências}

ABA - Associação Brasileira de Anunciantes. Glossário de Internet. 2006. Disponível em: <http://www.aba.com.br/wp-content/uploads/content/a07f0bc4387dfba8a0c76bc5 d0224e85.pdf>.

ABES - Associação Brasileira das Empresas de Software. Brazilian Software Market: Scenario and Trends, 2018. São Paulo: ABES, 2018.

ABES - Associação Brasileira das Empresas de Software. Mercado brasileiro de software: panorama e tendências, 2019. São Paulo: ABES, 2019.

ABES - Associação Brasileira das Empresas de Software. Mercado Brasileiro de Software Panorama e Tendências 2020. ABES: 2020.

ABES - Associação Brasileira das Empresas de Software. Associados. ABES, 2021. Disponível em: <https://abessoftware.com.br/associados/>.

ABÍLIO, Ludmila Costhek. Plataformas digitais e uberização: Globalização de um Sul administrado? Contracampo, Niterói, v. 39, n. 1, p. 12-26, abr./jul. 2020.

ABÍLIO, Ludmila Costhek et al. Condições de trabalho de entregadores via plataforma digital durante a Covid-19. Revista Jurídica Trabalho e Desenvolvimento Humano, Campinas, v. 3, n. 1, 2020, p. 1-21.

AFONSO, Carlos A. Internet no Brasil - alguns dos desafios a enfrentar. Informática Pública, Belo Horizonte, v. 4, n. 2, p. 169-184, 2002.

ALBAGLI, Sarita. Technical-Scientific-Informational Milieu, Networks and Territories. In: MELGAÇO, Lucas; PROUSE, Carolyn (eds.). Milton Santos: A Pioneer in Critical Geography from the Global South. London: Springer, 2017.

ALCANTARA, Chris et al. How Big Tech got so big: Hundreds of acquisitions. The Washington Post, 2021. Disponível em: <https://www.washingtonpost.com/technology/interactive/2021/amazon-applefacebook-google-acquisitions/>.

ALVES, Vicente Eudes Lemos. Modernização agropecuária e urbanização na região de cerrados do Centro-Norte do Brasil: as novas dinâmicas urbanas no oeste da Bahia. In: ALVES, Vicente Eudes Lemos (org.). Modernização e regionalização nos cerrados do Centro-Norte do Brasil: Oeste da Bahia, Sul do Maranhão e do Piauí e Leste de Tocantins. Rio de Janeiro: Consequência, 2015. p. 227-268.

AMARESAN, Swetha. The Top 36 SaaS Companies \& Products to Watch in 2020. HubSpot, 2020. Disponível em: <https://blog.hubspot.com/service/top-saas-companies>.

AMORIM, Guilherme; FERNANDES, Jean; MENDES, Sabrina. Estados Unidos: overview do principal mercado-alvo das empresas do Brasil IT+. 2018. 20 slides. Disponível em: 
<http://www.brasilitplus.com/brasilit/upload/download/1548945559brasilitoferta_270618_eua.pdf>.

ANATEL - Agência Nacional de Telecomunicações. Glossário de Termos da Anatel - Serviço. 2009. Disponível em: <https://www.anatel.gov.br/legislacao/glossario? view=faq\&catid=19\&faqid=2674>.

ANATEL - Agência Nacional de Telecomunicações. Painel de dados - Acessos. 2020. Disponível em: <https://www.anatel.gov.br/paineis/acessos>.

ANTUNES, Ricardo. 0 privilégio da servidão: o novo proletariado de serviços na era digital. 2. ed. São Paulo: Boitempo, 2020.

ANTUNES, Ricardo; BRAGA, Ruy (orgs.). Infoproletários: degradação real do trabalho virtual. São Paulo: Boitempo, 2009.

APP ANNIE. Top Apps. App Annie Intelligence, 2021. Disponível em: <https://www.appannie.com/intelligence/top-apps>.

ARROYO, Mónica. A regulação do território no contexto da globalização (uma trama entre as formas globais, nacionais e locais). In: SOUZA, Álvaro José de et al. (orgs.). Paisagem território região: em busca da identidade. Cascavel: EDUNIOESTE, 2000. p. 115-124.

ARROYO, Mónica. A vulnerabilidade dos territórios nacionais Latino-americanos: o papel das finanças. In: LEMOS, Amália I. G. de et al. (orgs.). Questões territoriais na América Latina. Buenos Aires: Consejo Latinoamericano de Ciencias Sociales - CLACSO; São Paulo: USP, 2006. p. 177-190.

ARROYO, Mónica. A globalização pensada a partir do espaço geográfico. In: MENDONÇA, Francisco de A. et al. (orgs.). Espaço e tempo: complexidade e desafios do pensar e do fazer geográfico. Curitiba: Associação de Defesa do Meio Ambiente e Desenvolvimento de Antonina (ADEMADAN), 2009.

ARROYO, Mónica. Redes e circulação no uso e controle do território. In: ARROYO, Mónica; CRUZ, Rita de Cássia Ariza da (org.). Território e circulação: a dinâmica contraditória da globalização. São Paulo: FAPESP/PPGH/CAPES/Annablume Geografias, 2015.

ARROYO, Mónica. Digitalização e financeirização do território: uma imbricação que se renova no capitalismo do século XXI. In: RENA, Natacha; BRANDÃO, Marcela; MEDEIROS, Daniel; SÁ, Isabel (orgs.). Urbanismo Biopolítico. Belo Horizonte: Agência de Iniciativas Cidadãs, 2021. p. 143-156.

ASH, James et al. Digital turn, digital geographies? Progress in Human Geography, v. 42, n. 1, p. 25-43, 2016.

ASSANGE, Julian et al. Cypherpunks - liberdade e o futuro da internet. São Paulo: Boitempo, 2013.

ASSANGE, Julian. Quando o Google encontrou o WikiLeaks. São Paulo: Boitempo, 2015.

BACELAR, Tânia. Dinâmica regional brasileira nos anos noventa: rumo à desintegração 
competitiva?. In: CASTRO, Iná Elias de et al. (orgs.). Redescobrindo o Brasil: 500 anos depois. 2. ed. Rio de Janeiro: Bertrand Brasil, 2000. p. 73-89.

BALMANT, Ocimara. Inteligência artificial individualiza ensino e ajuda professores. São Paulo: Folha de S. Paulo, 2018.

BARBOSA, Fabio et al. Computação em Nuvem - Parte 1: O que contratar? InfoQ, 2017. Disponível em: <https://www.infoq.com/br/articles/contratar-computacaonuvem/>.

BATHELT, Harald et al. Clusters and knowledge: local buzz, global pipelines and the process of knowledge creation. Progress in Human Geography, v. 28, n. 1, p. 31-56, 2004.

BAYM, Nancy K. Personal connections in the Digital Age. Malden: Polity, 2010.

BELLUZZO, Luiz Gonzaga de M. O dinheiro e as transfigurações da riqueza: uma economia política da globalização. In: FIORI, José Luís; TAVARES, Maria da Conceição (orgs.). Poder e dinheiro: uma economia política da globalização. São Paulo: Vozes, 1997. p. 151-193.

BENAKOUCHE, Tamara. Tecnologia é sociedade: contra a noção de impacto tecnológico. In: DIAS, Leila Christina; SILVEIRA, Rogério L. L. da (orgs.). Redes, sociedades $e$ territórios. Santa Cruz do Sul: EDUNISC, 2005. p. 79-106.

BERNARDES, Adriana. A nova divisão territorial do trabalho brasileira e a produção de informações na cidade de São Paulo (as empresas de consultoria). In: SANTOS, Milton; SILVEIRA, María Laura. O Brasil: território e sociedade no início do século XXI. 15. ed. Rio de Janeiro: Record, 2011. p. 413-432.

BERTOLLO, Mait. A capilarização das redes de informação no território brasileiro pelo smartphone. 2019. Tese (Doutorado em Geografia Humana) - Faculdade de Filosofia, Letras e Ciências Humanas, Universidade de São Paulo, São Paulo, 2019. 241 f.

BIENAYMÉ, Alain. L'économie des innovations technologiques. Paris: Presses Universitaires de France, 1994.

BLANCO, Jorge. Territorio, circulación y redes. In: ARROYO, Mónica; CRUZ, Rita de Cássia Ariza da (orgs.). Território e circulação: a dinâmica contraditória da globalização. São Paulo: FAPESP/PPGH/CAPES/Annablume Geografias, 2015.

BOM DIA PIAUÍ. Vendedor de Teresina cobra $R \$ 2$ para chamar motoristas de aplicativo para quem não sabe usar smartphone. TV Clube, 2020. Disponível em: <https://g1.globo.com/pi/piaui/noticia/2020/01/28/vendedor-de-teresina-cobra-r2-para-chamar-motoristas-de-aplicativo-para-quem-nao-sabe-usarsmartphone.ghtml>.

BONILLA, Marcelo; CLICHE, Gilles (eds.). Internet y Sociedad en América Latina y el Caribe, investigaciones para sustentar el diálogo. Quito: FLACSO Ecuador - IDRC, 2001.

BOSCHMA, Ron. Proximity and innovation: a critical assessment. Regional Studies, v. 39, n. 
1, p. 61-74, 2005.

BRASIL. Ministério da Indústria, Comércio Exterior e Serviços. Departamento de Competitividade Internacional em Comércio e Serviços. Serviços 2017 - Panorama do Comércio Exterior. 2017.

BRASIL. Ministério da Agricultura, Pecuária e Abastecimento. Mapa lança aplicativo para que produtores tenham acesso a informações sobre seguro rural. Mapa, 2020. Disponível em: <https://www.gov.br/agricultura/pt-br/assuntos/noticias/mapa-lancaaplicativo-do-programa-de-seguro-rural>.

BRASIL. Ministério da Economia. APL. Secretaria Especial de Comércio Exterior e Assuntos Internacionais, 2021. Disponível em: <https://www.gov.br/produtividade-ecomercio-exterior/pt-br/assuntos/competitividade-industrial/arranjos-produtivoslocais-apl>.

BRAUDEL, Fernand. Civilização material, economia e capitalismo, vol. 2: Séculos XV-XVIII: os jogos das trocas. 2. ed. São Paulo: WMF Martins Fontes, 2009.

BRUNER, Jon. Software, Hardware, Everywhere. In: BRUNER, Jon et al. Software \& Hardware Collide. Sebastopol: O'Reilly Media, 2014.

BRUSCHI, Valéria et al. Mais Marx: material de apoio à leitura d'O Capital, Livro I. São Paulo: Boitempo, 2016.

BUCHER, Taina; HELMOND, Anne. The Affordances of Social Media Platforms. In: BURGESS, Jean; POELL, Thomas; MARWICK, Alice (eds.). The SAGE Handbook of Social Media. Londres; Nova Iorque: SAGE, 2017.

BYNUM, William. Uma breve história da ciência. Porto Alegre: L\&PM, 2018.

CABRAL, Alex de Lima et al. Glossário de termos técnicos de T.I. 4. ed. São Paulo: Senac São Paulo, 2017.

CAIRNCROSS, Frances. The death of distance: how the communications revolution will change our lives. Boston: Harvard Business School Press, 2001.

CALLEGARI, Lucas. Tecnologia permite a seguradoras esmiuçar comportamento dos motoristas. São Paulo: Folha de S. Paulo, 2018.

CAREY, Scott. Biggest technology acquisitions of 2020. Computerworld, 2020. Disponível em: <https://www.computerworld.com/article/3513439/biggest-technologyacquisitions-of-2020.html>.

CARR, Nicholas G. Does IT matter?: information technology and the corrosion of competitive advantage. Boston: Harvard Business School Publishing, 2004.

CARVALHO, Monica; BONZO, Marcel; ZENAIDE, Vitor. Coronavírus: O mundo nunca mais será o mesmo. Google IAT Insider Report, 2020.

CASTELLS, Manuel. The Rise of the Network Society. The Information Age: Economy, Society and Culture Vol 1. Oxford: Blackwell, 1996. 
CASTILLO, Ricardo. Sistemas orbitais e uso do território: integração eletrônica e conhecimento digital do território brasileiro. 1999. 317 f. Tese (Doutorado em Geografia Humana) - Faculdade de Filosofia, Letras e Ciências Humanas, Universidade de São Paulo, São Paulo, 1999.

CASTILLO, Ricardo et al. Três dimensões da solidariedade em Geografia: autonomia político-territorial e tributação. Experimental, São Paulo, n. 3, p. 69-99, set. 1997.

CATAIA, Márcio. Território Nacional e Fronteiras Internas. A fragmentação do território brasileiro. 2001. 163 f. Tese (Doutorado em Geografia Humana) - Faculdade de Filosofia, Letras e Ciências Humanas, Universidade de São Paulo, São Paulo, 2001.

CATAIA, Márcio Antonio; RIBEIRO, Luis Henrique Leandro. Análise de situações geográficas: notas sobre metodologia de pesquisa em Geografia. Revista da Associação Nacional de Pós-graduação e Pesquisa em Geografia (Anpege), Dourados, v. 11, n. 15, p. 930, jan./jun. 2015.

CBINSIGHTS. The Complete List of Unicorn Companies. 2021. Disponível em: <https://www.cbinsights.com/research-unicorn-companies>.

CEPAL - Comisión Económica para América Latina y el Caribe. Estado de la banda ancha en América Latina y el Caribe 2016. Santiago de Chile: Naciones Unidas, 2016.

CEPAL - Comisión Económica para América Latina y el Caribe. Universalizar el acceso a las tecnologías digitales para enfrentar los efectos del COVID-19. Informe Especial COVID-19 n. 7. Santiago de Chile: Naciones Unidas, 2020.

CETIC.BR - Centro Regional de Estudos para o Desenvolvimento da Sociedade da Informação. Pesquisa sobre o uso das tecnologias de informação e comunicação nos domicílios brasileiros - TIC Domicílios 2019. São Paulo: Comitê Gestor da Internet no Brasil, 2019. Disponível em: <https://cetic.br/pt/pesquisa/domicilios/>.

CETIC.BR - Centro Regional de Estudos para o Desenvolvimento da Sociedade da Informação. Painel TIC COVID-19. Pesquisa sobre o uso da Internet no Brasil durante a pandemia do novo coronavírus. 1a edição: atividades na Internet, cultura e comércio eletrônico. São Paulo: Comitê Gestor da Internet no Brasil, 2020.

CHANG, Fay et al. Bigtable: A Distributed Storage System for Structured Data. OSDI, 2006. Disponível

em:

<https://static.googleusercontent.com/media/research.google.com/en/us/ archive/bigtable-osdi06.pdf>.

CHAUI, Marilena. Meios de comunicação, democracia, autoritarismo e poder. In: MORAES, Dênis de (org.). Poder midiático e disputas ideológicas. Rio de Janeiro: Consequência, 2019. p. 13-34.

CINTRA, Luiz. Inteligência artificial antecipa problemas na área de Recursos Humanos. São Paulo: Folha de S. Paulo, 2018.

COE, Neil; DICKEN, Peter; HESS, Martin. Global production networks: realizing the potential. Journal of Economic Geography, v. 8, n. 3, p. 271-295, 2008. 
CORDEIRO, André. A Internet num feixe de luz. São Paulo: Revista .br., CGI.br, abr. 2016.

CORDEIRO, Letícia. Backhaul: uma pedra no caminho. Teletime, ano 12, n. 120, abr./2009. Disponível em: <http://www.teletime.com.br/4/2009/backhaul-uma-pedra-nocaminho/tt/137662/revista.aspx>.

CORREAA, Roberto Lobato. Os centros de gestão do território: uma nota. Território, Rio de Janeiro, v. 1, n. 1, p. 23-30, 1996.

CORRÊA, Roberto Lobato. Estudos sobre a rede urbana. Rio de Janeiro: Bertrand Brasil, 2006.

DAVENPORT, Thomas H.; BARTH, Paul; BEAN, Randy. How 'Big Data' Is Different. MIT Sloan Management Review, Massachusetts, v. 54, n. 1, set. 2012.

DEAN, Jeffrey; GHEMAWAT, Sanjay. MapReduce: Simplified Data Processing on Large Clusters. Proceedings of the 6th Symposium on Operating Systems Design and Implementation. São Francisco, 2004. Disponível em: <https://www.usenix.org/legacy/publications/library/proceedings/osdi04/tech/ full_papers/dean/dean_html/index.html>.

DE CHIARA, Márcia. Produtor rural terá crédito por aplicativo. O Estado de S. Paulo, 2021. Disponível em: <https://economia.estadao.com.br/noticias/geral,produtor-ruraltera-credito-por-aplicativo,70003717074>.

DIAS, Leila Christina. Redes: emergência e organização. In: CASTRO, Iná Elias de; GOMES, Paulo César da C.; CORRÊA, Roberto Lobato (orgs.). Geografia: Conceitos e Temas. Rio de Janeiro: Bertrand Brasil, 1995.

DIAS, Leila Christina. Redes eletrônicas e novas dinâmicas no território brasileiro. In: CASTRO, Iná Elias de; GOMES, Paulo César da C.; CORRÊA, Roberto Lobato (orgs.). Brasil: Questões atuais da reorganização do território. Rio de Janeiro: Bertrand Brasil, 1996.

DIAS, Leila Christina. Os sentidos da rede - notas para discussão. In: DIAS, Leila Christina; SILVEIRA, Rogério L. L. da (orgs.). Redes, sociedades e territórios. Santa Cruz do Sul: EDUNISC, 2005. p. 11-28.

DICKEN, Peter. Global shift: mapping the changing contours of the world economy. 6. ed. Nova Iorque: The Guilford Press, 2011.

DIEGUEZ, Flávio. Crescente e dependente. Reportagem, n. 43, p. 61, abr. 2003.

DINIZ, Eduardo H. Cinco décadas de automação. GV-executivo, v. 3, n. 3, p. 55-60, ago./out. 2004.

DODGE, Martin; KITCHIN, Rob. Outlines of a world coming in existence: pervasive computing and the ethics of forgetting. Environment and Planning B, v. 34, n. 3, p. 431$445,2007$.

DOWBOR, Ladislau. O capitalismo se desloca: novas arquiteturas sociais. São Paulo: Edições Sesc São Paulo, 2020. 
DYER-WITHEFORD, Nick. Cyber-Proletariat: global labour in the digital vortex. Londres: Pluto Press, 2015.

EAQ - Entidade Aferidora de Qualidade de Banda Larga. Glossário. 2017. Disponível em: <https://www.brasilbandalarga.com.br/bbl/mobile/glossary>.

ELETRONET. Quem é a Eletronet? Eletronet, 2021. Disponível em: $<$ https://www.eletronet.com/empresa/>.

ERWIN, Beate; KARAMAN, Fanny. The Sharing Economy Part 1: New Business Models + Traditional Tax Rules Don't Mix. Insights, v. 4, n. 10, p. 25-30, 2017. Disponível em: $<$ http://publications.ruchelaw.com/news/2017-10/sharing-economy-part-i-uberairbnb.pdf>.

EUROMONEY. What is blockchain? Euromoney Learning, 2021. Disponível em: <https://www.euromoney.com/learning/blockchain-explained/what-isblockchain>.

EUZÉBIO, Emerson Flávio. Fronteira e horizontalidade na Amazônia: as cidades gêmeas de Tabatinga (Brasil) e Letícia (Colômbia). Dissertação (Mestrado em Geografia Humana) - Faculdade de Filosofia, Letras e Ciências Humanas, Universidade de São Paulo, São Paulo, 2011.

EVASO, Alexander Sergio. O espaço vertiginoso. 2006. Dissertação (Mestrado em Geografia Humana) - Faculdade de Filosofia, Letras e Ciências Humanas, Universidade de São Paulo, São Paulo, 2006.

FERNANDES, Bernardo Mançano. Sobre a tipologia de territórios. In: SAQUET, Marcos Aurélio; SPOSITO, Eliseu Savério (orgs.). Territórios e territorialidades. São Paulo: Expressão Popular, 2009.

FIGUEIRÓ, Belisa. Rádios do interior se reinventam com tecnologia de streaming. São Paulo: Folha de S. Paulo, 2018.

FILGUEIRAS, Victor; ANTUNES, Ricardo. Plataformas digitais, Uberização do trabalho e regulação no Capitalismo contemporâneo. Contracampo, Niterói, v. 39, n. 1, p. 27-43, abr./jul. 2020.

FONTES, Virgínia. O capital, frações, tensões e composições. In: CAMPOS, Pedro Henrique Pedreira; BRANDÃO, Rafael Vaz da Motta (orgs.). Dimensões do empresariado brasileiro: história, organização e ação política. Rio de Janeiro: Consequência, 2019. p. 259-277.

FRANCO, Vera. Amazônia com cidadania. São Paulo; Brasília: ARede, 2010.

FRANKLIN, Michael; HALEVY, Alon; MAIER, David. From Databases to Dataspaces: A New Abstraction for Information Management. ACM SIGMOD Record, 2005. Disponível em: <https://homes.cs.washington.edu/ alon/files/dataspacesDec05.pdf>.

FREEMAN, Christopher; PEREZ, Carlota. Structural crises of adjustment, business cycles and investment behaviour. In: DOSI, Giovanni et al. Technical change and economic theory. Londres: Pinter Publishers, 1988, p. 38-66. 
FUCHS, Christian. Digital labour and Karl Marx. Nova Iorque: Routledge, 2014.

FURTADO, Celso. Raízes do subdesenvolvimento. 3. ed. Rio de Janeiro: Civilização Brasileira, [2003] 2014.

GAUDIN, Thierry. L'écoute des silences - les institutions contre l'innovation. Paris: Union generale d'Éditions, 1978. Disponível em: $<$ http://classiques.uqac.ca/contemporains/gaudin_thierry/ecoute_des_silences/ ecoute_des_silences.pdf>.

GOOGLE. TANNAT, um novo cabo para a América do Sul. O Blog do Google Brasil, 5 nov. 2015. Disponível em: <https://brasil.googleblog.com/2015/11/tannat-um-novo-cabopara-america-do-sul.html>.

GROSSMANN, Luís Osvaldo. PTT faz a diferença para pequenos e médios provedores. Revista Abranet, São Paulo, Editora Convergência Digital, dez. 2015.

GSMA. The Internet Value Chain. A study on the economics of the internet. Londres: GSMA, 2016.

HARRIS, Derrick. The history of Hadoop: From 4 nodes to the future of data. Gigaom, 2013. Disponível em: <https://gigaom.com/2013/03/04/the-history-of-hadoop-from-4nodes-to-the-future-of-data/>.

HARVEY, David. Condição pós-moderna: uma pesquisa sobre as origens da mudança cultural. 20. ed. São Paulo: Loyola, 2010.

HIGACHI, Hermes. A abordagem neoclássica do progresso técnico. In: PELAEZ, Victor; SZMRECSÁNYI, Tamás (orgs.). Economia da Inovação Tecnológica. São Paulo: Hucitec, 2006. p. 67-86.

HOFFMANN, Stacie; LAZANSKI, Dominique; TAYLOR, Emily. Standardising the splinternet: how China's technical standards could fragment the internet. Journal of Cyber Policy, v. 5, n. 2, p. 239-264, 2020.

HOLST, Arne. Leading SaaS providers by market capitalization 2019. Statista, 2020. Disponível em: <https://www.statista.com/statistics/802855/worldwide-largest-saasproviders-market-cap/>.

HOROWITZ, Julia. Why Amazon is the 'perfect' moneymaking machine. CNN Business, 2021. Disponível em: <https://edition.cnn.com/2021/04/30/investing/premarket-stockstrading/index.html>.

HUDDLESTON JR., Tom. How much revenue tech giants like Amazon and Apple make per minute. CNBC Make It, 2021. Disponível em: <https://www.cnbc.com/2021/05/01/howmuch-revenue-tech-giants-like-amazon-and-apple-make-per-minute.html>.

HUERTAS, Daniel Monteiro. Por dentro da trama de caminhos rodoviários e ferroviários: circulação e uso do território na dinâmica regional. In: ALVES, Vicente Eudes Lemos (org.). Modernização e regionalização nos cerrados do Centro-Norte do Brasil: Oeste da Bahia, Sul do Maranhão e do Piauí e Leste de Tocantins. Rio de Janeiro: 
Consequência, 2015. p. 45-64.

HUGHES, Thomas P. La evolución de los grandes sistemas tecnológicos. In: THOMAS, H.; BUCH, A. (orgs.). Actos, actores y artefactos: sociología de la tecnología. Bernal: Universidad Nacional de Quilmes, 2008. p. 101-144.

HUWS, Ursula. Labor in the Global Digital Economy: the cybertariat comes of age. Nova Iorque: Monthly Review, 2014.

IANNI, Octavio. Teorias da Globalização. 4. ed. São Paulo: Civilização Brasileira, 1997.

IBGE - Instituto Brasileiro de Geografia e Estatística. Sistema IBGE de Recuperação Automática - SIDRA. Demografia das Empresas e Estatísticas de Empreendedorismo. IBGE, 2018. Disponível em: <https://sidra.ibge.gov.br/pesquisa/demografia-dasempresas/tabelas>.

IBGE - Instituto Brasileiro de Geografia e Estatística. Estratégia Geral de Tecnologia da Informação e Comunicação do IBGE - EGTI 2019-2020. Rio de Janeiro: IBGE, 2019.

IBGE - Instituto Brasileiro de Geografia e Estatística. Regiões de influência das cidades: 2018. IBGE, Coordenação de Geografia. Rio de Janeiro: IBGE, 2020.

ICIBE - Instituto Ciberespacial. Novo aplicativo facilita a compra de produtos da agricultura familiar paraense. Portal Icibe, 2020. Disponível em: $<$ https://portalicibe.ufra.edu.br/index.php? option=com_content\&view=article\&id=68:app-icibe>.

INVESTSP - Agência Paulista de Promoção de Investimentos e Competitividade. Tecnologia da Informação e Comunicação. InvestSP, 2021. Disponível em: <https://www.investe.sp.gov.br/setores-de-negocios/tecnologia-da-informacao-ecomunicacao/>.

IOZZI, Fabíola Lana. Políticas territoriais das empresas de telecomunicações no Brasil: universalização do serviço de telefonia fixa. 2005. Dissertação (Mestrado em Geografia) - Instituto de Geociências, Universidade Estadual de Campinas, Campinas, 2006. $154 \mathrm{f}$.

ISNARD, Hildebert. O espaço geográfico. Coimbra: Almedina, 1982.

ISRAEL, Carolina Batista. Redes digitais, espaços de poder: sobre conflitos na reconfiguração da Internet e as estratégias de apropriação civil. 2019. 378 f. Tese (Doutorado em Geografia Humana) - Faculdade de Filosofia, Letras e Ciências Humanas, Universidade de São Paulo, São Paulo, 2019.

JONES, Katie. Ranked: The World's Most Downloaded Apps. Visual Capitalist, 2020. Disponível em: <https://www.visualcapitalist.com/ranked-most-downloadedapps/>.

KAHIL, Samira Peduti. Os pólos complementares: tecnoesfera e psicoesfera. Mimeo., s.d.

KURBALIJA, Jovan. Uma introdução à governança da internet. São Paulo: Comitê Gestor da Internet no Brasil, 2016. 
LA ROVERE, Renata Lèbre. Paradigmas e trajetórias tecnológicas. In: PELAEZ, Victor; SZMRECSÁNYI, Tamás (orgs.). Economia da Inovação Tecnológica. São Paulo: Hucitec, 2006. p. 285-301.

LANDIVAR, Liana Christin. The Relationship Between Science and Engineering Education and Employment in STEM Occupations. American Community Survey Reports, ACS-23, U.S. Census Bureau, Washington, DC, 2013.

LÉVY, Jacques. Entre sociedade civil e sociedade política. In: SANTOS, Milton; SOUZA, Maria Adélia Ap. de; SILVEIRA, María Laura (orgs.). Território: globalização e fragmentação. São Paulo: Hucitec, 1994. p. 221-232.

LEWANDOWSKY, Stephan et al. The Debunking Handbook 2020. Skeptical Science, 2020. Disponível em: <https://sks.to/db2020>.

LI, Henry. Martech in Demand: What is a DSP and Why Should You Consider It?. Treasure Data, 2018. Disponível em: $<$ https://blog.treasuredata.com/blog/2018/12/11/martech-in-demand-what-is-adsp-and-why-should-you-consider-it/>.

LOPES, Áurea. O que é que a Bahia tem. São Paulo; Brasília: ARede, 2010.

LOPES, José Leite. Ciência e liberdade: escritos sobre ciência e educação no Brasil. Rio de Janeiro: Editora UFRJ; CBFP/MCT, 1998.

LOPES, Mauro de Rezende; FORNAZIER, Armando. Modalidades de Compras Públicas de Alimentos da Agricultura Familiar no Brasil. São Paulo: GV Agro, 2015.

MAHMOUDI, Dillon. Making Software, Making Regions: Labor Market Dualization, Segmentation, and Feminization in Austin, Portland and Seattle. Portland: Portland State University, ProQuest Dissertations Publishing, 2017.

MÄKILÄ, Tuomas et al. How to define Software-as-a-Service - an empirical study of Finnish SaaS providers. In: TYRVÄINEN, P.; JANSEN, S.; CUSUMANO, M. A. (eds.) ICSOB 2010: Software Business. Lecture Notes in Business Information Processing, v. 51. Berlin, Heidelberg: Springer, 2010.

MALECKI, Edward J.; WEI, Hu. A Wired World: The Evolving Geography of Submarine Cables and the Shift to Asia. Annals of the Association of American Geographers, v. 99, n. 2, p. 360-382, abr. 2009.

MARIANI, Daniel; TAKAHASHI, Fábio. Levantamento sistematiza 134 bilhões de visualizações. São Paulo: Folha de S. Paulo, 2017.

MARTÍNEZ, Juliana et al. Internet y políticas públicas socialmente relevantes: ¿Por qué, cóomo y en qué incidir? In: BONILLA, Marcelo; CLICHE, Gilles (eds.). Internet y Sociedad en América Latina y el Caribe, investigaciones para sustentar el diálogo. Quito: FLACSO Ecuador - IDRC, 2001.

MARTINS, Carlos Eduardo. Globalização, dependência e neoliberalismo na América Latina. São Paulo: Boitempo, 2011. 
MASCARO, Alysson Leandro. Estado e forma política. São Paulo: Boitempo, 2013.

MASSEY, Doreen. Pelo espaço. Rio de Janeiro: Bertrand, 2008.

MATHIAS, Paul. Qu'est-ce que l'internet? Paris: Vrin, 2009.

MATTELART, Armand. Sociedade do conhecimento e controle da informação e da comunicação. Encontro Latino de Economia Política da Informação, Comunicação e Cultura, Salvador, 2005. p. 1-22.

MAZZUCATO, Mariana. O estado empreendedor: desmascarando o mito do setor público vs. setor privado. São Paulo: Portfolio-Penguin, 2014.

MBEMBE, Achille. The digital age erases the divide between humans and objects. The Mail \& Guardian, 2017. Disponível em: <https://mg.co.za/article/2017-01-06-00-the-digitalage-erases-the-divide-between-humans-and-objects/>.

MCCARTHY, John et al. A Proposal for the Dartmouth Summer Research Project on Artificial Intelligence. $1955 . \quad$ Disponível em: <http://www-formal.stanford.edu/jmc/history/dartmouth/dartmouth.html>.

MCLUHAN, Marshall. The Gutenberg Galaxy: The Making of Typographic Man. Toronto: University of Toronto Press, 1962.

MEIRELLES, Fernando S. Uso da TI - Tecnologia de Informação nas Empresas. Pesquisa Anual do FGVcia. FGV EAESP, 2020.

MENEZES, Thales de. Streaming dá fôlego ao setor e molda consumo. São Paulo: Folha de S. Paulo, 2017.

MIAN, Sheraz. Previewing Big Tech Earnings. Zacks, 2020. Disponível em: <https://www.zacks.com/commentary/1083124/previewing-big-tech-earnings>.

MILAN, Stefania; VAN DER VELDEN, Lonneke. The alternative epistemologies of data activism. DCS - Digital Culture and Society, v. 2, n. 2, p. 57-74, 2016.

MONSERRAT FILHO, José. Direito e política na era espacial: podemos ser mais justos no espaço do que na Terra? Rio de Janeiro: Vieira \& Lent, 2007.

MOREIRA, Assis. 'Big techs' pagam 76\% menos imposto. Valor Econômico, 2021. Disponível em: $\quad<$ https://valor.globo.com/brasil/noticia/2021/04/07/big-techs-pagam-76menos-imposto.ghtml>.

MOREIRA, Ruy. Qué es la Geografía. La Paz: Vicepresidencia del Estado Plurinacional de Bolivia, 2017.

MOREIRA, Anelize; POMAR, Marcos Hermanson. De ambulante a motorista de aplicativo: Brasil tem 39 milhões no trabalho informal. São Paulo: Brasil de Fato, 2019. Disponível em: <https://www.brasildefato.com.br/2019/05/03/de-ambulante-amotorista-de-aplicativo-brasil-tem-39-milhoes-no-trabalho-informal/>.

MUSSO, Pierre. A filosofia da rede. In: PARENTE, André (org.). Tramas da rede: novas dimensões filosóficas, estéticas e políticas da comunicação. Porto Alegre: Sulina, 
2004. p. 17-38.

NASRALLAH, Amal. Receita e o software de prateleira, personalizado, customizado e Saas para fins de IRRF-CIDE exterior. 2017. Disponível em: <https://tributarionosbastidores.com.br/2017/05/saas/>.

NBS - Nomenclatura Brasileira De Serviços. 1.1506.21.00 - Serviços de hospedagem de aplicativos e programas software como serviço (SaaS). NBS, 2021. Disponível em: <http://nbs.economia.gov.br/en/concepts/servicos-de-hospedagem-de-aplicativose-programas-software-como-servico-saas.html>.

NEGROPONTE, Nicholas. A vida digital. São Paulo: Companhia das Letras, 1995.

NEVES, Caco. “Ajudei o Brasil a entrar na era digital”. São Paulo: Revista Todos, 2017.

NEWMAN, Mark. Networks. 2. ed. Oxford: Oxford University Press, 2018.

O'BRIEN, Richard. Global financial integration: the end of geography. New York: The Royal Institute of International Affairs and Council on Foreign Relations Press, 1992.

OBSERVATÓRIO BRASILEIRO DE APLS. Observatório APL, 2021. Disponível em: $<$ https://www.observatorioapl.gov.br/>.

OECD - Organization for Economic Cooperation and Development. The OECD-WTO Balanced Trade in Services Statistics. 2018. Disponível em: <https://stats.oecd.org/Index.aspx? DataSetCode=BATIS_EBOPS2002>.

OHMAE, Kenichi. The borderless world: power and strategy in the interlinked economy. New York: Harper Business, 1999.

OPPONG, Thomas. 50 Failed Startup Lessons: 50 Startup Founders Reveal Why Their Startups Failed. Londres: AllTopStartups, 2015.

PACHÉ, Gilles. L'enterprise éclatée représentation économique de l'espace productif. In: BAKIS, Henry (ed.). Communications et territoires. Paris: La Documentation Française, 1990. p. 83-92.

PARISER, Eli. O filtro invisível: o que a internet está escondendo de você. Rio de Janeiro: Zahar, 2012.

PASTRÉ, Olivier. L'informatisation et l'emploi. Paris: La Découverte/Maspero, 1983.

PERRIN, Fernanda. Regulamentação deixa espaço para fintechs crescerem. São Paulo: Folha de S. Paulo, 2018a.

PERRIN, Fernanda. Supermercados e redes de fast-food avançam no autoatendimento. São Paulo: Folha de S. Paulo, 2018b.

PESQUISA FAPESP. Novo satélite para o sistema de comunicação do Brasil é lançado ao espaço. São Paulo: Pesquisa Fapesp, 2017.

PESSALI, Huáscar Fialho; FERNÁNDEZ, Ramón García. A tecnologia na perspectiva da economia institucional. In: PELAEZ, Victor; SZMRECSÁNYI, Tamás (orgs.). Economia 
da Inovação Tecnológica. São Paulo: Hucitec, 2006. p. 87-111.

PIRAGIBE, Clélia. Indústria da informática: desenvolvimento brasileiro e mundial. Rio de Janeiro: Campus, 1985.

POSSAS, Silvia. Concorrência e inovação. In: PELAEZ, Victor; SZMRECSÁNYI, Tamás (orgs.). Economia da Inovação Tecnológica. São Paulo: Hucitec, 2006. p. 13-40.

PRIMI, Lilian. Bico high tech. São Paulo: Caros Amigos, 2017.

QUEIROZ, Kristian Oliveira de. Centralidade periférica e integração relativizada - uma leitura de Tefé no Amazonas. Tese (Doutorado em Geografia Humana) - Faculdade de Filosofia, Letras e Ciências Humanas, Universidade de São Paulo, São Paulo, 2015.

RACONTEUR. Cloud for Business. Londres: Raconteur Media, 2020.

RAFFESTIN, Claude. Por uma geografia do poder. São Paulo: Ática, 1993.

RAMONET, Ignacio. Geopolítica da pós-verdade: a informação na era das fake news. In: MORAES, Dênis de (org.). Poder midiático e disputas ideológicas. Rio de Janeiro: Consequência, 2019. p. 113-130.

RATTNER, Henrique. Informática e tecnocracia. Revista Brasileira de Tecnologia, Brasília, v. 15, n. 1, p. 25-28, jan./fev. 1984.

REPORTAGEM. Salve o pirata. Reportagem, n. 41, fev. 2003a.

REPORTAGEM. Opinião: propriedade intelectual. Reportagem, n. 49, out. 2003b.

RETEGUI, Lorena Marisol; PEREA, Raúl Guillermo. Telecomunicaciones: acceso, políticas y mercado. El caso de la telefonía móvil en Argentina. Question/Cuestión, La Plata, v. 1, n. 35, p. 433-446, jul./set. 2012.

RIBEIRO, Ana Clara Torres. Matéria e espírito: o poder (des)organizador dos meios de comunicação. In: PIQUET, Rosélia; RIBEIRO, Ana Clara Torres. Brasil, território da desigualdade: descaminhos da modernização. Rio de Janeiro: Jorge Zahar, 1991.

RIBEIRO, Ana Clara Torres. A natureza do poder: técnica e ação social. Interface Comunicação, Saúde, Educação, v. 4, n. 7, p. 13-24, 2000.

RIBEIRO, Ana Clara Torres. Teorias da ação. Rio de Janeiro: Letra Capital, 2014.

RIBEIRO, Luis Henrique Leandro. Território e macrossistema de saúde: os programas de fitoterapia no Sistema Único de Saúde (SUS). 305 f. Tese (Doutorado em Geociências) - Instituto de Geociências, Universidade Estadual de Campinas, Campinas, 2015.

RIBEIRO, Ricardo. Aplicativo brasileiro traduz manual de carro para o motorista. São Paulo: Folha de S. Paulo, 2018.

RIBEIRO, Lia; CORNILS, Patrícia. Vias para o desenvolvimento. São Paulo; Brasília: ARede, 2010.

RNP. REDE NACIONAL DE PESQUISA. Promovendo o uso inovador de redes avançadas no Brasil. RNP.br, 2010. 
ROCKMANN, Roberto. O desafio de compartilhar. São Paulo: Revista .br., CGI.br, abr. 2015.

RONCOLATO, Murilo. Força para empreender. São Paulo: Revista .br., CGI.br, nov. 2013.

ROSA, Gabriel. Falta de acesso digital trava agricultura de precisão no país. São Paulo: Folha de S. Paulo, 2018.

ROSELINO, José Eduardo. Análise da Indústria Brasileira de Software com Base em uma Taxonomia das Empresas: Subsídios para a Política Industrial. Revista Brasileira de Inovação, v. 5, n. 1, p. 157-201, 2006.

ROSER, Max; RITCHIE, Hannah; ORTIZ-OSPINA, Esteban. Internet. Our World in Data, 2021. Disponível em: <https://ourworldindata.org/internet>.

SANTANA, Ivone. Angola Cables leva cabo submarino a Fortaleza e inicia fase terrestre. Valor Econômico, 19 fev. 2018. Disponível em: <http://www.valor.com.br/empresas/5332775/angola-cables-leva-cabo-submarinofortaleza-e-inicia-fase-terrestre>.

SANTOS, Milton. Sociedade e Espaço: a Formação Social como Teoria e como Método. Boletim Paulista de Geografia, São Paulo, n. 54, p. 81-99, jun. 1977.

SANTOS, Milton. A Geografia e a nova dimensão do planeta. Revista Brasileira de Tecnologia, Brasília, v. 15, n. 5, p. 13-21, set./out. 1984.

SANTOS, Milton. A urbanização brasileira. São Paulo: Hucitec, 1993.

SANTOS, Milton. Da Política dos Estados à Política das Empresas. Cadernos da Escola do Legislativo, Belo Horizonte, v. 3, n. 6, p. 9-23, jul./dez. 1997.

SANTOS, Milton. Por uma outra globalização: do pensamento único à consciência universal. 2. ed. Rio de Janeiro: Record, 2000.

SANTOS, Milton. O País Distorcido. São Paulo: Publifolha, 2002.

SANTOS, Milton. O espaço dividido: os dois circuitos da economia urbana dos países subdesenvolvidos. São Paulo: Editora da Universidade de São Paulo, 2004.

SANTOS, Milton. O retorno do território. In: SANTOS, Milton. Da totalidade ao lugar. São Paulo: Editora da Universidade de São Paulo, 2005.

SANTOS, Milton. Por uma Geografia Nova: da crítica da Geografia a uma Geografia crítica. 6. ed., 1. reimpr. São Paulo: Editora da Universidade de São Paulo, 2008.

SANTOS, Milton. A natureza do espaço: técnica e tempo, razão e emoção. 4. ed., 5. reimpr. São Paulo: Editora da Universidade de São Paulo, [1996] 2009.

SANTOS, Milton; RIBEIRO, Ana Clara Torres. O conceito de Região Concentrada. UFRJ, IPPUR, Departamento de Geografia, 1979 (mimeo).

SANTOS, Milton; SILVEIRA, María Laura. O Brasil: território e sociedade no início do século XXI. 15. ed. Rio de Janeiro: Record, [2001] 2011.

SANTOS, Milton et al. O papel ativo da Geografia - um manifesto. Laboplan - FFLCH - USP. 
Florianópolis, XII ENG, 2000.

SANTOS, Theotonio dos. Prefácio. In: MARTINS, Carlos Eduardo. Globalização, dependência e neoliberalismo na América Latina. São Paulo: Boitempo, 2011.

SCHIAFFINO, Guillermo; PARSERISAS, Derlis Daniela. Fenómeno financiero y convergencia tecnológica en los dinamismos de los circuitos de la economía urbana en Argentina. In: CONGRESO NACIONAL DE GEOGRAFÍA DE UNIVERSIDADES PÚBLICAS, 7., JORNADAS DE GEOGRAFÍA DE LA UNLP, 21., 2019, La Plata, Actas... La Plata: FaHCE, 2019, p. 1-21. Disponível em: <http://jornadasgeografia.fahce.unlp.edu.ar/frontpage/actas/ponencias/Schiaffino.pdf>.

SCHOLZ, Trebor. Cooperativismo de plataforma: contestando a economia do compartilhamento corporativa. São Paulo: Fundação Rosa Luxemburgo; Editora Elefante; Autonomia Literária, 2016.

SCHWAB, Klaus. A quarta revolução industrial. São Paulo: Edipro, 2016.

SCHWAB, Klaus; DAVIS, Nicholas. Aplicando a quarta revolução industrial. São Paulo: Edipro, 2018.

SENSOR TOWER. Q4 2019 - Store Intelligence Data Digest. Sensor Tower, 2020. Disponível em: <https://go.sensortower.com/rs/351-RWH-315/images/Sensor-Tower-Q4-2019Data-Digest.pdf>.

SILVA, Adriana Maria Bernardes da. A contemporaneidade de São Paulo: produção de informações e novo uso do território brasileiro. 2001. Tese (Doutorado em Geografia Humana) - Faculdade de Filosofia, Letras e Ciências Humanas, Universidade de São Paulo, São Paulo, 2001.

SILVA, Catia Antonia da. O fazer geográfico em busca de sentidos ou a Geografia em diálogo com a sociologia do tempo presente. In: SILVA, Catia Antonia da; CAMPOS, Andrelino; MODESTO, Nilo Sérgio d'Avila. Por uma geografia das existências: movimentos, ação social e produção do espaço. Rio de Janeiro: Consequência, 2014.

SILVA, Catia Antonia da. Política pública e território: passado e presente da efetivação de direitos dos pescadores artesanais no Brasil. Rio de Janeiro: Consequência, 2015.

SILVA, Douglas Vieira da. Brasil é o $3^{\circ}$ país que mais faz download de aplicativos no mundo. Tecmundo, 2019. Disponível em: <https://www.tecmundo.com.br/internet/147273brasil-3-pais-download-aplicativos-mundo.htm>.

SILVA, Paulo Fernando Jurado da. Geografia das Telecomunicações no Brasil: um esforço de síntese. Revista Cerrados, Montes Claros, v. 16, n. 2, p. 3-30, jul./dez. 2018.

SILVEIRA, Márcio Rogério. As cinco revoluções e evoluções logísticas e seus impactos sobre o território brasileiro. In: SILVEIRA, Márcio Rogério; LAMOSO, Lisandra Pereira; MOURÃO, Paulo Fernando Cirino (orgs.). Questões nacionais e regionais do território brasileiro. São Paulo: Expressão Popular, 2009. p. 13-42.

SILVEIRA, María Laura. Concretude territorial, regulação e densidade normativa. 
Experimental, São Paulo, v. 1, n. 2, p. 35-45, mar. 1997.

SILVEIRA, María Laura. Uma situação geográfica: do método à metodologia. Território, Rio de Janeiro, ano IV, n. 6, p. 21-28, jan./jun. 1999.

SILVEIRA, María Laura. O espaço da globalização: usos diversos, comando único. In: SOUZA, Álvaro José de et al. (orgs.). Milton Santos: cidadania e globalização. São Paulo, Bauru: Saraiva, AGB-Bauru, 2000. p. 121-127.

SILVEIRA, María Laura. Finanças, consumo e circuitos da economia urbana na cidade de São Paulo. Cadernos CRH, v. 22, n. 55, p. 65-76, 2009.

SILVEIRA, María Laura. Geografia e mundo contemporâneo: pensando as perguntas significativas. Boletim Campineiro de Geografia, v. 2, n. 2, p. 205-2019, 2012.

SILVEIRA, María Laura. Circuitos da economia urbana na globalização - Novas técnicas, novas encruzilhadas. In: LENCIONI, Sandra; BLANCO, Jorge (orgs.). Argentina e Brasil: territórios em redefinição. Rio de Janeiro: Consequência, 2016. p. 85-107.

SILVEIRA, Sérgio Amadeu da. Apresentação - WikiLeaks e as tecnologias de controle. In: ASSANGE, Julian. Quando o Google encontrou o WikiLeaks. São Paulo: Boitempo, 2015. p. 11-18.

SIMONDON, Gilbert. Du mode d'existence des objects techniques. Paris: Aubier, 1989.

SOARES, Marcelo. Câmera substitui teclado e faz a vida dos idosos mais fácil. São Paulo: Folha de S. Paulo, 2018.

SOFTEX. A indústria de software no Brasil 2002: fortalecendo a economia do conhecimento. Campinas: Softex, 2002.

SOFTEX. Cadernos temáticos do Observatório: TIC no agronegócio. Brasília: Softex, 2016.

SOUZA, Marcelo Lopes de. Dos espaços de controle aos territórios dissidentes: escritos de divulgação científica e análise política. Rio de Janeiro: Consequência, 2015.

SPOSITO, Eliseu Savério. Desenvolvimento regional do Brasil: uma leitura pela ótica da quarta revolução industrial. In: OLIVEIRA, Floriano Godinho de et al. (orgs.). Espaço e economia: geografia econômica e a economia política. Rio de Janeiro: Consequência, 2019. p. 19-50.

STARTUP GENOME LLC. Global Ecosystem Report 2019. 2019. Disponível em: <https://startupgenome.com/reports/global-startup-ecosystem-report-2019>.

STATISTA. Distribution of Android app developers worldwide as of 1st quarter 2018, by country. Statista, 2018. Disponível em: <https://www.statista.com/statistics/271988/androidapp-developer-country/>.

STEDA, Melissa. Tecnologias da informação e território: políticas para o setor de software no Brasil. 2015. 126 f. Dissertação (Mestrado em Geografia) - Instituto de Geociências, Universidade Estadual de Campinas, Campinas, 2015.

STEPHAN, Danae. Avanço de agronegócio ajuda a turbinar indústrias e startups. São Paulo: 
Folha de S. Paulo, 2018.

TAVOLARI, Bianca. AirBnB: do compartilhamento do quarto vazio à exploração por empresas. $\quad$ LabCidade, $2019 . \quad$ Disponível em: <http://www.labcidade.fau.usp.br/airbnb-do-compartilhamento-do-quarto-vazio-aexploracao-por-empresas/>.

TELEGEOGRAPHY. Submarine Cable Map. PriMetrica, Inc., 2021. Disponível em: <https://www.submarinecablemap.com/>.

TELESÍNTESE. Pricewaterhousecoopers é a Entidade Aferidora da Qualidade da banda larga. Telesíntese, 2012. Disponível em: <https://www.telesintese.com.br/pricewaterhousecoopers-e-a-entidade-aferidorada-qualidade-da-banda-larga/>.

TENÓRIO, Fernando G.; VALLE, Rogerio (orgs.). Fábrica de software. Rio de Janeiro: Editora FGV, 2012.

THÉRY, Hervé; MELLO-THÉRY, Neli Aparecida de. Atlas do Brasil: Disparidades e Dinâmicas do Território. 3. ed. São Paulo: Editora da Universidade de São Paulo, 2018.

TIGRE, Paulo Bastos. Inovação e Teorias da Firma em Três Paradigmas. Revista de Economia Contemporânea, v. 2, n. 1, p. 67-111, jan./jun. 1998.

TOLEDO JUNIOR, Rubens de. Território e densidades técnicas: redes de fibra óptica no Brasil. $161 \mathrm{f}$. 2002. Tese (Doutorado em Geografia Humana) - Faculdade de Filosofia, Letras e Ciências Humanas, Universidade de São Paulo, São Paulo, 2002.

TOLEDO JUNIOR, Rubens de. Telecomunicações e uso do território brasileiro. In: SOUZA, Maria Adélia Aparecida de (org.). Território brasileiro, Usos e Abusos. São Paulo, Edições Territorial, 2003. p. 93-107.

TOZI, Fábio. Rigidez normativa e flexibilidade tropical: investigando os objetos técnicos no período da globalização. 2012. Tese (Doutorado em Geografia Humana) - Faculdade de Filosofia, Letras e Ciências Humanas, Universidade de São Paulo, São Paulo, 2012.

TOZI, Fábio. A estratégia da Uber no Brasil: a informação como fator produtivo e o território como recurso da empresa. In: SEMINÁRIO GOVERNANÇA DAS REDES E O MARCO CIVIL DA INTERNET, 2., 2016, Belo Horizonte. Anais... Belo Horizonte: Instituto de Referência em Internet e Sociedade, 2017. p. 191-196.

TOZI, Fábio. O território brasileiro como recurso das plataformas digitais de transporte por aplicativos. In: ENCONTRO NACIONAL DA ANPEGE, 13., 2019, São Paulo. Anais... São Paulo: ANPEGE, 2019.

TOZI, Fábio. Uma geografia da uberização no Brasil. 2020. Disponível em: <https://outraspalavras.net/cidadesemtranse/uma-geografia-da-uberizacao-nobrasil/>.

TUNES, Regina. Uma abordagem crítica da inovação e do conhecimento na geografia do capitalismo contemporâneo. In: OLIVEIRA, Floriano Godinho de et al. (orgs.). Espaço 
e economia: geografia econômica e a economia política. Rio de Janeiro: Consequência, 2019. p. 135-162.

TURING, Alan M. Computing Machinery and Intelligence. Mind, v. 59, n. 236, p. 433-460, out. 1950.

UFPA - Universidade Federal do Pará. Glossário - Termos/Internet. 2019. Disponível em: $<$ http://www.aedmoodle.ufpa.br/mod/glossary/view.php? $\mathrm{id}=121625 \&$ mode=\&hook=ALL\&sortkey=\&sortorder=\&fullsearch=0\&page=-1>.

VALENTE, Jonas. Operadoras em defensiva para desregulamentar o setor. MídiaComDemocracia, abr. 2016.

VENCESLAU, Igor. Meio técnico-científico-informacional e comércio eletrônico no território brasileiro: agentes, conflitos e estratégias. In: ENCONTRO NACIONAL DA ANPEGE, 13., 2019, São Paulo. Anais... São Paulo: ANPEGE, 2019.

VOPSON, Melvin M. The world's data explained: how much we're producing and where it's all stored. The Conversation, 2021. Disponível em: <https://theconversation.com/the-worlds-data-explained-how-much-wereproducing-and-where-its-all-stored-159964>.

WAYNE, Leslie. How Delaware Thrives as a Corporate Tax Haven. The New York Times, 2012. Disponível em: <https://www.nytimes.com/2012/07/01/business/how-delawarethrives-as-a-corporate-tax-haven.html>.

WEF - World Economic Forum. The Future of Jobs Report. Cologne/Geneva: World Economic Forum, 2018.

WOLFF, Simone. Informatização do trabalho e reificação: uma análise à luz dos programas de qualidade total. Campinas: Editora da Unicamp; Londrina: EDUEL, 2005.

ZANATTA, Rafael A. F. Como participar do Comitê Gestor da Internet: um manual para a sociedade civil. IDEC; Coalizão Direitos na Rede, 2016.

ZANATTA, Rafael A. F. Economias do compartilhamento: superando um problema conceitual. In: ZANATTA, Rafael A. F.; PAULA, Pedro C. B. de; KIRA, Beatriz (orgs.). Economias do compartilhamento e o Direito. Curitiba: Juruá, 2017. p. 79-106.

ZAPAROLLI, Domingos. Oportunidades digitais. São Paulo: Pesquisa Fapesp, 2017.

ZOOK, Matthew. The geography of the Internet industry: venture capital, dot-coms, and local knowledge. Oxford: Blackwell, 2005.

ZUSMAN, Perla. As geometrias do poder do ciberespaço. Boletim Campineiro de Geografia, Campinas, v. 9, n. 2, p. 335-349, 2019. 


\section{Anexos}

Tabela 1. Brasil. Empresas produtoras de software por ano de criação (1967-2019).

\begin{tabular}{lll}
\hline Ano & Quantidade de empresas & Porcentagem do total (\%) \\
\hline 2019 & 3597 & 7,0 \\
2018 & 4598 & 9,0 \\
2017 & 2988 & 6,0 \\
2016 & 2446 & 5,0 \\
2015 & 2133 & 4,0 \\
2014 & 2341 & 5,0 \\
2013 & 2297 & 5,0 \\
2012 & 2385 & 5,0 \\
2011 & 2374 & 5,0 \\
2010 & 2401 & 5,0 \\
2009 & 2199 & 4,0 \\
2008 & 2185 & 4,0 \\
2007 & 1757 & 4,0 \\
2006 & 1862 & 4,0 \\
2005 & 1876 & 4,0 \\
2004 & 1702 & 3,0 \\
2003 & 1379 & 3,0 \\
2002 & 1205 & 2,0 \\
2001 & 1315 & 3,0 \\
2000 & 1167 & 2,0 \\
1999 & 837 & 2,0 \\
1998 & 784 & 2,0 \\
1997 & 677 & 1,0 \\
1996 & 622 & 1,0 \\
1995 & 583 & 1,0 \\
1994 & 479 & 1,0 \\
1993 & 381 & 1,0 \\
1992 & 307 & 1,0 \\
1991 & 307 & 1,0 \\
1990 & 221 & 0,0 \\
1989 & 161 & 0,0 \\
1988 & 156 & 0,0 \\
1987 & 152 & 0,0 \\
1986 & 130 & 0,0 \\
1985 & 56 & 0,0 \\
1984 & 35 & 0,0 \\
1983 & 31 & 0,0 \\
1982 & 24 & 0,0 \\
1981 & 18 & 0,0 \\
1980 & 11 & 0,0 \\
1979 & 7 & 0,0 \\
1978 & 8 & 0,0 \\
1977 & 8 & 0,0 \\
1976 & 6 & 0,0 \\
& &
\end{tabular}




\begin{tabular}{lll}
1975 & 4 & 0,0 \\
1974 & 4 & 0,0 \\
1973 & 6 & 0,0 \\
1972 & 5 & 0,0 \\
1971 & 3 & 0,0 \\
1970 & 0 & 0,0 \\
1969 & 1 & 0,0 \\
1968 & 4 & 0,0 \\
1967 & 2 & 0,0 \\
\hline \multicolumn{2}{l}{ Fonte: elaboração própria, a partir de dados da Receita Federal do Brasil (2020). }
\end{tabular}

Tabela 2. Brasil. Empresas produtoras de aplicativos por ano de criação.

\begin{tabular}{lll}
\hline Ano & Quantidade de empresas & Porcentagem do total (\%) \\
\hline 2019 & 69 & 13,0 \\
2018 & 93 & 17,0 \\
2017 & 77 & 14,0 \\
2016 & 54 & 10,0 \\
2015 & 37 & 7,0 \\
2014 & 34 & 6,0 \\
2013 & 27 & 5,0 \\
2012 & 24 & 5,0 \\
2011 & 14 & 3,0 \\
2010 & 8 & 2,0 \\
2009 & 9 & 2,0 \\
2008 & 7 & 1,0 \\
2007 & 10 & 2,0 \\
2006 & 14 & 3,0 \\
2005 & 9 & 2,0 \\
2004 & 5 & 1,0 \\
2003 & 7 & 1,0 \\
2002 & 4 & 1,0 \\
2001 & 2 & 0,0 \\
2000 & 6 & 1,0 \\
1999 & 2 & 0,0 \\
1998 & 1 & 0,0 \\
1997 & 2 & 0,0 \\
1996 & 3 & 1,0 \\
1995 & 1 & 0,0 \\
1994 & 1 & 0,0 \\
1993 & 2 & 0,0 \\
1992 & 0 & 0,0 \\
1991 & 2 & 0,0 \\
1990 & 1 & 0,0 \\
1989 & 3 & 1,0 \\
1988 & 1 & 0,0 \\
1987 & 2 & 0,0 \\
1986 & 1 & 0,0 \\
\hline Fonte: elaboração própria, a partir de dados da Receita Federal do Brasil (2020). &
\end{tabular}


Tabela 3. Brasil. Empresas produtoras de software por unidade da federação (2020).

\begin{tabular}{lll}
\hline UF & Quantidade de empresas Porcentagem do total (\%) \\
\hline SP & 24267 & 48,0 \\
RJ & 4729 & 9,0 \\
MG & 3904 & 8,0 \\
PR & 3225 & 6,0 \\
RS & 3192 & 6,0 \\
SC & 2575 & 5,0 \\
DF & 1414 & 3,0 \\
CE & 929 & 2,0 \\
BA & 924 & 2,0 \\
GO & 849 & 2,0 \\
PE & 810 & 2,0 \\
ES & 654 & 1,0 \\
PB & 325 & 1,0 \\
MT & 321 & 1,0 \\
PA & 310 & 1,0 \\
RN & 289 & 1,0 \\
MS & 289 & 1,0 \\
AM & 265 & 1,0 \\
MA & 213 & 0,0 \\
SE & 172 & 0,0 \\
AL & 156 & 0,0 \\
PI & 137 & 0,0 \\
TO & 84 & 0,0 \\
RO & 81 & 0,0 \\
AP & 34 & 0,0 \\
AC & 23 & 0,0 \\
RR & 17 & 0,0 \\
\hline Fonte: & 170690
\end{tabular}

Fonte: elaboração própria, a partir de dados da Receita Federal do Brasil (2020). 
Tabela 4. Brasil. Empresas produtoras de aplicativos por unidade da federação (2020).

\begin{tabular}{lll}
\hline UF & Quantidade de empresas & Porcentagem do total (\%) \\
\hline SP & 224 & 42,0 \\
MG & 51 & 10,0 \\
SC & 43 & 8,0 \\
RJ & 41 & 8,0 \\
PR & 34 & 6,0 \\
RS & 33 & 6,0 \\
GO & 17 & 3,0 \\
DF & 16 & 3,0 \\
CE & 12 & 2,0 \\
BA & 11 & 2,0 \\
ES & 9 & 2,0 \\
PE & 9 & 2,0 \\
MA & 5 & 1,0 \\
MS & 4 & 1,0 \\
RN & 3 & 1,0 \\
AM & 3 & 1,0 \\
AL & 3 & 1,0 \\
PB & 3 & 1,0 \\
SE & 3 & 1,0 \\
PI & 2 & 0,0 \\
RO & 2 & 0,0 \\
MT & 2 & 0,0 \\
PA & 2 & 0,0 \\
TO & 1 & 0,0 \\
AP & 0 & 0,0 \\
AC & 0 & 0,0 \\
RR & 0 & 0,0 \\
Fonte: elaboração própria, a partir de dados da Receita Federal do Brasil (2020).
\end{tabular}


Tabela 5. Profissões fundamentais à produção de software como serviço, listadas na Classificação Brasileira de Ocupações (CBO-2002).

\begin{tabular}{ll}
\hline Código & Ocupação \\
\hline 2122 & Engenheiros em computação \\
$2122-05$ & Engenheiro de aplicativos \\
& Engenheiro de sistemas \\
$2122-15$ & operacionais em computação \\
& Administradores de tecnologia \\
2123 & da informação \\
& Administrador de banco de \\
$2123-05$ & dados
\end{tabular}

Sinônimo

Engenheiro de softwares computacionais, Engenheiro de sistemas computacionais Engenheiro de software computacional básico, Engenheiro de suporte de sistemas operacionais em computação

2123-10 Administrador de redes

2123-15

Administrador de sistemas

Tecnólogo em banco de dados

Administrador de rede e de sistemas computacionais, Administrador de sistema operacional de rede, Tecnólogo em rede de computadores

Analista de aplicativo básico - software, operacionais

Administrador de sistemas computacionais, Administrador de sistemas operacionais de rede Administrador em segurança da

Analista em segurança da informação,

2123-20

2124 informação

Especialista em segurança da informação, Analistas de tecnologia da

Tecnólogo em segurança da informação informação

Analista de sistemas (informática), Analista de sistemas para internet, Analista de Analista de desenvolvimento de sistemas web (webmaster), Consultor de sistemas

tecnologia da informação, Tecnólogo em análise de desenvolvimento de sistema, Tecnólogo em processamento de dados, Tecnólogo em sistemas para internet Analista de comunicação

Analista de redes de comunicação de dados

2124-15

2124-20
Analista de sistemas de automação

Analista de suporte computacional (teleprocessamento), Analista de rede, Analista de telecomunicação

Analista de suporte de banco de dados, Analista de suporte de sistema, Analista de suporte técnico 
Técnicos de desenvolvimento

3171-05 Programador de internet

$3171-10$

Programador de sistemas de informação

Programador de máquinas -

Programador de computador, Programador

de processamento de dados, Programador de sistemas de computador, Técnico de aplicação (computação), Técnico em programa de computador

3171-15 ferramenta com comando numérico

3171-20 Programador de multimídia Artistas visuais, desenhistas Programador de aplicativos educacionais e de entretenimento, Programador de CDROM

2624 industriais e conservadores restauradores de bens culturais Desenhista industrial gráfico

Desenhista de páginas da internet (web (designer gráfico) Gerentes de tecnologia da designer) informação Gerente de desenvolvimento de sistemas

Gerente de programação de sistema

1425-15 Gerente de produção de Gerente de operação de tecnologia da tecnologia da informação Gerente de projetos de informação

1425-25 tecnologia da informação Gerente de segurança de tecnologia da informação Tecnólogo em gestão da tecnologia da informação

2031 Pesquisadores das ciências Tecnólogo em gestão de sistema de informação naturais e exatas 2031-05 Pesquisador em ciências da computação e informática

Fonte: elaboração própria, a partir da Classificação Brasileira de Ocupações (CBO-2002). 
Tabela 6. Arranjos Produtivos Locais que desenvolvem software e aplicativos.

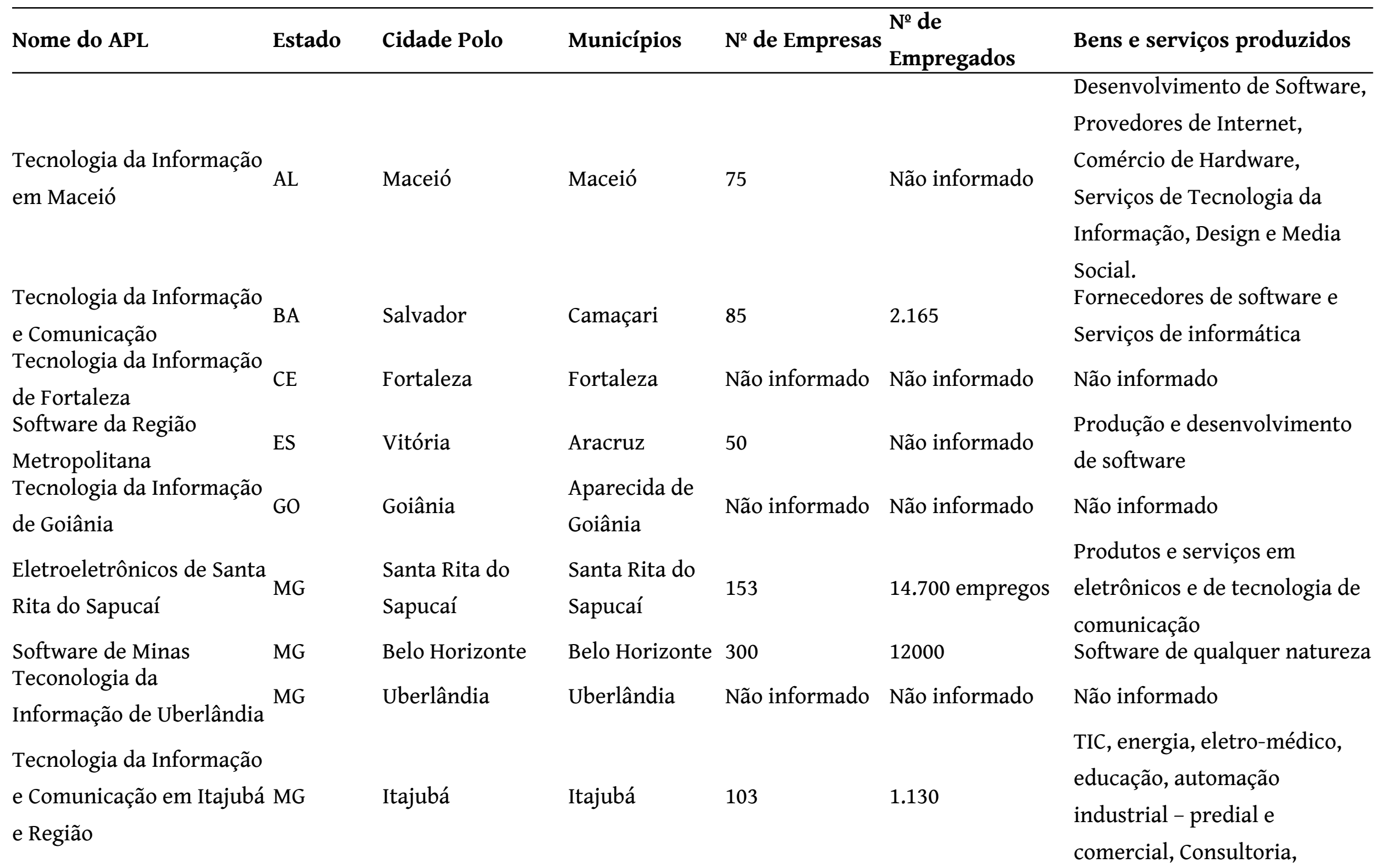




\section{TICs da Região}

Metropolitana de Belo

Horizonte

TICs da Zona da Mata

MG

$$
\text { Viçosa }
$$

Viçosa

Ananindeua

11

56

Metropolitana de Belém

\section{Software}

PB

Tecnologia da Informação PB

Porto Digital

PE

Recife

Recife

300

9.000

Iguassu IT

PR

\section{João Pessoa}

Campina Grande

João Pessoa

Campina

Grande

Não informado Não informado

(n)


Rondon

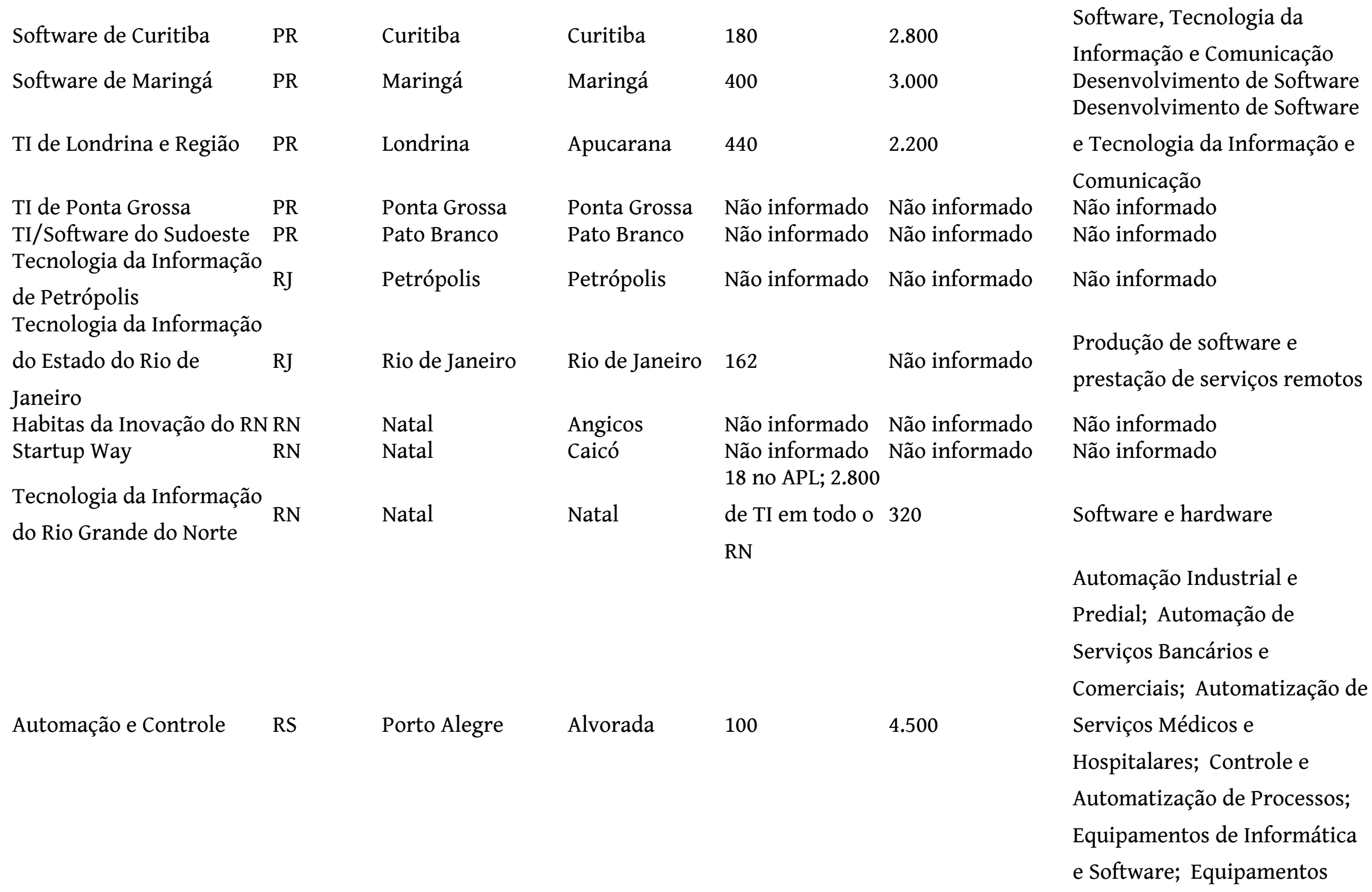


Industriais; Geração,

Transmissão e Distribuição de

Energia; Sistemas de

Segurança e Monitoramento;

Soluções Agrícolas;

Telecomunicações

Tecnologia da Informação

da Serra Gaúcha

$\mathrm{RS}$

Tecnologia da Informação

e Comunicação da Região RS

\section{Central}

Tecnologia da Informação

e Comunicação da Região RS

Norte

Tecnologia da Informação

e Comunicação de SC

Florianópolis

Tecnologia da Informação

da Grande Aracaju

$\mathrm{SE}$$$
\text { da Grande Aracaju }
$$

Eletroeletrônico de Garça SP
Caxias do Sul

Antônio Prado 80

500

Santa Maria Caçapava do SulNão informado Não informado

Almirante

Passo Fundo

Tamandaré do 60

Sul

Florianópolis

Biguaçu

2.900

50.000

Aracaju

Aracaju

Não informado

Não informado

Garça

Garça

72

5.000
Software, Tecnologia da

Informação e Comunicação

Não informado

Software, Tecnologia da

Informação e Comunicação

Hardware, Software e Serviços em tecnologia da informação e comunicação

Não informado

Reatores para lâmpadas ou tubos de descargas;

Automatizadores para portões, portas sociais automáticas, cancelas e acessórios; produtos de Iluminação, Proteção, Segurança e Informática. 
Games da Região

Metropolitana de SP

Software de Ribeirão Preto

- Polo Industrial de Software da Região de SP Ribeirão Preto - PISO
Desenvolvimento de jogos

digitais para todas as

plataformas, sejam de entretenimento ou "jogos

sérios", aplicados à educação, Aproximadamente treinamento, saúde, etc.

2.000

Envolve a produção de jogos

proprietários ou sob

encomenda, serviços ligados à gamificação, e produtos interativos para dispositivos de Realidade Virtual. Desenvolvimento de softwares de gestão empresarial, projetos de CRM (Customer Relationship Management), ERP (Enterprise Resource

Planning), gestão de processos, BI (Business Intelligence), tecnologia RIS (Radiology Information System), sistemas de gestão pública, fábrica de software e sistemas para gestão de companhias aéreas; 


\section{Software do Oeste Paulista SP}

Tecnologia da Informação

de Campinas

SP

Tecnologia da Informação de Marília - APL TI Marília SP de Marilia - APL TI María

\section{Presidente \\ Prudente}

Álvares

Machado

80

400

Campinas

Campinas

Não informado

Não informado

Marília

Álvaro de

Carvalho

180

3.500

São José dos

TICVALE

SP

TIC Rio Preto

$\mathrm{SP}$

São José do Rio Adolfo Cerca de $790 \quad$ Cerca de 4000 consultoria em TI

Desenvolvimento de Software, processamento de dados,

desenvolvimento de páginas

de internet, desenvolvimento

de aplicativos, criação e gestão

de banco de dados

\section{Não informado}

Fábrica e serviços de software, infraestrutura, mobile, outsourcing, sistemas de gestão, automação industrial, desenvolvimento web e ecommerce, sistemas de comércio eletrônico, sistemas de meio de pagamento, startups, fintechs, edutechs, erps, transformação digital, digitalização da indústria, tecnologias para indústria 4.0 Desenvolvimento de software, hardware e serviços de TI Desenvolvimento e

Preto empresas colaboradores diretos licenciamento de programas de computador; suporte 
técnico, manutenção e outros

serviços em TI; consultoria em

tecnologia da informação;

provedores de serviços de

aplicação e internet; web

design

Fonte: Observatório Brasileiro de APLs, 2021. 